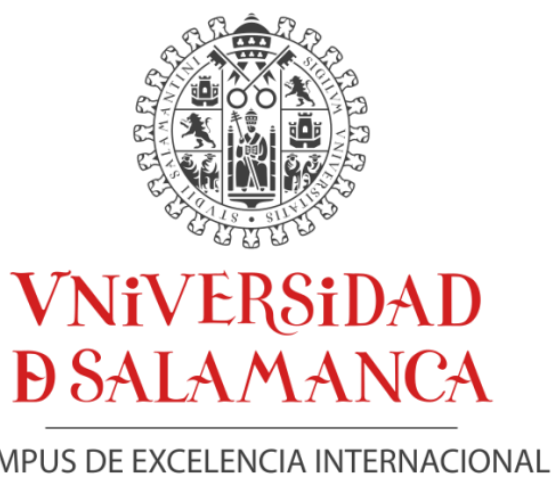

CAMPUS DE EXCELENCIA INTERNACIONAL

\title{
INFECCIÓN ADQUIRIDA EN UNA UNIDAD DE CUIDADOS INTENSIVOS. ANÁLISIS DESCRIPTIVO Y CON MINERÍA DE DATOS
}

TRABAJO DE INVESTIGACIÓN PARA LA OBTENCIÓN DEL GRADO DE DOCTOR EN MEDICINA POR LA UNIVERSIDAD DE SALAMANCA

Juan Carlos Ballesteros Herráez.

Salamanca, 2015 



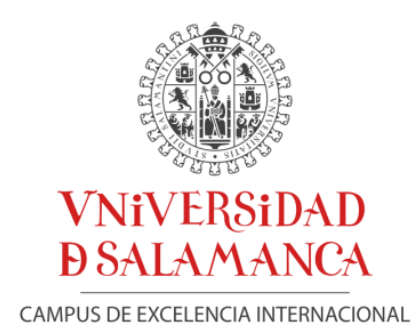

Fernando Sánchez Hernández y María N. Moreno García, Doctores por la Universidad de Salamanca, y Profesores Titulares de Universidad en la Universidad de Salamanca,

\section{H A C E M O S C O N S T A R:}

Que el estudio llevado a cabo como trabajo de Tesis Doctoral, titulado "Infección adquirida en una Unidad de Cuidados Intensivos. Análisis descriptivo y con minería de datos", ha sido realizado por Juan Carlos Ballesteros Herráez bajo nuestra dirección.

Que a nuestro juicio, el mismo, reúne suficientes requisitos científicos para optar al Grado de Doctor por la Universidad de Salamanca.

En Salamanca, a 10 de Marzo de 2015

Fdo.: Prof. Dr. F. Sánchez

Fdo: Prof ${ }^{a}$. Dra. M.N. Moreno 



\section{ÍNDICE GENERAL DE LA TESIS}

I. Índice de abreviaturas........................................................ .5

II. Índice de figuras..........................................................

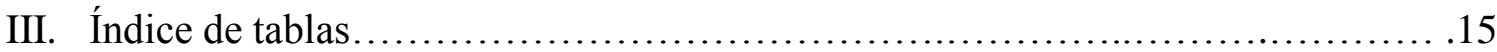

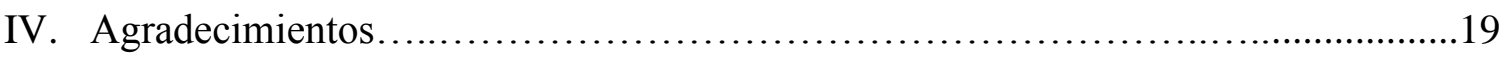

V. Prólogo............................................................23

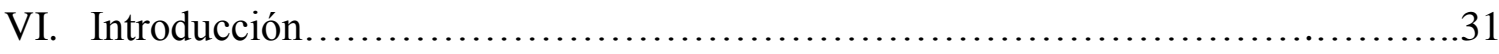

1. Vigilancia de la infección nosocomial...............................34

1.1. Definición de vigilancia......................................35

1.2. Objetivos del sistema de vigilancia.............................36

1.3. Componentes de la vigilancia...................................37

1.4. Análisis e interpretación de los datos.............................37

1.5. Medidas de frecuencia de infección nosocomial....................38

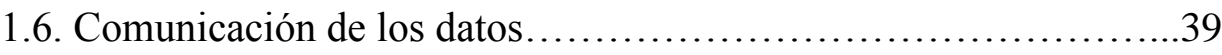

1.7. Redes de vigilancia........................................40

2. Vigilancia de la infección en UCI. Programa ENVIN ...................42

2.1. Antecedentes del programa ENVIN ..........................44

2.2. Características de la base de datos..............................44

2.3. Utilidad del programa ENVIN ..................................46

3. Etiopatogenia de la infección nosocomial...............................46

4. Epidemiología de la infección nosocomial..............................48

5. Fisiopatología de la infección nosocomial.............................52

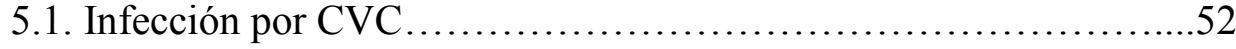

5.1.1. Fisiopatología de la infección CVC .....................52

5.1.2. Factores de riesgo de infección por CVC................53

5.1.3. Microbiología de la infección por CVC..................54

5.2. Neumonía asociada a ventilación mecánica.......................55

5.1.1. Fisiopatología de la infección NAVM..................55

5.2.2. Factores de riesgo de infección por NAVM.............56

5.2.3. Microbiología de la infección por NAVM..............57

5.3. Infección urinaria asociada a sondaje vesical.....................59

5.3.1. Fisiopatología de la ITUSV ............................59 
5.3.2. Factores de riesgo de ITUSV .........................60

5.3.3. Microbiología de la ITUSV ..........................60

5.3.4. Prevención de la ITUSV ..................................62

6. Realidad Local....................................................63

6.1. Inicio de la Vigilancia..................................63

6.2. Estudio piloto............................................63

6.3. Proyecto Bacteriemia-Zero................................66

6.4. Proyecto Neumonía-Zero.....................................72

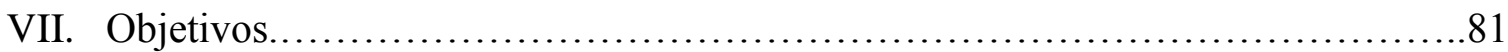

VIII. Material y métodos...................................................... 85

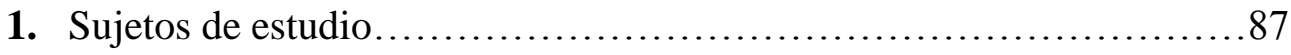

2. Tabla de factores de riesgo...................................88

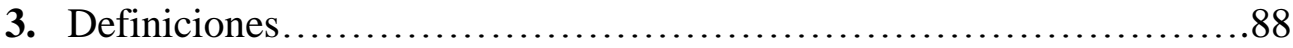

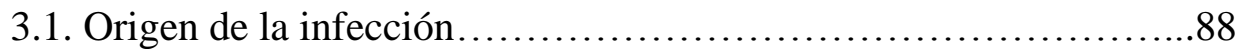

3.2. Infecciones adquiridas en UCI............................... 89

3.2.1. Definición de caso de bacteriemia............................89

3.2.2. Definición de caso de NAMV ...........................89

3.2.3. Definición de caso de ITUSV .........................93

4. Infecciones controladas .........................................93

5. Factores de riesgo............................................. 94

6. Medidas de frecuencia............................................95

7. Validación de los datos...........................................95

8. Estadística descriptiva...........................................96

9. Estadística comparativa........................................96

10. Minería de datos.............................................. 100

10.1. Algoritmos de selección de atributos......................100

10.1.1. CFS (correlation-based feature subset selection)....100

10.1.2. Índice de ganancia...........................................101

10.2. Algoritmos de clasificación................................102

10.2.1. Árboles de decisión.................................... 102

10.2.2. Redes bayesianas................................104

10.2.3.Multiclasificadores.............................105

10.3. Métodos de asociación...................................106 


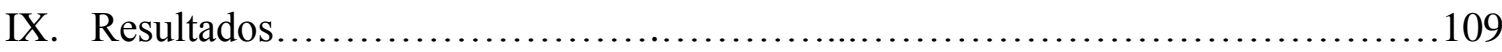

1. Estudio descriptivo..................................................111

1.1. Descriptivo General...........................................111

1.2. Análisis de los datos generales..................................115

1.3. Infección adquirida en UCI....................................118

1.3.1. Momento adquisición infección..................124

1.3.2. NAVM.........................................125

1.3.3. BRCVC ......................................129

1.3.4. ITUSV........................................ 131

1.3.5. Bacteriemias secundarias........................134

2. Estudio comparativo........................................................

2.1. Comparación periodos de estudio..................................136

2.2. GH-Biplot.........................................................

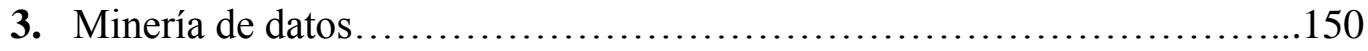

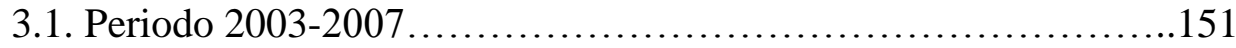

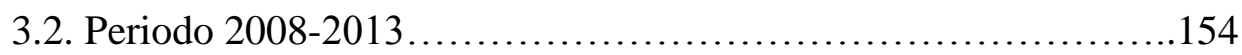

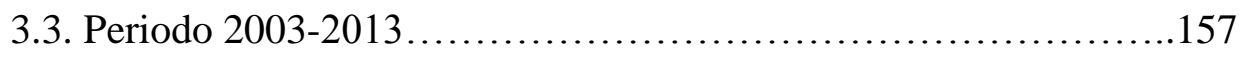

3.4. Estudio de mortalidad.............................................161

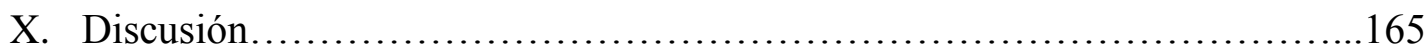

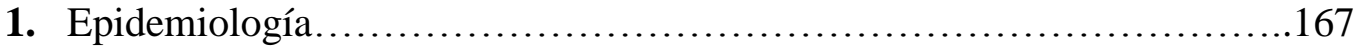

2. Etiología............................................................

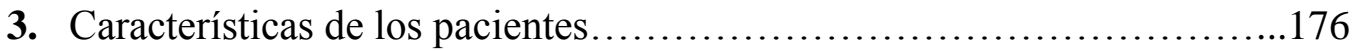

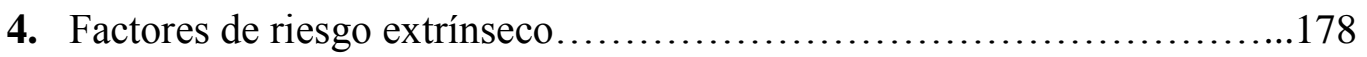

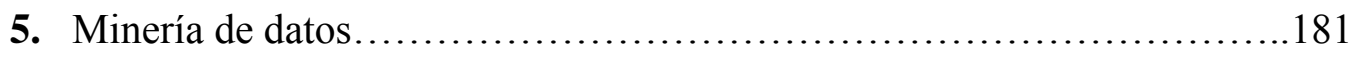

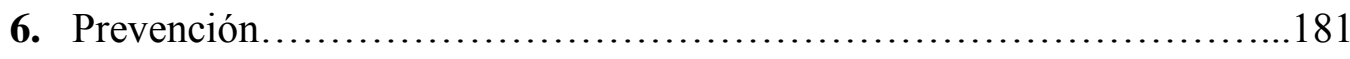

7. Impacto de la infección nosocomial en el paciente crítico...................183

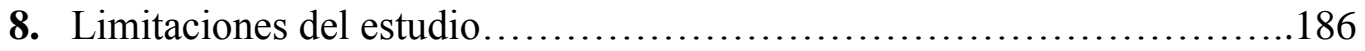

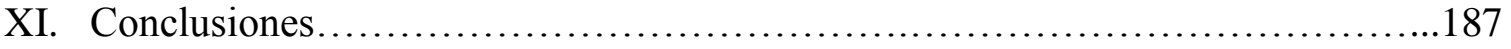

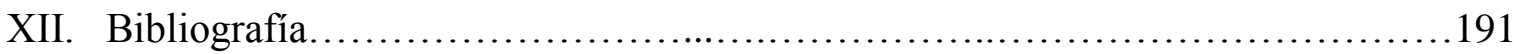


A lo largo del texto de este trabajo, utilizaremos las abreviaturas reseñadas en este apartado, utilizando las mismas desde la primera vez que aparezcan los términos objeto de abreviatura. No obstante, intencionadamente, en algunos puntos, títulos y encabezamientos, e incluso en apartados completos (i.e: conclusiones), no haremos uso de las mismas, con el fin de facilitar el seguimiento del texto.

ANOVA: Analisis de la Varianza.

APACHE: Acute Physiology and Chronic Health Evaluation.

ASP: Active Server Pages.

BAL: Lavado Broncoalveolar.

BRCVC: Bacteriemia relacionada con catéter venoso central.

BZ: Bacteriemia Zero.

CA: Catéter arterial.

CDC: Centers for Diseases Control.

CFU: Unidades Formadoras de Colonias.

CFS: Correlation-based Feature Subset Selection.

CVC: Catéter Venoso Central.

DDS: Descontaminación Digestiva Selectiva.

DI: Densidad de Incidencia.

ECDC: European Center for Disease Prevention and Control.

ELISA: Enzyme-Linked ImmunoSorbent Assay.

ENEAS: Estudio Nacional sobre los Efectos Adversos ligados a la Hospitalización.

ENVIN: Estudio Nacional de Vigilancia de la Infección Nosocomial en los Servicios de Medicina Intensiva.

EPIC: European Prevalence of Infection in Intensive Care

EPINE: Estudio de la Prevalencia de la Infección Nosocomial en España.

EPPS: European Point Prevalence Survey of Healthcare Associated Infections and Antimicrobial Use.

GRADE: Grading of Recomendations Assesment, Developement and Evaluation Working Group.

GTEI: Grupo de Trabajo de Enfermedades Infecciosas.

HELICS: Hospitals in Europe Link for Infection Control through Surveillance.

HFVVC: Hemofiltración veno-venosa continua. 
IN: Infección Nosocomial.

INICC: International_Nosocomial_Infection Control Consortium.

ITUSV: Infección del Tracto Urinario Relacionada con Sondaje Vesical.

MSC: Ministerio de Sanidad y Consumo.

NAVM: Neumonía Asociada a la Ventilación Mecánica.

NEJM: New England Journal of Medicine.

NHSN: National Healthcare Safety Network.

NNIS: National Nosocomial Infections Surveillance.

NPT: Nutrición parenteral total

NZ: Neumonía Zero.

OMS: Organización Mundial de la Salud.

SAPS: Simplified Acute Physiology Score.

SARM: Staphylococcus Aureus Resistente a Meticilina.

SEMICYUC: Sociedad Española de Medicina Intensiva Crítica y Unidades Coronarias.

SEEIUC: Sociedad Española de Enfermería Intensiva y Unidades Coronarias.

SNG: Sonda Naso Gástrica.

SQL: Structured Query Language.

SOFA: Sequential Organ Failure Assesment index Score.

SV: Sonda Vesical.

SYREC: Incidentes y Efectos Adversos en Medicina Intensiva. Seguridad y Riesgo en el Paciente Crítico.

SMI: Servicios de Medicina Intensiva.

TAC: Tomografía Axial Computerizada.

TI: Tasas de Incidencia.

UCI: Unidad de Cuidados Intensivos.

UCIHC: Unidad de Cuidados Intensivos Hospital Clínico.

VM: Ventilación Mecánica. 
Figura 1: Cartel Alianza Mundial para la Seguridad de los pacientes................26

Figura 2: Pagina inicial recogida de datos por paciente del programa ENVIN.........45

Figura 3: Patogenia de la infección nosocomial...................................48

Figura 4: Grupos de germenes aislados en infecciones intraUCI.

Datos informe ENVIN 2013 .................................................. 50

Figura 5: Patogenia de la BRCVC. ...........................................53

Figura 6: Grupos de germenes aislados en las BRCVC. Datos informe ENVIN 2013...54

Figura 7: Grupos de germenes aislados en las NAVM. Datos informe ENVIN 2013 ...58

Figura 8: Grupos de germenes aislados en las ITUSV. Datos informe ENVIN 2013 _..61

Figura 9: Cartel higiene de manos...........................................66

Figura 10: Cartel programa integral de seguridad. ...............................68

Figura 11: Cartel de resumen de medidas BZ .................................. 72

Figura 12: Cartel de resumen de medidas NZ. ...................................74

Figura 13: Tabla de recogida de factores de riesgo programa ENVIN $2013 \ldots \ldots \ldots \ldots . . .88$

Figura 14: Geometría del GH-Biplot........................................ 99

Figura 15: Algoritmo básico de aprendizaje de árboles de decisión..................104

Figura 16: Rango de edad de los pacientes estudiados............................111

Figura 17: Distribución de los pacientes por sexo. ............................. 112

Figura 18: Enfermedad de base de los pacientes estudiados........................112

Figura 19: Distribución de los pacientes por APACHE II........................ 112

Figura 20: Distribución de las estancias de los pacientes..........................................113

Figura 21: Factores de riesgo de infección................................... 113

Figura 22: Procedencia de los pacientes................................... 114

Figura 23: Relación edad mortalidad............................................116

Figura 24: Relación APACHE II y mortalidad....................................117

Figura 25: Porcentaje de infección nosocomial según APACHE II...................118

Figura 26: Infecciones estudiadas............................................ 119

Figura 27: Distribución de las infecciones intraUCI............................119

Figura 28: Distribución de los gérmenes aislados en las infecciones intraUCI...........120 
Figura 29: Evolución de los grupos de gérmenes.............................121

Figura 30: Evolución de la tasa de infección en el periodo estudiado.................123

Figura 31: Tiempo de adquisición de infección respecto al ingreso hospitalario.......124

Figura 32: Tiempo de adquisición de infección respecto al ingreso en UCI...........125

Figura 33: Evolución de las tasas de NAVM................................... 126

Figura 34: Evolución de la tasa de uso de VM.................................... 126

Figura 35: Respuesta sistémica en la NAVM. ................................ 128

Figura 36: Evolución de la tasa de BRCVC. . ..................................... 130

Figura 37: Evolución de la tasa de uso de CVC. . ............................... 130

Figura 38: Distribución de los gérmenes en las BRCVC. .......................131

Figura 39: Evolución de la tasa de ITUSV. . ................................... 132

Figura 40: Evolución de la tasa de uso de ITUSV. .............................133

Figura 41: Distribución de los gérmenes en las ITUSV . ..........................134

Figura 42: Evolución de las tasas de bacteriemia secundaria. . ..................... 134

Figura 43: Foco de origen de las bacteriemias secundarias. . ......................135

Figura 44: Distribución de los gérmenes en las bacteriemias secundarias.............136

Figura 45: Porcentaje de infecciones por periodos de estudio......................136

Figura 46: Distribución de las infecciones por periodos de estudio.................137

Figura 47: GH-Biplot para NAVM. . ......................................... 147

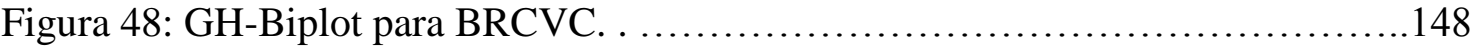

Figura 49: GH-Biplot para las ITUSV. ...................................... 149

Figura 50: Distribución de valores de las variables periodo 2003-2007..............151

Figura 51: Exactitud y precisión para cada clase según tipo de algoritmo con los

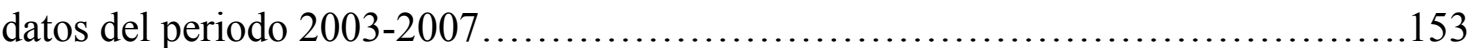

Figura 52: Árbol de decisión J48 para el periodo 2003-2007......................154

Figura 53: Distribución de los valores de las variables periodo $2008-2013 . \ldots \ldots \ldots \ldots . .154$

Figura 54: Exactitud y precisión para cada clase según tipo de algoritmo con los datos del periodo 2008-2013. 
Figura 55: Árbol de decisión J48 para el periodo 2008-2013. ......................157

Figura 56: Distribución variables periodo 2003-2013..........................157

Figura 57: Exactitud y precisión para cada clase según tipo de algoritmo con los

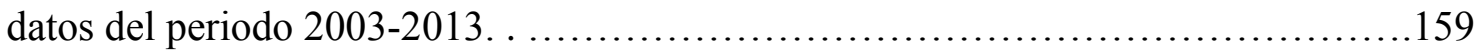

Figura 58: Árbol de decisión J48 para el periodo 2003-2013. ....................160

Figura 59: Distribución variables para el atributo mortalidad. .......................161

Figura 60: Exactitud y precisión para cada clase según tipo de algoritmo. .............163

Figura 61: Árbol de decisión J48 para el atributo mortalidad. .......................164 
Tabla 1: Indicadores de calidad del paciente critico SEMICYUC. .................. 35

Tabla 2: Ejemplos de diferentes medidas de frecuencia estudio EPINE. ................38

Tabla 3: Ejemplos de diferentes medidas de frecuencia estudio ENVIN. ...............39

Tabla 4: Ejemplos de indicadores de vigilancia de infección nosocomial. .............43

Tabla 5: Etiología de infección nosocomial informe ENVIN 2013. ..................49

Tabla 6: Distribución grampositivos informe ENVIN 2013. ......................50

Tabla 7: Distribución gramnegativos informe ENVIN 2013. .....................51

Tabla 8: Distribución hongos informe ENVIN 2013. .......................... 51

Tabla 9: Etiología de BRCVC informe ENVIN 2013 ..............................55

Tabla 10: Etiología de NAVM informe ENVIN 2013. ...........................58

Tabla 11: Etiología de ITUSV informe ENVIN 2013. .........................61

Tabla 12: Recomendaciones CDC para prevención BRCVC. ........................70

Tabla 13: Definiciones de recomendaciones del CDC. ...........................70

Tabla 14: Clasificación de la evidencia y el grado de recomendación según el sistema GRADE. .................................................. 73

Tabla 15: Resumen de las recomendaciones en el proyecto neumonía-zero. ............77

Tabla 16: Tipo de cirugía al ingreso. ........................................ 114

Tabla 17: Infección según cirugía urgente al ingreso. ............................115

Tabla 18: Relación edad infección. ...........................................115

Tabla 19: Relación APACHE II-infección. .......................................116

Tabla 20: Relación Mortalidad-infección. .......................................117

Tabla 21: Distribución de las infecciones adquiridas en UCI. .......................118

Tabla 22: Gérmenes aislados en las infecciones adquiridas en UCI. ...................120

Tabla 23: Tasa de infección adquirida en UCI. ..................................... 122

Tabla 24: Incidencia de NAVM. ............................................. 125

Tabla 25: Diagnóstico clínico de NAVM. .................................... 127

Tabla 26: Diagnóstico microbiológico de NAVM. ...............................127

Tabla 27: Etiología global de las NAVM...................................... 128

Tabla 28: Etiología de las NAVM según el momento de aparición. ..................129

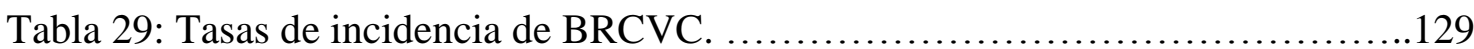

Tabla 30: Etiología de las BRCVC............................................ 131

Tabla 31: Tasas de incidencia de ITUSV. .................................... 133

Tabla 32: Etiología de las ITUSV. ........................................133 
Tabla 33: Tasas de incidencia de bacteriemias secundarias. 133

Tabla 34: Etiología de las bacteriemias secundarias.

Tabla 35: Distribución porcentual de las características estudiadas de los pacientes con NAVM, comparando los dos periodos.

Tabla 36: Distribución porcentual de los diagnósticos

de los pacientes con NAVM, comparando los dos periodos.

Tabla 37: Distribución porcentual de los factores de riesgo

de los pacientes con NAVM, comparando los dos periodos.

Tabla 38: Distribución porcentual de las características estudiadas

de los pacientes con BRCVC, comparando los dos periodos.

Tabla 39: Distribución porcentual de los diagnósticos estudiados

de los pacientes con BRCVC, comparando los dos periodos.

Tabla 40: Distribución porcentual de los factores de riesgo estudiados

de los pacientes con BRCVC, comparando los dos periodos.

Tabla 41: Distribución porcentual de las características estudiadas

de los pacientes con ITUSV, comparando los dos periodos.

Tabla 42: Distribución porcentual de los diagnósticos estudiados

de los pacientes con ITUSV, comparando los dos periodos.

Tabla 43: Distribución porcentual de los factores de riesgo estudiados

de los pacientes con ITUSV, comparando los dos periodos.

Tabla 44: Resultados de los algoritmos de clasificación para el periodo 2003-2007...153

Tabla 45: Resultados de los algoritmos de clasificación para el periodo 2008-2013 ...156

Tabla 46: Resultados de los algoritmos de clasificación para el periodo 2003-2013 ...159

Tabla 47: Resultados de los algoritmos de clasificación.

Tabla 48: Comparación de la DI infección adquirida en UCI

en los estudios analizados

Tabla 49: Comparación del uso de dispositivos invasivos en los estudios analizados..172 


\section{Agradecimientos}


uiero empezar agradeciendo de manera infinita al Prof. Dr. D. Fernando Sánchez Hernández, por animarme a realizar esta tesis y aceptar dirigirla sin dudarlo un instante, por todos sus esfuerzos dedicados durante su realización, asumiendo el trabajo extra que eso significaba a su ya sobrecargada agenda. También quiero agradecerle su paciencia y sus frases de ánimo y apoyo en todo este tiempo; espero que sepa lo importantes que han sido en la elaboración de este trabajo. Especialmente en los momentos de dificultad y desconcierto en la realización de la tesis.

A la Profa. Dra. Dña. María N. Moreno García, codirectora de esta tesis doctoral, por su trabajo en la realización de la sección de la minería de datos, y por su implicación y su esfuerzo en hacer comprensible algo que jamás pensaba que yo llegaría a comprender.

Al Profa. Dra. Mercedes Sánchez Barba, por su inestimable ayuda con el análisis estadístico de los datos. Siempre dispuesta a resolver mis dudas en cuanto surgían, con su gran conocimiento y toda la paciencia del mundo en un campo tan difícil, a veces, para mí. 
A mis compañeros de la Unidad de Cuidados Intensivos, especialmente al Dr. D. Ángel Rodríguez Encinas, por su apoyo, colaboración e implicación en la ejecución de los proyectos Bacteriemia-Zero y Neumonía-Zero a lo largo de estos años.

A todo el personal de la Unidad de Cuidados Intensivos, quienes han realizado las medidas para conseguir el reto del control de la infección en nuestro Servicio, gracias a su trabajo y esfuerzo diario, en ocasiones no siempre valorado. Quiero agradecer el cariño que siempre me han tenido, las ganas que han mostrado, y la colaboración que siempre han puesto de su parte, haciendo que trabajar con ellos sea tan fácil. Sin ellos el control de la infección en la UCI sería imposible.

Mención especial a Carmen, secretaria de la Unidad, por su ayuda a la hora de introducir los datos de los pacientes en la base de datos, sin su esfuerzo la recogida de datos no sería lo mismo.

A mi familia, por su amor, especialmente a mi padre que seguro que hubiera disfrutado este momento, y porque siempre me han apoyado.

A Begoña, por el tiempo que nos ha quitado la preparación de esta tesis, por su apoyo y su cariño, durante el tiempo que ha requerido este trabajo, y por su sacrificio y su esfuerzo, para que no tuviese otras preocupaciones.

A María y a Claudia, mis hijas, que cada día me motivan a trabajar más y mejor por ellas, espero que les pueda servir de ejemplo en la vida. 
as infecciones adquiridas en el hospital se pueden considerar como un “asesino silencioso". Según estadísticas americanas, uno de cada cinco pacientes que ingresan en los servicios sanitarios sufrirá una infección durante su ingreso en el hospital. Esto conlleva un incremento de la estancia de hasta 17 días en los pacientes que se infectan, con el incremento de la morbimortalidad y los costos asociados. Analizando la mortalidad atribuible de las infecciones nosocomiales (IN) esta es muy superior a la producida por enfermedades más frecuentes como el cáncer de pulmón o de próstata.

La medicina en el pasado solía ser simple, poco efectiva y relativamente segura, pero en la actualidad se ha transformado en compleja, efectiva, pero potencialmente peligrosa. Por ello, en el año 1.999 se publica por la Academia Nacional del Instituto de Medicina de Estados Unidos ${ }^{1}$ el informe "To err is human”, en el cual se estima que hasta 98.000 pacientes mueren al año por errores médicos cometidos en los hospitales americanos. Esta causa supone un mayor número de fallecimientos que los ocurridos por causas que reciben mayor atención pública, como son los accidentes de tráfico, y el cáncer de mama.

En las unidades de cuidados intensivos (UCI), la complejidad y gravedad de los enfermos, con procedimientos invasivos diagnósticos y terapéuticos, con múltiples interacciones profesionales-paciente, hacen que la incidencia de infección adquirida durante su estancia en especial la asociada a dispositivos puede aumentar hasta uno de cada cinco pacientes ingresados en estas unidades. 
En el año 2.002, Leape ${ }^{2}$ publica en el New England Journal of Medicine, que entre todos de los sistemas de notificación voluntarios de efectos adversos, los que notifican IN destacan tanto por su número como por su impacto. Esta notificación debe tener como objetivo la mejora de la seguridad, y la disminución de las mismas.

En el informe de la National Nosocomial Infections Surveillance ${ }^{3}$ (NNIS) de 2004 se demuestra como los pacientes críticos son más susceptibles de desarrollar infecciones relacionadas con dispositivos, aunque la frecuencia de las mismas puede variar según el tipo de pacientes ingresados en estas unidades siendo más frecuentes en las UCI con pacientes traumáticos, médicos y pediátricos.

Durante los años 2005-2006 la Organización Mundial de la Salud (OMS), promovió la Alianza Mundial por la Seguridad de los Pacientes", bajo el lema "El cuidado limpio es un cuidado seguro" (figura 1). Se desarrolló una campaña con el objeto de
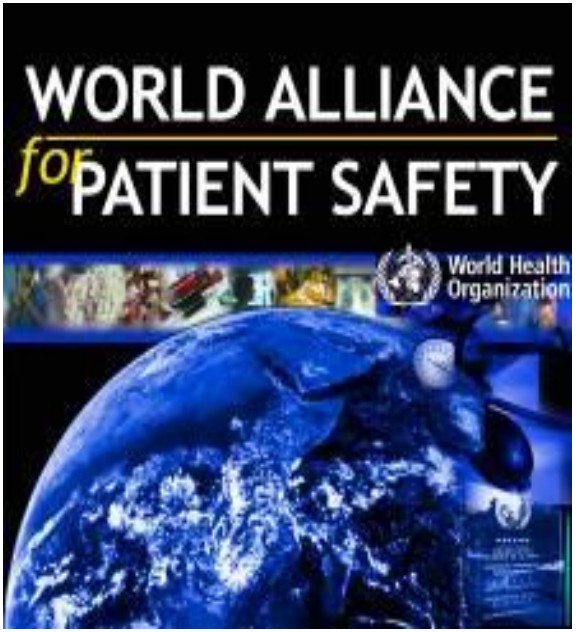

Figura 1: Cartel Alianza Global para la Seguridad de los pacientes. mejorar la seguridad de los pacientes, mediante el uso de medidas que salvan vidas, en especial para disminuir las infecciones asociadas a los cuidados sanitarios en el que se promueven practicas seguras, haciendo especial hincapié en el lavado de $\operatorname{manos}^{5}$.

La cultura de seguridad también llega a nuestro país, y se realiza el Estudio Nacional sobre los Efectos Adversos ligados a la Hospitalización ${ }^{6}$ (ENEAS) en el año 2005. Sobre una muestra de 5624 pacientes en 24 hospitales públicos españoles, tenía como objeto estimar la incidencia de los efectos adversos en el hospital, los reingresos por efectos adversos y los efectos adversos evitables. La incidencia de efectos adversos es del 9.1\% de los pacientes estudiados, siendo de éstos un 37.4\% los relacionados con la medicación, y las IN el segundo efecto adverso más frecuente. Se consideran evitables un $56.6 \%$ de todas las infecciones ${ }^{7}$. 
En el año 2006, para analizar la repercusión de la bacteriemia relacionada con catéter venoso central (BRCVC), Wenzel $^{8}$ analiza 6000 altas hospitalarias entre 6 millones de pacientes ingresados en hospitales de agudos en EEUU durante un año. Estos pacientes generan aproximadamente 18 millones de días de estancia en UCI. Un 54\% de los pacientes son portadores de catéter venoso central (CVC), lo que supone de un modo aproximado 9.7 millones de días de CVC. Estimando una tasa de infección por catéter de 5\%odías de CVC, producen 48.600 BRCVC, la mortalidad cruda de los pacientes con BRCVC es del 50\%, por lo que unos 24.300 pacientes fallecerán por dicha infección, la mortalidad atribuible a la BRCVC se estima en un $35 \%$, por lo que se puede considerar que aproximadamente 17.000 pacientes fallecen directamente como consecuencia de una BRCVC.

Ese mismo año se publica el estudio realizado por Pronovost ${ }^{9}$, dentro de una estrategia encaminada a mejorar la seguridad de los pacientes críticos en el Estado de Michigan. Realiza un estudio en 103 UCIs, para demostrar la reducción de la tasa de incidencia (TI) de BRCVC mediante la aplicación de medidas sencillas, basadas en la evidencia clínica y de escaso coste. Consiguen disminuir la TI de BRCVC de 7.7\%odías de CVC, a tan solo 1.4 BRCVC tras 18 meses de estudio.

A partir del estudio ENEAS en España, hemos asistido a una mejora de la cultura de seguridad en los hospitales, realizándose, en el año 2007 el estudio, "Incidentes y Efectos Adversos en Medicina Intensiva. Seguridad y Riesgo en el Paciente Crítico"(SYREC) ${ }^{10}$. La incidencia de errores y eventos adversos en Servicios de Medicina Intensiva (SMI) varía entre el 1\% al 32\%. La probabilidad de sufrir al menos un incidente relacionado con la seguridad, por el hecho de estar ingresado en una UCI, es del 62\%. En el día de estudio, se produjeron 1,22 incidentes por cada paciente ingresado, por lo que prácticamente todos los enfermos críticos están expuestos a sufrir un error. De todos los efectos adversos notificados las IN suponen un $8.1 \%$ del total.

En España, se conocían las tasas de BRCVC de las UCI participantes en el estudio nacional de vigilancia de la infección nosocomial en servicios de medicina intensiva $(\text { ENVIN })^{11,12}$. Tras la publicación del estudio de Pronovost, la Sociedad Española de Medicina Intensiva Crítica y Unidades Coronarias (SEMICYUC), junto con la Agencia 
de Calidad del Ministerio de Sanidad y Consumo (MSC), promueven el proyecto Bacteriemia-Zero (BZ). Mediante la utilización de una metodología similar a la americana, se pretendía disminuir la TI de BRCVC a menos de 4\%o días de CVC. Para la realización de este proyecto, se contó con el asesoramiento del grupo de Michigan y la OMS y se invitó a la participación de todas las comunidades autónomas.

Durante los meses de Octubre a Diciembre del 2007, se realizó un estudio piloto ${ }^{13}$ con participación de la UCI del Hospital Clínico Universitario, en el que a pesar de las dificultades iniciales para su implantación, se consiguió disminuir la tasa de BRCVC. Tras los ajustes definitivos del proyecto, y la aprobación del mismo por las Consejerías de Sanidad de todas las comunidades autónomas, se consigue realizar definitivamente el proyecto BZ a nivel nacional entre los meses de Enero del 2009 a Junio del 2010 consiguiendo los objetivos esperados.

Tras la implantación de las medidas de $\mathrm{BZ}^{14}$, se demuestra que no solo disminuyen las BRCVC, sino que lo hacen todas las infecciones adquiridas en UCI, en especial las neumonías asociadas a ventilación mecánica (NAVM), sin haber realizado ninguna medida específica para ello.

Durante el año 2010 las TI se mantienen en cifras similares al año anterior, por lo que se decide realizar otro proyecto mediante la colaboración de la SEMICYUC, el MSC, y las comunidades autónomas denominado Neumonía-Zero $(\mathbf{N Z})^{15}$, para disminuir la TI de NAVM a menos de 9\%o días de VM. Se realiza de Abril del 2011 a Diciembre del 2012, consiguiendo una reducción de la tasa nacional a 6.8 NAVM por 1000 días de VM.

Así pues, a lo largo de esta década, se ha pasado de considerar las infecciones adquiridas en UCI como un mal inevitable, como una consecuencia de la hospitalización y un precio a la sofisticación tecnológica, a tener una visión más crítica, considerando que las infecciones pueden evitarse, no deben ocurrir, y considerándose un fallo del sistema de seguridad, y un efecto adverso de los cuidados sanitarios que son evitables.

Basados en todas las consideraciones previas, el objetivo de este trabajo, es analizar la evolución de las tasas de infección adquirida en la UCI del Hospital Clínico 
Universitario de Salamanca, analizando las características de los pacientes ingresados, las infecciones diagnosticadas, y los gérmenes aislados.

Así, se pretende entender de una manera más profunda, qué pacientes son los más susceptibles de sufrir infección, y cuáles son sus factores de riesgo, para intentar realizar medidas de prevención demostradas en la evidencia científica para disminuir el riesgo de adquisición de infección, dada las implicaciones de la misma en cuanto a incremento de mortalidad atribuible, y de la estancia en UCI y costes asociados.

Analizados los datos de este prólogo, consideramos, pues, de sumo interés y originalidad, hacer un estudio de la importancia de la vigilancia de la infección nosocomial adquirida en UCI. No solo como descripción de la misma, sino valorando la eficacia de medidas realizadas en el periodo de estudio, para intentar mejorar la seguridad dentro de las UCIs y para disminuir específicamente las BRCVC y la NAVM. El objetivo será que el control del número de infecciones adquiridas en UCI, disminuya la morbimortalidad de los pacientes potencialmente infectados de manera significativa, así como los costes que hubieran supuesto el tratamiento de estas infecciones si hubieran sucedido. 
as infecciones nosocomiales se definían como aquellas que son adquiridas durante la estancia hospitalaria, después de las 48 horas del ingreso en el hospital, y que no estaban presentes, ni en periodo de incubación, antes del ingreso del paciente. Hoy este término ha quedado obsoleto, y se prefiere hablar de infecciones relacionadas con la asistencia sanitaria, debido a que los cuidados sanitarios no siempre se llevan a cabo en el hospital, puesto que se han desarrollado unidades de hospitalización a domicilio, centros geriátricos con cuidados asistidos, hemodiálisis, hospitales de día, y servicios de emergencia prehospitalaria.

Es bien conocido el impacto de estas infecciones en la morbilidad y mortalidad, prolongación de estancias hospitalarias, aumento del coste sanitario, mayor uso de antibióticos, y emergencia de gérmenes resistentes. La aplicación de medidas de vigilancia y prevención de la IN, han conseguido disminuir la incidencia de las misma, la mortalidad, y los costes.

En las UCI se diagnostican entre la cuarta y quinta parte de todas las IN, en especial las que tienen mayor impacto en la evolución de los pacientes, como son las NAVM y las BRCVC. La mayoría de las infecciones que se diagnostican en las UCI se relacionan con dispositivos invasivos que alteran las barreras de defensa natural, y pueden favorecer la transmisión de agentes patógenos, que suelen tener elevadas tasas de resistencias antimicrobianas, y forman parte de la flora de las UCI, que son seleccionados mediante la utilización de antimicrobianos de amplio espectro. 


\section{VIGILANCIA DE LA INFECCIÓN NOSOCOMIAL}

La vigilancia de la $\mathrm{IN}^{16}$ es un objetivo esencial, ya que la información obtenida facilita al personal sanitario el conocimiento de la evolución de las TI, así como los cambios del patrón de resistencia-sensibilidad de los patógenos endémicos en cada UCI. La comparación secuencial de las TI, permite realizar una valoración de la calidad asistencial, introducir medidas de corrección, y evaluar las medidas implantadas. La vigilancia tiene como prioridad vigilar las infecciones más frecuentes, las que tienen mayor efecto en la morbilidad y mortalidad, y costes (días de estancia y días de tratamiento antibiótico). Éstas, están asociadas a dispositivos invasivos ${ }^{17}$, y pueden ser evitables como:

- NAVM.

- BRCVC.

- ITUSV.

Esta actividad debe ser una de las misiones a desempeñar por los intensivistas en las UCI. En la actualidad, se considera a las IN como efecto adverso de los cuidados sanitarios, un fallo de la seguridad del paciente. Se consideran un evento prevenible, por ello se establecen los sistemas de vigilancia que sirven para monitorizar las TI, y la detección de brotes de infección por patógenos multirresistentes.

La SEMICYUC publicó en 2005 los indicadores de calidad del paciente crítico $^{18}$, que se han revisado y actualizado en $2011^{19}$, considerándose estándares de calidad respecto a las enfermedades infecciosas, los más importantes se muestran en la tabla 1. 


\begin{tabular}{|c|c|c|c|}
\hline INDICADOR & DIMIENSION & TIPO & ESTÁNDAR \\
\hline DI BRCVC & $\begin{array}{l}\text { Seguridad y } \\
\text { efectividad }\end{array}$ & Resultado & 4 \%o días de CVC \\
\hline DI ITUSV & $\begin{array}{l}\text { Seguridad y } \\
\text { efectividad }\end{array}$ & Resultado & 4,5 \%o días de SV \\
\hline DI NAVM & $\begin{array}{l}\text { Seguridad y } \\
\text { Efectividad }\end{array}$ & Resultado & $12 \%$ días de $\mathrm{VM}$ \\
\hline $\begin{array}{l}\text { RESUCITACIÓN PRECOZ DE } \\
\text { LA SEPSIS } \\
\text { GRAVE / SHOCK SÉPTICO }\end{array}$ & Efectividad & Proceso & $95 \%$ \\
\hline $\begin{array}{l}\text { TRATAMIENTO ANTIBIÓTICO } \\
\text { EMPÍRICO } \\
\text { INADECUADO EN LA } \\
\text { INFECCIÓN } \\
\text { ATENDIDA EN LAS UCI }\end{array}$ & $\begin{array}{l}\text { Seguridad y } \\
\text { efectividad }\end{array}$ & Resultado & $10 \%$ \\
\hline INFECCIONES POR SARM & $\begin{array}{l}\text { Seguridad y } \\
\text { efectividad }\end{array}$ & Resultado & $<2.5 \%$ \\
\hline $\begin{array}{l}\text { INDICACIÓN DE } \\
\text { AISLAMIENTOS }\end{array}$ & $\begin{array}{ll}\text { Seguridad } & y \\
\text { adecuación } & \end{array}$ & Proceso & $100 \%$ \\
\hline $\begin{array}{l}\text { INICIO PRECOZ } \\
\text { ANTIBIOTERAPIA EN LA } \\
\text { SEPSIS GRAVE }\end{array}$ & $\begin{array}{l}\text { Efectividad } \mathrm{y} \\
\text { seguridad }\end{array}$ & Proceso & $100 \%$ \\
\hline
\end{tabular}

\subsection{DEFINICIÓN DE VIGILANCIA}

La vigilancia en salud pública, se define como el proceso de recogida sistemática, continua, análisis, interpretación, y difusión, de los datos referidos a un determinado evento relacionado con la salud, con objeto de utilizarlos en acciones sobre ella, para reducir la morbilidad y mortalidad, y mejorar la misma ${ }^{20}$.

El proceso de vigilancia es dinámico y permite determinar la frecuencia de las infecciones nosocomiales, detectar cambios en la frecuencia de las mismas, instaurar medidas de control, y determinar si las intervenciones son efectivas ${ }^{21}$. 


\subsection{OBJETIVOS DEL SISTEMA DE VIGILANCIA}

Aunque el objetivo principal es la reducción de las tasas de $\mathrm{IN}$, podemos establecer otros ${ }^{22}$ :

- Reducir al mínimo la incidencia de IN, identificando a los pacientes de mayor riesgo, de manera que se puedan introducir medidas selectivas para la prevención de infecciones y que sean costo-efectiva.

- Establecer niveles endémicos de las IN, detectar cambios de los patrones de sensibilidad, y conocer los factores de riesgo de infección.

- Detectar a tiempo real la posible existencia de un brote epidémico, o la presencia de infecciones por gérmenes especialmente problemáticos.

- Determinar la necesidad de adoptar medidas especiales de control de brotes, y evaluar los efectos de estas medidas de control.

- Estandarizar la información y permitir la comparación entre unidades.

- Evaluar la calidad asistencial, puesto que los resultados de los programas de IN son indicadores fiables de proceso y resultado, y constituyen el centro de los programas de mejora continua de la calidad.

- Evaluar el coste económico de la infección, y utilizarlo como instrumento de gestión y planificación sanitaria. 


\subsection{COMPONENTES DE LA VIGILANCIA}

La vigilancia es un proceso dinámico que no solo se compone de la recogida sistemática de los datos, sino también el análisis inmediato y la interpretación de los mismos, con propuesta de solución, y la comunicación de estos a aquellos que tienen capacidad de realizar los $\operatorname{cambios}^{17}$. Es lo que se denomina "información para la acción"

- Planificación: identificar la población y las infecciones que se van a vigilar. La vigilancia debe centrarse en los procesos de alto riesgo para aumentar la eficacia de la misma. En las UCIs está justificada por la alta frecuencia de infecciones en estas unidades. Las características de los pacientes críticos los hacen especialmente vulnerables al desarrollo de complicaciones infecciosas.

- Utilización de definiciones consensuadas: la aceptación de definiciones y criterios diagnósticos de infecciones nosocomiales estandarizados y aceptados por todos, permite disminuir la variabilidad y mejorar la comparación de los datos ${ }^{23}$.

- Recogida de los datos: se debe definir los datos que se recogerán, las fuentes de la información, y los responsables de su recogida. Se recomienda una recogida activa realizada por personal formado específicamente en el control de la IN. Puede ser prospectiva o retrospectiva, aunque la capacidad para detectar infecciones es similar en ambos métodos de vigilancia. Sin embargo, la recogida prospectiva tiene la ventaja de permitir la detección precoz de aumento de tasas o de gérmenes multirresistentes, y anticipar la implantación de medidas de control.

\subsection{ANALISIS E INTERPRETACIÓN DE LOS DATOS}

El propósito de la vigilancia no es solo obtener información acerca de las infecciones, sino identificar problemas rápidamente, y realizar cambios para reducir riesgos de infección. Para ello se pueden realizar estudios de prevalencia, y estudios de incidencia ${ }^{24}$. 
- Estudios de prevalencia: permiten conocer la proporción de pacientes que tienen infección en un momento determinado, son estudios transversales sencillos de realizar, que permiten conocer las tasas de prevalencia. Estos estudios tienen sesgos porque la estancia hospitalaria de los pacientes infectados es mayor, y aumenta la tasa de pacientes infectados durante el periodo que se realiza el estudio. Un ejemplo de este estudio es el EPINE $^{25}$.

- Estudios de incidencia: son considerados el modelo de referencia. Permiten la identificación de infecciones, exige la observación de todos los pacientes dentro de una población en un periodo determinado. Esta clase de vigilancia es más eficaz para detectar las diferencias de las TI de infección, seguir las tendencias, vincular las infecciones con los factores de riesgo y hacer comparaciones entre unidades y hospitales. Estos estudios exigen más trabajo, más tiempo y son más costosos que los estudios de prevalencia. El ejemplo de este tipo de estudio es el ENVIN ${ }^{12}$.

\subsection{MEDIDAS DE FRECUENCIA DE INFECCION NOSOCOMIAL}

- La prevalencia determina la proporción de pacientes que padece una determinada enfermedad, en un momento o periodo de tiempo determinado.

\begin{tabular}{|l|l|l|}
\hline MEDIDAS DE & DEFINICIÓN & CÁLCULO \\
\hline Pacientes con IN & $\begin{array}{l}\text { Porcentaje de pacientes que presentan } \\
\text { IN en el periodo de estudio. }\end{array}$ & $\begin{array}{l}\text { Total pacientes con IN/total } \\
\text { pacientes x 100 }\end{array}$ \\
\hline Bacteriemia & $\begin{array}{l}\text { Prevalencia de bacteriemia nosocomial } \\
\text { entre todos los pacientes estudiados }\end{array}$ & $\begin{array}{l}\text { Pacientes con bacteriemia } \\
\text { nosocomial/total pacientes } x \\
100\end{array}$ \\
\hline BRCVC & $\begin{array}{l}\text { Prevalencia de BRCV entre todos los } \\
\text { pacientes con CVC. }\end{array}$ & $\begin{array}{l}\text { Pacientes con BRCV/total } \\
\text { pacientes CVC x 100 }\end{array}$ \\
\hline Neumonía postoperatoria & $\begin{array}{l}\text { Prevalencia de neumonía nosocomial } \\
\text { entre todos los pacientes que han sido } \\
\text { operados }\end{array}$ & $\begin{array}{l}\text { Pacientes con neumonía } \\
\text { postquirúrgica/total pacientes } \\
\text { intervenidos x 100 }\end{array}$ \\
\hline NAVM & $\begin{array}{l}\text { Prevalencia de NAMV entre todos los } \\
\text { pacientes con VM. }\end{array}$ & $\begin{array}{l}\text { Pacientes con NAVM/total } \\
\text { pacientes VM x 100 }\end{array}$ \\
\hline
\end{tabular}

Tabla 2: Ejemplos de diferentes medidas de frecuencia estudio EPINE. 
- La incidencia se define como el número de casos nuevos de una infección que se desarrolla en una población en un periodo de tiempo determinado. Hay dos tipos de medidas de incidencia:

- Tasa de incidencia (TI): proporción de individuos sanos que desarrollan una infección a lo largo de un periodo de tiempo concreto. Se obtiene dividiendo el número de infecciones por el total de pacientes que cumplen los criterios de inclusión. Se expresa en porcentaje.

- Densidad de incidencia (DI): expresa el dividendo entra el número de casos de una infección, por el total de estancias o por el número total de exposición al factor de riesgo. Se expresa en número de infecciones por 1000 días de estancia, o por 1000 días de exposición.

\begin{tabular}{|l|l|}
\hline MEDIDA DE INCIDENCIA & CÁLCULO \\
\hline TI NAMV & $\mathrm{n}^{\circ}$ total de NAVM / total pacientes incluidos x 100 \\
\hline TI NAMV & $\mathrm{n}^{\circ}$ total de NAVM / total pacientes con VM x 100 \\
\hline DI NAMV & $\mathrm{n}^{\circ}$ total de NAVM / total días de UCI x 1000 \\
\hline DI NAMV & $\mathrm{n}^{\circ}$ total de NAVM / total días de VM x 1000 \\
\hline
\end{tabular}

Tabla 3: Ejemplos de diferentes medidas de frecuencia estudio ENVIN.

\subsection{COMUNICACIÓN DE LOS DATOS}

Los datos objetos de vigilancia ${ }^{25}$ deben comunicarse a los servicios asistenciales y a todos los profesionales del servicio, y deben difundirse entre los directivos de los hospitales como herramientas de gestión clínica ${ }^{12,26}$. A partir de los datos obtenidos los hospitales y las UCIs, deberán desarrollar una línea de acción para el control de las infecciones. Estas medidas pueden ser de dos tipos: programas de prevención, y acciones de control. Las primeras conllevan actividades de programación y protocolización, definición de las actividades a realizar, implantarlas y evaluarlas, mientras que las últimas consisten en el mantenimiento de los programas preventivos llevados a cabo. 


\subsection{REDES DE VIGILANCIA}

- EPINE $^{26,27}:$ El Estudio de Prevalencia de las Infecciones Nosocomiales en España, es promovido por la Sociedad Española de Medicina Preventiva, Salud Pública e Higiene Hospitalaria. Se realiza anualmente desde 1.990, con la misma metodología y en más de 250 hospitales. Es un instrumento de vigilancia epidemiológica que consiste en realizar una vez al año una encuesta transversal exhaustiva en hospitales de pacientes agudos, de acuerdo con una metodología común, y con el objetivo de determinar la prevalencia de la IN y sus factores de riesgo. Se realiza durante dos semanas al año, y está enfocado más a una valoración global del hospital, que a unidades concretas. La regularidad de este estudio permite conocer la evolución de las infecciones. En la actualidad y a partir del año 2012, está en proceso de convergencia con la red de vigilancia europea European Prevalence Survey of Healthcare Associated Infection and Antimicrobial Use (EPPS).

- NNIS $^{3}$ : National Nosocomial Infections Surveillance System. Es el prototipo de estudio de incidencia. Desarrollado en EEUU y promovido por los Centers for Disease Control and Prevention (CDC). Fue el primer programa de vigilancia de la infección que se utilizó una metodología estandarizada, siendo de participación voluntaria. Se lleva a cabo desde los años 70, en el que los hospitales participan voluntariamente aportando las TI de infección. El NNIS utiliza protocolos estandarizados y ofrece criterios clínicos y de laboratorio para definir las distintas infecciones. Los objetivos del programa NNIS son describir la epidemiología de las infecciones hospitalarias, promover la vigilancia epidemiológica en los hospitales de Estados Unidos, y facilitar la comparación de las TI entre hospitales para mejorar la calidad asistencial. La metodología del programa consiste en la recogida prospectiva de información por grupos específicos de pacientes: UCIs, unidades neonatales, pacientes quirúrgicos. Dado que las infecciones adquiridas en UCI son las que tienen mayor morbimortalidad asociada el NNIS ha generado una serie de indicadores que han servido como referencia para estudios de vigilancia desarrollados posteriormente ${ }^{17}$. 


\section{- HELICS $^{28}$ : Hospitals in Europe Link for Infection Control through} Surveillance. Siguiendo el modelo estadounidense del NNIS, varios países europeos desarrollaron sistemas nacionales o regionales de vigilancia de la infección y en este sentido la Unión Europea patrocinó el proyecto HELICS para la estandarización de la vigilancia de infecciones adquiridas en los hospitales ya que se calcula que en la Unión Europea hay unos tres millones de IN al año y 50.000 muertes atribuibles. Por medio de seminarios realizados durante la década de 1990, se unificaron los métodos y se preparó la creación de una base de datos europea en la que los representantes nacionales aportaban los datos nacionales con una metodología similar. En el año 2003 ya se recogieron datos globales y actualmente ambos sistemas de vigilancia están homologados bajo la coordinación del European Centre for Disease Prevention and Control (ECDC), agencia de la Unión Europea creada para fortalecer las defensas de Europa contra las enfermedades infecciosas donde se recogen los datos de resistencias a los antimicrobianos y las infecciones asociadas a los cuidados sanitarios. El programa HELICS incluye principalmente datos de infección quirúrgica y de pacientes críticos.

- ENVIN $^{12}$ : Es un estudio multicéntrico, prospectivo, anual, que se realiza durante tres meses para conocer la TI de las infecciones adquiridas en las UCIs especialmente las relacionadas con dispositivos invasivos como la NAVM, la BRCVC y las ITUSV. Fue desarrollado por la SEMICYUC, presentándose el primer informe en 1994, basado en los datos de las primeras 34 UCIs participantes. Paulatinamente el número de UCIs participantes fue creciendo hasta 173 unidades, con casi 20.000 pacientes incluidos en el periodo de estudio oficial en el año 2012. Se incluyen todos los pacientes ingresados en la UCI durante más de 24 horas, y el seguimiento se realiza hasta el alta de la UCI, o hasta un máximo de 60 días. Los enfermos se clasifican en función de la enfermedad de base, en médicos, quirúrgicos, traumáticos y coronarios. La gravedad se valora mediante el sistema Acute Physiology and Chronic Health Evaluation (APACHE II). ${ }^{29}$ Se estudian las infecciones que tienen relación de forma directa con factores de riesgo conocidos, y/o se asocian con una mayor morbilidad y mortalidad entre los pacientes críticos, como las NAVM, BRCVC, ITUSV y bacteriemias secundarias. Se realiza de acuerdo con los criterios para definir estas infecciones, que han sido publicados por los $\mathrm{CDC}^{30}$. Desde el año 2005 el programa 
ENVIN se ha transformado en ENVIN-HELICS adaptándose a la metodología europea.

\section{VIGILANCIA INFECCION EN UCI. PROGRAMA ENVIN.}

En las UCIs se diagnostican entre la cuarta y quinta parte de todas las IN, en especial las que tienen mayor impacto sobre la evolución de los pacientes críticos, como son las neumonías y las bacteriemias. La mayoría de estas infecciones están relacionadas con dispositivos invasivos que alteran las defensas del organismo, y pueden favorecer la trasmisión de patógenos entre pacientes.

La introducción de la metodología del sistema de vigilancia, ha supuesto una gran ayuda para abordar las enfermedades infecciosas en las UCI. Ha permitido conocer la evolución anual de las tasas de NAVM, BRCVC e ITUSV, en las UCI españolas, las etiologías de las infecciones, los datos de resistencias y sensibilidades antimicrobianas, y el uso de antibióticos. Los informes anuales se publican en la revista oficial de la especialidad ${ }^{31}$.

El conocimiento de las TI relacionadas con el empleo de dispositivos invasores, es uno de los elementos necesarios para evaluar la calidad asistencial de los SMI. Esto permite realizar una valoración de la misma, introducir medidas de control, y evaluar las medidas implantadas. En estos momentos, cerca de 200 UCIs españolas utilizan el programa ENVIN-HELICS para conocer sus TI, y evaluar si sus indicadores de infección se encuentran dentro de las cifras recomendadas por la SEMICYUC.

Las TI son un indicador de calidad ${ }^{19}$, por lo que los directivos de los hospitales deben posibilitar el desarrollo de sistemas de vigilancia de IN en pacientes críticos, facilitando los medios y el personal para ello. La vigilancia es el primer paso para establecer programas de intervención dirigidos a optimizar la asistencia sanitaria, y mejorar la calidad de nuestros hospitales. La vigilancia solo tiene sentido si su objetivo es disminuir la incidencia de IN. 
Los indicadores de calidad utilizados en la infección de nosocomial (tabla 4) pueden ser de estructura, de proceso, o de resultados. Hasta ahora los indicadores de calidad más utilizados han sido los de resultados, que permitían saber la TI en cada centro, y hacer retroalimentación al personal con el objeto de mejorar esta tasa. Con estos indicadores la infección ya ha sucedido, y siempre "se llega tarde". Las nuevas tendencias en vigilancia de la IN se centran en complementar estos datos con indicadores de estructura y proceso, si bien los indicadores de resultados basados en la experiencia del programa ENVIN son los que más consenso tienen. Se está trabajando en el diseño de indicadores de estructura y proceso estandarizados.

Los indicadores de estructura deben contener los pilares fundamentales para la vigilancia de la IN: la existencia de un programa de control de infecciones, personal formado con asignación de tareas específicas para el control de la infección, y las infraestructuras necesarias para llevar a cabo dicho programa. Si estos indicadores faltan, difícilmente se va a llevar a cabo la vigilancia y prevención.

\begin{tabular}{|l|l|}
\hline \multicolumn{2}{|l|}{ EJEMPLOS DE INDICADORES DE VIGILANCIA DE IN } \\
\hline Indicadores & Ejemplo \\
\hline De resultados & Tasa de IN. \\
& Tasa de NAVM. \\
Tasa de BRCVC. & Tasa de ITU-SV. \\
\hline De procesos & $\begin{array}{l}\text { Adherencia a práctica de higiene de manos. } \\
\text { Adherencia a medidas BZ. } \\
\text { Adherencia a medidas NZ. } \\
\text { Adherencia protocolo de profilaxis quirúrgica. }\end{array}$ \\
\hline De estructura & $\begin{array}{l}\text { Equipo de control de la infección nosocomial. } \\
\text { Adecuada ratio enfermería-paciente } \\
\text { Dispensadores de solución hidroalcohólica. }\end{array}$ \\
\hline
\end{tabular}

Tabla 4. Ejemplos de indicadores de vigilancia de infección nosocomial

Los indicadores de procesos nos permiten observar si se están cumpliendo las medidas preventivas durante la realización de los diferentes procedimientos, lo que permite actuar en tiempo real para mejorar el desarrollo de los mismos antes de que 
aparezca la infección, es decir, nos hacen ser previsores antes de que aparezcan los resultados.

\subsection{ANTECEDENTES DEL PROGRAMA ENVIN}

Hasta el inicio de los noventa, la vigilancia de la infección en UCI se hacía de manera discontinua e irregular. En una encuesta publicada en 1996, realizada en 1.005 UCI europeas, se demostró que solo el 19\% disponían de sistemas de vigilancia de IN continuos, y un $32 \%$ de manera discontinua. Se realizó con metodologías variadas, y no comparables, con pacientes y en unidades de características muy diferentes ${ }^{32}$. A inicios de los noventa, se inicia la vigilancia de la IN por la sociedad de medicina preventiva mediante el sistema EPINE. Utilizando una metodología transversal, se demostró que la tasa de IN en las UCI estaba en torno a un $25 \%$ de los pacientes ingresados en estas unidades. Los datos del EPINE sobreestiman la TI adquirida en UCI, porque no diferenciaban si la infección había sido adquirida durante su estancia, o si es que el paciente había ingresado por una infección. Además, al ser un estudio de prevalencia, era más fácil incluir pacientes más graves, con mayor estancia hospitalaria, y con mayor tasa de infección. Esto favoreció por parte de la SEMICYUC, la elaboración de un programa informático diseñado por intensivistas para valorar la TI asociada a dispositivos.

\subsection{CARACTERISTICAS DE LA BASE DE DATOS}

La base de datos ENVIN-HELICS consta de cuatro módulos principales (figura 2):

- Datos demográficos y epidemiológicos: donde se recoge la fecha de ingreso en UCI, la edad, el APACHE II, el tipo de paciente y la clase de ingreso. Con los años, se han ido añadiendo más registros, como los factores de riesgo de infección previo al ingreso: enfermedades como diabetes, cirrosis, insuficiencia renal, neoplasias, inmunodepresión, etc., además de factores de riesgo de infección adquiridos durante su estancia, como la existencia de dispositivos invasivos, nutrición parenteral, cirugía urgente, etc. 


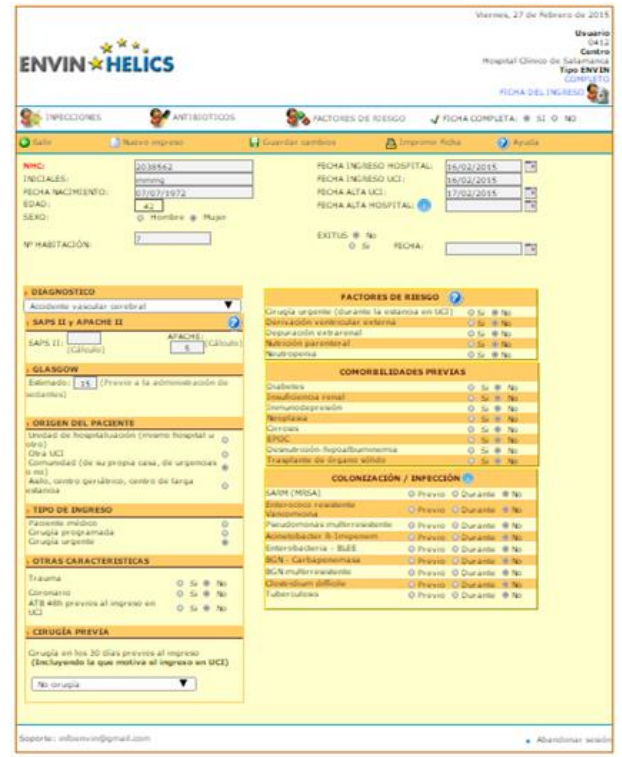

Figura 2: Pagina inicial de recogida de datos por paciente del programa ENVIN-HELICS.
- Factores de riesgo: el programa recoge las fechas de inicio y final de los factores de riesgo analizados: VM, ventilación no invasiva, presencia de CVC, tubo orotraqueal o cánulas de traqueotomía, sonda vesical.

- Infecciones: se recogen todas las infecciones diagnosticadas durante la estancia en UCI, clasificándolas como comunitarias, nosocomiales extraUCI y nosocomiales intraUCI. Permite recoger el tipo de infección, los gérmenes identificados, y los antibiogramas e los mismos.

- Antibióticos: permite recoger todos los antibióticos utilizados, los días de uso, la infección para la que se utiliza, y el tipo de uso que se realiza. Registra los cambios que se realizan de antibióticos, y el motivo del mismo, así como si el tratamiento empírico utilizado es adecuado o no.

Por lo tanto, la base de datos ENVIN-HELICS permite el control de las TI adquirida en UCI, los gérmenes aislados con su patrón de sensibilidad, y los antibióticos de referencia. Permitirá también el control administrativo de los pacientes ingresados en la unidad.

En el programa ENVIN, las infecciones objeto de vigilancia son las asociadas a dispositivos: NAVM, BRCVC, ITUSV, y bacteriemias secundarias. Se han utilizado distintas medidas de frecuencia, siendo el numerador el número de infecciones controladas de cada tipo, mientras que para el denominador se han utilizados diferentes valores como: número total de pacientes, número total de pacientes con el factor de riesgo relacionado con la infección, número de días de estancia en UCI, o número de días en que está presente el factor de riesgo de cada infección, como se describió en la 
tabla 3. De todas ellas, la DI con el factor de riesgo asociado a cada infección, es la que mejor permite expresar la evolución de la TI a lo largo de los años.

\subsection{UTILIDAD DEL PROGRAMA ENVIN}

El programa ENVIN está integrado en la actividad habitual de las UCIs en nuestro país, y nos proporciona gran información que permite conocer las TI locales de infección, y poder compararlas con las nacionales, o con otras unidades similares, es un indicador de calidad asistencial ${ }^{33}$. Entre sus fortalezas se incluye el identificar las tasas reales de la infección adquirida en cada unidad, y poder detectar brotes epidémicos, o conocer problemas de infraestructura. Permite realizar estudios epidemiológicos homogéneos, con unificación de los criterios diagnósticos, y de las definiciones de infección.

Los resultados están auditados, la base de datos tiene un sistema de control que permite minimizar los errores en la introducción de los datos, además un 10\% de los pacientes introducidos en la base de datos nacional son revisados por auditores externos para verificar la calidad de los $\operatorname{mismos}^{34}$.

Por último la unificación de la base de datos ENVIN con el programa HELICS, permite conocer no solo la tasa local y nacional, sino también nuestra posición respecto al resto de países que participan en el programa europeo ${ }^{35}$.

Todas estas fortalezas han conseguido que el registro ENVIN-UCI haya sido reconocido en diciembre del 2014, como registro de interés para el Sistema Nacional de Salud por el MSC.

\section{ETIOPATOGENIA DE LA INFECCION NOSOCOMIAL.}

La flora habitual de los pacientes, tiene una función protectora que evita la colonización por otros gérmenes patógenos. Cuando se produce un desequilibrio en esta flora, bien por desaparición o modificación de la flora habitual, o por sobrecrecimiento de la flora patógena, se facilita la colonización por gérmenes 
patógenos. No siempre que existe esta colonización se produce infección, ya que se tienen que producir algunas condiciones, como el aumento del inoculo bacteriano, o la disminución de los mecanismos de defensa del portador se puede producir infección ${ }^{36}$.

Al ingresar un paciente en la UCI puede estar colonizado por su flora habitual y no tener ningún tipo de infección, o ingresar por alguna infección adquirida fuera de UCI. Ésta puede ser comunitaria, asociada a los cuidados sanitarios, o infección nosocomial según los casos (figura 3).

Si al ingreso en la UCI el paciente no tiene signos de infección, puede que la desarrolle de modo precoz en las primeras 48 horas de ingreso. Habitualmente en pacientes sanos sin factores de riesgo, serán gérmenes comunitarios que colonizan en la orofaringe y tubo digestivo del paciente, que constituyen la flora endógena. Las infecciones adquiridas por esta vía se denominan infecciones primarias endógenas, y están causadas por flora que tiene el paciente en su aparato digestivo al ingreso en la UCI. Esta flora puede ser comunitaria, si el paciente viene de su domicilio, o asociada a los cuidados sanitarios, si el paciente ha sido tratado previamente con antibióticos, está ingresado en una residencia, o acude a hemodiálisis o a hospital de día, o si han estado previamente colonizados por gérmenes multirresistentes. Los gérmenes más frecuentemente aislados serán: S. Pneumoniae, S. Aureus, H. Influenzae, M. Catarralis. Estas infecciones representan aproximadamente el $50 \%$ de todas las infecciones.

Cuando el paciente lleva más de 48 horas ingresado en el hospital o en la UCI se produce un sobrecrecimiento y colonización por microorganismos de origen nosocomial, que suelen ser endémicos de las UCIs y que sustituyen la flora primaria endógena. Estos gérmenes, habitualmente del tracto digestivo de los pacientes, constituyen la flora endógena secundaria, siendo sus infecciones conocidas como infecciones endógenas secundarias o tardías. En este grupo suelen predominar las enterobacterias, como E. Coli, P. Aeuruginosa, Klebsiella Spp..., siendo más frecuente la aparición de formas multirresistentes. Estas infecciones suponen aproximadamente el $35-40 \%$ de las infecciones adquiridas en UCI. 


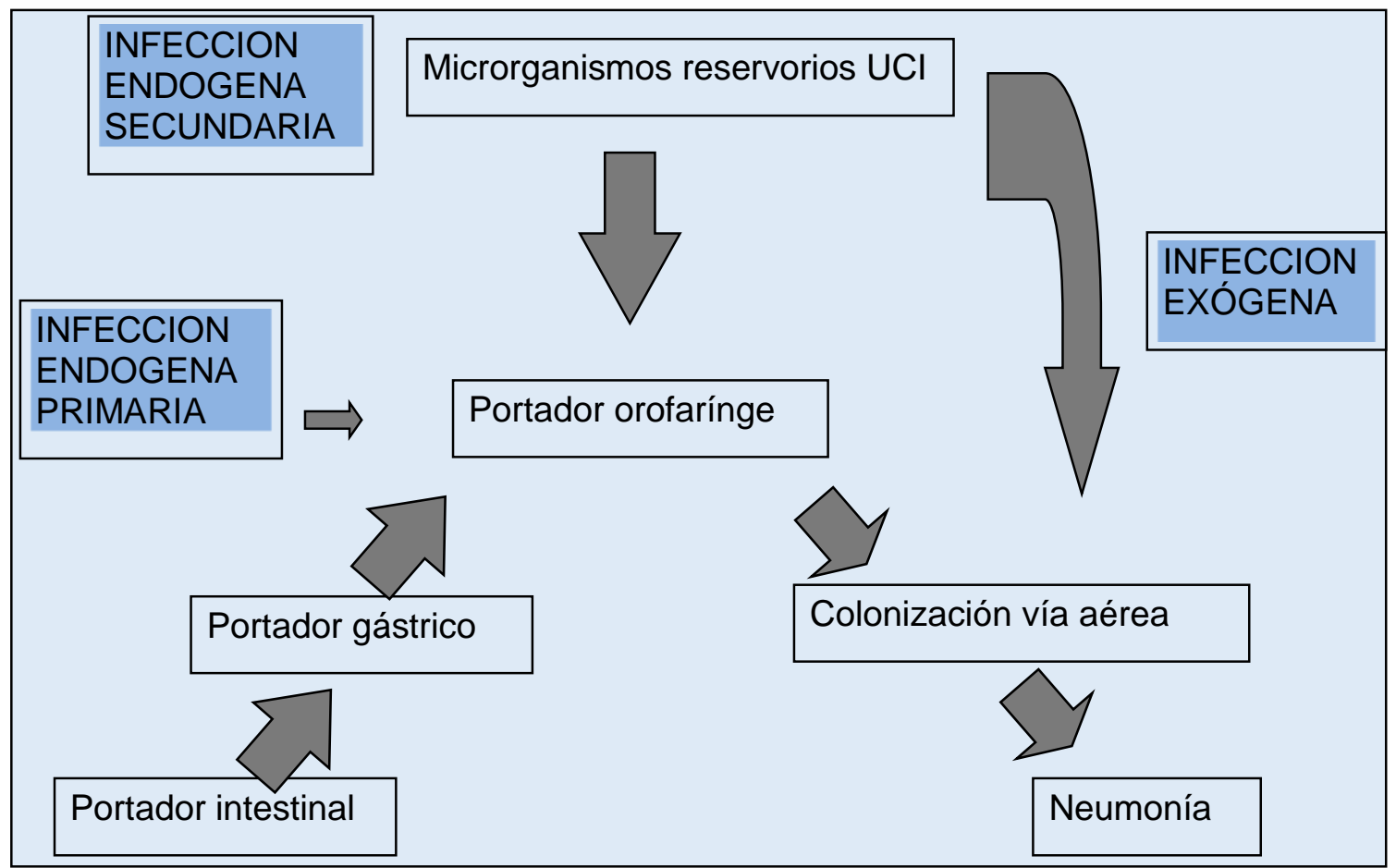

Figura 3: Patogenia de la infección nosocomial.

Existe otro mecanismo de producción de $\mathrm{IN}$, que es la adquisición de flora exógena. Es aquella en la que el microorganismo no coloniza previamente al paciente, y se suele transmitir de forma cruzada a través del personal sanitario. Es flora endémica de la UCI, y se conocen como infecciones exógenas. Suelen ser el 10-15\% de las infecciones adquiridas en las UCI.

\section{EPIDEMIOLOGIA DE LA INFECCION NOSOCOMIAL}

En la tabla 5, se observan los gérmenes más frecuentes responsables de la infección adquirida en UCI en el informe ENVIN del año $2013^{31}$. El germen aislado con mayor frecuencia en todas las infecciones adquiridas en UCI es la P. Aeruginosa, en un $14.51 \%$ del total de infecciones. Si observamos el tiempo de aparición de la infección, en las precoces (en los primeros 4 días del ingreso), el orden de frecuencia de los gérmenes varía siendo E. Coli el más frecuente con un 17,13\% de los aislamientos, seguidos de S. Aureus 11.315\%, P. Aeruginosa 9.57, y K. Pneumoniae $6.83 \%$. Si el tiempo de adquisición de la infección es más tardío (mayor de 7 días de ingreso), la etiología varía: P. Aeruginosa 15.59\%, E. Coli 13.13\%, K. Pneumoniae 7.14 y S. Epidermidis 6,87\%. 


\begin{tabular}{|c|c|c|c|c|c|c|c|c|c|c|}
\hline \multirow[t]{2}{*}{ GERMEN } & \multicolumn{2}{|c|}{ TOTAL } & \multicolumn{2}{|c|}{$<7$ DIAS } & \multicolumn{2}{|c|}{$>7$ DIAS } & \multicolumn{2}{|c|}{$<4$ DIAS } & \multicolumn{2}{|c|}{$>4$ DIAS } \\
\hline & $N$ & $\%$ & $N$ & $\%$ & $N$ & $\%$ & $N$ & $\%$ & $N$ & $\%$ \\
\hline P. Aeruginosa & 196 & 14.51 & 42 & 9.57 & 154 & 16.89 & 19 & 8.80 & 177 & 15.59 \\
\hline E. Coli & 186 & 13.77 & 76 & 17.31 & 110 & 12.06 & 37 & 17.13 & 149 & 13.13 \\
\hline K. Pneumoniae & 98 & 7.25 & 30 & 6.83 & 68 & 7.46 & 17 & 7.87 & 91 & 7.14 \\
\hline S. Epidermidis & 87 & 6.44 & 26 & 5.92 & 61 & 6.69 & 9 & 4.17 & 78 & 6.87 \\
\hline E. Faecalis & 83 & 6.14 & 26 & 5.92 & 57 & 6.25 & 15 & 6.94 & 68 & 5.99 \\
\hline S. Aureus & 81 & 6.00 & 49 & 11.16 & 32 & 3.51 & 27 & 12.50 & 54 & 4.76 \\
\hline C. Albicans & 73 & 5.40 & 20 & 4.56 & 53 & 5.81 & 8 & 3.70 & 65 & 5.13 \\
\hline P. Mirabilis & 51 & 3.77 & 21 & 4.78 & 30 & 3.29 & 11 & 5.09 & 40 & 3.52 \\
\hline E. Faecium & 47 & 3.48 & 7 & 1.59 & 40 & 4.39 & 2 & 0.93 & 45 & 3.96 \\
\hline A. Baumannii & 44 & 3.22 & 4 & 0.91 & 40 & 4.39 & 2 & 0.93 & 42 & 3.70 \\
\hline
\end{tabular}

Tabla 5. Etiología de infección nosocomial informe ENVIN 2013

La distribución del global de los 13514 gérmenes identificados en las UCI españolas durante el periodo ENVIN del año 2013, se muestra las siguientes tablas. 


\section{DISTRIBUCION DE LOS GÉRMENES.}

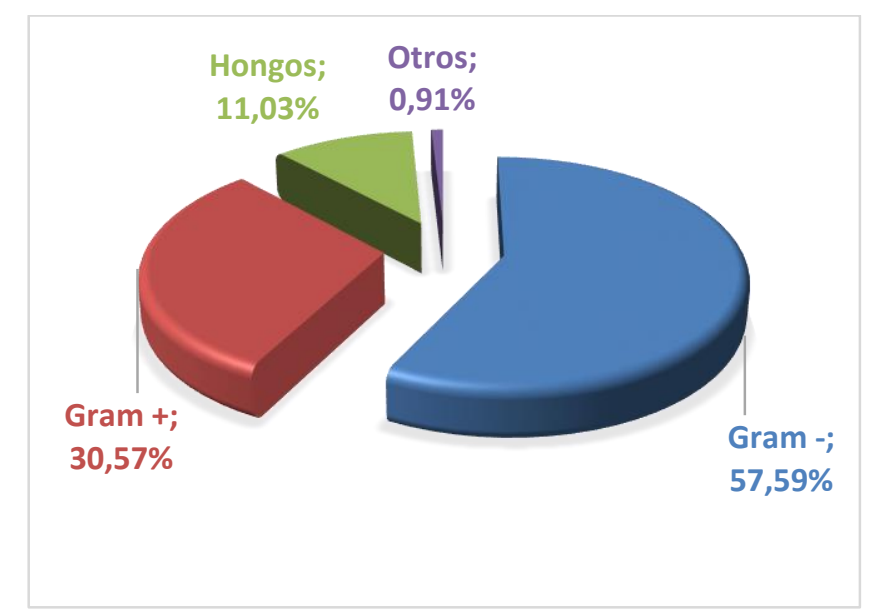

Figura 4: Grupos de germenes aislados en infecciones intraUCI. Datos informe ENVIN 2013.

o Grampositivos:

\begin{tabular}{|c|c|c|}
\hline \multirow[t]{2}{*}{ MICROORGANISMO } & \multicolumn{2}{|c|}{ TOTAL } \\
\hline & $\mathbf{N}$ & $\%$ \\
\hline S. Epidermidis & 87 & 21.07 \\
\hline E. Faecalis & 83 & 20.10 \\
\hline S. Aureus & 81 & 19.61 \\
\hline E. Faecium & 47 & 11.38 \\
\hline S. Coagulasa negativo & 40 & 9.69 \\
\hline Staph. Otros & 19 & 4.60 \\
\hline S. Pneumoniae & 15 & 3.63 \\
\hline SAMR & 13 & 3.15 \\
\hline Otros & 28 & 6.78 \\
\hline Total & 413 & 100 \\
\hline
\end{tabular}


○ Gramnegativos:

\begin{tabular}{|lrc|}
\hline MICROORGANISMO & \multicolumn{2}{c|}{ TOTAL } \\
\cline { 2 - 3 } & N & $\%$ \\
\hline P. Aeruginosa & 196 & 25.19 \\
\hline E. coli & 186 & 23.91 \\
\hline K. pneumoniae & 98 & 12.6 \\
\hline P. Mirabilis & 51 & 6.56 \\
\hline A. Baumannii & 44 & 5.66 \\
\hline E. Cloacae & 41 & 5.27 \\
\hline K. oxytoca & 24 & 3.08 \\
\hline E. Aerogenes & 24 & 3.08 \\
\hline S. Maltophila & 21 & 2.70 \\
\hline H. Influenzae & 20 & 2.57 \\
\hline M. Morganii & 17 & 2.19 \\
\hline S. Marcescens & 17 & 2.19 \\
\hline Otros & 39 & 4501 \\
\hline Total & $\mathbf{7 7 8}$ & $\mathbf{1 0 0}$ \\
\hline
\end{tabular}

Tabla 7: Distribución Gramnegativos. Informe ENVIN 2013.

○ Hongos:

\begin{tabular}{|lrr|}
\hline MICROORGANISMO & \multicolumn{2}{l|}{ TOTAL } \\
\cline { 2 - 3 } & N & $\%$ \\
\hline C. Albicans & 73 & 48.99 \\
\hline C. Glabrata & 23 & 15.44 \\
\hline C. Tropicalis & 19 & 12.75 \\
\hline C. Parapsilopsis & 15 & 10.07 \\
\hline Otros. & 19 & 12.75 \\
\hline Total & & \\
\hline
\end{tabular}

Tabla 8: Distribución hongos. Informe ENVIN 2013 


\section{FISIOPATOLOGIA DE LA INFECCIÓN NOSOCOMIAL}

Conocer los mecanismos de entrada y colonización de los microorganismos, puede facilitar la prevención de la IN.

Las UCIs son lugares con una alta concentración de pacientes graves, son áreas pequeñas con acumulación de personal, en ocasiones insuficiente para las demandas de trabajo, con baja relación enfermera paciente, y con mayor posibilidad de contagio horizontal. Los pacientes durante su ingreso se suelen colonizar con flora endógena secundaria, facilitándose la invasión a través de la pérdida de las barreras naturales por dispositivos invasivos, ya sea la piel en el caso de las BRCVC, la vía aérea en las NAVM, o la uretra en las ITUSV.

Describiremos los mecanismos patogénicos implicados en las principales infecciones asociadas a dispositivos.

\subsection{BRCVC.}

\subsubsection{FISIOPATOLOGIA DE LA BRCVC.}

Conocer cuál es la patogenia de la infección por CVC y los microorganismos implicados más frecuentes que la producen, nos ayudará a mejorar las estrategias de prevención y su tratamiento ${ }^{37}$.

Existen varias vías de infección de $\operatorname{los} \mathrm{CVC}^{38}$ (figura 5):

- Vía extraluminal: a través del punto de inserción del CVC, por migración de la flora de la piel a través del trayecto cutáneo de fibrina alrededor del mismo. Es la forma más frecuente $(45 \%)$.

- Vía endoluminal: los CVC se pueden infectar por esta vía a través de dos puertas de entrada: la vía más frecuente, es que la que se produce por vía externa, a 
través de las conexiones de los $\mathrm{CVC}$, los microorganismos, penetran por de las conexiones externas debido a las manipulaciones frecuentes (25\%). La vía de infección endoluminal se produce por la contaminación de los líquidos de infusión, este mecanismo es mucho menos habitual (2\%).

- Vía hematógena: los CVC se colonizan a partir de gérmenes procedentes de otras infecciones a distancia. Son menos frecuentes(3-10\%). La migración de los gérmenes desde el foco primario de infección provoca la colonización de trombos, que se forman en la punta del catéter y desarrollan el biofilm.

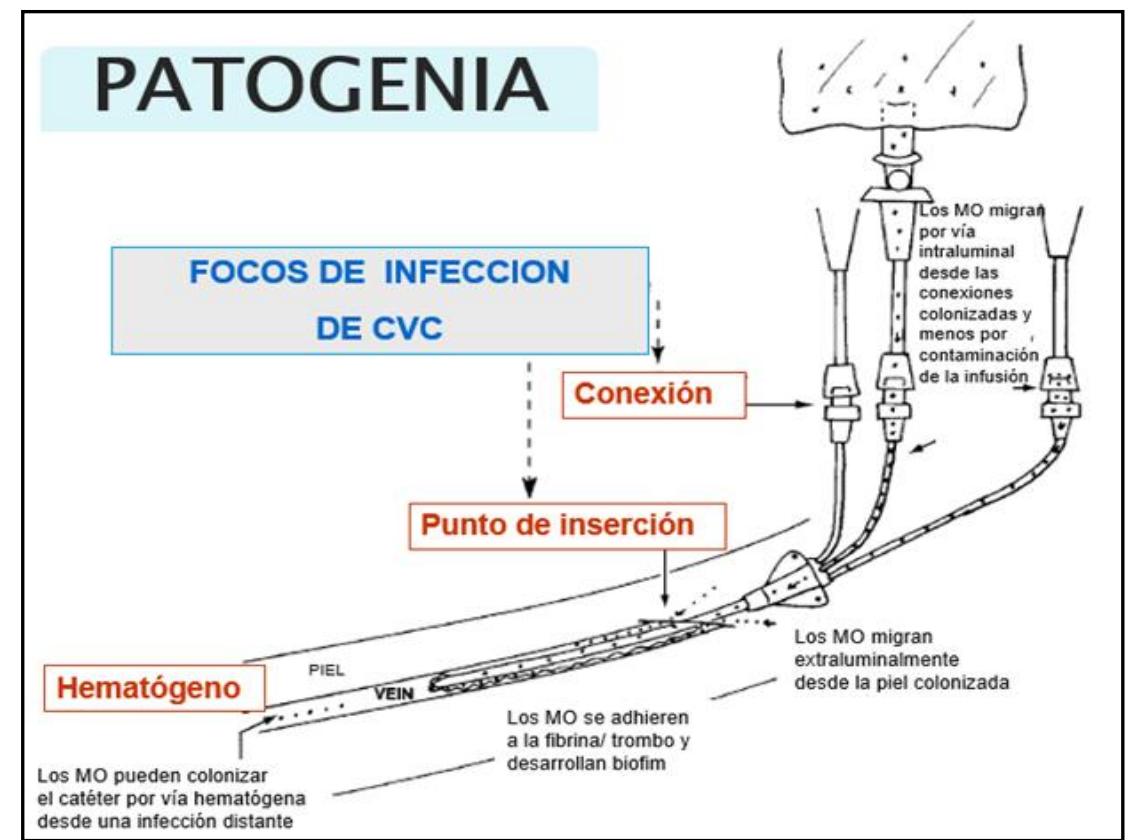

Figura 5: Patogenia de BRCVC. Adaptado del curso de formación de BZ

\subsubsection{FACTORES DE RIESGO DE INFECCION POR CVC}

Se han descrito numerosos factores de riesgo de infección por $\mathrm{CVC}^{39}$ :

- Infecciones con bacteriemia en otro lugar facilitan la infección hematógena.

- Colonización del catéter con microorganismos.

- Duración del CVC de más de 72 horas.

- Inexperiencia del personal que inserta el CVC. 
- Uso de llaves de tres pasos, aumentan el riesgo de colonización endoluminal.

- Según el lugar de la inserción: Menor riesgo para la subclavia. Mayor riesgo para la femoral y yugular interna.

- Los CVC con mayor número de luces aumentan el riesgo de BRCVC por el mayor trauma en el tejido subcutáneo, aumenta el número de manipulaciones, con mayor riesgo de contaminación de las conexiones del CVC.

- Administración de lípidos o NPT.

- Baja relación enfermera paciente.

\subsubsection{MICROBIOLOGÍA DE LA BRCVC}

La distribución de los 318 gérmenes aislados en las BRCVC en las UCI españolas durante el año 2013, se muestra en la siguiente figura:

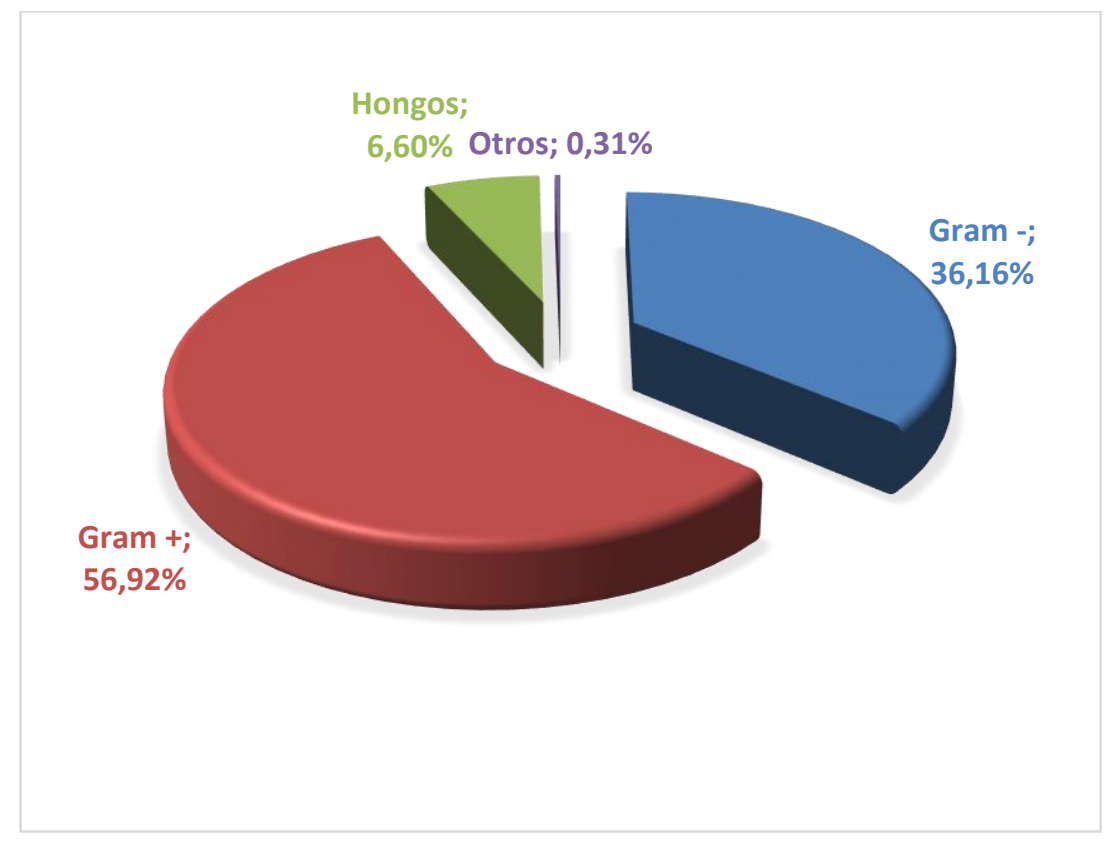

Figura 6: Grupos de germenes aislados en las BRCVC. Datos informe ENVIN 2013 
Los gérmenes más frecuentes encontrados en las BRCVC son:

\begin{tabular}{|c|c|c|c|c|c|c|}
\hline \multirow[t]{2}{*}{ MICROORGANISMO } & \multicolumn{2}{|c|}{ TOTAL } & \multicolumn{2}{|c|}{$<4$ DIAS } & \multicolumn{2}{|c|}{$>4$ DIAS } \\
\hline & $N$ & $\%$ & $N$ & $\%$ & $N$ & $\%$ \\
\hline S. Epidermidis & 81 & 25.47 & 8 & 32 & 73 & 24.91 \\
\hline S. Coagulasa negativo & 36 & 11.32 & 2 & 8 & 34 & 11.60 \\
\hline P. Aeruginosa & 27 & 8.49 & 2 & 8 & 25 & 8.53 \\
\hline E. Faecalis & 17 & 5.35 & 0 & 0 & 17 & 5.80 \\
\hline K. pneumoniae & 17 & 5.35 & 2 & 8 & 15 & 5.12 \\
\hline Staph. Otros & 16 & 5.03 & 1 & 4 & 15 & 5.12 \\
\hline C. Albicans & 13 & 4.09 & 0 & 0 & 13 & 4.44 \\
\hline A. Baumannii & 11 & 3.46 & 0 & 0 & 11 & 3.75 \\
\hline S. Aureus & 11 & 3.46 & 2 & 8 & 9 & 3.07 \\
\hline E. Faecium & 10 & 3.15 & 0 & 0 & 10 & 3.41 \\
\hline Otros & 111 & 24.83 & 8 & 32 & 36 & 12.28 \\
\hline Total & 318 & 100 & 25 & 100 & 293 & 100 \\
\hline
\end{tabular}

Tabla 9. Etiología de BRCVC informe ENVIN 2013.

En la tabla 9 mostramos los 10 gérmenes más frecuentes identificados, en el informe ENVIN del 2013. Hay un total de 318 BRCVC, de las cuales 293 se producen después de los 4 días de estancia en UCI, lo que indica que la BRCVC se produce de forma tardía, a lo largo de la evolución de los pacientes. La infección precoz es muy poco frecuente, relacionada con el momento de la inserción. La BRCVC se relaciona fundamentalmente con el mantenimiento del CVC.

\subsection{NAVM.}

\subsubsection{FISIOPATOLOGIA DE LA NAVM.}


Los mecanismos de entrada para el desarrollo de NAVM son ${ }^{41}$ :

- Vía aspirativa: Por macro o micro aspiraciones de secreciones procedentes de la orofarínge, y/o del estómago. Es el principal mecanismo de producción de las NAVM. Las secreciones colonizadas procedentes de la orofarínge o del contenido gástrico, pueden entrar a la vía respiratoria a través de las cuerdas vocales, que permanecen abiertas, atravesadas por el tubo endotraqueal. Si no se realiza correctamente el sellado de la vía aérea con el balón de neumotaponamiento, se puede permitir el paso de secreciones que se acumulan en el espacio subglótico.

- Inoculación directa (vía inhalatoria): A través del tubo endotraqueal, durante la aspiración de secreciones, fibrobroncoscopias o nebulizaciones. Es una infección cruzada mediante la contaminación del agua en los circuitos del ventilador, o de las soluciones nebulizadas, por inadecuada higiene de manos en la manipulación de la vía aérea, o mediante la colonización de equipos e instrumental.

- Translocación bacteriana: Mecanismo basado en la disfunción de la mucosa intestinal, que habitualmente actúa como barrera de protección entre los gérmenes de la luz intestinal y el torrente sanguíneo. Cuando esta barrera es sometida a isquemia, se puede favorecer el paso de bacterias y productos inflamatorios a la sangre. Es menos frecuente que los anteriores.

- Vía hematógena: Se produce por la colonización del pulmón desde un foco infeccioso extrapulmonar. Es un mecanismo excepcional.

\subsubsection{FACTORES DE RIESGO DE NAVM}

Podemos diferenciar entre factores intrínsecos, que son dependientes de las condiciones del paciente, frente a los que poco podemos hacer para evitarlos, y factores extrínsecos, que son dependientes de los cuidados intensivos en los que si podemos intervenir para prevenir las $\mathrm{NAVM}^{42}$. 


\section{- Factores intrínsecos:}

- Edad mayor de 60 años.

- Gravedad de la enfermedad de base.

- Patología traumática.

- Grandes quemados.

- Malnutrición.

- Parada cardiorrespiratoria.

- Disminución del nivel de conciencia.

- Existencia de sinusitis.

- Pacientes en postoperatorio de cirugía torácica y abdominal.

- Cualquier estado que provoque inmunodepresión.

- Enfermedad pulmonar obstructiva crónica.

- Diabetes.

- Alcoholismo.

- Factores extrínsecos:

- Duración prolongada de la VM.

- Intubación urgente.

- Reintubación.

- Alteración de los reflejos de la vía aérea.

- Presión inadecuada del balón de neumotaponamiento.

- Decúbito supino o posición del cabecero $<30^{\circ}$.

- Antiácidos.

- SNG.

\subsubsection{MICROBIOLOGÍA DE LA NAVM}

La distribución de los 493 gérmenes aislados en las NAVM, en las UCI españolas durante el año 2013 es la siguiente: 


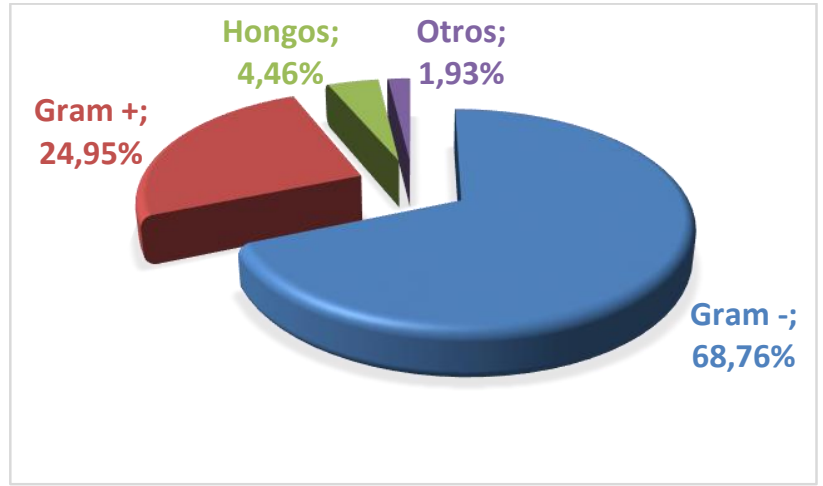

Figura 7: Grupos de germenes aislados en las NAVM. Datos informe ENVIN 2013

Los gérmenes más frecuentes encontrados en las NAVM diagnosticadas en España se muestran en la tabla 10.

\begin{tabular}{|c|c|c|c|c|c|c|c|c|c|c|}
\hline \multirow[t]{2}{*}{ GERMEN } & \multicolumn{2}{|c|}{ TOTAL } & \multicolumn{2}{|c|}{ <7 DIAS } & \multicolumn{2}{|c|}{$>7$ DIAS } & \multicolumn{2}{|c|}{ <4 DIAS } & \multicolumn{2}{|c|}{$>4$ DIAS } \\
\hline & $\boldsymbol{N}$ & $\%$ & $N$ & $\%$ & $N$ & $\%$ & $N$ & $\%$ & $N$ & $\%$ \\
\hline P. Aeruginosa & 104 & 21,10 & 24 & 13,19 & 80 & 25,72 & 12 & 12,0 & 92 & 23,41 \\
\hline S. Aureus & 64 & 12,98 & 38 & 20.88 & 26 & 8,36 & 20 & 20,0 & 44 & 11,20 \\
\hline K. Pneumoniae & 42 & 8,52 & 14 & 7,69 & 28 & 9,00 & 8 & 8,0 & 34 & 8,65 \\
\hline E. Coli & 41 & 8,32 & 19 & 10,44 & 22 & 7,07 & 10 & 10,0 & 31 & 7,89 \\
\hline A. Baumannii & 25 & 5,07 & 3 & 1,95 & 22 & 7,07 & 2 & 2,0 & 23 & 5,85 \\
\hline E. Cloacae & 25 & 5,07 & 10 & 5,49 & 15 & 4,82 & 6 & 6,0 & 19 & 4,83 \\
\hline H. Influenzae & 20 & 4,06 & 15 & 8,24 & 5 & 1,61 & 8 & 8,0 & 12 & 3,05 \\
\hline E. Aerogenes & 16 & 3,25 & 8 & 4,40 & 8 & 2,57 & 6 & 6,0 & 10 & 2,54 \\
\hline S. Pneumoniae & 15 & 3,04 & 12 & 6,59 & 3 & 0,96 & 9 & 9,0 & 6 & 1,53 \\
\hline S. Maltophila & 14 & 2,84 & 2 & 1,10 & 12 & 3,86 & 1 & 1,0 & 13 & 3,31 \\
\hline
\end{tabular}

Tabla 10. Etiología de NAVM. Informe ENVIN 2013.

Podemos observar como el germen más frecuente en las NAVM es la P. Aeruginosa, responsable del $20,1 \%$ de las mismas, seguida de S. Aureus con un 12,98\%. Sin embargo, su distribución varía en función del tiempo de adquisición de la infección: las neumonías precoces se producen fundamentalmente por flora endógena 
primaria, siendo S. Aureus el germen más frecuente en las NAVM adquiridas en los primeros días de ingreso en la unidad; las NAVM tardías, que se producen después de 7 días de ingreso, son los gérmenes de adquisición hospitalaria los principales responsables. P. Aeruginosa es responsable del 25,72\% de todas las NAVM. Esta diferente etiología tiene gran importancia a la hora de elegir el tratamiento antibiótico empírico, adecuado de estas neumonías.

\subsection{ITUSV}

\subsubsection{FISIOPATOLOGIA DE LA ITUSV}

Los microorganismos pueden colonizar la vejiga de diferentes maneras:

- $\quad$ Una de las formas puede ser durante la inserción de la SV, momento en el que se pueden arrastrar los gérmenes que colonizan el meato urinario y del extremo distal de la uretra.

- $\quad$ Por otro lado, una vez colocada la SV, existen dos vías por las que pueden entrar los gérmenes a la vejiga:

- Pueden entrar por vía extraluminal o perisonda. Este es el mecanismo más frecuente, sobre todo a partir del séptimo día de sondaje y siendo más habitual en mujeres (al ser más pequeña la longitud de la uretra). Se produce a través de una capa de moco periuretral, que se encuentra en el espacio entre la superficie externa de la uretra y la SV, que facilita la migración de las bacterias a la vejiga

○ Los gérmenes también pueden llegar a la vejiga por vía intraluminal, ascendiendo a través de la luz interna de la SV. Para evitar esta vía de infección, juega un papel muy importante los sistemas de drenaje cerrado. Aunque éste, en muchas ocasiones es abierto para la toma de muestras, lavados vesicales o para vaciado, o bien por accidente. Suele contaminarse más frecuentemente en las conexiones entre la sonda y el tubo colector, y la válvula de drenaje de la bolsa de circuito cerrado. 
Un último mecanismo más raro en este tipo de infecciones es la diseminación hematógena.

Los programas de prevención se encaminarán a evitar la entrada de microorganismos en el proceso de inserción de la $\mathrm{SV}$, y cuando esté colocado, en impedir su entrada ya sea por vía intra o extraluminal.

\subsubsection{FACTORES DE RIESGO ITUSV}

Los factores de riesgo pueden ser intrínsecos, que dependen de las características de los paciente y pueden alterar los mecanismos de defensa habitual, como son la edad avanzada, el sexo femenino, patologías de base como la insuficiencia renal, diabetes mellitus, inmunosupresión, malformaciones, historia de infecciones previas, y colonización del meato uretral.

Entre los factores de riesgo extrínsecos están el tratamiento antibiótico (por alteración de la flora), el SV (que produce un trauma local con inflamación), lo que facilita la infección y el mantenimiento de la SV, especialmente si se utiliza el sistema de drenaje abierto, y la instrumentación de la vía urinaria. Respecto a la SV, tiene gran importancia la indicación del sondaje, su duración, el tipo de sistema (los abiertos más riesgo), y la técnica de inserción, y los cuidados del mismo.

\subsubsection{MICROBIOLOGÍA DE LA ITUSV}

La distribución de los gérmenes aislados en las ITU-SV en las UCI españolas, durante el año 2013 se muestra en figura 8. 


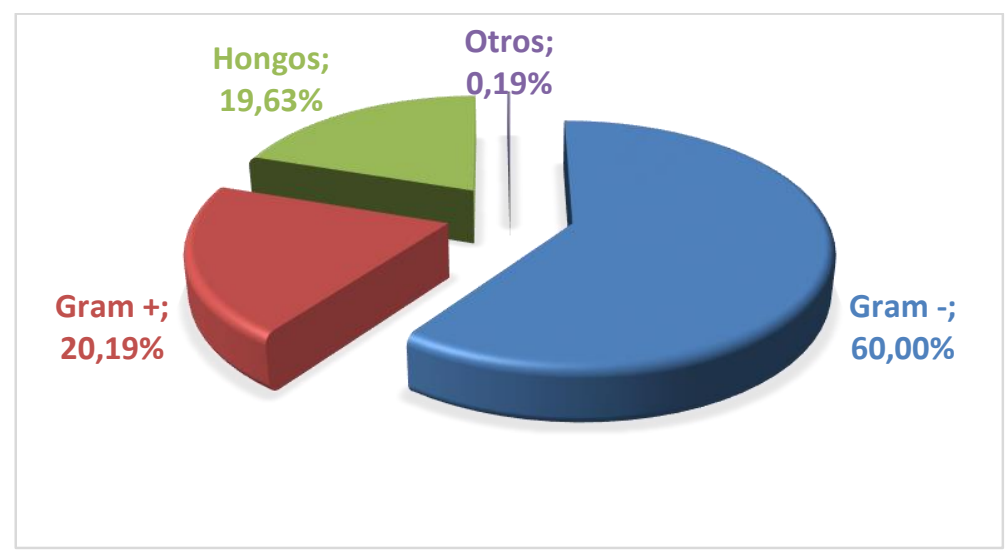

Figura 8: Grupos de germenes aislados en las ITUSV. Datos informe ENVIN 2013

Los microorganismos más frecuentemente encontrados en las ITUSV se describen en la tabla 11.

\begin{tabular}{|c|c|c|c|c|c|c|c|c|c|c|}
\hline \multirow[t]{2}{*}{ GERMEN } & \multicolumn{2}{|c|}{ TOTAL } & \multicolumn{2}{|c|}{$<7$ DIAS } & \multicolumn{2}{|c|}{$>7$ DIAS } & \multicolumn{2}{|c|}{$<4$ DIAS } & \multicolumn{2}{|c|}{$>4$ DIAS } \\
\hline & $\boldsymbol{N}$ & $\%$ & $N$ & $\%$ & $N$ & $\%$ & $N$ & $\%$ & $N$ & $\%$ \\
\hline E. Coli & 135 & 25.00 & 54 & 30.68 & 81 & 22.25 & 26 & 28.57 & 109 & 24.28 \\
\hline P. Aeruginosa & 65 & 12.04 & 12 & 6.82 & 53 & 14.56 & 5 & 5.49 & 60 & 13.36 \\
\hline C. Albicans & 55 & 10.19 & 17 & 9.66 & 38 & 10.44 & 7 & 7.69 & 48 & 10.69 \\
\hline E. Faecalis & 54 & 10.00 & 21 & 11.93 & 33 & 9.07 & 13 & 14.29 & 41 & 9.13 \\
\hline K. Pneumoniae & 39 & 7.22 & 13 & 7.39 & 26 & 7.14 & 7 & 7.69 & 32 & 7.13 \\
\hline P. Mirabilis & 39 & 7.22 & 16 & 9.09 & 23 & 6.32 & 9 & 9.89 & 30 & 6.68 \\
\hline E. Faecium & 26 & 4.81 & 2 & 4.14 & 24 & 6.59 & 1 & 1.10 & 25 & 5.57 \\
\hline C. Glabrata & 19 & 3.52 & 7 & 3.98 & 12 & 3.30 & 2 & 2.20 & 17 & 3.79 \\
\hline C. Tropicalis & 14 & 2.59 & 1 & 0.57 & 13 & 3.57 & 0 & 0 & 14 & 3.12 \\
\hline Enterococcus sp. & 12 & 2.22 & 6 & 3.41 & 6 & 1.65 & 3 & 3.30 & 9 & 2.00 \\
\hline
\end{tabular}

Tabla 11. Etiología de ITUSV. Informe ENVIN 2013.

Son infecciones fundamentalmente tardías, producidas por flora endógena secundaria, y con un porcentaje mayor de infecciones por hongos que otras IN. Entre 
las especies de Cándida aisladas, se observa un incremento de las formas no Albicans que son cerca del $50 \%$ de las candidurias identificadas.

\subsubsection{PREVENCIÓN DE LA ITUSV}

A lo largo del periodo de estudio analizado, no se ha realizado ninguna intervención específica para la prevención de la ITUSV, fundamentalmente por su escasa incidencia, y su escaso impacto en la mortalidad. Las recomendaciones de las guías de manejo clínico se pueden dividir en tres grupos ${ }^{42,43}$.

\section{- RECOMENDACIÓN ALTA: CATEGORIA I:}

- Educación y formación del personal implicado en la técnica de inserción y manejo de la SV.

- Utilizar SV solo en casos necesarios.

- Retirar la SV en cuanto sea posible

- Lavado de manos.

- Técnica inserción estéril.

- Mantener la sonda correctamente asegurado.

- Obtener cultivos de manera estéril.

- Evitar la obstrucción.

\section{- RECOMENDACIÓN MODERADA: CATEGORIA II:}

- Reeducación y formación periódica.

- Usar SV del menor calibre posible.

- Evitar lavados (salvo para desobstruir).

- Abstenerse de cuidados extraordinarios del meato.

- No cambiar las sondas a intervalos prefijados.

\section{- RECOMENDACIÓN DÉBIL: CATEGORIA III:}

- Considerar técnicas alternativas al SV.

- Cambiar el sistema recolector si se abre el circuito cerrado.

- Separar pacientes con infección de los no infectados.

- Evitar cultivos rutinarios. 


\section{REALIDAD LOCAL}

\subsection{INICIO DE LA VIGILANCIA}

En la UCI del Hospital Universitario de Salamanca, se realiza la vigilancia de la IN mediante el programa ENVIN en los meses de estudio nacional desde el año 2001. A partir del año 2003 comenzamos a realizar la vigilancia de manera continua y completa, durante todos los meses del año. Por ello, conocemos la etiología de las infecciones y su distribución, así como las características de los pacientes ingresados, con sus factores de riesgo de infección desde el año 2003. Esto permite comparar nuestras TI y la etiología de las mismas, con las recogidas en España en ese periodo y poder comprobar la evolución de las mismas y su comportamiento tras la realización de medidas para el control de las infecciones. ${ }^{44,45}$

Durante los primeros años de nuestro registro, la TI adquirida en UCI se elevó en 2003 hasta 25,95\% días de estancia, siendo ésta muy elevada comparándola con la tasa nacional, que fue de $16,64 \%$ días de estancia. Durante los tres primeros años de recogida de datos, la tasa se mantuvo por encima de 20\%o días de estancia, y siempre por encima de la nacional.

\subsection{ESTUDIO PILOTO}

Como ya comentamos en el prólogo, en diciembre del 2006, Pronovost publicó su experiencia para reducir la incidencia de BRCVC en el estado de Michigan. Consistía en una iniciativa para mejorar la seguridad de los pacientes críticos. El estudio realizado en 103 UCI del estado de Michigan, demostró la posibilidad de reducir la BRCVC a prácticamente a cero. Se pasa de una DI media de BRCVC de 7,7\%o días CVC, a 1,4\%o días de CVC tras 16-18 meses de intervención $(\mathrm{p}<0,002)$.

En diversos estudios realizados acerca de las intervenciones basadas en paquetes de medidas, se ha demostrado que, aunque las realizadas de forma unitaria 
puedan no tener gran fuerza en conseguir el objetivo perseguido, tomadas de forma conjunta, dan lugar a resultados significativos y duraderos ${ }^{46}$.

En el año 2008, basándose en el estudio de Pronovost, la Society for Heathcare Epidemiology of America y la Infections Diseases Society of America, publicaron las guías que contenían las estrategias a seguir para prevenir y monitorizar las $\mathrm{BRCVC}^{47}$. Utilizaron cinco procedimientos recomendados por el CDC, con evidencia científica demostrada:

$\checkmark$ Lavado de manos.

$\checkmark$ Uso de precauciones barrera máximas durante la inserción de CVC.

$\checkmark$ Limpieza de la piel con clorhexidina.

$\checkmark$ Evitar la inserción en femoral si es posible.

$\checkmark$ Retirar los CVC innecesarios.

Además de estos procedimientos se realizan otras medidas como:

$\checkmark$ Preparación del carro de CVC con el material necesario.

$\checkmark$ Uso de una lista de verificación para asegurar la adherencia a las prácticas de control de infección.

$\checkmark$ Detener la inserción cuando las prácticas no están siendo adecuadas.

$\checkmark$ Valoración diaria de la posibilidad de retirar CVC que ya no sean necesarios.

Se forman un equipo multidisciplinar entre personal médico y de enfermería de la unidad que lideran la intervención. Estos profesionales son formados en la intervención a realizar, en colaboración con los servicios de medicina preventiva que apoyaban la aplicación de la misma, y recogían los datos relacionados con las BRCVC. Se realiza formación a todos los profesionales en medidas de prevención, y en el impacto de las BRCVC. Y se informa del número (mensualmente), y de las tasas de BRCVC (trimestralmente). La intervención se desarrolló sin el uso de costosa tecnología, o aumento de los profesionales en UCI. 
Gracias a los acuerdos de la SEMICYUC con el MSC en el año 2007, se realiza una experiencia piloto $^{13}$ adaptando a nuestro medio el programa de Pronovost. El proyecto se lleva a cabo en hospitales de tres comunidades autónomas: Andalucía, Castilla-León y Cataluña. La UCI del Hospital Clínico Universitario participa en este estudio piloto, para valorar las medidas de BZ y se añade además una actuación para mejorar la cultura de seguridad de las UCI. Se evalúan un paquete de actuaciones ${ }^{48}$ basadas en la evidencia científica, para reducir la DI de las BRCVC. Estas medidas consistían:

\section{A: Plan de seguridad integral:}

1. Evaluar la cultura de seguridad (medición basal y periódica)

2. Formación en seguridad del paciente.

3. Identificar errores en la práctica habitual (por los profesionales).

4. Establecer alianzas con la dirección de la institución para la mejora de la seguridad.

5. Aprender de los errores.

\section{B: Programa BZ:}

1. Higiene adecuada de manos.

2. Uso de clorhexidina en la preparación de la piel.

3. Uso de medidas de barrera total durante la inserción de los CVC.

4. Preferencia de la vena subclavia como lugar de inserción.

5. Retirada de CVC innecesarios.

6. Manejo higiénico de los catéteres.

Se desarrolló un programa de formación del personal en estas medidas, y se llevaron a cabo una serie de herramientas para la facilitar la realización del proyecto, como la creación de un carro de CVC con todo el material necesario para ello, y con una lista de verificación de todo el material. Se realizó otra lista de verificación para la inserción de CVC, y una lista de comprobación de objetivos diarios. Todo ello, registrado 
en una base de datos, donde se podía conocer el grado de cumplimiento de estas medidas de la unidad, y compararlo con otras UCIs de la Comunidad y de toda España.

\subsection{PROYECTO BZ}

Tras el éxito del estudio piloto en el que participó nuestro Servicio, se implantó el programa en todo el territorio nacional a lo largo del año 2008. Después de evaluar los resultados, y hacer las correcciones necesarias se desarrolla definitivamente el proyecto BZ, de Enero de 2009 a Junio de $2010^{49}$.

Este proyecto, junto con el propio ENVIN-HELICS, formó parte de un acuerdo de colaboración de la SEMICYUC con la Agencia de Calidad del MSC. Esta fue la primera vez que se reconocía oficialmente de la labor de control de la infección llevada a cabo durante tantos años por los intensivistas españoles.

Las medidas del proyecto se desarrollan en los dos puntos.

\subsubsection{PAQUETE DE MEDIDAS PARA PREVENCIÓN DE BRCVC:}

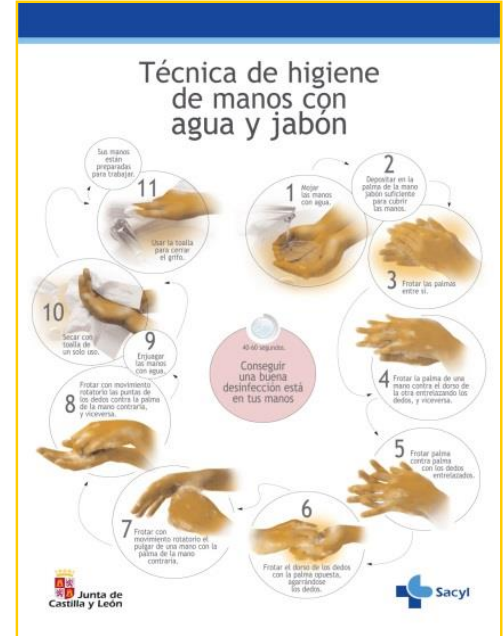

Figura 9: Cartel higiene de manos
- Higiene adecuada de manos (categoría IA): Se requiere una higiene de manos adecuada antes y después de palpar los lugares de inserción de los CVC, así como antes y después de insertar, reemplazar, acceder, reparar o proteger un catéter intravascular. Además, el uso de guantes no exime de la higiene de manos. Desde 1997, al menos 7 estudios prospectivos ha puesto de manifiesto que una mejora de la higiene de manos, reduce significativamente la aparición de diversas complicaciones infecciosas. Para una higiene adecuada de manos pueden utilizarse productos con base de alcohol o jabón antibacteriano, y agua con un lavado adecuado ${ }^{50}$. (figura 9) 
- Uso de clorhexidina en la preparación de la piel (categoría IA): desinfectar la piel con un antiséptico apropiado antes de la inserción del CVC, y durante los cambios de apósito. La solución de preferencia es clorhexidina al 2\%. La preparación del punto de inserción del CVC con una solución acuosa de gluconato de clorhexidina al $2 \%$, redujo las tasas de BRCVC en comparación con la preparación con povidona yodada al 10\%, o alcohol al $70 \%$. Otras preparaciones de clorhexidina podrían no ser tan eficaces. ${ }^{51}$

- Uso de medidas de barrera total durante la inserción de los CVC (categoría IA): Es importante utilizar una técnica aséptica para insertar CVC. La adopción de medidas de barrera máxima como gorro, guantes, mascarilla, bata estéril, campo quirúrgico con sábanas que recubran al paciente, reduce la incidencia de $\mathrm{BRCVC}$, en comparación con medidas de precaución general. ${ }^{52}$

- Preferencia de la vena subclavia como lugar de inserción (categoría IA): se prefiere la subclavia desde el punto de vista de control de la infección, pero deberán tenerse en cuenta otros factores como la posibilidad de complicaciones mecánicas, la presencia de coagulopatía, anatomía desfavorable o la experiencia del médico, a la hora de decidir dónde colocar el CVC. El lugar de inserción influye en el riesgo de BRCVC y flebitis. En el adulto la inserción en las extremidades inferiores tiene un riesgo mayor en la superiores. También se ha demostrado que los catéteres femorales, presentan una tasa de colonización y de infección más elevadas $^{53}$.

- Retirada de CVC innecesarios (categoría IA): Resulta evidente que el riesgo mayor de infección por CVC, es la presencia del mismo. Por ello, debe considerarse a diario si se puede prescindir del CVC.

- Manejo higiénico de los CVC (categoría IA): Debe reducirse al mínimo imprescindible la manipulación de las conexiones, y limpiar los puntos de inyección del catéter con alcohol isopropílico al 70\% antes de acceder con 
ellos al sistema venoso. La infección de CVC por vía intraluminal, es la responsable de la mayoría de las infecciones tardías por ello es conveniente utilizar una técnica adecuada ${ }^{54}$. Las válvulas de inyección sin aguja reducen los pinchazos accidentales, protegiendo al personal sanitario, pero su uso no higiénico pueden aumentar el riesgo de infección. La utilización de toallitas de alcohol al 70\% han demostrado reducir las tasas de infección ${ }^{55}$.

\subsubsection{PROGRAMA INTEGRAL DE SEGURIDAD.}

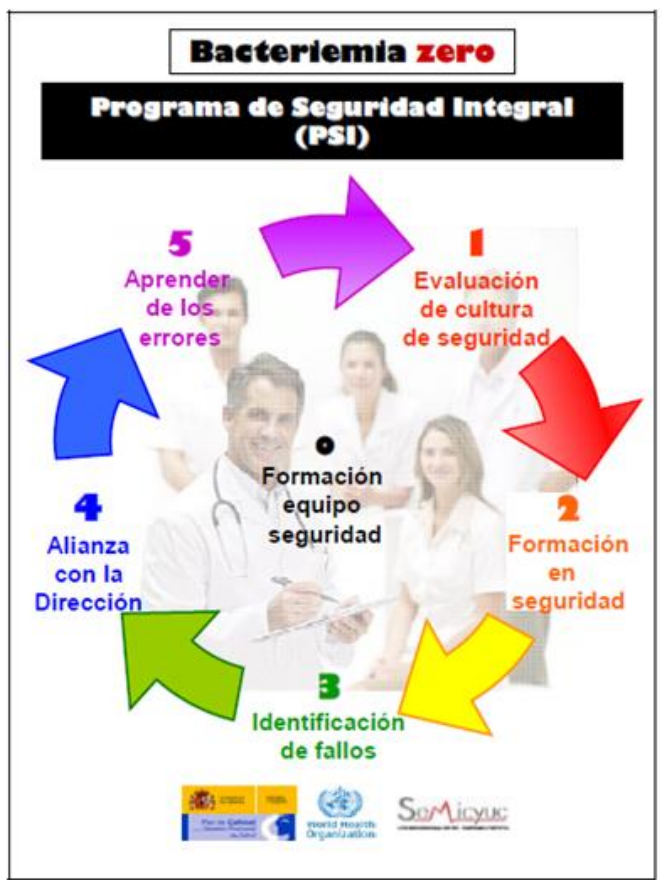

Figura 10: Cartel programa integral de seguridad
Entre los componentes del programa de seguridad (figura 10), se encuentran medidas específicas de formación, intervenciones dirigidas a la mejora de la comunicación entre los todos los profesionales que trabajan en las UCI, y reordenación del trabajo mediante la utilización de listas de comprobación, y monitorización de procedimientos e indicadores. Para garantizar la aplicación de las intervenciones a nivel local, se crearon equipos de seguridad del paciente en cada hospital, con participación de personal médico y de enfermería, con un núcleo responsable en cada hospital en colaboración con líderes autonómicos y nacionales.

- Formación: Es uno de los componentes fundamentales en los programas de prevención. Los programas educacionales son organizados de forma institucional, para que el personal conozca las prácticas seguras. Es el paso inicial para vencer la barrera del desconocimiento. Se debe facilitar al personal, el tiempo y los medios necesarios para poder realizarla. 
- Listas de verificación: son herramientas de seguridad que se han incorporado desde otros campos como la industria o la aviación ${ }^{56}$. Su objetivo es monitorizar el proceso, asegurando el cumplimiento de todos los pasos, sin dejar al azar ninguno de ellos, contribuyendo a fijar conductas correctas. Se realizó una lista de verificación de la inserción del CVC en el que el profesional de enfermería podía interrumpir el proceso, si este no se realiza adecuadamente.

- Objetivos diarios: la comunicación entre todos los miembros que atienden al paciente, es un punto clave para que el paciente reciba la mejor atención. Concretar cada uno de los puntos necesarios para el manejo del paciente, evita la confusión y disminuye la posibilidad de error. Debe ser un plan terapéutico estructurado que garantice la seguridad del paciente a tiempo en real, y la continuidad asistencial a lo largo de los turnos de trabajo por parte de todo el personal sanitario que atienden a los pacientes.

- Rondas de seguridad: uno de los elementos recomendados en el programa de seguridad integral, es la integración de un miembro del equipo directivo del hospital en las visitas a la UCI, para asegurar el cumplimento de las medidas del programa, analizar las TI y conocer las dificultades en forma de falta de medios materiales o profesionales. Esta actividad fue la de menor seguimiento en el proyecto.

En la tabla 13 se resumen las medidas recomendadas y en la tabla 13 las definiciones de las recomendaciones de los CDC. 


\section{Preinserción: Medidas para prevenir la BRCVC.}

1. Formación del personal sanitario acerca de la inserción, cuidados y mantenimiento de los CVC (IA)

2. Uso de una lista de verificación durante la inserción para asegurar el correcto cumplimiento de las medidas de prevención (IB)

3. Higiene de manos previa a la inserción de catéter y durante la manipulación (IA)

4. Evitar el uso de la vena femoral (IA)

5. Uso de un "carro de vía central" que incluya todo el material para su colocación (IB)

6. Uso de barreras asépticas máximas durante la inserción (IA)

7. Asepsia de la piel del punto de inserción con clorhexidina al $2 \%$.

Postinserción: Medidas para prevenir la BRCVC.

1. Vigilar diariamente el punto de inserción del CVC sin retirar el apósito (IB)

2. Utilizar preferiblemente apósitos transparentes semipermeables estériles, para poder valorar el punto de punción con las mínimas manipulaciones. (IA)

3. Si el punto de inserción rezuma, presenta hemorragia o el paciente presenta un exceso de sudoración utilizar un apósito de gasa. (II)

4. Se cambiará el apósito transparente una vez por semana y el apósito de gasa cada 3 días y cuando estén visiblemente sucios, húmedos o despegados (II)

5. Desinfección de las conexiones, tapones y puntos de inyección antes de acceder al catéter (IA).

6. Retirar los catéteres no necesarios (IA)

7. Cuidados específicos para los catéteres tunelizados.

8. Cambiar los equipos, alargaderas y conectores sin aguja con una frecuencia no superior a 72 horas y siempre que las conexiones estén visiblemente sucias o en caso de desconexión accidental (IA). En caso de soluciones lípídicas cambiar los sistemas cada 24 horas. (IA)

9. Cuando la inserción del catéter se ha realizado de forma urgente y sin técnica estéril se recomienda cambiar antes de las 48 horas y en lugar diferente. (II)

10. Realizar vigilancia de la BRCVC (IA)

Tabla 12. Recomendaciones CDC para prevención BRCVC.

\section{Definiciones de recomendaciones del CDC}

Categoría IA: Fuertemente recomendado para su implementación y fuertemente respaldado por estudios bien diseñados experimentales, clínicos o epidemiológicos.

Categoría IB: Fuertemente recomendado para su implementación y fuertemente soportado por algunos estudios experimentales, clínicos o epidemiológicos y con una fuerte teoría racional.

Categoría IC: Requerido por regulaciones estatales o federales, normas o estándares.

Categoría II: Sugerido para su implementación y soportado por estudios clínicos o epidemiológicos sugerentes y una teoría racional.

Tabla 13. Definiciones de recomendaciones del CDC. 
Aunque existía un control interno para asegurar la veracidad de la información acumulada en la base de datos, la limitación de recursos había impedido realización de auditorías externas. A partir del 2008, con el soporte del MSC, se ha realizado la monitorización de los datos de una parte importante de las UCI participantes, entre ellas la nuestra, para confirmar la calidad del estudio. Este control, aunque claramente recomendado, se realiza raramente en las redes de vigilancia ${ }^{33}$.

A partir del 2008, se produce un punto de inflexión en la TI, consiguiendo disminuirla hasta 16,3\%, por debajo de la tasa nacional. En los años siguientes, participando en el proyecto BZ de manera conjunta con más de 150 UCIs de toda España, conseguimos una disminución progresiva de la TI hasta mantener una tasa menor de 10\%, manteniéndose en estos últimos 4 años por debajo de la tasa nacional. El programa mostró que es posible reducir muy notablemente la BRCVC.

El programa BZ consigue disminuir, no sólo la TI de BRCVC que disminuye de 7,84\% días de CVC, a 1,88\% días de CVC, sino que también y sin realizar ninguna medida específica para ello, disminuye de manera significativa la TI de NAVM del 19,6\%o días de VM, a 7,54\%o días de VM.

Prevenir la IN es una de las mejores maneras de reducir el consumo de antibióticos. Por lo tanto, el beneficio de invertir en prevención es eficaz en términos de salud, y eficiente en una disminución del consumo de recursos, y probablemente disminuye los costes totales de la asistencia sanitaria, a la vez que mejora los resultados en salud de los pacientes.

El proyecto BZ significa un cambio fundamental en la valoración de la IN, considerándola un fallo en los sistemas de seguridad. Estas infecciones ya no son un problema inevitable asociado a la actividad hospitalaria, sino que se consideran un efecto adverso que se puede prevenir y evitar. Para ello, se propone la aplicación de un conjunto de medidas que han demostrado en estudios bien diseñados su eficacia para reducir las BRCVC. Además incluye, por primera vez, la aplicación del concepto "cultura de seguridad", y las herramientas desarrolladas en torno a dicho concepto (objetivos diarios, identificación de errores, propuesta de mejoras y rondas de seguridad). El proyecto 
potencia el protagonismo del personal enfermería, establece canales de intercambio de información entre el personal sanitario, mejora la comunicación, favorece la identificación de errores en la práctica diaria, propone objetivos de mejora en base a cambios de conductas, e inicia el camino de la mejora continuada. Todo ello sin duda significará una mejor atención a nuestros enfermos.

Estas medidas destinadas a la mejora de la cultura de la se-guridad y la prevención de la BRCVC, consiguieron, incluso con pacientes algo más graves y de mayor edad, y sin establecer medidas específicas para NAVM, reducir las tasas de éstas, por lo que podría concluirse que este descenso, se debe únicamente a la influencia de la rama de seguridad integral del programa BZ. Esta mejoría de las tasas nos permite mejorar nuestra posición respecto al resto de países europeos, ya que en las estadísticas del ECDC correspondientes a 2007, España se mantenía entre las redes de vigilancia con las tasas más elevadas.

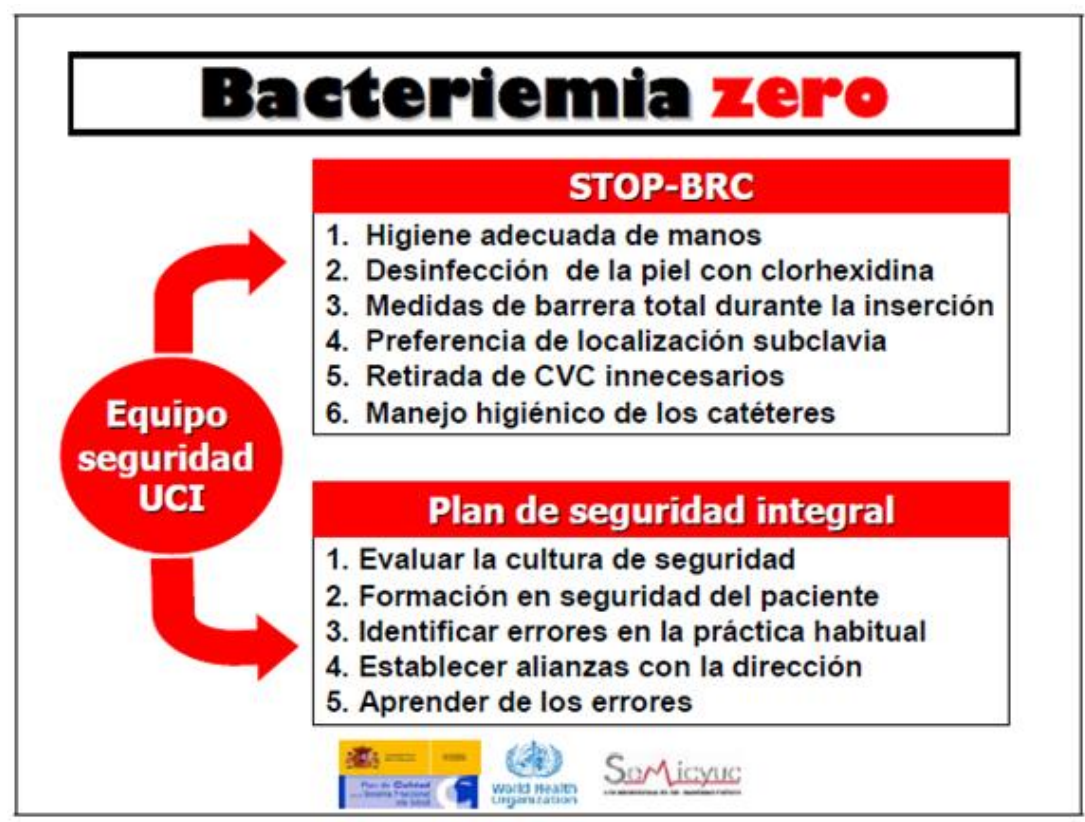

Figura 11: Póster de resumen medidas BZ.

\subsection{PROYECTO NZ}

Las tasas de NAVM que había disminuido en 2009, tras la realización del proyecto BZ, en el año 2010, se mantuvieron estables, pareciendo que el impacto del programa de seguridad tenía un límite, y que intentar disminuirla incidencia de NAVM requería unas 
medidas específicas. Como comentamos en el prólogo el proyecto $\mathrm{NZ}^{57}$, se inició en Abril del 2011, mediante un nuevo acuerdo de SEMICYUC y el MSC, al que se incorpora oficialmente a la Sociedad Española de Enfermería Intensiva y de Unidades Coronarias (SEEIUC). El proyecto nos ofreció otra oportunidad para mejorar la asistencia a nuestros pacientes, y así reducir la tasa de NAVM, que es infección más frecuente en los pacientes ingresados en las UCI. Además se mantienen las medidas de BZ que tan buenos resultados consiguieron.

Las medidas realizadas, además de continuar con el plan de seguridad integral, están basadas en la evidencia para la prevención de la NAVM. Se analizaron, a partir de las recomendaciones y revisiones realizadas por sociedades científicas y grupos de expertos, 35 medidas relacionadas con la prevención de la $\mathrm{NAVM}^{57}$. Para la clasificación de la calidad de la evidencia y fuerza de las recomendaciones se situó la propuesta del grupo GRADE (Grading of Recomendations Assesment, Developement and Evaluation Working Group) $)^{59}$ (tabla 14).

\section{Clasificación de la evidencia y el grado de recomendación según el sistema GRADE}

Alta: Es muy poco probable que nuevos estudios cambien la confianza que tenemos en el resultado estimado.

Moderado: Es probable que nuevos estudios tengan un impacto importante en la confianza que tenemos en el resultado estimado y que puedan modificar el resultado.

Baja: Es muy probable que nuevos estudios tengan un impacto importante en la confianza que tenemos en el resultado estimado y que puedan modificar el resultado.

Muy baja: Cualquier resultado estimado es muy incierto.

Para establecer el grado de recomendación, tanto positiva como negativa:

- Recomendación fuerte: se refiere a la decisión que tomaría la mayoría de las personas bien informadas.

- Recomendación débil: se refiere a la decisión que tomaría la mayoría de las personas bien informadas, aunque una minoría considerable no lo haría.

Tabla 14. Clasificación de la evidencia y el grado de recomendación según el sistema GRADE.

Se seleccionaron, de acuerdo a la eficacia, tolerabilidad, y aplicabilidad, siete medidas de carácter obligatorio para poder participar en el programa NZ, y otras tres recomendaciones optativas que no eran obligatorias, pero si se recomendables por el 
grupo de trabajo (figura12). Estas medidas fueron las siguientes según se recogen en el proyecto $\mathrm{NZ}^{57}$. Se resumen en la tabla 15 .

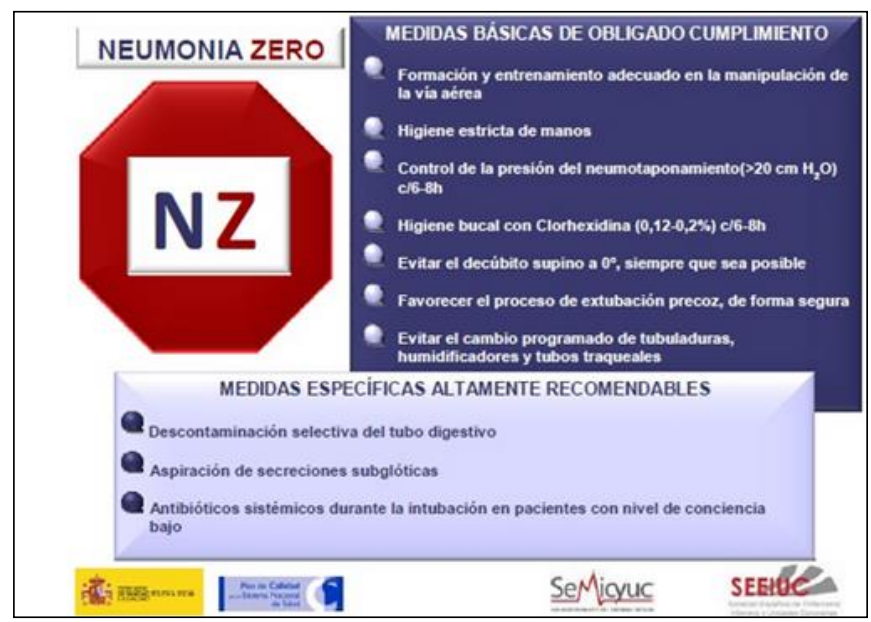

Figura 12: Cartel de resumen de medidas NZ.

\subsubsection{MEDIDAS BÁSICAS DE OBLIGADO CUMPLIMIENTO}

- Formación y entrenamiento apropiado en la manipulación de la vía aérea (aspiración de secreciones bronquiales) (Nivel de evidencia alto. Recomendación fuerte): Es fundamental dentro de un programa general en la UCI, la formación específica en la manipulación de la vía aérea y la aspiración de secreciones bronquiales por parte del personal de enfermería. Se incluye la contraindicación a la instilación rutinaria de suero fisiológico por los tubos endotraqueales y la necesidad de utilizar material de un solo uso.

- Higiene estricta de manos en el manejo de la vía aérea (Nivel de evidencia alto. Recomendación fuerte): es una recomendación para la prevención de todo tipo de infecciones, claramente establecida en los estándares de buenas prácticas junto con la utilización de guantes. El uso de guantes no exime la higiene de manos. Se debe proceder al lavado de manos antes y después de la manipulación de la vía aérea ${ }^{60}$. 
- Control y mantenimiento de la presión del neumotaponamiento por encima de $20 \mathrm{cmH}_{2} \underline{\mathrm{O}}$ (Nivel de evidencia moderado. Recomendación fuerte): Se realizará control, y se mantendrá por encima de $20 \mathrm{~cm}$ de agua antes de la higiene bucal. El control continuo de la presión dependerá de la disponibilidad en las UCI de la tecnología necesaria para ello. El control intermitente utilizando un manómetro es inexacto en el mantenimiento continuo en rango normal. El mantenimiento de la presión controlada con manómetro redujo significativamente las microaspiraciones de contenido gástrico, la colonización traqueobronquial y la incidencia de $\mathrm{NAVM}^{61}$.

- Higiene de la cavidad oral cada 6-8 horas utilizando clorhexidina $(0,12$ $\underline{0,2 \%}$ ) (Nivel de evidencia alto. Recomendación fuerte): Se protocoliza la higiene cada 8 horas utilizando soluciones de clorhexidina al 0,12\%. Antes debe comprobarse que la presión del neumotaponamiento esté por encima de $20 \%$ de agua. Se realizará formación y entrenamiento de esta técnica entre el personal auxiliar de enfermería que es el responsable de esta técnica en la mayoría de hospitales ${ }^{62}$.

- Evitar, siempre que sea posible, la posición de decúbito supino a $0^{\circ}$ (Nivel de evidencia moderado. Recomendación fuerte): Se debe evitar la posición de supino a $0^{\circ}$ en $\mathrm{VM}$, sobre todo en pacientes con nutrición enteral para evitar el reflujo gástrico. La posición recomendada es de $30-45^{\circ}$ si no existe contraindicación. Se comprobará la posición cada 8 horas ${ }^{63}$.

- Favorecer todos los procedimientos que permitan disminuir de forma segura la intubación y/o su duración (Nivel de evidencia bajo. Recomendación fuerte): No existe nivel de evidencia para esta recomendación. Entre las medidas que el proyecto propone, son aquellas que han demostrado reducir el tiempo de VM, como pueden ser: Disponer de un protocolo de desconexión de la ventilación ${ }^{64}$, evitar la intubación mediante el empleo de VM no invasiva ${ }^{65}$, disponer de protocolos de sedación que permitan disminuir las dosis y el tiempo de sedación ${ }^{66}$. 
- Evitar los cambios programados de las tubuladuras, humidificadores y tubos traqueales (Nivel de evidencia alto. Recomendación fuerte): se desaconseja el cambio rutinario de tubuladuras e intercambiadores de calor humedad, salvo malfuncionamiento de las mismas. Si se realiza el cambio, este no debe ser inferior a cada 7 días en el caso de tubuladuras, ni 48 horas en el caso de humidificadores ${ }^{67,68}$.

\subsubsection{MEDIDAS ESPECÍFICAS ALTAMENTE RECOMENDABLES:}

- Descontaminación selectiva del tubo digestivo (DDS) (Nivel de evidencia alto. Recomendación fuerte): Es la medida con más evidencias en la prevención de NAVM, y la única que ha demostrado impacto en la mortalidad. Su aplicación depende de su disponibilidad en las UCI. En pacientes con función digestiva conservada se administrará DDS orofaríngea y gástrica, en caso contrario solo orofaríngeo ${ }^{70}$.

Aspiración continua de secreciones subglóticas (Nivel de evidencia alto. Recomendación fuerte): Las evidencias de su efectividad son elevadas, en especial para prevenir las neumonías precoces. El sistema de aspiración, a baja presión, tiene que ser continuo y se controlará cada 8 horas su adecuado funcionamiento. En el caso que existan dudas de su funcionamiento se debe introducir $2 \mathrm{ml}$ de suero fisiológico por el sistema de aspiración. Su aplicación dependerá de la disponibilidad de tubos orotraqueales con sistema de aspiración subglótica ${ }^{71}$.

\section{Antibióticos sistémicos durante la intubación en pacientes con disminución del nivel de consciencia (Nivel de evidencia alto.} Recomendación fuerte): Esta medida previene las NAVM precoces en un grupo seleccionado de pacientes con disminución del nivel de consciencia. Se recomienda la administración de cefuroxima o amoxi-clavulanico, en las primeras horas después de la intubación ${ }^{72}$. 


\section{A: Medidas básicas de obligado cumplimiento:}

1. Formación y entrenamiento apropiado en la manipulación de la vía aérea.

2. Higiene estricta de manos en el manejo de la vía aérea.

3. Control y mantenimiento de la presión del neumotaponamiento por encima de $20 \mathrm{cmH} 2 \mathrm{O}$.

4. Higiene bucal cada 6-8 horas utilizando Clorhexidina $(0,12-0,2 \%)$.

5. Evitar, siempre que sea posible, la posición de decúbito supino a $0^{\circ}$.

6. Favorecer todos los procedimientos que permitan disminuir de forma segura la intubación y/o su duración.

7. Evitar los cambios programados de las tubuladuras, humidificadores y tubos traqueales

\section{B: Medidas específicas altamente recomendables:}

1. Descontaminación selectiva del tubo digestivo (DDS).

2. Aspiración continua de secreciones subglóticas.

3. Antibióticos sistémicos durante la intubación en pacientes con disminución del nivel de conciencia.

Tabla 15. Resumen de las recomendaciones en el proyecto NZ.

En nuestro servicio se realizan todas las medidas de obligado cumplimiento y las optativas, excepto la aspiración continua de secreciones subglóticas ya que no pudimos disponer del material preciso para ello por motivos económicos.

En los 5 últimos años hemos comprobado la repercusión de los programas de seguridad BZ y NZ, con una disminución de las tasas de IN que ha sido progresiva en el tiempo pero que han aumentado ligeramente en el año 2013 tras la finalización de los proyectos $\mathrm{BZ}$ y NZ y la relajación en la realización de medidas estrictas y controladas de control de la IN, por lo que podemos considerar que la realización de dichas constituye una barrera de protección frente a la adquisición de infección en UCI.

Globalmente, los pacientes que han adquirido alguna infección en UCI, han descendido paulatinamente desde el $8.63 \%$ en $2009,9.68 \%$ en 2010 , y $6.62 \%$ en 2011 , con un ligero repunte tras finalizar la recogida de datos de BZ y NZ a 7.97\% en 2012, a 9.2 en 2013. 
Si analizamos las infecciones asociadas a dispositivos controladas por ENVIN (NAVM, ITUSV y BRCVC), tan solo el 6,16\% de pacientes ingresados sufrió esta complicación en 2012. Destaca la reducción espectacular de la tasa de NAVM a 7,27\%o días de VM, superando ampliamente el objetivo fijado al inicio del proyecto NZ. Y también es motivo de satisfacción, el mantenimiento a la baja de las tasas de BRCVC, dos años después de acabado oficialmente el proyecto BZ. Además, las tasas de bacteriemia secundaria a otros focos, que aumentaron durante el proyecto, han iniciado un declive, acercándose a las cifras basales de 2008.

La disminución de las infecciones adquiridas en UCI, ha supuesto una reducción significativa de los antibióticos destinados a tratar las mismas, tanto en número de indicaciones, como en días de tratamiento. Si la disminución del uso de antimicrobianos es un objetivo para luchar contra las resistencias, optimizar el tratamiento de todas las infecciones adquiridas en UCI debe incluirse inmediatamente en las agendas de los intensivistas. Esta, junto a otras acciones de optimización como reducción del espectro, ajuste de la duración de los tratamientos y mejoría en el diagnóstico precoz de las infecciones debería formar parte del próximo reto, el control de las resistencias bacterianas en nuestras UCI. Este proyecto con el nombre de Resistencia-zero se está desarrollando en la actualidad.

La información obtenida desde el registro ENVIN-HELICS, permite conocer la evolución de las infecciones adquiridas en las UCI desde una triple perspectiva: local, nacional, y europea, y a cada nivel le corresponde un diferente análisis y la toma de decisiones para minimizar estas complicaciones infecciosas. Tan importante como conocer los datos nacionales y la comparación con otros registros de países europeos, es el análisis de la situación de cada UCI en particular. Las diferencias con los datos nacionales, deben de ser observados con prudencia dadas las diferencias entre las UCI participantes, pero la estratificación de los indicadores de mayor interés por percentiles, ayuda a posicionar a cada UCI y a identificar desviaciones que deben de estudiarse de forma dirigida. 
La prevención de la infección es una de las mejores maneras de reducir costos, tanto por la disminución del consumo de antibióticos, como disminución de estancias hospitalarias. Por lo tanto la inversión en prevención es eficaz en términos de salud, y eficiente en una disminución del consumo de recursos y en la disminución de los costes totales de la asistencia sanitaria, a la vez que mejora los resultados en salud de los pacientes. 
lo largo del periodo estudiado, se han recogido de manera continua los 1 datos de los pacientes ingresados en la UCI del Hospital Clínico Universitario, en la base de datos ENVIN-HELICS. Con el análisis de los datos obtenidos nos planteamos los siguientes objetivos.

\section{OBJETIVOS PRINCIPALES:}

1. Conocer y describir la tasa de infección adquirida en UCI, y las tasas de las infecciones asociadas a dispositivos. Las mismas, han de ser adquiridas durante la estancia de los pacientes, en la UCI del Servicio de Medicina Intensiva del Hospital Universitario de Salamanca, en el periodo comprendido entre los años 2003 y 2013.

2. Conocer la evolución de las infecciones adquiridas durante el periodo estudiado, comparando las tasas de infección en los periodos anterior y posterior a la implantación de las medidas realizadas en los proyectos bacteriemia-zero y neumoníazero. 
3. Valorar, en consecuencia, la efectividad de las medidas realizadas en los proyectos bacteriemia-zero y neumonía-zero, con criterios clínicos, estadísticos, y de novedosas técnicas de minería de datos.

\section{OBJETIVOS SECUNDARIOS:}

1. Comparar nuestros resultados con las tasas de infección nacional del mismo periodo.

2. Conocer la etiología de las infecciones, y la evolución de los gérmenes causantes de las mismas, a lo largo del periodo de estudio.

3. Conocer las características de los pacientes, los diagnósticos de ingreso y los factores de riesgo de infección, de los pacientes con infección asociada a dispositivos en el periodo de estudio.

4. Comparar las características de los pacientes que tienen infección, con los que no la adquieren, identificando los factores de riesgo de dicha infección. 


\section{MATerial y Métodos}


ara la realización de este estudio hemos utilizado los siguientes material y métodos.

\section{SUJETOS DE ESTUDIO}

Para la realización del presente trabajo de Tesis Doctoral, se han revisado de forma retrospectiva todos los pacientes ingresados en la UCI del Hospital Clínico Universitario de Salamanca, durante el periodo del 1 de Enero del 2003 al 31 de Diciembre de 2013. Esta unidad consta con 16 camas, de las cuales 12 se destinan a pacientes polivalentes, y 4 a postoperatorio inmediato de Cirugía Cardiaca.

Los pacientes objetos del estudio, debieron estar durante más de 24 horas en la unidad. Todos los pacientes incluidos fueron seguidos hasta su alta de UCI.

Los enfermos fueron clasificados en función de la patología de base en médicos, quirúrgicos, traumáticos, y coronarios. Los pacientes se han considerado quirúrgicos cuando ingresaron de forma programada después de una intervención quirúrgica. El nivel de gravedad ha sido valorado mediante el sistema APACHE II $^{29}$. La cirugía urgente, fue definida como la necesidad de intervención quirúrgica no programada, antes o durante la estancia en UCI. 


\section{TABLA DE FACTORES DE RIESGO}

Se recogen diariamente los nuevos pacientes, los que están ingresados en el momento del cambio de guardia, los que presentan vía aérea artificial, estén intubados o con traqueotomía. Se recogen, también, todos los pacientes con CVC, incluidos CVC de acceso periférico, con CA, y con SV. Todos ellos, se utilizan para el cálculo de los denominadores de la DI de las distintas infecciones.

\begin{tabular}{|c|c|c|c|c|c|c|}
\hline \multicolumn{7}{|c|}{ Estudio ENVIN-HELICS } \\
\hline \multicolumn{7}{|c|}{ Numero de pacientas } \\
\hline Mes: & 1201 & & Paclentes con & Paclentes con & Paclentes con & Paclentes con \\
\hline & Paclentes & Paclentes & Ventllacion & Sonda & Catster & Cateter \\
\hline Dla del mes & & & & & & \\
\hline 1 & & & & & & \\
\hline 2 & & & & & & \\
\hline 3 & & & & & & \\
\hline 4 & & & & & & \\
\hline 5 & & & & & & \\
\hline 6 & & & & & & \\
\hline 7 & & & & & & \\
\hline 8 & & & & & & \\
\hline 9 & & & & & & \\
\hline 10 & & & & & & \\
\hline 11 & & & & & & \\
\hline 12 & & & & & & \\
\hline 13 & & & & & & \\
\hline 14 & & & & & & \\
\hline 15 & & & & & & \\
\hline 16 & & & & & & \\
\hline 17 & & & & & & \\
\hline 18 & & & & & & \\
\hline 19 & & & & & & \\
\hline 20 & & & & & & \\
\hline 21 & & & & & & \\
\hline 22 & & & & & & \\
\hline 23 & & & & & & \\
\hline 24 & & & & & & \\
\hline 25 & & & & & & \\
\hline 26 & & & & & & \\
\hline 27 & & & & & & \\
\hline 28 & & & & & & \\
\hline 29 & & & & & & \\
\hline 30 & & & & & & \\
\hline 31 & & & & & & \\
\hline Totales & & & & & & \\
\hline
\end{tabular}

Figura 13: Tabla de recogida de factores de riesgo programa ENVIN.

\section{DEFINICIONES}

\subsection{ORIGEN DE LA INFECCIÓN}

- Comunitario: Cuando a juicio del clínico, los signos de infección aparecen antes del ingreso en un hospital. 
- Intra-UCI: Cuando a juicio del clínico, los signos de infección aparecen durante su estancia en la UCI.

- Extra-UCI: Cuando a juicio del clínico, los signos de infección aparecen durante su estancia hospitalaria antes de su ingreso en la UCI.

- Otro hospital: Cuando a juicio del clínico, los signos de infección aparecen durante la estancia del paciente en otro hospital.

\subsection{INFECCIONES ADQUIRIDAS EN UCI}

- Infección adquirida en UCI: Aquella que ocurre transcurridas 48 de estancia en la UCI.

- Episodio de segunda infección: Para establecerlo se precisa la combinación de nuevos signos y síntomas, la evidencia radiográfica (en el caso de neumonía), y otros test diagnósticos.

\subsubsection{DEFINICION DE CASO DE BACTERIEMIA}

Se considera una sola opción:

- Un hemocultivo positivo para un patógeno reconocido, o que el paciente presente al menos uno de los siguientes signos o síntomas: fiebre $\left(>38^{\circ} \mathrm{C}\right)$, escalofríos, hipotensión, y dos hemocultivos positivos a un microorganismo contaminante cutáneo habitual (a partir de dos muestras de sangre diferentes extraídas dentro de un intervalo de 48 horas), más síntomas clínicos.

- Contaminantes cutáneos: S. Coagulasa negativo (Epidermidis, Saprophiticus, etc), Micrococcus. Spp., P. Acnes., Bacillus. Spp., Corinebacterium. Spp. Cuando se incluya uno de estos microorganismos, hay un mensaje de confirmación que dice: "Para seleccionar este microorganismo, debe tener dos frascos de hemocultivos positivos". 


\section{A. BRCVC}

- Diagnóstico tras retirada del CVC: Aislamiento del mismo microorganismo (especie e idéntico antibiograma) en hemocultivo extraído de vena periférica, y en un cultivo cuantitativo o semicuantitativo de punta de catéter, en un paciente con cuadro clínico de sepsis, y sin otro foco aparente de infección. En caso de S. Coagulasa negativo, se exigirá el aislamiento del microorganismo al menos en dos 2 frascos de hemocultivos periféricos.

- Diagnóstico sin retirada del CVC: Cuadro clínico de sepsis, sin otro foco aparente de infección, en el que se aísla el mismo microorganismo en hemocultivos simultáneos cuantitativos en una proporción superior o igual a 5:1 en las muestras extraídas a través de catéter, respecto a las obtenidas por venopunción.

\section{B. BACTERIEMIA SECUNDARIA}

- Bacteriemia (o funguemia) secundaria: Cuadro clínico de sepsis, en el que se aísla uno o más microorganismos en uno o más hemocultivos, en un paciente con un foco de infección conocido, siempre que exista coincidencia entre los microorganismos aislados en el foco de infección, y en el hemocultivo o en ausencia de microorganismos en la infección conocida, si los microorganismos aislados en el hemocultivo son compatibles con el foco de infección (B. Fragilis en sangre y foco de infección abdominal).

- La bacteriemia relacionada con los líquidos de infusión se considera secundaria.

\section{BACTERIEMIA DE FOCO DESCONOCIDO}

- Episodio de bacteriemia en el que no es posible identificar ningún foco (catéter u otros focos).

\subsubsection{DEFINICIÓN DE CASO DE NAVM}


En pacientes sin enfermedad cardiaca o pulmonar, basta con una placa de tórax o una tomografía axial computerizada (TAC) positivas. Para pacientes con enfermedad cardiaca subyacente, dos o más radiografías de tórax o TAC sucesivas, con una imagen sugestiva de neumonía o enfermedad pulmonar, y al menos uno de los siguientes:

- Fiebre $>38^{\circ} \mathrm{C}$ sin otro origen, con leucopenia $\left(<4.000 \mathrm{~mm}^{3}\right)$ o leucocitosis, $\left(\geq 12.000 / \mathrm{mm}^{3}\right)$ y al menos uno de los siguientes (al menos dos si sólo neumonía clínica: criterios N4 y N5):

- Aparición de esputo purulento, o cambio en las características del esputo (color, olor, cantidad, consistencia), tos o disnea, o taquipnea.

- Auscultación sugestiva: crepitantes, roncus, sibilancias.

- Deterioro del intercambio gaseoso (desaturación de O2, aumento de las demandas de oxígeno, o de la demanda ventilatoria)

De acuerdo al método diagnóstico utilizado, se clasifican en cinco clases, según la precisión del diagnóstico microbiológico.

- NEUMONIA N1: Diagnóstico bacteriológico realizado mediante cultivo cuantitativo positivo, a partir de una muestra mínimamente contaminada del tracto respiratorio:

- Lavado broncoalveolar (BAL) con un punto de corte $\geq 10^{4} \mathrm{CFU} / \mathrm{ml} \mathrm{o} \geq 5 \%$ de células conteniendo bacterias intracelulares al examen microscópico directo en muestra de BAL (clasificado en la categoría diagnóstica BAL)

- Cepillo protegido con un punto de corte $\geq 10^{3} \mathrm{CFU} / \mathrm{ml}$

- Aspirado distal protegido con un punto de corte $\geq 10^{3} \mathrm{CFU} / \mathrm{ml}$

- NEUMONIA N2: Diagnóstico bacteriológico realizado mediante cultivo cuantitativo positivo, a partir de una muestra posiblemente contaminada del tracto respiratorio:

- Cultivo cuantitativo de muestra del tracto respiratorio inferior (aspirado endotraqueal) con un punto de corte de $10^{6} \mathrm{CFU} / \mathrm{ml}$ 
- NEUMONIA N3: Métodos microbiológicos alternativos:

- Hemocultivo positivo no relacionado con otro foco de infección.

- Crecimiento positivo en cultivo de líquido pleural.

- Punción aspirativa positiva pleural o de absceso pulmonar.

- Evidencia de neumonía en examen histológico pulmonar

- Diagnóstico positivo de neumonía por virus o microorganismos particulares (Legionella, Aspergillus, Mycobacteria, Mycoplasma, Pneumocystis carinii)

- Detección positiva de antígeno viral o anticuerpos a partir de secreciones respiratorias.

- Examen directo positivo o cultivo positivo de secreciones bronquiales o tejido.

- Seroconversión (por ejemplo: virus influenza, Legionella, Chlamydia).

- Detección de antígenos en orina (Legionella o Neumococo)

- NEUMONIA N4: Cultivo positivo de esputo, o no-cuantitativo de muestra del tracto respiratorio.

- NEUMONIA N5: Sin microbiología positiva, solo criterios clínicos

El programa muestra un encabezado con el grupo de técnica al que corresponde, y con controles para que el número de colonias corresponda al grupo que se ha asignado.

Algunas etiologías son muy improbables como causantes de infección, y su aislamiento en muestras respiratorias, corresponde en realidad a colonizaciones. Estos patógenos son en general cualquier especie de Cándida (independientemente de su concentración en la muestra respiratoria), S. Coagulasa negativo, y el resto de los contaminantes de piel. Cuando se asigne esta etiología saldrá el mensaje "Este microorganismo es poco probable como etiología de una neumonía", para recordar que lo más probable es que se trate de una colonización.

\subsubsection{DEFINICION DE CASO DE ITUSV}


- No debe existir signos clínicos y/o microbiológicos, de infección urinaria en el momento del sondaje urinario.

- Criterios clínicos: Debe de cumplir al menos uno de los siguientes síntomas o signos:

- Fiebre $>38^{\circ}$.

- Tensión en zona suprapúbica o urgencia urinaria.

- Piuria: $10^{3}$ leucocitos/ mL.

- Criterios microbiológicos:

- Pacientes sin tratamiento antibiótico: Cultivo de orina: con aislamiento de $10^{5} \mathrm{UFC} / \mathrm{mL}$ de no más de dos microorganismos.

- Pacientes con tratamiento antibiótico: Cultivo de orina con aislamiento en un urocultivo de $<10^{5} \mathrm{UFC} / \mathrm{mL}$ de un único microorganismo.

En general, cuando se aísla más de un microrganismo en el urocultivo, se considera que la muestra está contaminada y por lo tanto debe repetirse.

\section{INFECCIONES CONTROLADAS}

Se han identificado sólo aquellas infecciones relacionadas de forma directa con factores de riesgo conocidos, y/o que se asocian con mayor morbilidad y mortalidad entre los pacientes críticos ${ }^{73}$ :

- NAVM.

- ITUSV.

- Bacteriemias de origen desconocido y BRCVC.

- Bacteriemias secundarias.

Los criterios utilizados para definir estas infecciones han sido los publicados por el CDC europeo $^{74}$, y se pueden consultar en el manual ENVIN-HELICS (hws.vhebron.net/envin-helics/). Se ha definido como bacteriemia primaria, la presencia 
de bacteriemias de origen desconocido, y/o BRCVC. Las BRCVC se han incluido en este trabajo con las bacteriemias primarias.

El programa ENVIN recoge información sobre la respuesta sistémica de cada una de las infecciones controladas. Los criterios utilizados para la definición de sepsis, sepsis severa y shock séptico corresponden a la conferencia de consenso de $2001^{74}$.

Para confirmar el diagnóstico de infección el programa incluye una advertencia “COnfirma que tiene infección y no tiene respuesta inflamatoria?, ya que se considera que si no hay respuesta inflamatoria sistémica, es muy poco probable que se trate de una infección, sobre todo para NAVM y BRCVC. Hay causas de disminución de la respuesta inflamatoria sistémica en nuestros pacientes, como es la administración de inmunosupresores (sobre todo esteroides), antiinflamatorios, sedación, opiáceos, relajantes musculares, técnicas de depuración extrarrenal con reposiciones frías, técnicas de hipotermia, por lo que es necesario tener en cuenta estas circunstancias, si se confirma que el paciente tiene una infección sin respuesta inflamatoria sistémica.

\section{FACTORES DE RIESGO}

Los factores de riesgo de cada infección se han calculado de forma global para todos los enfermos ingresados durante el periodo ${ }^{75}$. Para ello, se han contabilizado diariamente los pacientes con VM, SV, así como el número de CVC, incluidos los catéteres de arteria pulmonar, NPT, hemodiálisis, y los que incorporan reservorios. También se han contabilizado los pacientes con CA. Así mismo, se ha incorporado información de los factores de riesgo intrínsecos y extrínsecos, para adquirir infecciones.

\section{MEDIDAS DE FRECUENCIA}

Se han utilizado como indicador de frecuencia las TI, y de DI, de cada una de las infecciones controladas. 
La TI, expresada en porcentaje, incluye en el numerador el número absoluto de la infección analizada, y en el denominador el número total de pacientes de riesgo:

a) el número total de pacientes incluidos en el estudio.

b) el número total de pacientes con el factor de riesgo relacionado con la infección.

La DI, de cada infección analizada, incluye en el numerador el número absoluto de la infección analizada y en el denominador:

a) el número de días de riesgo de todos los pacientes ingresados, por mil.

b) el número de días de presencia del factor de riesgo relacionado con cada infección, por mil.

\section{VALIDACION DE LOS DATOS}

La base de datos ENVIN, tiene una utilidad interna, que es la posibilidad de comprobación de ciertos errores. A través de un botón que se encuentra en el formulario inicial, y que se denomina VALIDACION DE DATOS, se accede a una pantalla en la que se pueden imprimir las listas de:

- Pacientes en los que no constan los factores de riesgo extrínsecos: Este dato es importante para calcular densidades de incidencia, según exposición al factor. Si estos datos faltan, es difícil saber si realmente el paciente no ha sido instrumentalizado en absoluto, o se han olvidado de introducir estos datos.

- Pacientes en los que no consta la fecha del alta. Esta variable es de suma importancia, no sólo porque permite calcular la estancia en UCI, sino porque además una vez introducida la fecha del alta el programa, obliga a introducir otros datos considerados de interés (edad, sexo, éxitus, APACHE o Simplified Acute Phisiology Score (SAPS), enfermedad de base, cirugía urgente hasta tratamiento antibiótico). Si falta la fecha del alta en alguno de los pacientes, no se podrán comprobar las fechas de finalización 
de los informes que vienen a continuación. Si se da el caso, el programa envía un mensaje avisando.

- Antibióticos en los que la fecha de finalización, es posterior al alta.

- Pacientes en los que la fecha de finalización de la intubación o traqueotomía, es posterior al alta.

- Pacientes en los que la fecha de finalización del CVC, es posterior al alta.

- Pacientes en los que la fecha de finalización del CA, es posterior al alta.

- Pacientes en los que la fecha de finalización de la SV, es posterior al alta.

\section{ESTADÍSTICA DESCRIPTIVA}

El programa web, se encuentra alojado en un servidor corporativo. Se accede a través de una página web (hws.vhebron.net/envin-helics/). La base de datos consta de un conjunto de tablas relacionadas entre sí, que se rellenan a través de unos formularios. El programa está dotado de un sistema para controlar errores, y confirmar los datos introducidos.

Los análisis estadísticos se han desarrollado en programas escritos en lenguaje ASP (Active Server Pages), y visual Basic, una tecnología de Microsoft ${ }^{\circledR}$ para páginas web, que facilita la programación mediante objetos integrados y que permite mantener diversas variables, mientras se trabaja de página en página. El análisis estadístico se realiza con el programa SPSS.

\section{ESTADÍSTICA COMPARATIVA}

Para la realización de comparación entre los dos periodos analizados, los datos se analizaron mediante con el programa estadístico IBM SPSStatistics, versión 20.0. Para el análisis descriptivo, se calcularon medias y desviaciones típicas para las variables cuantitativas, y frecuencias y porcentajes para las variables cualitativas. En el estudio comparativo se utilizó el test t de Student, y cuando los grupos a comparar eran más de dos, se utilizó el análisis de la varianza (ANOVA), si los datos seguían distribución normal. Para los datos que no seguían distribución normal, se utilizaron los 
correspondientes versiones no paramétricos, de los test anteriormente nombrados. En el caso de dos grupos en estudio, se utilizó la U de Mann-Whitney, y cuando en el estudio intervenían más de dos grupos, el test de Kruskal Wallis. El análisis de variables cualitativas se llevó a cabo con el test Chi-Cuadrado, o el test de Fisher, dependiendo del tamaño de muestra de trabajo. El nivel de significación estadística empleado fue de $p<$ 0,05 .

Para determinar la asociación conjunta de las variables más relevantes en el estudio, se realizó un análisis multivariante mediante GJ-Biplot con el programa MultBiplot ${ }^{76}$.

\section{GH-BIPLOT}

Un biplot es una representación gráfica de datos multivariantes ${ }^{77}$. De acuerdo con Galindo $^{78}$, es una forma de representar de modo conjunto filas y columnas, es decir, individuos y variables de una matriz cualquiera, donde para representarlas se utilizan los elementos de la matriz como productos internos de vectores. De la misma manera que un diagrama de dispersión muestra la distribución conjunta de dos variables, un BIPLOT representa tres o más variables ${ }^{79}$.

En un biplot las variables son representadas por vectores, que se dirigen hacia donde existe más variabilidad para cada una de dichas variables, y los individuos son representados por puntos en el plano.

La fundamentación teórica de los biplot clásicos, se basa en la descomposición de la matriz de datos $\mathrm{Z}$ de orden ( $\mathrm{n}$ individuos $\mathrm{x} \mathrm{D}$ variables), y de rango $\mathrm{s}$, por una de bajo $\operatorname{rango}(\mathrm{q}<\mathrm{s})$

$$
\mathrm{Z}=\mathrm{GH}^{\prime} \text {, }
$$

donde $\mathrm{G}$ es una matriz de orden $\mathrm{n}$ x s y $\mathrm{H}$ una matriz de orden $\mathrm{D}$ x s.

Las $\mathrm{n}$ filas de $\mathrm{G}$, y las $\mathrm{D}$ deH, proporcionan las coordenadas de los $\mathrm{n}$ individuos, $\mathrm{y}$ de las D variables, en un espacio euclídeo s-dimensional (con la misma dimensión que el rango $\mathrm{r}$ de $\mathrm{Y}$ ). 
La descomposiciones de $\mathrm{Z}$ en el producto de las matrices $\mathrm{G}$ y $\mathrm{H}^{\prime}$, pueden realizarse de infinitas maneras distintas, cumpliéndose sea cual sea la descomposición que se realice, que el producto escalar ordinario del i-ésimo punto fila deG con el j-ésimo punto columna de $\mathrm{H}^{\prime}$ con respecto al origen, es igual al $(\mathrm{i}, \mathrm{j})$-ésimo elemento $\mathrm{y}_{\mathrm{ij}}$ de la matriz $\mathrm{Z}$.

La asignación del valor propio a los factores G, nos lleva al llamado JK-biplot $(\mathrm{G}=\mathrm{U} \Sigma$ y $\mathrm{H}=\mathrm{V})$, para este biplot se impone la métrica $\mathrm{HH}^{\prime}=\mathrm{I}$ en el espacio de las filas de la matriz Z, luego $Z^{\prime} Z=G^{\prime}$. Por lo tanto, este biplot preserva la métrica usual entre las filas, pero no entre las columnas, obteniéndose alta calidad de representación para las filas.

La asignación del valor propio a los factores $\mathrm{H}$, nos lleva al llamado GH-biplot $(\mathrm{G}=\mathrm{U}$ y $\mathrm{H}=\mathrm{V} \Sigma)$. Cómo trabajamos con la métrica identidad en el espacio de las filas, $\mathrm{G}$ debe verificar que $\mathrm{GG}^{\prime}=\mathrm{I}$, es decir, $\mathrm{Z}^{\prime} \mathrm{Z}=\mathrm{HH}^{\prime}$, por lo tanto este biplot preserva la métrica usual entre las columnas, pero no entre las filas, por lo que se obtiene una alta calidad de representación para las columnas.

La factorización para el HJ-biplot ${ }^{78}$ sería $\mathrm{G}=\mathrm{U} \Sigma$ y $\mathrm{H}=\mathrm{V} \Sigma$. Para el HJ-biplot, los elementos de la matriz Z están centrados por filas y columnas, por lo que la métrica introducida en el espacio de las filas es equivalente a la inversa de la matriz de covarianzas entre variables, mientras que en el espacio de las columnas, la métrica es equivalente a la inversa de la matriz de dispersión entre los individuos. La representación de filas y columnas es simultánea, por lo que se obtienen la misma calidad de representación tanto para los individuos (filas), como para las variables (columnas).

Las propiedades de los marcadores filas y columnas, dependen del biplot elegido. El conocimiento de estas propiedades es de fundamental importancia a la hora de la elección del tipo de Biplot a utilizar, así como para la interpretación de los resultados obtenidos. Como el interés de este trabajo se centra en los marcadores columnas (variables), vamos a ver las propiedades de los marcadores del GH-Biplot.

Para este tipo de biplot, la longitud del vector aproxima la desviación estándar de la variable que representa, y el coseno del ángulo entre dos variables aproxima la correlación entre las variables asociadas. Es decir, dos variables separadas por un ángulo pequeño están fuertemente relacionadas, si forman un ángulo obtuso están relacionadas pero 
de forma inversa y por último si forman un ángulo recto están incorreladas. También podemos destacar que la proyección de un punto fila (individuo) sobre un vector columna (variable), es aproximadamente el elemento transformado de la matriz de datos inicial y por último que la distancia entre dos puntos (individuos) es aproximadamente la distancia de Mahalanobis entre las filas y no la distancia euclidea.

Todo lo dicho anteriormente viene representado en la siguiente figura.

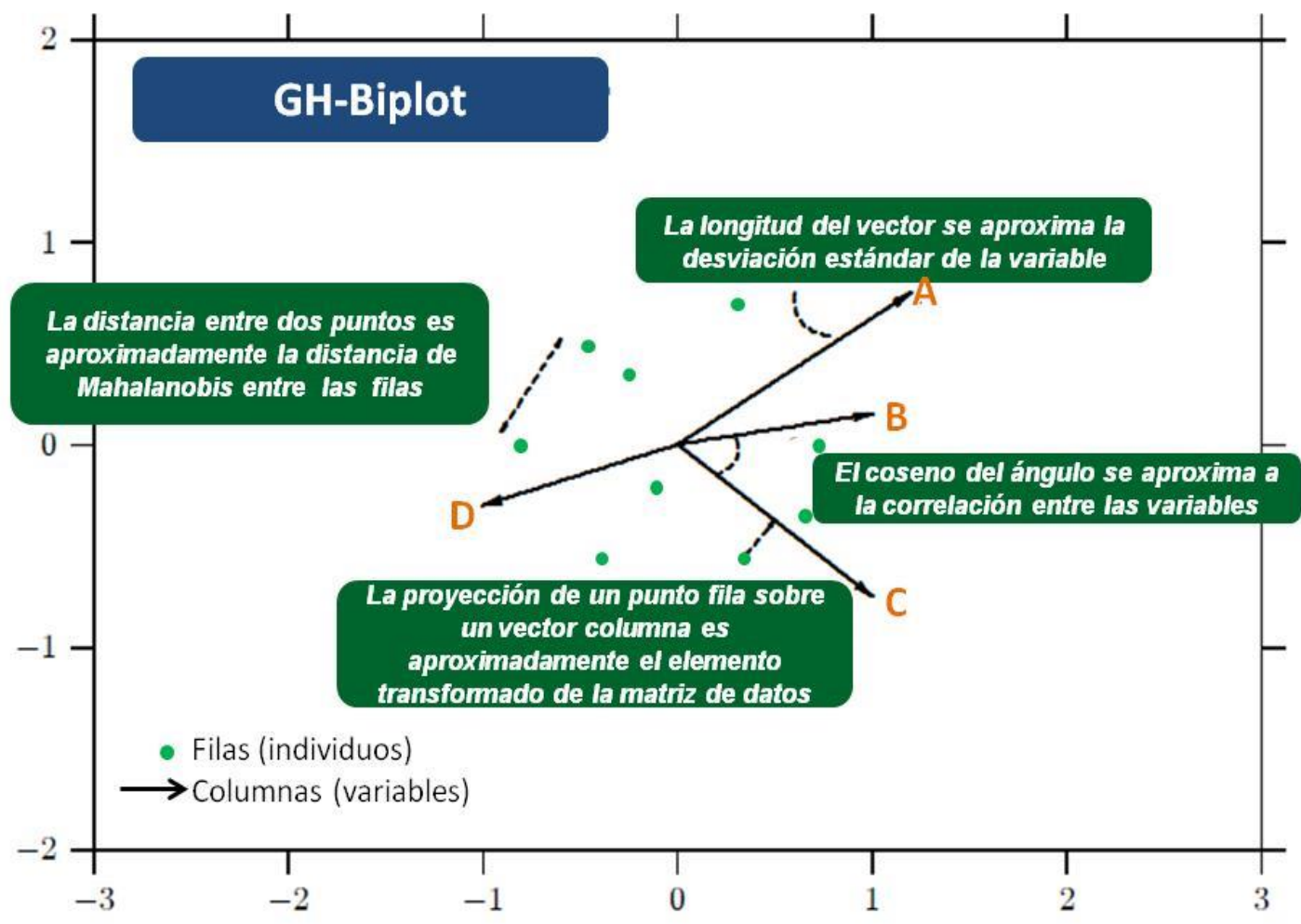

Figura 14: Geometría del GH-biplot

\section{MÉTODOS UTILIZADOS EN EL ESTUDIO DE MINERÍA DE DATOS}

En los estudios llevados a cabo, se han utilizado dos tipos de algoritmos. En primer lugar, se han aplicado dos métodos de selección de atributos, también denominados métodos de selección de características, para determinar cuáles son las variables más influyentes en la clasificación de los pacientes. Posteriormente se han aplicado varios 
algoritmos de clasificación con objeto de construir modelos que permitan predecir a qué clase pertenecen los pacientes no clasificados, a partir de otros atributos conocidos de dichos pacientes. Una vez aplicados los algoritmos de clasificación, se ha realizado un estudio comparativo de la precisión obtenida con el fin de determinar cuál o cuáles son los más adecuados para el área de aplicación objeto de este trabajo.

Finalmente, se han aplicado dos algoritmos de reglas de asociación, con el fin de obtener patrones que reflejen el comportamiento de los datos, y ayuden a determinar qué influencia tiene en la variable objetivo los valores del resto de los atributos mediante reglas que relacionan los valores de varios atributos simultáneamente.

En todos los casos se ha utilizado la implementación que proporciona la herramienta Weka (http://www.cs.waikato.ac.nz/ml/weka) de dichos algoritmos.

\subsection{ALGORITMOS DE SELECCIÓN DE CARACTERíSTICAS}

Se han aplicado dos algoritmos muy utilizados que suelen proporcionar buenos resultados, el algoritmo CFS (Correlation-based Feature Subset Selection) y un método basado en el índice de ganancia de información, que aporta cada atributo disponible.

\subsubsection{CFS}

Este método ${ }^{80}$ evalúa la importancia de un subconjunto de atributos o características, teniendo en cuenta su capacidad individual de predicción de la clase, junto con el grado de redundancia entre ellos. Serán seleccionados por tanto, aquellos subconjuntos de atributos que tienen una alta correlación con la clase, y baja correlación entre ellos.

La aceptación o rechazo de atributos, depende del grado en que contribuyen a predecir la clase en áreas del espacio de ejemplos no predichas por otras características. Para ello, se utiliza la siguiente función de evaluación del subconjunto de características: 


$$
M_{S}=\frac{k \overline{r_{c f}}}{\sqrt{k+k(k-1) \overline{r_{f f}}}}
$$

donde $\mathrm{M}_{\mathrm{s}}$ representa el "mérito" o relevancia de un subconjunto $\mathrm{S}$ que contiene $\mathrm{k}$ características, $\overline{r_{c f}}$ es la correlación media clase-característica (f $\in \mathrm{S}$ ), y $\bar{r}_{f f}$ es la intercorrelación media característica-característica. El numerador representa el poder de predicción de un conjunto de características, mientras que el denominador representa el grado de redundancia entre dichas características.

\subsection{2. ÍNDICE DE GANANCIA}

Este método evalúa la importancia de un atributo (característica) en función de la ganancia de información que proporciona con respecto a la clase.

El índice de ganancia (GI) de información se puede definir de la forma siguiente: GI (Clase, Atributo $)=I($ Clase $)-I($ Clase, Atributo $)$

Siendo I (Clase) la cantidad esperada de información (entropía) de la clase, y P(Clase, Atributo) la cantidad esperada de información de la clase dado el atributo. La entropía para un conjunto de variables $v_{i}$ se define en función de las probabilidades de dichas variables $P\left(v_{i}\right)$ :

$$
\mathrm{I}\left(P\left(v_{1}\right), \ldots, P\left(v_{\mathrm{n}}\right)\right)=\sum_{\mathrm{i}=1}^{\mathrm{n}}-P\left(v_{\mathrm{i}}\right) \log _{\mathrm{n}} P\left(v_{\mathrm{i}}\right)=\text { entropía }
$$

En el método se evalúan los valores de ganancia de cada uno de los atributos y se ordenan por dicho valor. Los de mayor ganancia serán los más importantes y por tanto los que más influencia tienen en la clasificación.

\subsection{ALGORITMOS DE CLASIFICACIÓN}

Los algoritmos supervisados, también conocidos como algoritmos predictivos o de aprendizaje automático, predicen el valor de un atributo (etiqueta) de un conjunto de 
datos, conocidos otros atributos (atributos descriptivos). A partir de datos cuya etiqueta se conoce, se induce una relación entre dicha etiqueta y otra serie de atributos. Esas relaciones sirven para realizar la predicción en datos cuya etiqueta es desconocida. Esta forma de trabajar se conoce como aprendizaje supervisado.

Cuando el atributo etiqueta toma valores discretos, los algoritmos supervisados reciben el nombre de algoritmos de clasificación y cada valor de la etiqueta representa una clase.

De los múltiples algoritmos de clasificación que existen en minería de datos, se han seleccionado para este estudio los más representativos. Aunque se han probado muchos, en el estudio sólo se documentan aquellos que han proporcionado mejores resultados.

En primer lugar se han aplicado algoritmos de clasificación individuales, dos árboles de decisión (J48 y Random Forest), y una red bayesiana, y posteriormente se han construido y probado tres multiclasificadores (Random Commetees, Boosting y Bagging), utilizando como clasificador de base Random Tree para el primero, y el algoritmo de inducción de árboles de decisión J48 para los dos últimos.

\subsubsection{ARBOLES DE DECISIÓN}

Un árbol de decisión es un conjunto de condiciones organizadas en una estructura jerárquica, de tal manera que la decisión final a tomar se puede determinar siguiendo las condiciones que se cumplen desde la raíz del árbol, hasta alguna de sus hojas.

La inducción del árbol, se realiza mediante un proceso en el que se van separando los ejemplos, en función de la evaluación de determinadas condiciones relacionadas con los valores de los atributos. El algoritmo comienza identificando la variable más importante (aquella que se considera que influye más en la clasificación), y se le asocia el nodo raíz del árbol. Todos los ejemplos del conjunto de entrenamiento se chequean frente a esa condición. Los que satisfacen la condición, se colocan en la rama izquierda 
del árbol, y los que no en la derecha (para condiciones binarias). A continuación se decide cual es la siguiente variable en importancia y se repite el proceso.

El modelo matemático utilizado para seleccionar los atributos que influyen en la clasificación, así como los valores de los atributos que van a formar parte de las condiciones, se basa en la cantidad esperada de información (entropía) que proporciona el atributo. En la figura siguiente se recoge el seudocódigo de un algoritmo básico.

Usualmente el proceso de inducción de los árboles conlleva un proceso de poda, consistente en evitar la separación repetitiva utilizando atributos que no tienen evidente relevancia, aun cuando no se haya conseguido la clasificación completa de los datos. La poda se realiza para evitar el problema de sobreadaptación (overfitting), que consiste en encontrar una regularidad irrelevante en los datos.

El algoritmo J48 es una versión avanzada de uno de los algoritmos de árboles de decisión más conocidos y utilizados, $\mathrm{C} 4.5^{81}$, el cual es un método basado en la ganancia de información que dispone de procedimientos de poda del árbol basados en reglas.

Random forest $^{82}$ es un clasificador que ajusta un número variable de árboles de decisión, a varios subconjuntos obtenidos seleccionando aleatoriamente un número determinado de atributos. 


\section{ALGORITMO Partición(N.nodo, E:cijo de ejemplos)

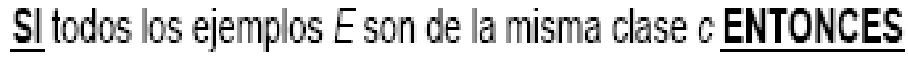 \\ Asignar la clase $c$ al nodo $N$. \\ SALIR: I/ Esta rama es pura, ya no hay que seguir partiendo. N es hoja. \\ SINO \\ Particiones : $=$ generar posibles particiones. \\ MejorPartición:= seleccionar la mejor partición según el criterio de partición. \\ PARA CADA condición $i$ de la partición elegida. \\ Añadir un nodo hijo i a $N$ y asignar los ejemplos consistentes a cada hijo ( $\left.E_{i}\right)$. \\ Partición $\left(i, E_{i}\right)$. I/ Realizar el mismo procedimiento global con cada hijo. \\ FIN PARA \\ FIN SI \\ FIN ALGORITMO}

Para clasificar un cito de ejemplos $E$, se invoca con la llamada Partición $(R, E)$, donde $R$ es un nodo raíz de un árbol por empezar.

Figura 15: Algoritmo básico de aprendizaje de árboles de decisión

\subsubsection{REDES BAYESIANAS}

El aprendizaje de redes bayesianas proporciona estructuras que relacionan variables, y llevan asociadas distribuciones de probabilidades condicionales relativas a dichas variables. El proceso de aprendizaje para un conjunto de datos D consiste en encontrar, entre todos los grafos posibles, el grafo $\mathrm{G}$ que mejor represente el conjunto de dependencias/independencias entre los datos. Para ello, se requiere calcular las probabilidades a posteriori de todos los grafos. La complejidad de este problema es NPduro, por lo que no es factible una solución exacta, y hay que recurrir a métodos de búsqueda heurística. Es necesario, por tanto, establecer una métrica de calidad que represente la adecuación de una red bayesiana a un conjunto de datos, y buscar la solución que maximice esa métrica mediante un procedimiento de optimización. Los algoritmos de búsqueda más utilizados son K2, B, TAN, y BAN. En este estudio se han utilizado los algoritmos de búsqueda $\mathrm{K}^{83}$ y TAN N ${ }^{84}$. 


\subsubsection{MULTICLASIFICADORES}

Son métodos que combinan modelos de clasificación obtenidos con diferentes métodos básicos, o con diferentes conjuntos de entrenamiento, con el fin de mejorar la precisión de las predicciones. Otra ventaja adicional de estas técnicas es la reducción del problema de sobreadaptación (overfitting), que consiste en encontrar una regularidad en los datos propia del conjunto de entrenamiento, y que no puede hacerse extensiva a otros datos. Los multiclasificadores construyen un conjunto de hipótesis, y combinan de alguna forma las predicciones del conjunto para clasificar ejemplos, seleccionando en cada caso la mejor predicción entre todas las ofrecidas por los diferentes modelos. La votación mayoritaria es el criterio de selección más simple y más utilizado. Existen muchos procedimientos para la creación de multiclasificadores: Bagging, Boosting, LogitBoost, Co-learning, Stacking, Cascading, etc.

En este estudio se han utilizado los métodos de Bagging y AdaBoost, este último es una variante del método de Boosting.

El método de Bagging (Bootstrap AGGregatING) ${ }^{85}$, consiste en crear diferentes clasificadores con el mismo algoritmo, pero con diferentes conjuntos de entrenamiento. Cada uno de éstos se crea por selección aleatoria, y con reemplazamiento (puede haber ejemplos repetidos) de una muestra de ejemplos del mismo tamaño que el conjunto de entrenamiento original. Una muestra bootstrap de tamaño $n$, se genera al seleccionar $n$ instancias del conjunto de entrenamiento de manera aleatoria. De este modo, se crean tantas muestras bootstrap del mismo tamaño, como clasificadores existan, y cada clasificador se entrena con una réplica bootstrap. De entre todas las predicciones ofrecidas por los clasificadores, se selecciona la que tenga mayor número de votos.

Boosting $^{86}$ se basa en la ponderación de los ejemplos. De forma iterativa se van construyendo modelos que minimicen los errores de los construidos previamente, mediante la asignación de pesos mayores a los ejemplos clasificados incorrectamente en la iteración anterior. En cada iteración, este método aprende un modelo que minimiza la suma de los pesos de los ejemplos clasificados erróneamente. Los errores de cada iteración se utilizan para actualizar los pesos de los ejemplos del conjunto de 
entrenamiento, de manera que se incremente el peso de los ejemplos errados, y se reduzca el peso de los ejemplos acertados. Además, cuando se utilizan para clasificar ejemplos reales, también se ponderan los modelos en función de su comportamiento en la fase de prueba.

AdaBoost es la variante de Boosting más conocida. En un ciclo se aprende un modelo a través de la evidencia ponderada, se estima el error del modelo, y dependiendo del valor del error se detiene el algoritmo o se continúa el proceso repitiendo el ciclo. Si se continúa iterando, se actualizan los pesos de los ejemplos clasificados de forma acertada, se almacena el modelo y se efectúa la normalización del peso de todos los ejemplos.

En Random Committees, cada clasificador de base se construye usando diferentes subconjuntos generados de forma aleatoria, sin necesidad de que éstos sean mutuamente excluyentes. La predicción final es el promedio de las predicciones generadas por los clasificadores de base individuales.

\subsection{MÉTODOS DE ASOCIACIÓN}

Pertenecen a la categoría de métodos no supervisados, o de descubrimiento del conocimiento, los cuales revelan patrones y tendencias en los datos disponibles, y se aplican con el fin de encontrar información oculta. El propósito de la información descubierta no es la predicción, sino su uso en la toma de decisiones.

El análisis de asociación persigue el establecimiento de relaciones entre instancias individuales, o grupos de instancias de la base de datos. Una regla de asociación tiene la forma "Si X entonces Y", donde X es la parte antecedente de la regla, e Y la parte consecuente.

Se pueden establecer diferentes medidas para evaluar la validez de las reglas, aunque la mayoría de ellas se basan en dos factores fundamentales: 
- Factor de confianza o previsibilidad: Frecuencia con que tiene lugar la regla en relación con las veces que ocurre $X$.

- Factor de soporte o prevalencia: Relación entre el número de veces que tiene lugar la regla, y el número total de registros de la base de datos.

Tanto en la parte antecedente, como en la parte consecuente de la regla, pueden aparecer los valores de varios atributos conjuntamente.

Existe una aplicación especial de las reglas de asociación en la que los modelos de las mismas, pueden utilizarse con fines de predicción o clasificación. En ese caso, las reglas inducidas deben contener en su parte consecuente únicamente valores del atributo etiqueta, es decir, la parte consecuente se debe corresponder con las clases en un problema de clasificación. En este caso se denominan reglas de asociación de clases, y los algoritmos que las generan se denominan de clasificación asociativa.

Uno de los algoritmos de reglas de asociación más utilizados es el algoritmo Apriori $^{87}$, el cual iterativamente va reduciendo el soporte mínimo hasta encontrar el número de reglas especificado que superen un determinado umbral de confianza. Este algoritmo se puede adaptar para generar reglas de asociación de clases, que pueden utilizarse en problemas de clasificación. Esta adaptación se conoce con el nombre de Predictive Apriori ${ }^{88}$, el cual busca con un umbral de soporte creciente, las mejores $n$ reglas según un valor de confianza corregido basado en el soporte. 


\section{Resultados}




\section{ESTUDIO DESCRIPTIVO}

\subsection{DESCRIPTIVO GENERAL}

En el periodo de estudio ingresaron en la unidad 8791 pacientes, de los cuales presentaban criterios de inclusión 8.543, que generaron un total de $\mathbf{4 4 . 1 9 5}$ estancias, recogidas en la tabla mensual de factores.6.525 pacientes $(76,37 \%)$ precisaron VM, que produjeron 27.385 días de VM. 7.932 pacientes $(92,83 \%)$ con CVC generaron un total de 42.233 días de CVC (84.271 cuando se incluyen los catéteres arteriales). 8.101 pacientes $(94,85 \%$,) tuvieron SV con un total de 43.594 días de SV. La edad media de los pacientes incluidos en este estudio fue de 64,66 $\pm 14,93$ años, con un mínimo de 14, y un máximo de 94. Los rangos de edad, se muestran en la siguiente figura.

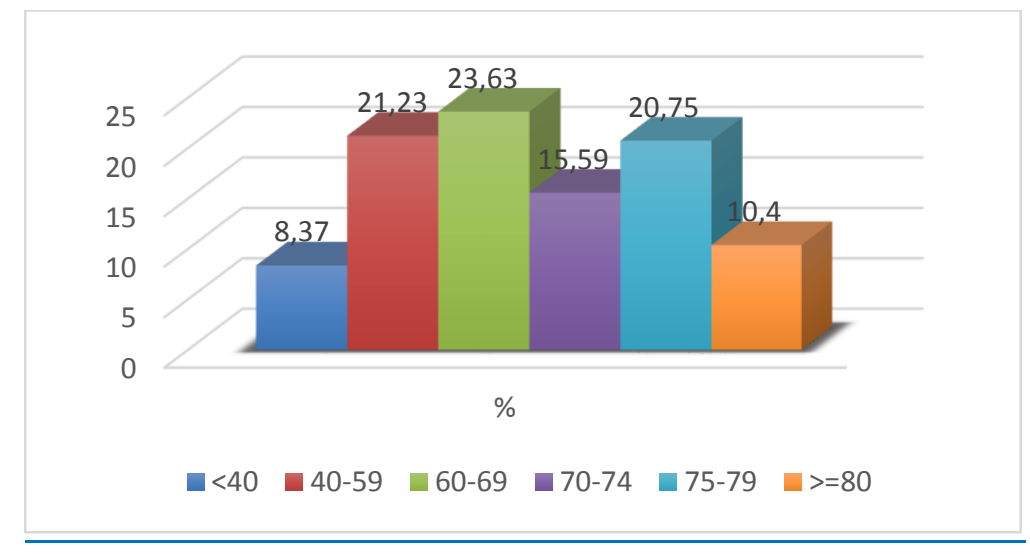

Figura 16: Rango de edad de los pacientes estudiados 
En cuanto a la distribución por sexos, un $67,03 \%$ son varones, y un $32,96 \%$ mujeres.

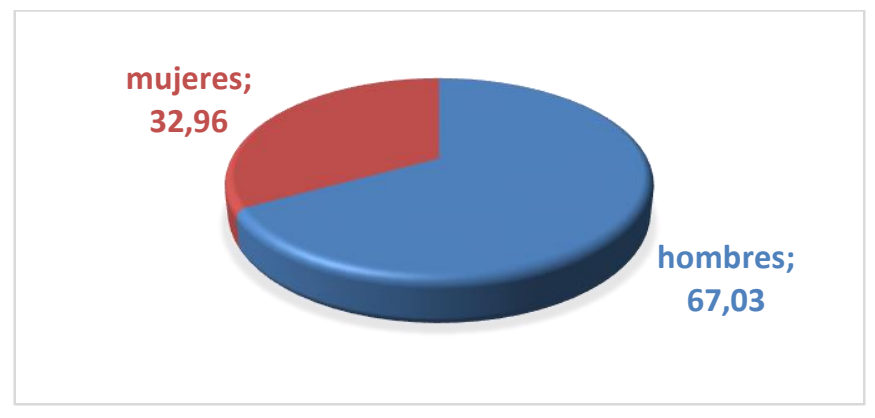

Figura 17: Distribución de los pacientes por sexo.

En 855 pacientes $(10,48 \%)$ se realizó cirrugía urgente.

La enfermedad de base más habitual, fue quirúrgica en un 55,57\%. La distribución del total se expresa en la siguiente figura.

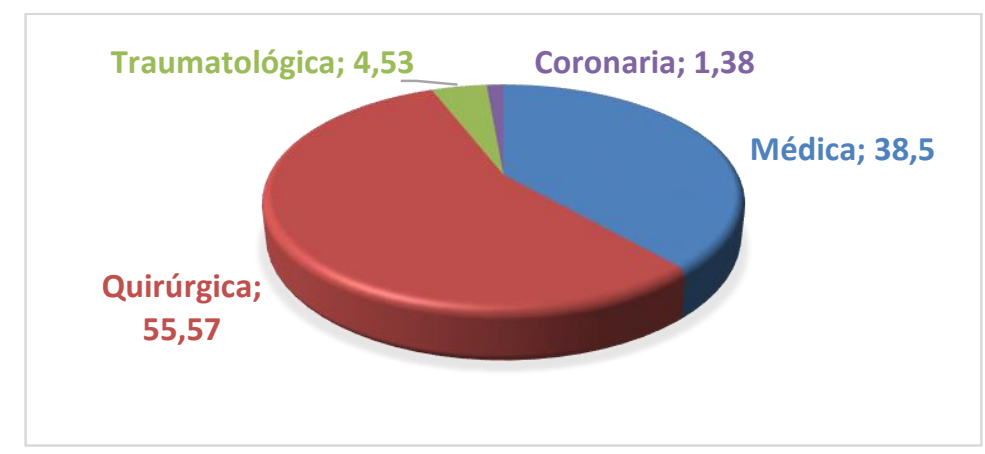

Figura 18: Enfermedad de base de los pacientes estudiados

Fallecieron un total de 833 pacientes, con una mortalidad del 10,70\%.

El APACHE II fue 15,37 $\pm 7,5$, con unos rangos que se expresan en la siguiente figura.

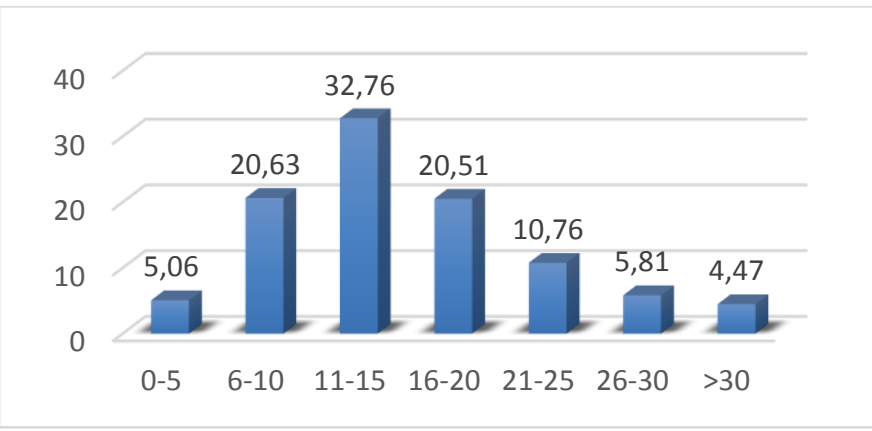

Figura 19: Distribución de los pacientes por APACHE II. 
La estancia media fue de 64,26 $\pm 9,67$ días, con un máximo de 183. La distribución de estancias se muestra en la siguiente figura.

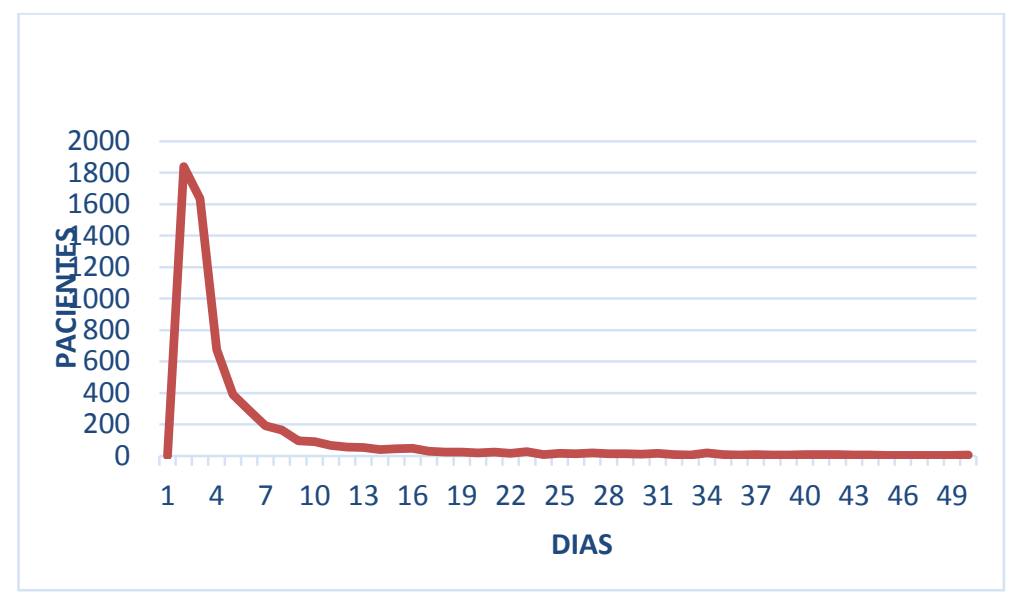

Figura 20: Distribución de las estancias de los pacientes.

En cuanto a los factores de riesgo para infección asociada a dispositivos, un $76,38 \%$ de los pacientes precisaron VM a través de vía aérea artificial, ya sea tubo orotraqueal, o cánula de traqueotomía. El 94,86\% de los pacientes precisaron SV, y un 92,83\% CVC. Otros factores de riesgo se comenzaron a recoger a partir del año 2006, con las modificaciones que se realizaron en la base de datos ENVIN-HELICS. Un 85,21\% de los pacientes recibieron tratamiento antibiótico $(19,26 \%$ de los pacientes previo al ingreso en UCI). Los nuevos factores de riesgo estudiados se expresan en la figura 21.

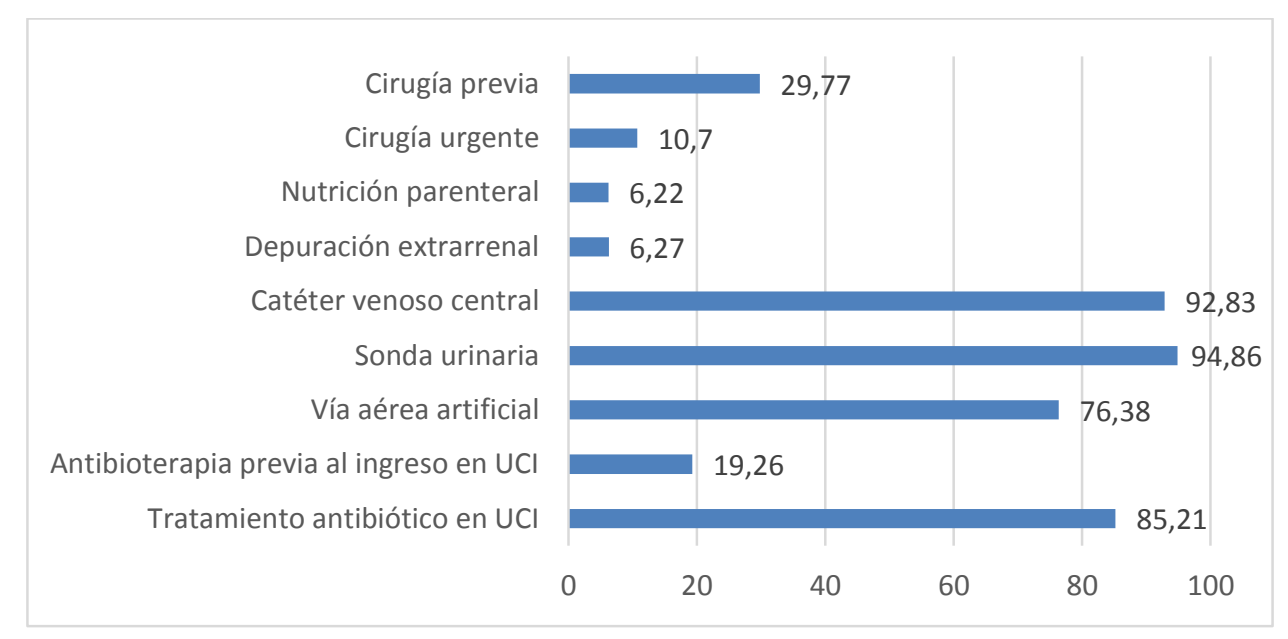

Figura 21: Factores de riesgo de infección. 
Como hemos dicho anteriormente, la base de datos se modificó a partir del año 2006. Además de las TI, los gérmenes, y unas características básicas de los pacientes, se incluyeron más datos respecto a la epidemiología, y los factores de riesgo. Los datos que presentamos a continuación, se refieren solo a los pacientes ingresados a partir de abril de 2006.

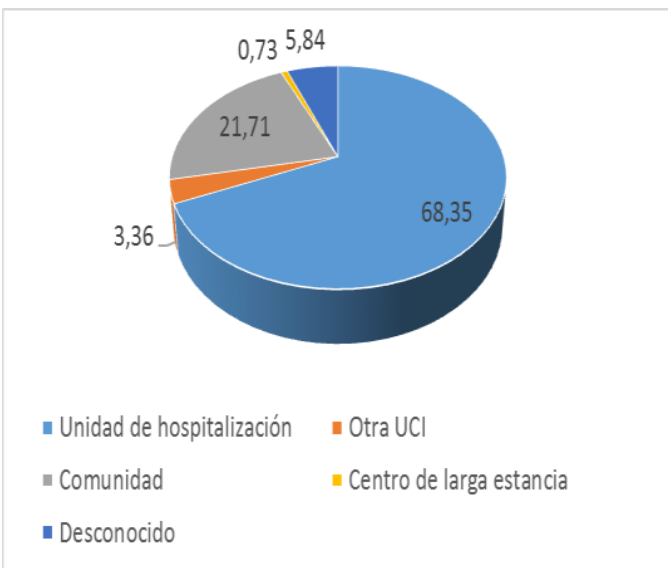

Figura 22: Procedencia de los pacientes.
Respecto a la procedencia al ingreso en la UCI, la mayor parte $(68,35 \%)$ provenían de una planta de hospitalización. El segundo grupo fueron los que procedieron de su domicilio (21,71\%). Los trasladados desde otras UCI, o los que residen en centros socio-sanitarios (3,36\% y $0,73 \%$ respectivamente), fueron muy poco frecuentes.

En cuanto a la distribución del tipo de cirugía al ingreso, la más frecuente es cirugía cardiaca, con un total del 20,42\% entre coronarios y valvulares, seguida de cirugía abdominal en un 6,46\% de los pacientes (cirugía hepato-pancreática y esofágica, sobre todo). El resto de cirugías se expresa en la tabla $\mathrm{n}^{\circ} 16$.

\begin{tabular}{lcc} 
CIRUGÍA PREVIA & N & $\%$ \\
Cirugía coronaria & 321 & 5,24 \\
Cirugía cardiaca & 930 & 15,18 \\
Cirugía vascular & 42 & 0,69 \\
Neurocirugía & 4 & 0,07 \\
Cirugía torácica & 41 & 0,67 \\
Cirugía abdominal & 402 & 6,56 \\
Cirugía maxilofacial & 3 & 0,05 \\
Cirugía O.R.L. & 11 & 0,18 \\
Cirugía urológica & 11 & 0,18 \\
Transplante de riñón & 1 & 0,02 \\
Transplante de páncreas & 26 & 0,42 \\
Otra cirugía & 32 & 0,52 \\
Total & $\mathbf{1 8 2 4}$ & $\mathbf{2 9 , 7 7}$ \\
Sin cirugía previa & 4303 & 70,23 \\
\multicolumn{1}{c}{ Tabla 16: Tipo de cirugía al ingreso } &
\end{tabular}




\subsection{ANALISIS DE LOS DATOS GENERALES}

La cirugía urgente en nuestra serie, supone un aumento del riesgo de estancia hasta más de 9 días, y un aumento del riesgo de infección adquirida en UCI.

\begin{tabular}{lcccccc|} 
CIRUGIA & N & $\%$ & $\begin{array}{c}\text { Estancia } \\
\text { Media }\end{array}$ & APACHE II & $\begin{array}{c}\text { Exitus } \\
(\%)\end{array}$ & $\begin{array}{c}\text { Enfermos con al } \\
\text { menos } \\
\text { una infección } \\
(\%)\end{array}$ \\
\hline NO & 6907 & 89,2 & 5,49 & 15,10 & 7,90 & 3,94 \\
SI & 855 & 10,98 & 14,62 & 18,36 & 22,29 & 18,22 \\
\hline
\end{tabular}

Tabla 17: Infección según tipo de cirugía al ingreso.

Respecto a la edad, en la tabla $\mathrm{n}^{\circ} 18$ podemos observar que el grupo mayor de pacientes, está entre los 60-69 años, siendo un 23,78\%, de toda la serie. En cuanto a la estancia media, no encontramos diferencias por tramos de edad. En relación con la mortalidad, es mayor en el grupo de 75-80 años. Las infecciones han sido ligeramente más frecuentes en los pacientes entre 60-75 años.

\begin{tabular}{|c|c|c|c|c|c|c|}
\hline EDAD & $\mathbf{N}$ & $\%$ & $\begin{array}{c}\text { Estancia } \\
\text { Media }\end{array}$ & APACHE II & $\begin{array}{c}\text { Exitus } \\
(\%)\end{array}$ & $\begin{array}{l}\text { Enfermos con al } \\
\text { menos } \\
\text { una infección } \\
(\%)\end{array}$ \\
\hline$<40$ & 369 & 7,84 & 6,15 & 10,67 & 5,69 & 2,44 \\
\hline $40-59$ & 1017 & 21,60 & 6,62 & 13,66 & 8,26 & 4,42 \\
\hline $60-69$ & 1117 & 23,72 & 6,25 & 14,87 & 8,50 & 5,46 \\
\hline $70-74$ & 703 & 14,93 & 6,61 & 15,71 & 8,25 & 5,26 \\
\hline $75-79$ & 990 & 21,02 & 5,96 & 16,96 & 10,40 & 4,65 \\
\hline$>=80$ & 513 & 10,89 & 6,05 & 17,49 & 9,55 & 4,29 \\
\hline
\end{tabular}

Tabla 18: Relación edad-infección. 


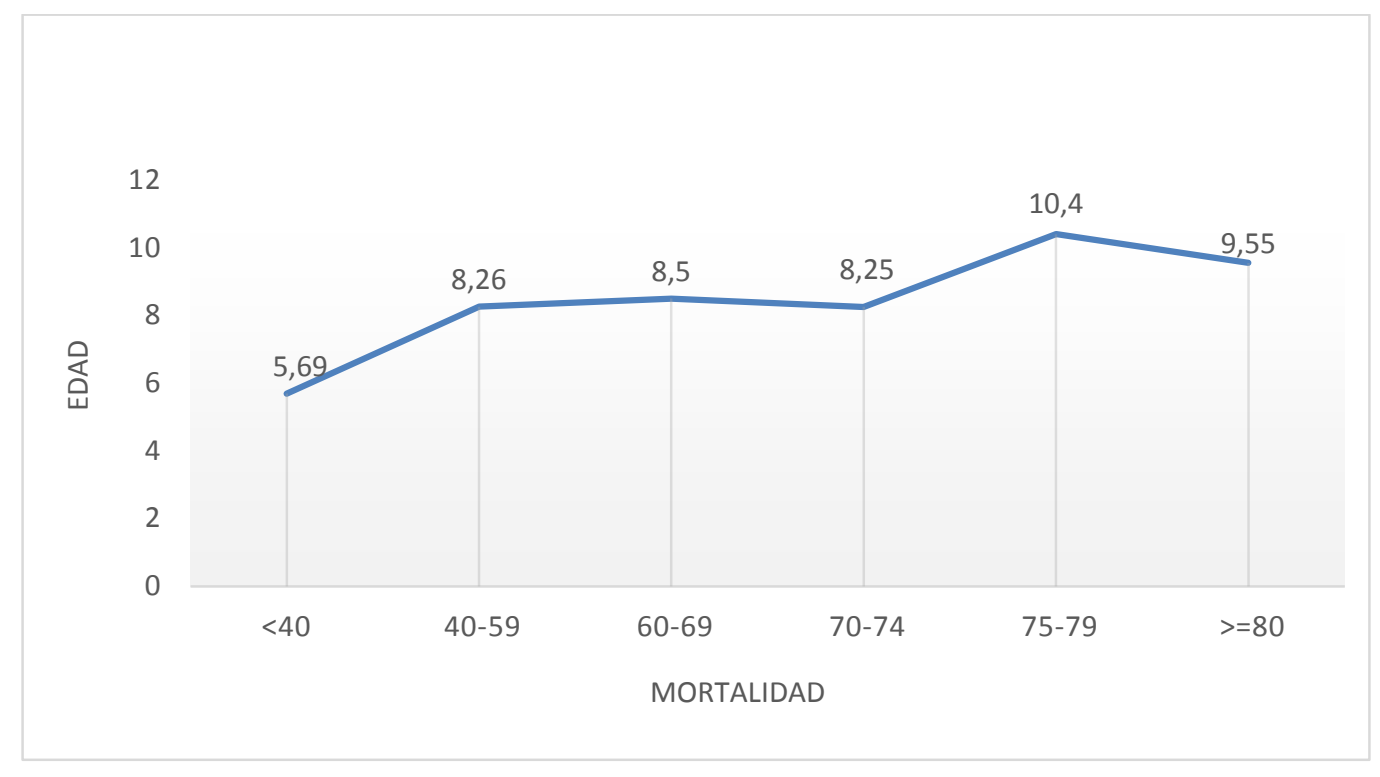

Figura 23: Relación edad-mortalidad.

En la tabla $n^{\circ} 19$ podemos observar la distribución de los pacientes en relación a la gravedad del APACHE II. El porcentaje de pacientes con IN es mínimo para pacientes con APACHE II, menor de 15, aumentando exponencialmente a partir de 15 puntos. Los pacientes con APACHE II mayor de 30, tienen menor incidencia de IN que los situados entre 20 y 30. Este hecho lo podemos explicar por la elevada mortalidad precoz de los pacientes con puntuación mayor de 30, lo que hace que fallezcan en los primeros días de estancia, antes de las primeras 48 horas, a partir de las que aparecen ya las infecciones adquiridas en UCI.

\begin{tabular}{|lccccc|} 
APACHE II & $\mathbf{N}$ & $\%$ & $\begin{array}{c}\text { Estancia } \\
\text { Media }\end{array}$ & $\begin{array}{c}\text { Exitus } \\
(\%)\end{array}$ & $\begin{array}{c}\text { Enfermos con } \\
\text { al menos } \\
\text { una infección } \\
(\%)\end{array}$ \\
\hline $0-5$ & 322 & 5,26 & 2,70 & 0,00 & 1,55 \\
$6-10$ & 1287 & 21,01 & 3,78 & 0,62 & 2,18 \\
$11-15$ & 1971 & 32,17 & 4,68 & 2,18 & 3,86 \\
$16-20$ & 1273 & 20,78 & 7,64 & 8,01 & 7,46 \\
$21-25$ & 659 & 10,76 & 10,54 & 22,76 & 15,78 \\
$26-30$ & 347 & 5,66 & 11,63 & 35,73 & 16,71 \\
$>30$ & 268 & 4,37 & 9,99 & 48,88 & 13,06 \\
\hline
\end{tabular}

Tabla 19: Relación APACHE II-infección. 


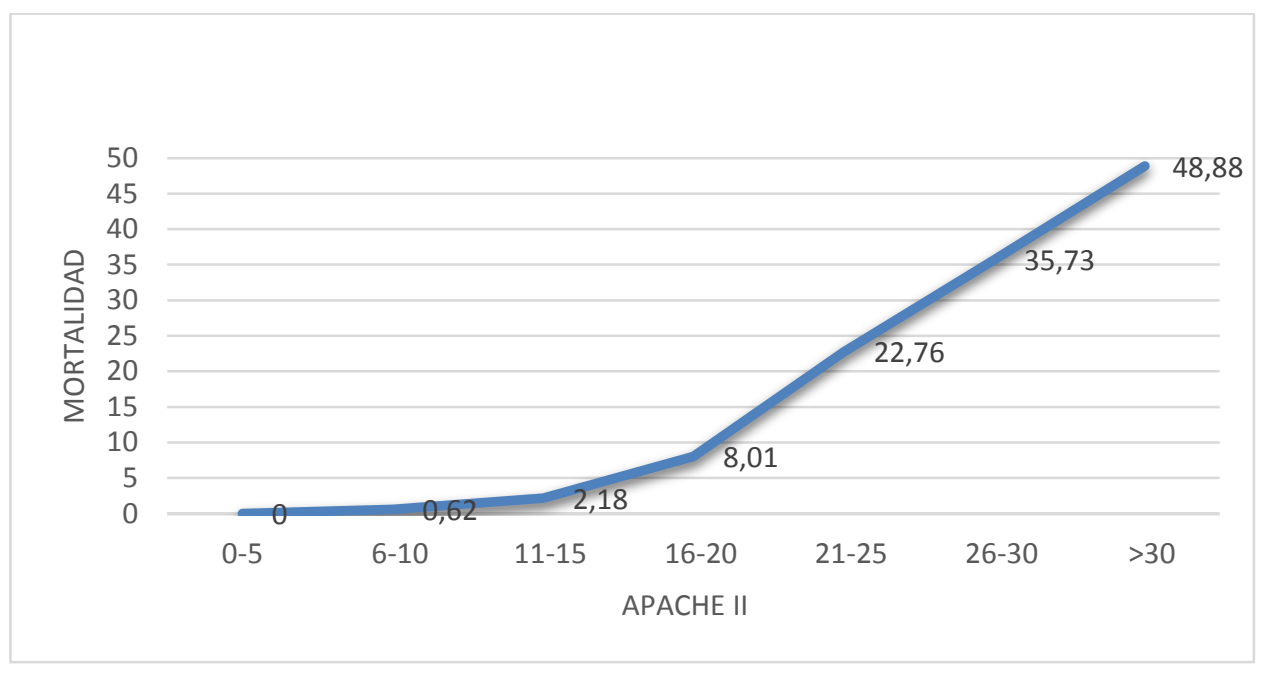

Figura 24: Relación APACHE II y mortalidad.

Los pacientes que fallecieron, como podemos observar en la tabla $\mathrm{n}^{\circ} 20$, han tenido mayor gravedad, mayor estancia media, y mayor cantidad de infecciones adquiridas en UCI, que los que sobrevivieron.

\begin{tabular}{|lccccc|} 
EXITUS & N & $\%$ & $\begin{array}{c}\text { Estancia } \\
\text { Media }\end{array}$ & APACHIE II & $\begin{array}{c}\text { Enfermos con al menos } \\
\text { una infección (\%) }\end{array}$ \\
\hline SI & 833 & 10,7 & 12,52 & 25,27 & 20,25 \\
NO & 6948 & 89,3 & 5,63 & 14,38 & 3,59 \\
\hline
\end{tabular}

Tabla 20: Relación Mortalidad-infección.

\section{PORCENTAJES DE PACIENTES CON INFECCION SEGUN APACHEII}

El porcentaje de infecciones estudiadas en relación a la gravedad, se expresa en la figura $\mathrm{n}^{\circ} 25$. En relación a las NAVM, la mayor incidencia se encuentra en el grupo con APACHE II entre 20 y 30, siendo algo menor en los pacientes con APACHE II mayor de 30 puntos. Para las BRCVC y las ITUSV, encontramos una incidencia similar en los tramos de APACHE II mayor de 20. 


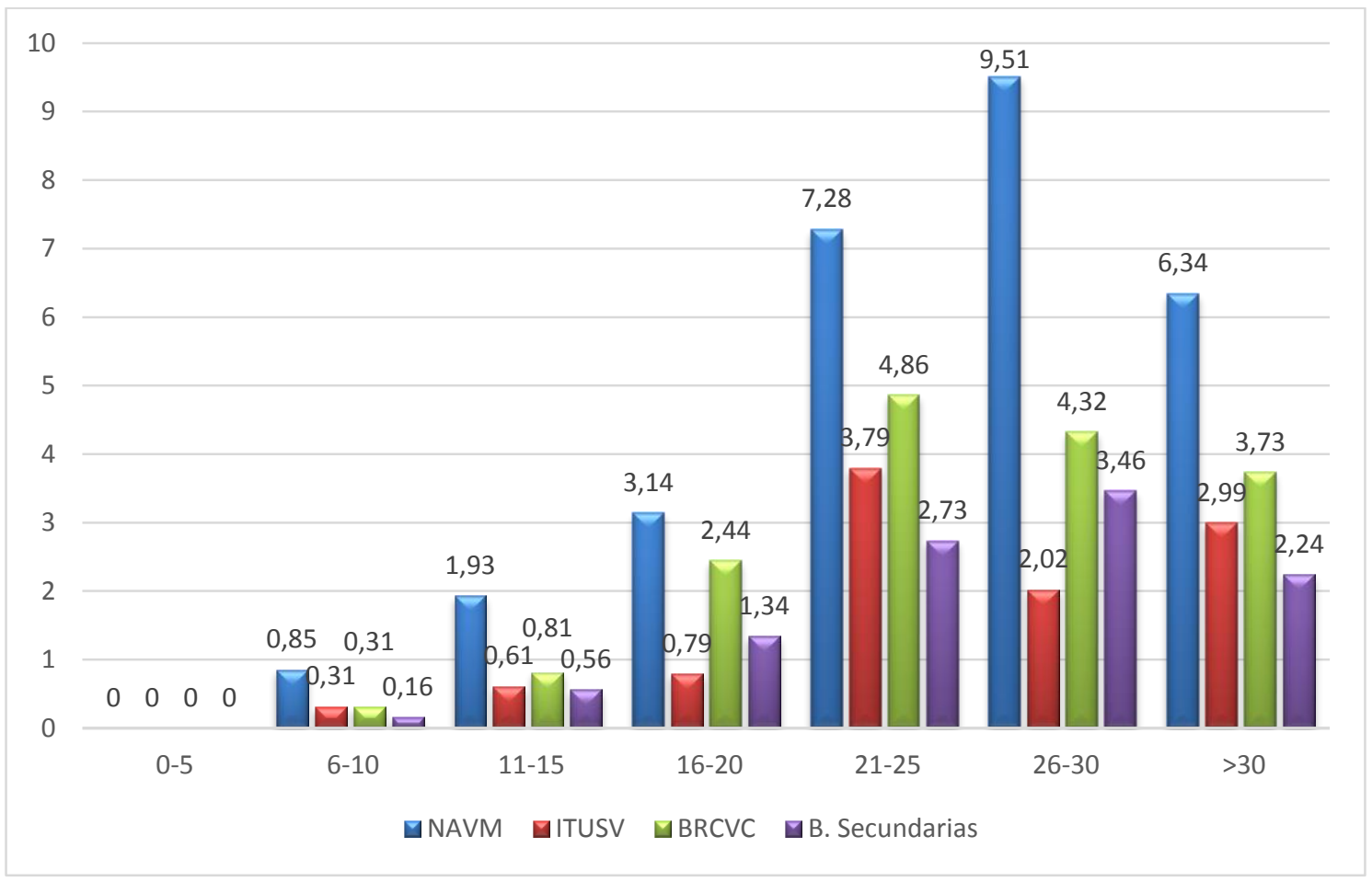

Figura 25: Porcentaje de infección nosocomial según APACHE II

\subsection{INFECCIONES ADQUIRIDAS INTRAUCI}

Las infecciones que hemos estudiado, en este trabajo, son las sometidas a vigilancia ENVIN. Como vemos en la tabla ${ }^{\circ} 21$, se han diagnosticado un total de 999 infecciones. Para nuestro estudio solo consideramos las que están relacionadas con dispositivos invasivos, siendo en total 747 infecciones.

\section{TODAS LAS INFECCIONES ADQUIRIDAS EN UCI}

Localización $\mathrm{N}$

Neumonía relacionada con ventilación mecánica o intubación

Bacteriemia primaria y relacionada con catéter venoso central

Infección urinaria relacionada con sonda uretral

Bacteriemias secundarias

Total infecciones ENVIN

Tabla 21: Distribución de las infecciones adquiridas en UCI. 


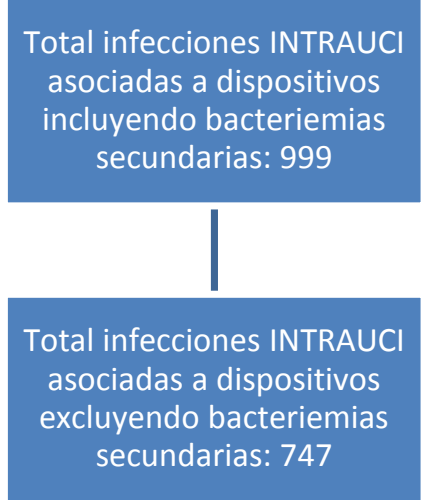

Figura 26: Infecciones estudiadas.

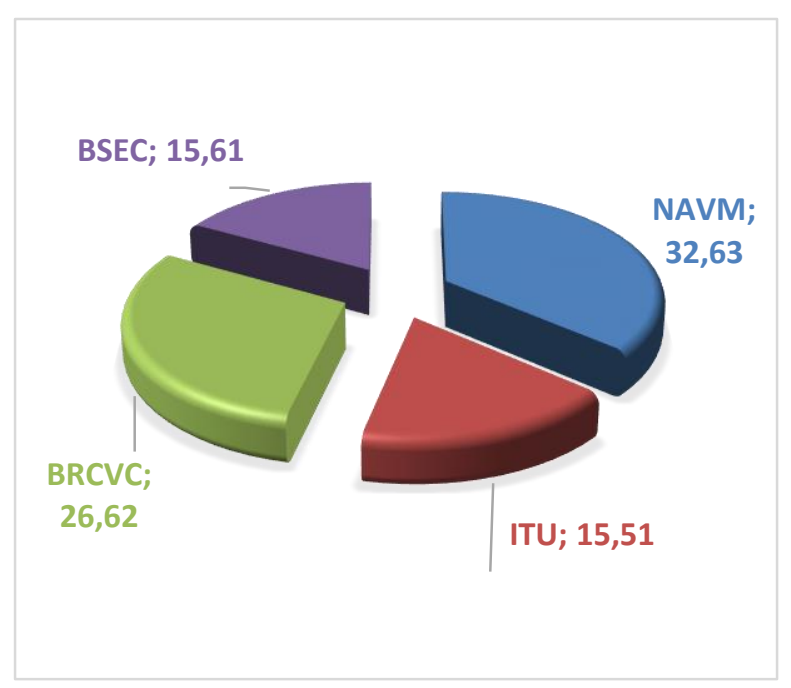

Figura 27: Distribución de las infecciones intra-UCI
De un total de 999 infecciones diagnosticadas, las más frecuentes adquiridas en nuestra unidad fueron las NAVM, con un porcentaje de $32.63 \%$.Les siguen las BRCVC en un $26,62 \%$, estando el tercer lugar ocupado por las ITUSV, en un $15,51 \%$, $\mathrm{y}$ por último las bacteriemias secundarias en un $15,21 \%$.

En la tabla $\mathrm{n}^{\circ} 22$ describimos los gérmenes aislados en las infecciones estudiadas. El microorganismo más frecuente fue P. Aeruginosa, en un 15,62\% de todos los aislamientos, le sigue S. Epidermidis en un 10,82\%, A. Baumanii con un 10,17\%, E. Coli un $9,47 \%$ y en quinto lugar C. Albicans, con un 6,26\%. Estas cinco especies suponen algo más del 50\% de todos los aislamientos en nuestra UCI. Seguidamente, en la tabla 22, se describen el resto de los gérmenes identificados según su frecuencia. 


\section{MICROORGANISMOS AISLADOS EN INFECCIONES ADQUIRIDAS}

\section{EN UCI}

\section{Microorganismo}

P. Aeruginosa

S. Epidermidis

A. Baumannii

E. Coli

C. Albicans

S. Aureus

S. Marcescens

E. Faecium

E. Cloacae

E. Faecalis

K. Pneumoniae

SAMR

S. Coagulasa negativo

S. Maltophilia

K. Oxytoca

C. Spp

M. Morganii

H. Influenzae

C. Glabrata

P. Mirabilis

Otros*

NUMERO TOTAL DE MICROORGANISMOS

*Otros: 38 gérmenes con menos de 7 aislamientos.

\section{N \%}

19215.62

13310.82

12510.17

1169.43

$77 \quad 6.26$

$62 \quad 5.04$

$56 \quad 4.55$

$45 \quad 3.66$

$44 \quad 3.58$

$38 \quad 3.09$

$37 \quad 3.01$

$35 \quad 2.84$

$30 \quad 2.44$

$\begin{array}{ll}28 & 2.27\end{array}$

$27 \quad 2.19$

$27 \quad 2.19$

$24 \quad 1.95$

$19 \quad 1.54$

$15 \quad 1.56$

90.93

10510.93

960100

Tabla 22: Gérmenes aislados en las infecciones adquiridas en UCI.

La distribución de los gérmenes, causantes de las infecciones ENVIN en todo el periodo estudiado, se muestra en la figura $\mathrm{n}^{\circ} 28$.-

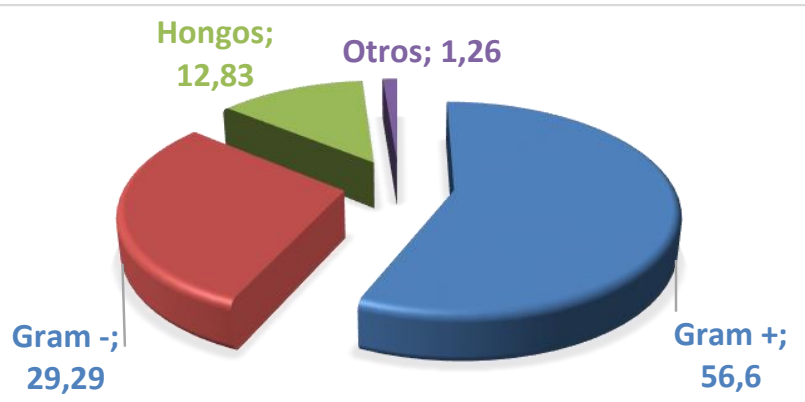

Figura 28: Distribución de los gérmenes aislados en las infecciones adquiridas en UCI.

En la figura $n^{\circ} 29$ se muestra la distribución de los gérmenes, según su grupo, a lo largo del periodo estudiado. La distribución se mantuvo de manera constante en los 
primeros cuatro años de recogida de datos, con un porcentaje de gramnegativos en torno al 55\%. Durante los años 2007 y 2008, se produjo un aumento del porcentaje de gramnegativos hasta el 65\%, debido a la aparición de una epidemia por A. Baumanii, que redujo de manera importante las infecciones por grampositivos. Tras el control de la infección por A. Baumanii,en los años 2009-2010, se produjo un aumento de los aislamientos por hongos con cifras mayores del 20\%. En los últimos años de evolución, observamos un crecimiento de gramnegativos y hongos, y un descenso de grampositivos, respecto al periodo de inicio de estudio.

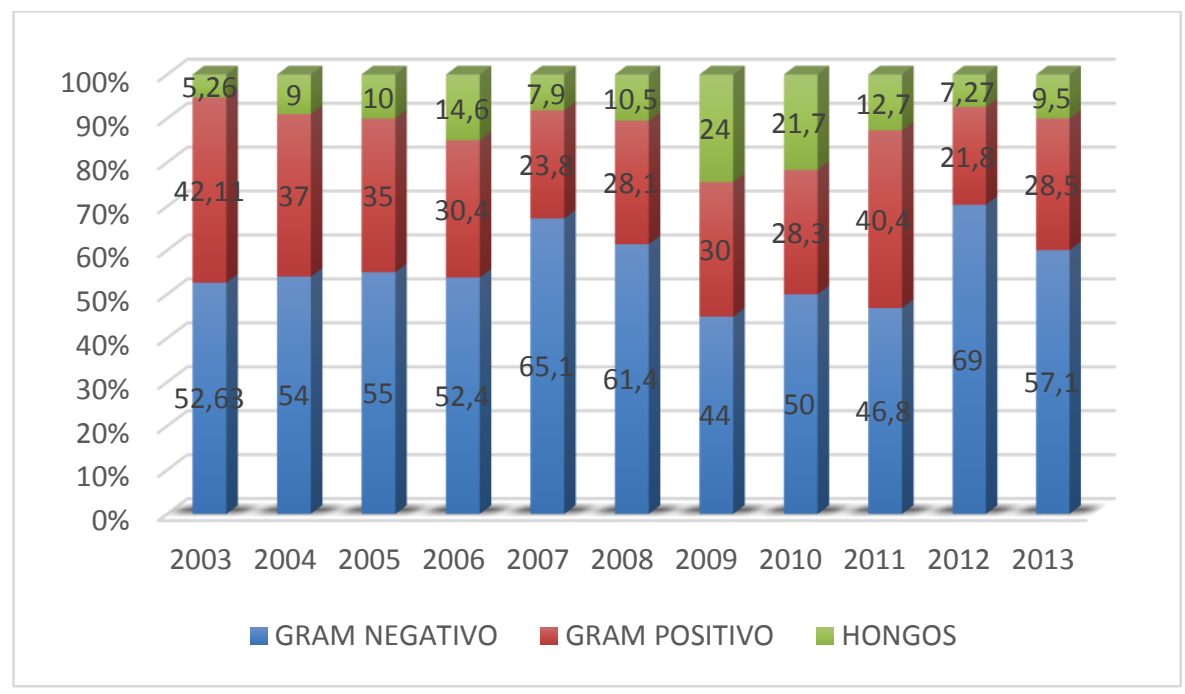

Figura 29: Evolución de los grupos de gérmenes en el periodo estudiado.

Respecto a los gramnegativos, en relación con el inicio del estudio, P. Aeruginosa en los últimos años se ha incrementado hasta acercarse al porcentaje inicial. A. Baumanii, en la actualidad, ha sido erradicado tras el brote de los años 2007-2008.

Han aumentado los aislamientos por otros patógenos gramnegativos, como S. Marcenses, desde un $0.83 \%$ en el primer año de estudio, hasta un $12.17 \%$ en el 2013 , manteniendo una tendencia ascendente desde el año 2010.

Respecto a los grampositivos, S. Epidermidis ha ido disminuyendo desde cifras mayores del 10\%, a cifras en torno a 7\%, en relación con el descenso de las infecciones por CVC. Sin embargo, otros gérmenes grampositivos como E. Faecium, han ido 
aumentando de manera significativa en el periodo de estudio, manteniendo una tendencia ascendente desde el año 2009.

Las infecciones por C. Albicans se mantienen en torno al 5\% de aislamientos durante todo el periodo de estudio, excepto el año 2009, en que se duplican las tasas de infección por este germen.

En cuanto a la incidencia de las infecciones, el programa ENVIN distingue dos grupos. El que incluye las bacteriemias secundarias a otros focos, que sobreestima la tasa de infección asociada a dispositivos, ya que se incluyen estas bacteriemias de otro origen. Son focos abdominales, urinarios, respiratorios, con lo que en ocasiones una misma infección, por ejemplo una NAVM que provoca una bacteriemia secundaria a foco respiratorio, el programa las recogería como dos infecciones. Por ello, para valorar las tasas de las infecciones asociadas a los dispositivos invasivos propios de la UCI, solo tendremos en cuanta las infecciones adquiridas en UCI, sin incluir las bacteriemias secundarias.

La tasa general de incidencia, incluyendo bacteriemias secundarias a infección de otros focos, y sin incluir las mismas, se muestra en la siguiente tabla.

\section{TASAS GENERALES DE INCIDENCIA}

A) Incluyendo las bacteriemias secundarias a infección de otros focos 999 Infecciones

8453 Pacientes ingresados $\mathbf{1 1 , 8 1}$ infecciones por cada 100 pacientes ingresados en

44195 Estancias (Tabla mensual de factores) 22,60 infecciones por 1000 días de estancia en UCI

B) Sin incluir las bacteriemias secundarias a infección de otros focos 747 Infecciones

8453 Pacientes ingresados $\mathbf{8 , 8 3}$ infecciones por cada 100 pacientes ingresados en

44195 Estancias (Tabla mensual de factores) 16,90 infecciones por 1000 días de estancia en UCI

Tabla 23: Tasa de infección adquirida en UCI.

En la figura $n^{\circ} 30$, se muestra la evolución a lo largo del periodo de estudio de las TI de IN, sin incluir las bacteriemias secundarias. 


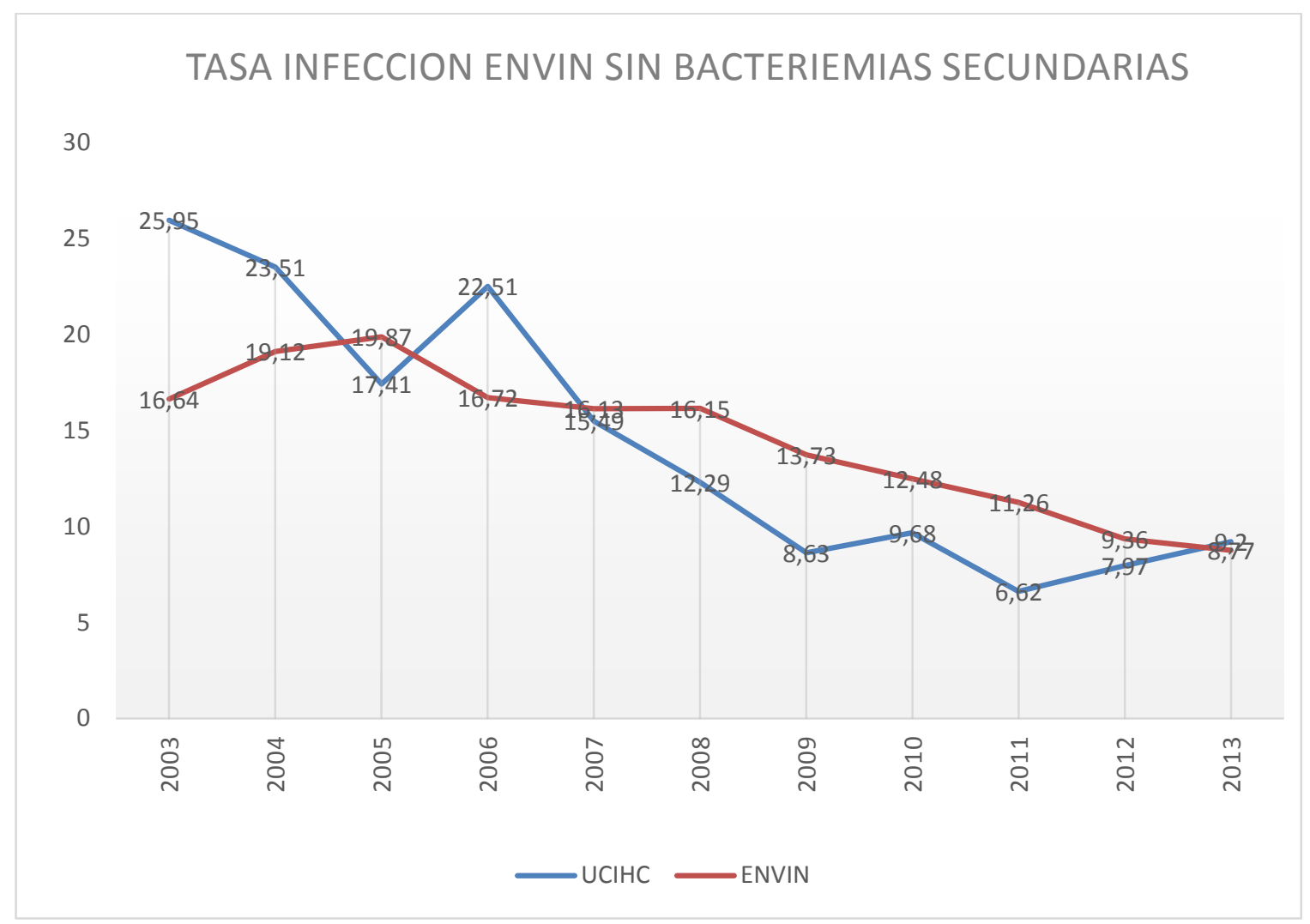

Figura 30: Evolución de la tasa de infección en el periodo estudiado

En esta figura podemos observar la evolución de las TI adquiridas en UCI a lo largo del periodo de estudio en nuestra unidad (UCIHC), y su comparación con las tasas nacionales recogida en los informes anuales (ENVIN). Durante los primeros años de nuestro registro, la TI adquirida en UCI se elevó en el año 2003 hasta 25,95\%o días de estancia, con una importante diferencia respecto a la nacional, que fue de $16,64 \%$. Durante los primeros años de recogida de datos en nuestra unidad, la TI se mantuvo siempre por encima de la nacional, con una tendencia descendente que la igualan a la nacional en el año 2005.

En el año 2007 se comenzó con el estudio piloto sobre las medidas de BZ. A partir de este año, se produce un punto de inflexión en nuestra TI, consiguiendo disminuirla hasta $16,3 \%$, manteniéndose por debajo de la TI nacional. Durante los años siguientes, con la participación en los proyectos BZ y NZ, conseguimos una disminución progresiva de las TI adquirida en UCI, hasta llegar a una tasa menor de 10\%, que se mantuvo hasta el año 2012 por debajo de la tasa nacional. 
En el año 2013, tras el final de los proyectos, se produce un repunte de la TI respecto a los años en los que se llevaron a cabo, mientras que la TI nacional continúa con una tendencia descendente. A pesar de este ligero aumento, las TI siguen siendo muy inferiores a las del inicio de recogidas de los datos, similares a las tasas españolas.

\subsubsection{MOMENTO DE ADQUISICION DE LA INFECCIÓN}

En la figura $\mathrm{n}^{\circ} 31$, se muestra el tiempo de aparición de las infecciones estudiadas, desde el ingreso en el hospital. Son infecciones que se producen de manera tardía, a partir del $20^{\circ}$ día de ingreso, siendo las más precoces en su diagnóstico las NAVM, y las más tardías las ITUSV.

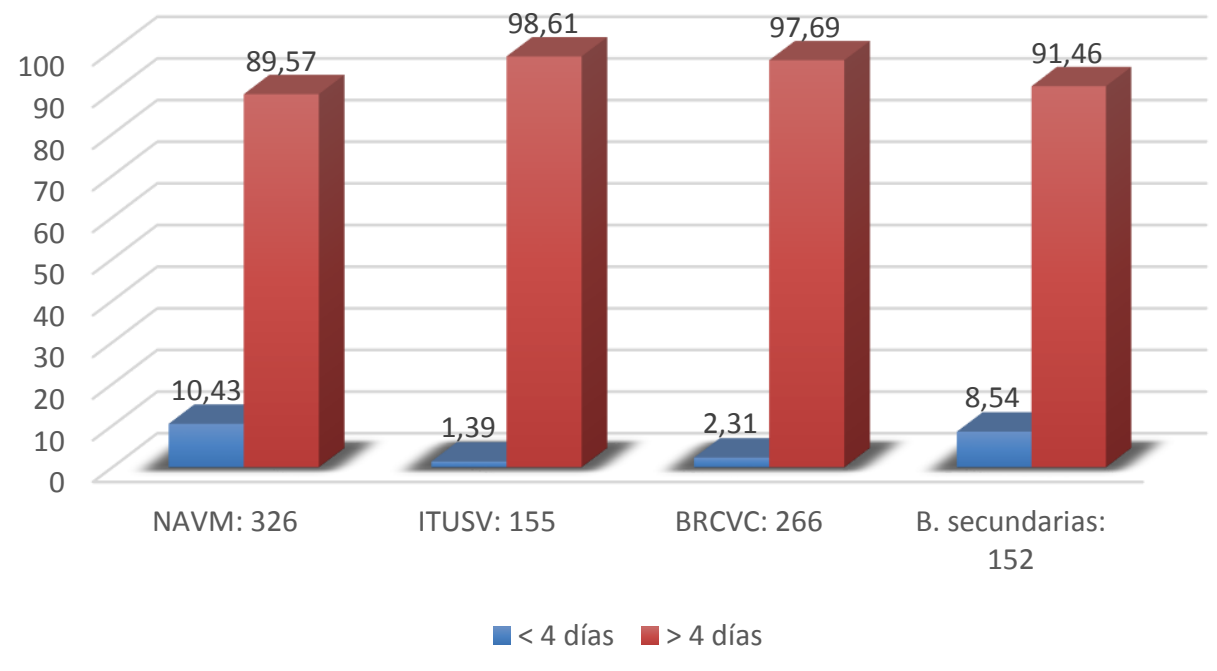

Figura 31: Tiempo de adquisición de la infección respecto al ingreso hospitalario.

Desde el ingreso del paciente en la UCI, la infección se produce de manera tardía, a partir de la $2^{\mathrm{a}}$ semana de ingreso. Por la diferente patogenia de las distintas infecciones, su comportamiento es algo diferente. Son más precoces las NAVM, hasta un 25\% de las mismas, dentro de los primeros 4 días del ingreso. Las más tardías desde el ingreso en UCI, son las BRCVC, que en un 92,31\% aparecen después del $4^{\circ}$ día de estancia en UCI. 


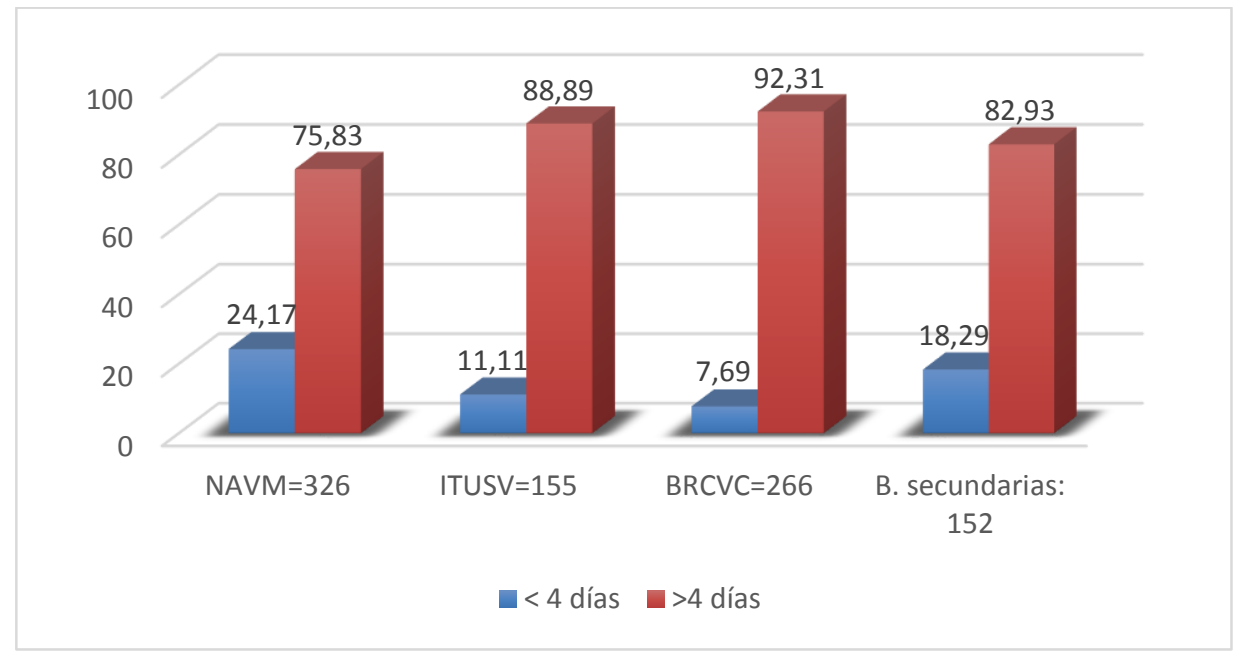

Figura 32: Tiempo de adquisición de la infección respecto al ingreso en la UCI.

\subsubsection{NAVM.}

Se diagnosticaron 326 NAVM, en un total de 278 pacientes. Las TI se muestran en la siguiente tabla. La ratio de utilización de VM (días de VM / días de estancia) es 0,59. En la tabla ${ }^{\circ} 24$ se describen las DI, y la TI de NAMV.

\section{TI NAMV/}

\section{NAVM}

8453 pacientes ingresados

6207 pacientes con VM
3,85 NAVM por 100 pacientes ingresados en UCI

$\mathbf{5 , 2 5}$ NAVM por 100 pacientes con VM

\section{NA VM}

44195 días de estancia

27385 días de VM
7,37 NAVM por 1000 días de estancia en UCI

11,90 NAVM por 1000 días de VM

Tabla 24: Incidencia de NAVM. 
La distribución de la NAVM, y de la ratio de VM, se muestran, en las siguientes figuras.

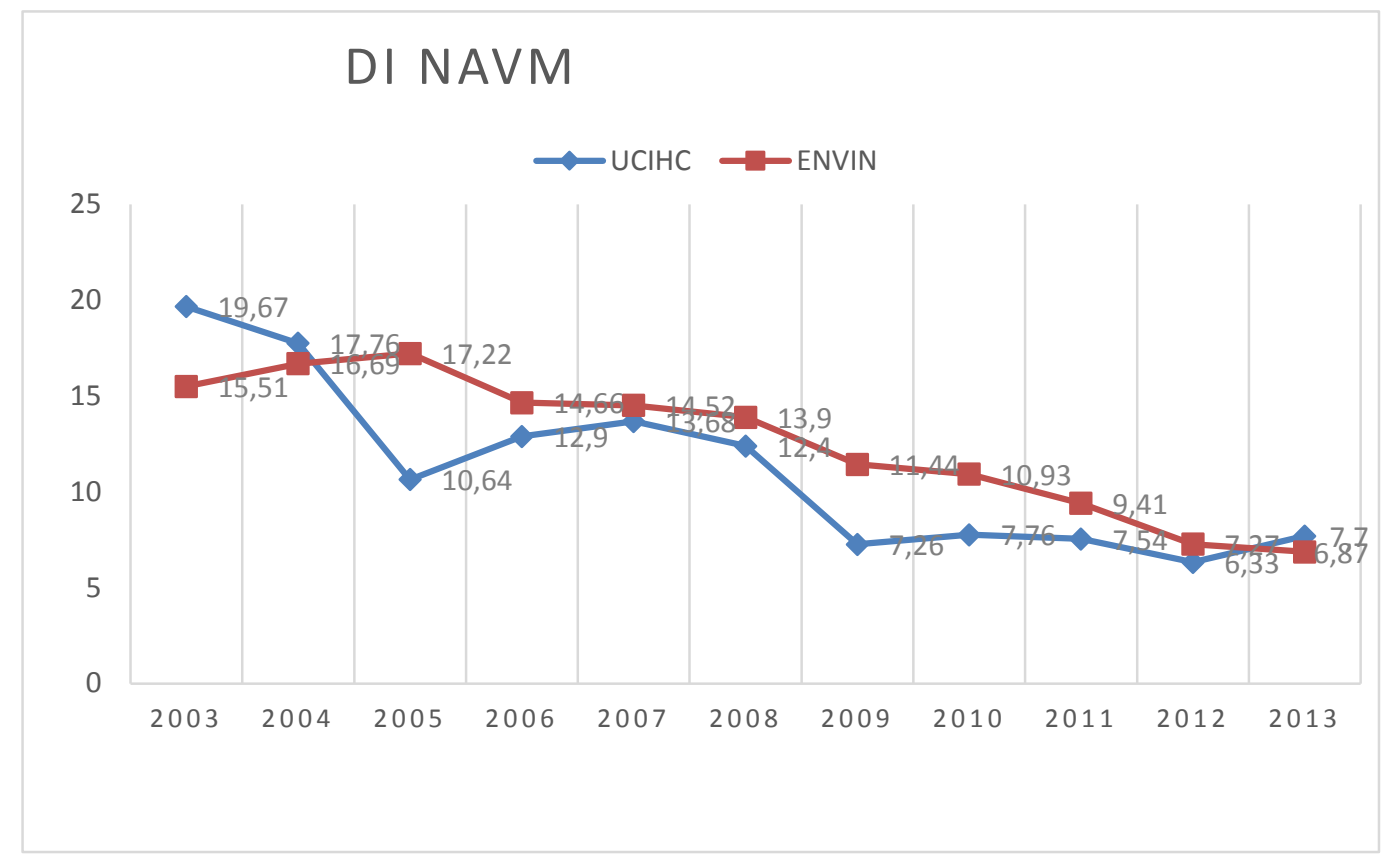

Figura 33: Evolución de las tasas de NAVM.

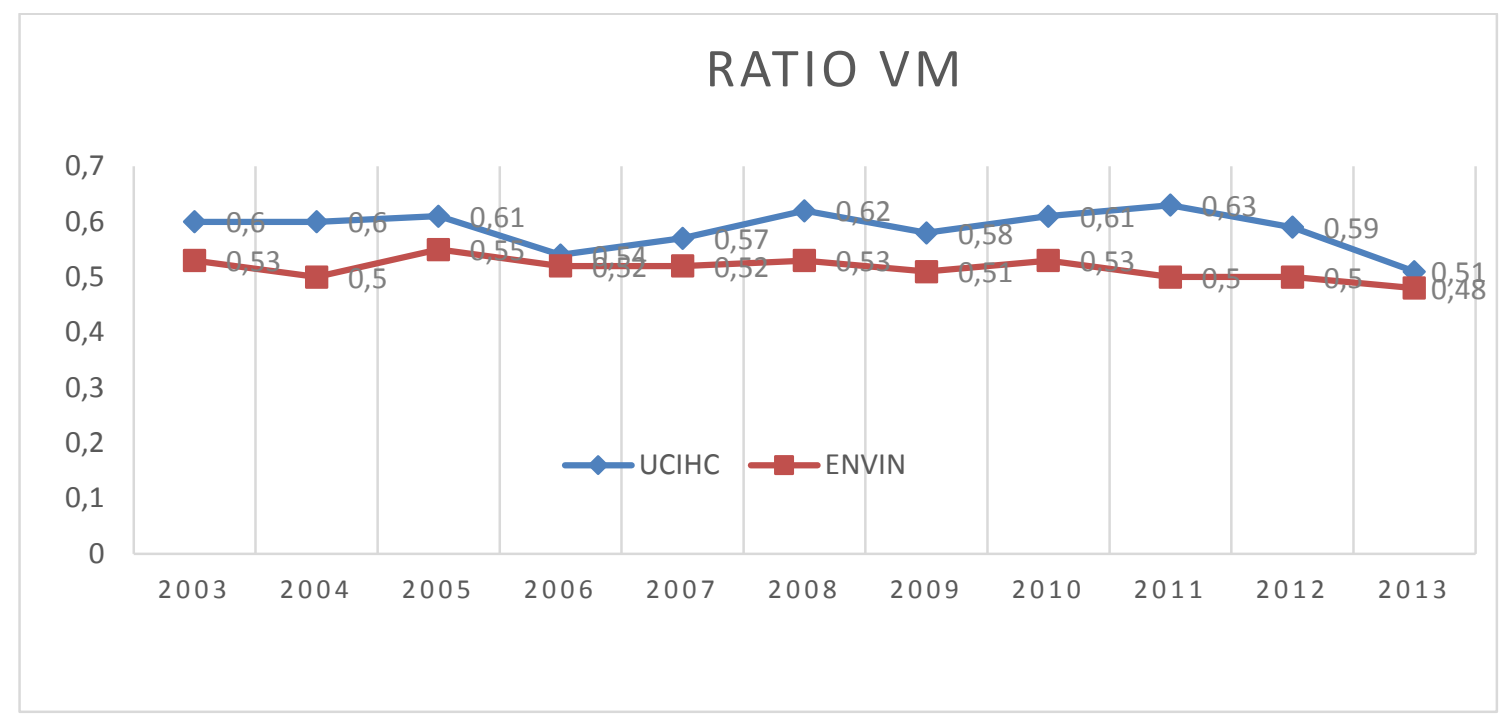

Figura 34: Evolución de la tasa de uso de VM.

Con una ratio de uso de VM prácticamente constante a lo largo del periodo estudiado, las TI de NAVM muestran una tendencia descendente, especialmente a partir del año 2009, cuando finaliza el periodo de medidas BZ. Desde entonces se han mantenido prácticamente en cifras similares, llegando a un mínimo de 6,33\%o días de VM en 2012, al finalizar el programa NZ. 
Para los siguientes datos, solo analizamos a los pacientes ingresados a partir de 2006, cuando se empezaron a estudiar más profundamente las NAVM en la base de datos ENVIN.

En cuanto al diagnóstico clínico de NA VM, se muestra en la tabla nº 25 .

$\begin{array}{lcc}\text { DIAGNOSTICO CLINICO } & \text { N } & \% \\ \text { Cavitación de un infiltrado pulmonar } & 8 & 3,77 \\ \text { Clínica compatible más nuevo y persistente infiltrado radiológico } & 169 & 79,72 \\ \text { Extensión de un infiltrado previo y empeoramiento clínico (2 } 2^{a} \text { neumonía) } & 31 & 14,62 \\ \text { Otro criterio diagnóstico clínico } & 4 & 1,89\end{array}$

Tabla 25: Diagnóstico clínico de NAVM.

La mayoría de las neumonías $(79,72 \%)$ se diagnostican con criterios N1, mediante aspirado bronquial, con un punto de corte $>100.000$ UFC. Esto aporta un diagnóstico de NAVM de buena calidad.

$\begin{array}{lcc}\text { CLASIFICA CIÓN DE NEUMONÍAS DE ACUERDO CON LOS } & \text { N } & \% \\ \text { RESULTADOS MICROBIOLÓGICOS } & 161 & 76,30 \\ \text { Aspirado distal (BAS) protegido con un punto de corte>=10(3) CFU/ml } & \mathbf{1 6 1} & \mathbf{7 6 , 3 0} \\ \text { Total Neumonía } 1 & 38 & 18,01 \\ \text { Aspirado endotraqueal cuantitativo con un punto de corte de 10(6) CFU/ml } & \mathbf{3 8} & \mathbf{1 8 , 0 1} \\ \text { Total Neumonía } 2 & 3 & 1,42 \\ \text { Hemocultivo positivo (no relacionado con otro foco de infección) } & \mathbf{3} & \mathbf{1 , 4 2} \\ \text { Total Neumonía } 3 & 5 & 2,37 \\ \text { Cultivo positivo de esputo o aspirado traqueal no-cuantitativo } & \mathbf{5} & \mathbf{2 , 3 7} \\ \text { Total Neumonía } 4 & 4 & 1,89 \\ \text { Sin microbiología positiva } & \mathbf{4} & \mathbf{1 , 9 0} \\ \text { Total Neumonía } 5 & \mathbf{2 1 1} & \mathbf{1 0 0 , 0 0} \\ \text { Total Neumonías } & & \end{array}$

Tabla 26: Diagnóstico microbiológico de NAVM.

La respuesta sistémica a la NAVM, se muestra en la siguiente figura. La respuesta más frecuente es sepsis en un 41,04\%, seguida de sepsis grave en un 20,75\% 


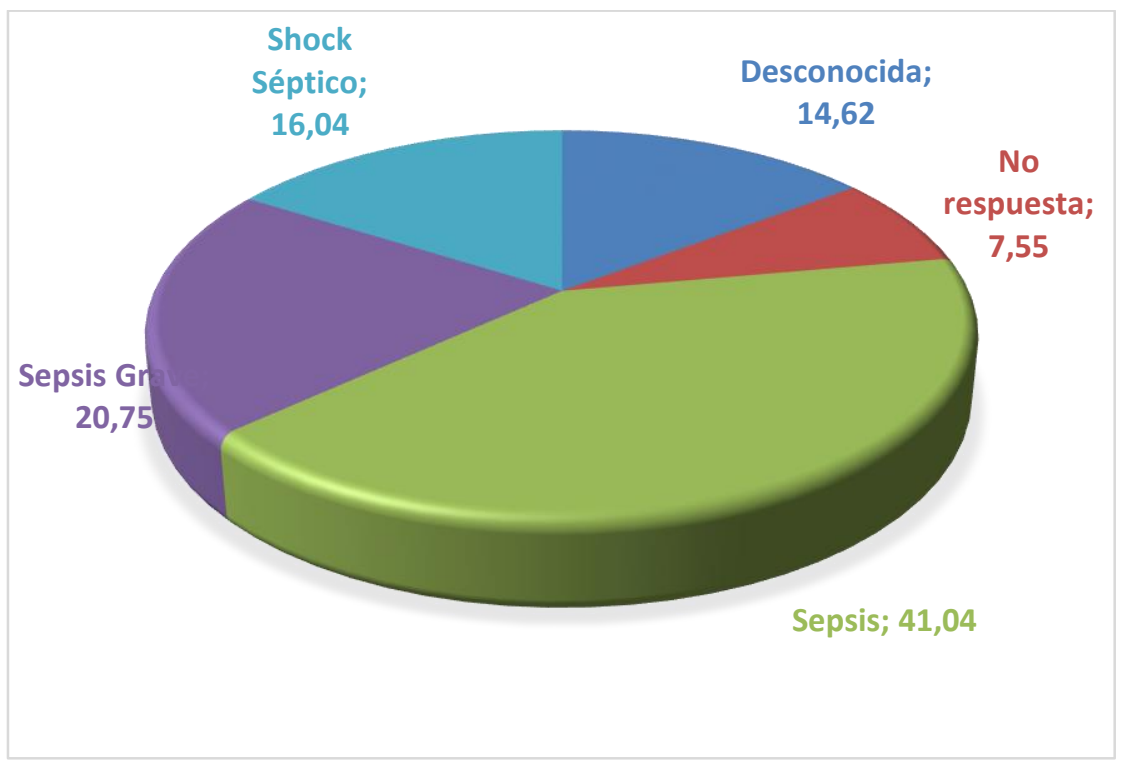

Figura 35: Respuesta sistémica de las NAVM.

La etiología global de las NAVM, diagnosticada en este periodo se muestra en la tabla $\mathrm{n}^{\circ}$ 27. Los gérmenes más frecuentes son P. Aeruginosa 21,89\% y A. Baumanii 12,7\%. Prácticamente, todos los aislamientos de S. Aureus corresponden a NAVM precoces, como se puede ver en la tabla $n^{\circ} 29$.

\begin{tabular}{|c|c|c|}
\hline MICROORGAN & & \\
\hline Microorganismo & $\mathbf{N}$ & $\%$ \\
\hline P. Aeruginosa & 81 & 21,89 \\
\hline A. Baumannii & 47 & 12,70 \\
\hline S. Aureus & 34 & 9,18 \\
\hline E. Coli & 31 & 8,37 \\
\hline S. Marcescens & 21 & 5,67 \\
\hline SAMR & 19 & 5,13 \\
\hline H. Influenzae & 15 & 4,05 \\
\hline K. Pneumoniae & 14 & 3,78 \\
\hline E. Cloacae & 13 & 3,51 \\
\hline S. Pneumoniae & 7 & 1,89 \\
\hline Otros & 88 & 23,78 \\
\hline Total & 370 & 100 \\
\hline
\end{tabular}

En la siguiente tabla desglosamos la etiología de las NAMV según el momento de aparición. Identificamos 157 NAMV adquiridas en los 7 primeros días de estancia, y 169 a partir del $7^{\circ}$ día. Su etiología varía, de acuerdo a la etiopatogenia de la NAVM. Mostramos los gérmenes más frecuentes en cada grupo. 
NA VM $<7$ DIAS

\section{NAVM > 7 DIAS}

MICROORGANISMO

N \%

S. Aureus

26

16,56

MICROORGANISMO

E. Coli

21

13,37

A.baumannii

P. aeruginosa

16

10,19

S. Marcescens

15

9,55

SAMR

10

6,36

S. Maltophilia

6,36

B. Cepacia

5,73

A. Fumigatus

5,73

E. Coli

$6 \quad 3,82$

K Pneumoniae

$6 \quad 3,82$

E. Faecalis

Tabla 28: Etiología de las NAVM según su aparición.

\subsubsection{BRCVC}

Identificamos un total de 266 BRCVC en 233 pacientes. Las TI de BRCVC, se muestran en la siguiente tabla.

\section{TASAS DE INCIDENCIA}

$\mathrm{N}^{\mathrm{o}}$ de BRCVC 266 total de pacientes $\mathbf{8 4 5 3}$

$\mathrm{N}^{\mathrm{o}}$ de BRCVC 266 total de pacientes $\mathbf{7 8 2 7}$

$\mathrm{N}^{\mathrm{o}}$ de BRCVC 266 total de estancias 44195

(Tabla mensual de factores)

\section{TABLA MENSUAL DE FACTORES}

$\mathrm{N}^{\mathrm{o}}$ de bacteriemias $\mathbf{2 6 6}$

Total días de catéter, incluidos arteriales $\mathbf{8 4 2 7 1}$

$42233 \mathrm{CA}+\mathbf{4 2 0 3 8}$ CVC $=\mathbf{8 4 2 7 1}$ Catéter

Ratio de utilización 1,90

Tabla 29: Tasas de incidencia de BRCVC.

La evolución de las BRCVC, a lo largo del periodo de estudio, se muestra en la figura 36. Tiene una tendencia descendente paralela a la experimentada por las tasas nacionales. El mínimo, 0,95\%o días de CVC, se consiguió en el año 2011 al finalizar el periodo de recogida de medidas del programa BZ.
3,14 BRCVC por cada 100 pacientes

3,32 BRCVC por 100 pacientes con CVC

6,01 BRCVC por 1000 días de estancia

3,15 BRCVC por 1000 días de catéter 


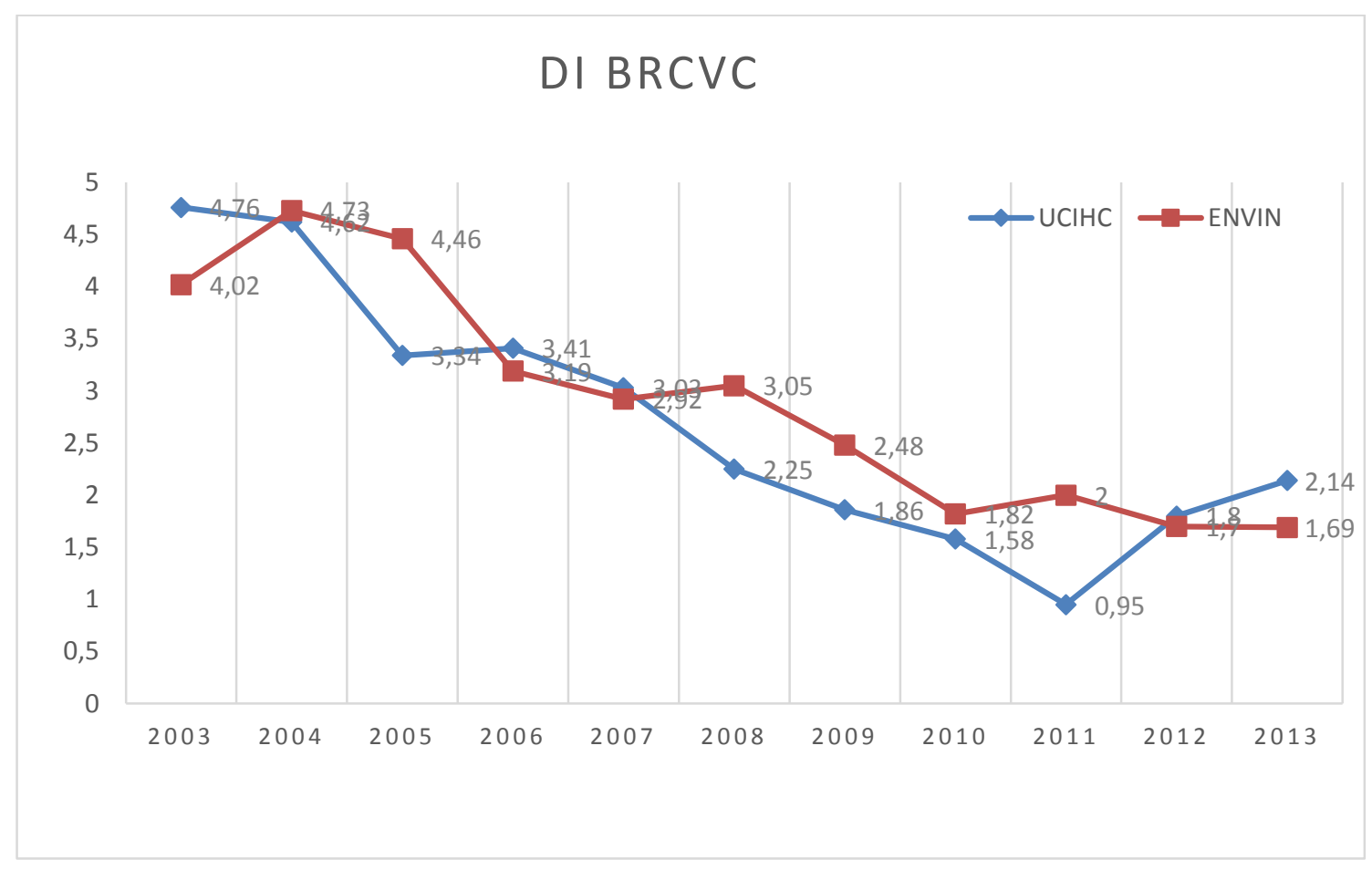

Figura 36: Evolución de la tasa de BRCVC.

La ratio de utilización de CVC y CA, como se muestra en la figura 37, es mayor en nuestro servicio que en las UCIs españolas, manteniéndose constante a lo largo del periodo estudiado.

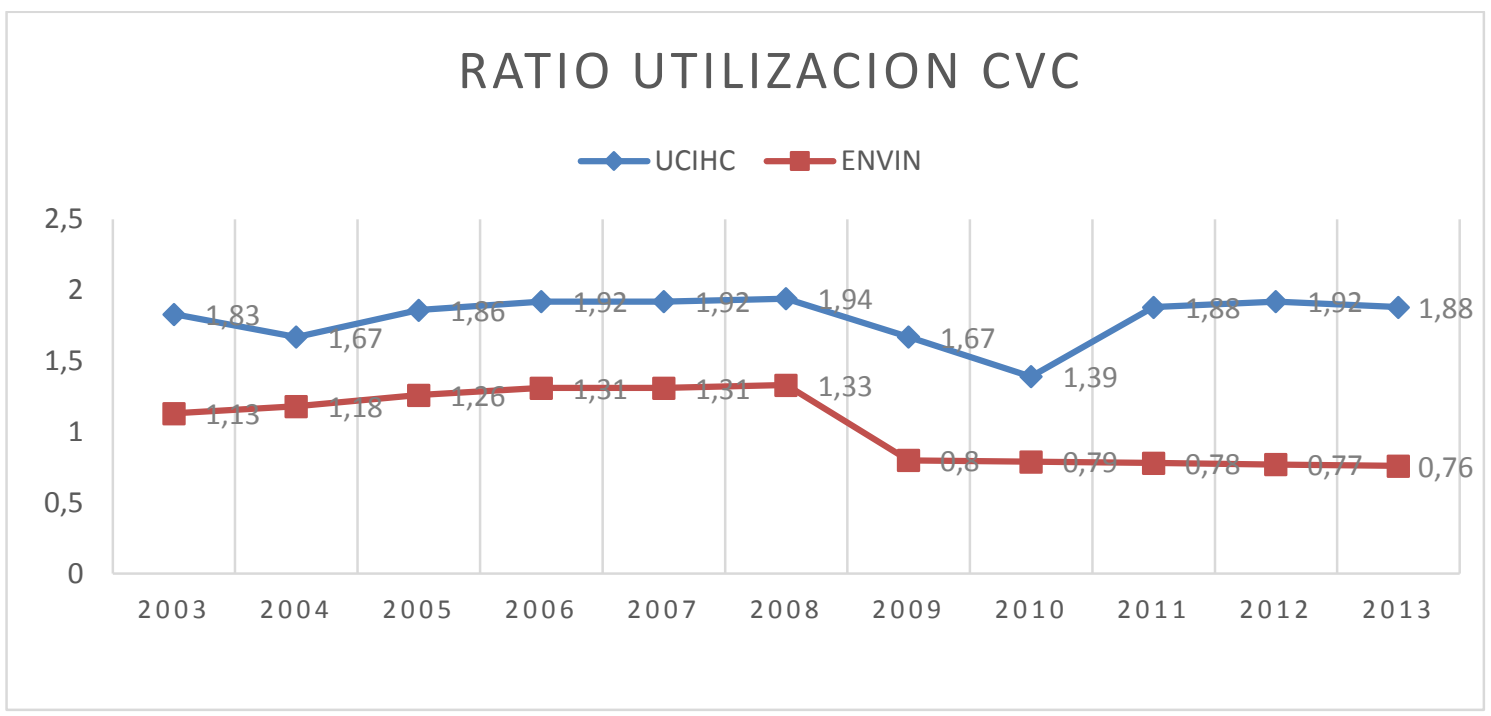

Figura 37: Evolución de la tasa de uso de CVC.

La etiología más frecuente de la BRCVC, fueron los grampositivos con un $58,94 \%$. En las siguientes tabla y figura, se muestran los gérmenes más frecuentes aislados en estas infecciones, y la distribución según el tipo de microorganismos. 


\begin{tabular}{lcc}
\multicolumn{3}{l}{ MICROORGANISMOS AISLADOS EN LAS BRCVC } \\
\hline MICROORGANISMO & N & \% \\
S. Epidermidis & 54 & 20,30 \\
S. Coagulasa negativo & 27 & 10,16 \\
C. Albicans & 13 & 4,88 \\
P. Aeruginosa & 12 & 4,51 \\
S. Marcescens & 10 & 3,75 \\
E. Coli & 8 & 3,00 \\
SAMR & 7 & 2,63 \\
Staph. otros & 6 & 2,25 \\
A. Baumannii & 5 & 1,87 \\
S. Aureus & 4 & 1,50 \\
Otros & 120 & 45,11 \\
Total & 266 & 100
\end{tabular}

Tabla 30: Etiología de las BRCVC.

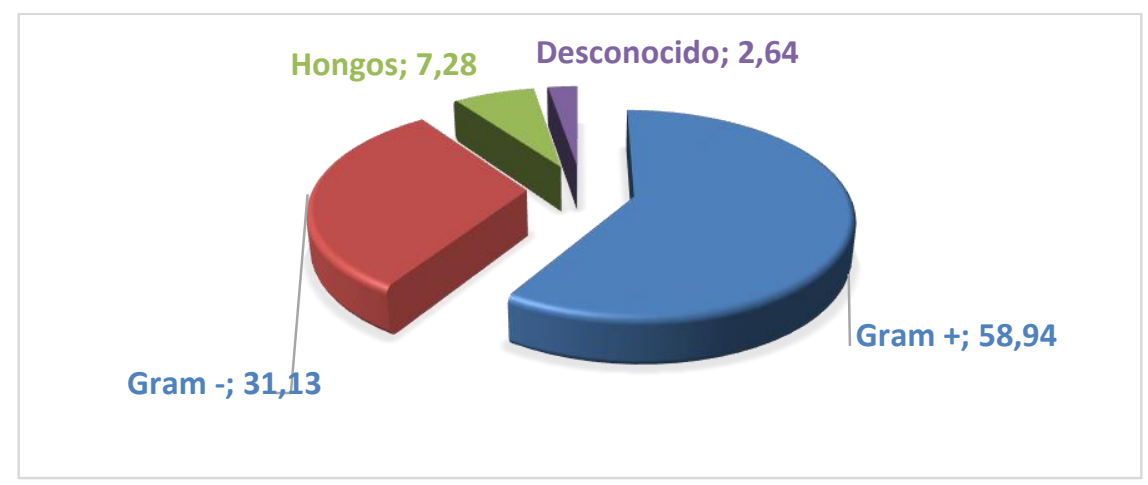

Figura 38: Distribución de los gérmenes en las BRCVC

\subsubsection{ITUSV}

Se han diagnosticado 155 ITUSV en 118 pacientes. La TI se muestra en la tabla $n^{\circ} 31$.

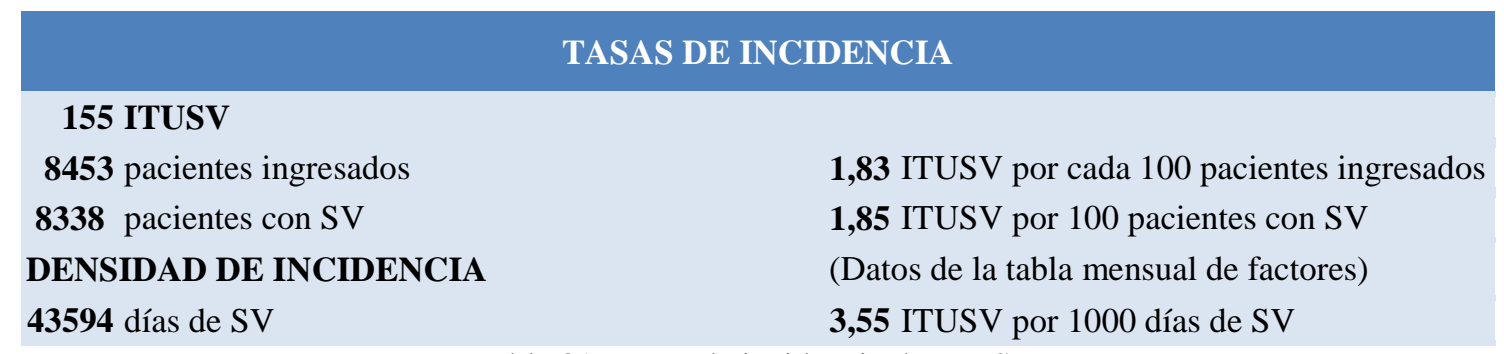

Tabla 31: Tasas de incidencia de ITUSV. 
Como se puede ver en la figura n $^{\circ}$ 39, la evolución de la DI de ITUSV, disminuyó a lo largo del periodo estudiado, y se mantuvo a partir del año 2004 por debajo de la tasa nacional.

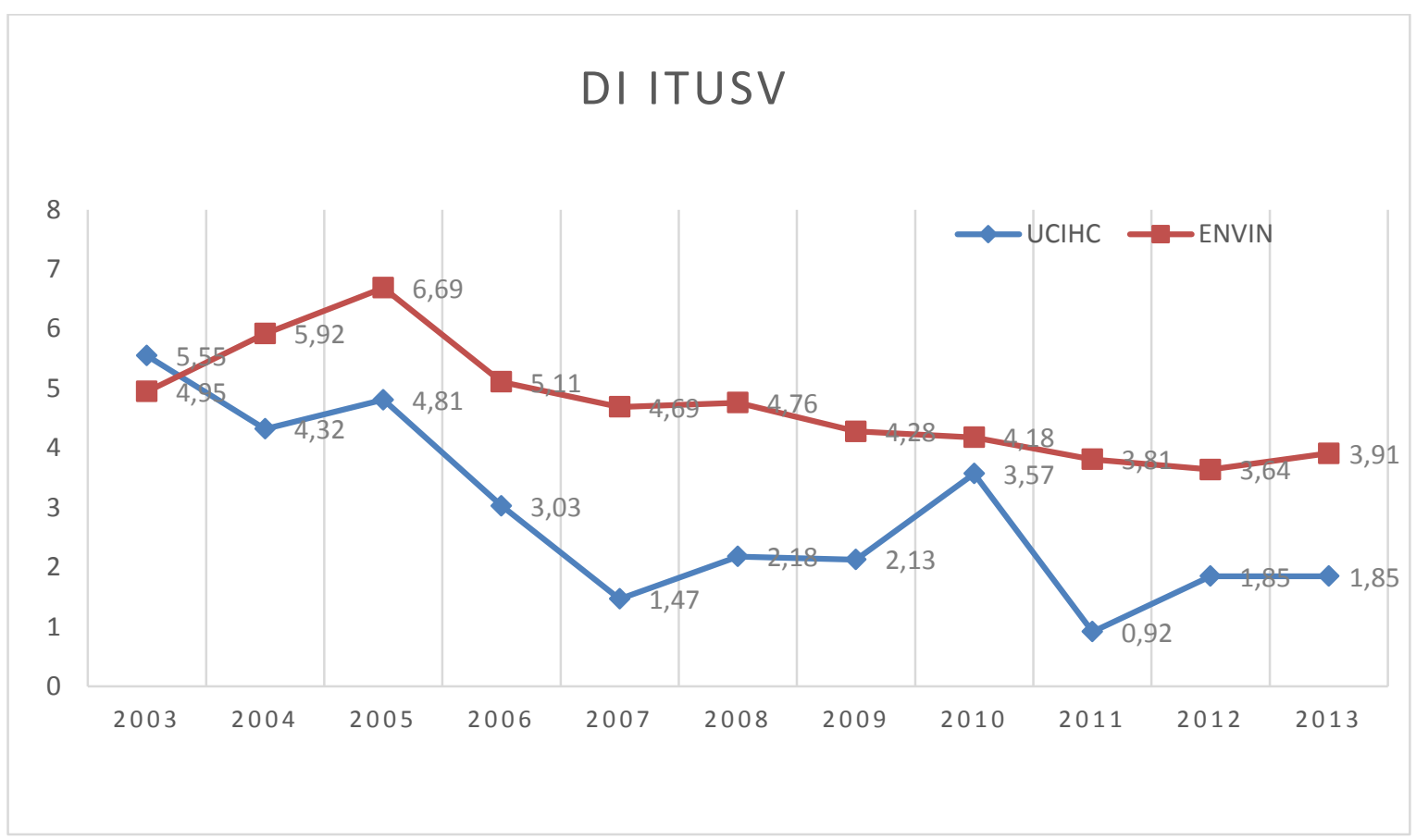

Figura 39: Evolución de la tasa de ITUSV. 


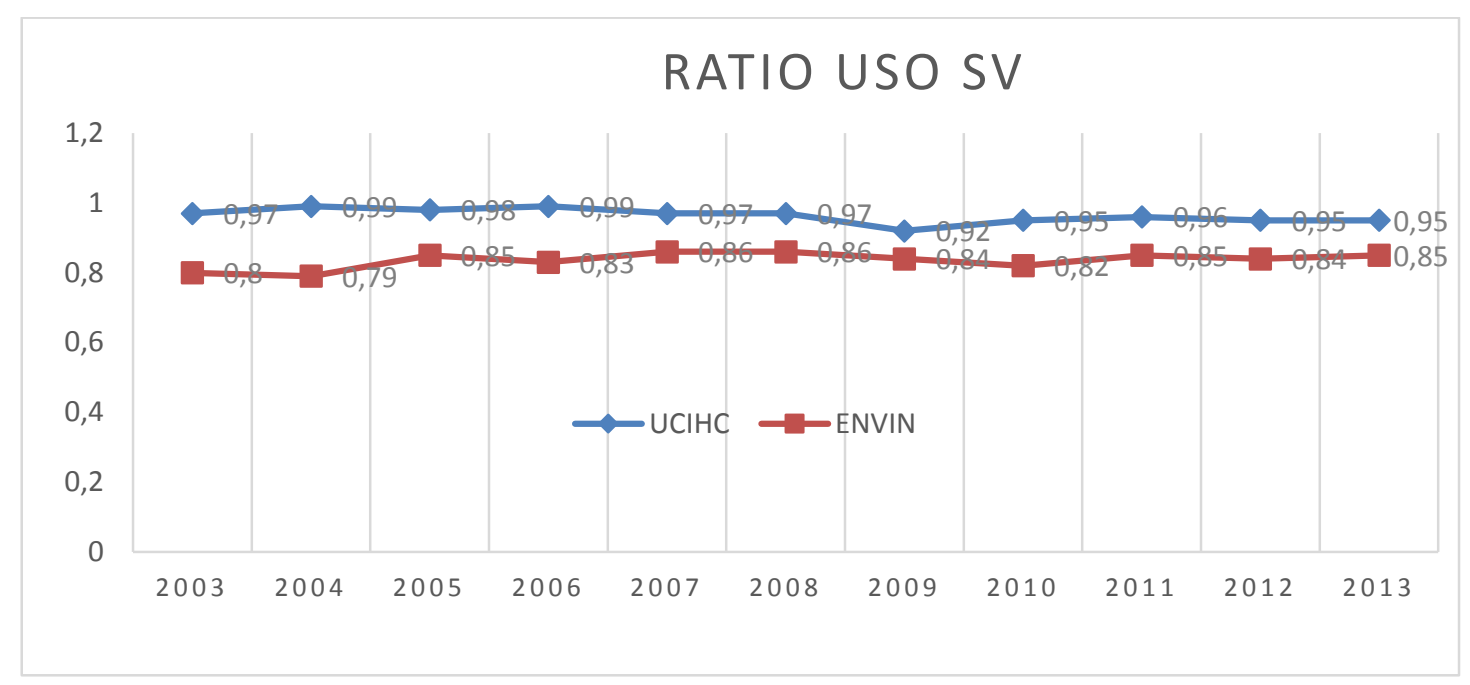

Figura 40: Evolución de la tasa de uso de ITUSV.

Como observamos, la ratio de utilización de SV, en nuestra unidad se mantiene en torno al 0.95 , por encima de la utilización en las UCIs españolas.

Los gérmenes más frecuentemente aislados se describen en la tabla 32:

\begin{tabular}{lcc}
\multicolumn{2}{c}{ MICROORGANISMOS AISLADOS EN LAS ITUSV } \\
MICROORGANISMO & N & $\%$ \\
Pseudomonas aeruginosa & 35 & 22,29 \\
Candida albicans & 32 & 20,38 \\
Candida spp & 13 & 8,28 \\
Candida glabrata & 12 & 7,64 \\
Escherichia coli & 12 & 7,64 \\
Acinetobacter baumannii & 11 & 7,00 \\
Enterobacter cloacae & 4 & 2,54 \\
Serratia marcesnces & 4 & 2,54 \\
Klebsiella oxytoca & 4 & 2,54 \\
Candida tropicalis & 2 & 1,27 \\
Otros & 28 & 17,83 \\
Total & 157 & 100
\end{tabular}

Tabla 32: Etiología de las ITUSV

Su distribución, por grupo de gérmenes, fue la siguiente: 


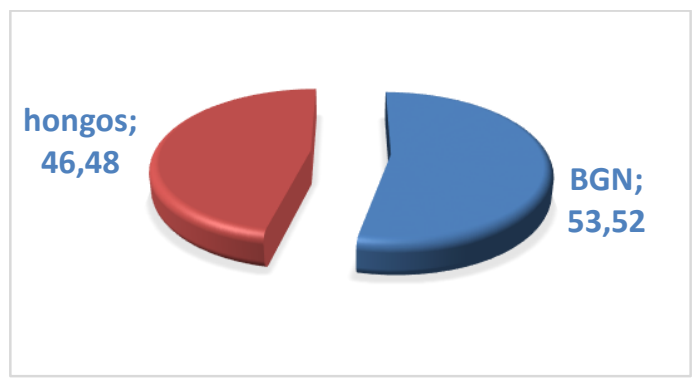

Figura 41: Distribución de los gérmenes en las ITUSV.

\subsubsection{BACTERIEMIAS SECUNDARIAS}

Se han diagnosticado 152 bacteriemias secundarias, en 135 pacientes. La TI se muestra en la tabla $\mathrm{n}^{\circ} 33$.

\begin{tabular}{|c|c|}
\hline \multicolumn{2}{|c|}{ TASAS DE INCIDENCIA } \\
\hline $\mathrm{N}^{\mathrm{o}}$ de bacteriemias 152 total de pacientes 8453 & 1,79bacteriemias por cada 100 pacientes \\
\hline $\begin{array}{l}\mathrm{N}^{\mathrm{o}} \text { de bacteriemias } 152 \text { total de estancias } 44195 \\
\text { (Tabla mensual de factores) }\end{array}$ & $\mathbf{3 , 4 3}$ bacteriemias por 1000 días de estancia \\
\hline
\end{tabular}

Tabla 33: Tasas de incidencia de bacteriemias secundarias.

La evolución de las tasas de bacteriemias secundarias, se muestra en la figura $\mathrm{n}^{\mathbf{0}}$ 42. Al inicio del periodo de estudio, las tasas eran muy elevadas, descendiendo desde del año 2005 hasta igualarse con las nacionales. En el año 2013 se produjo un aumento de la incidencia de bacteriemias secundarias.

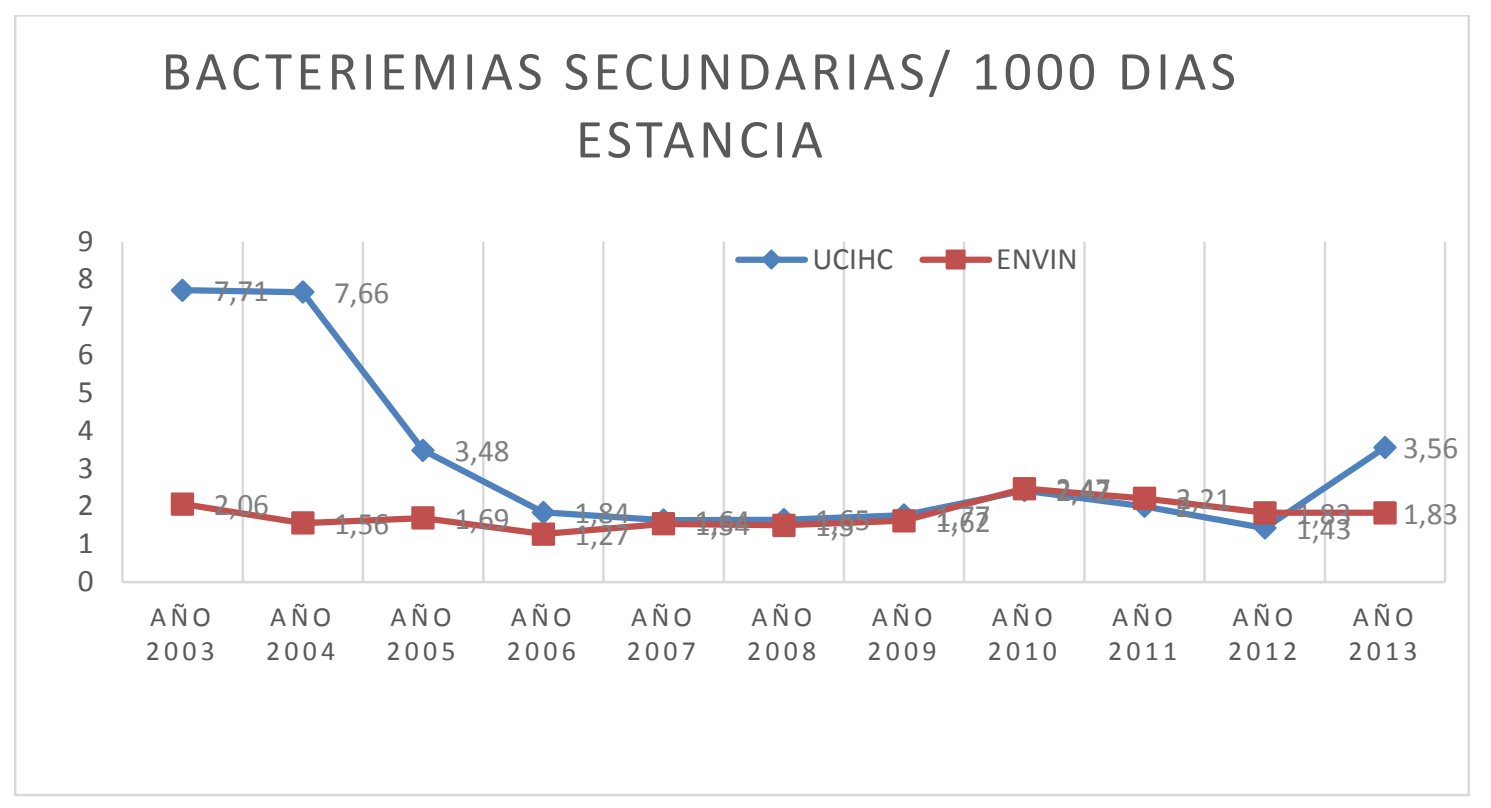

Figura 42: Evolución de las tasas de bacteriemia secundaria. 
La distribución de las bacteriemias secundarias se muestra en la figura 43. Como vemos, el origen más frecuente fue el foco abdominal, que no está relacionado con las infecciones asociadas a dispositivos. Por ello, para el cálculo de la TI adquirida en UCI, no consideramos las bacteriemias secundarias, que no se pueden evitar con medidas encaminadas a disminuir las BRCVC y NAVM.

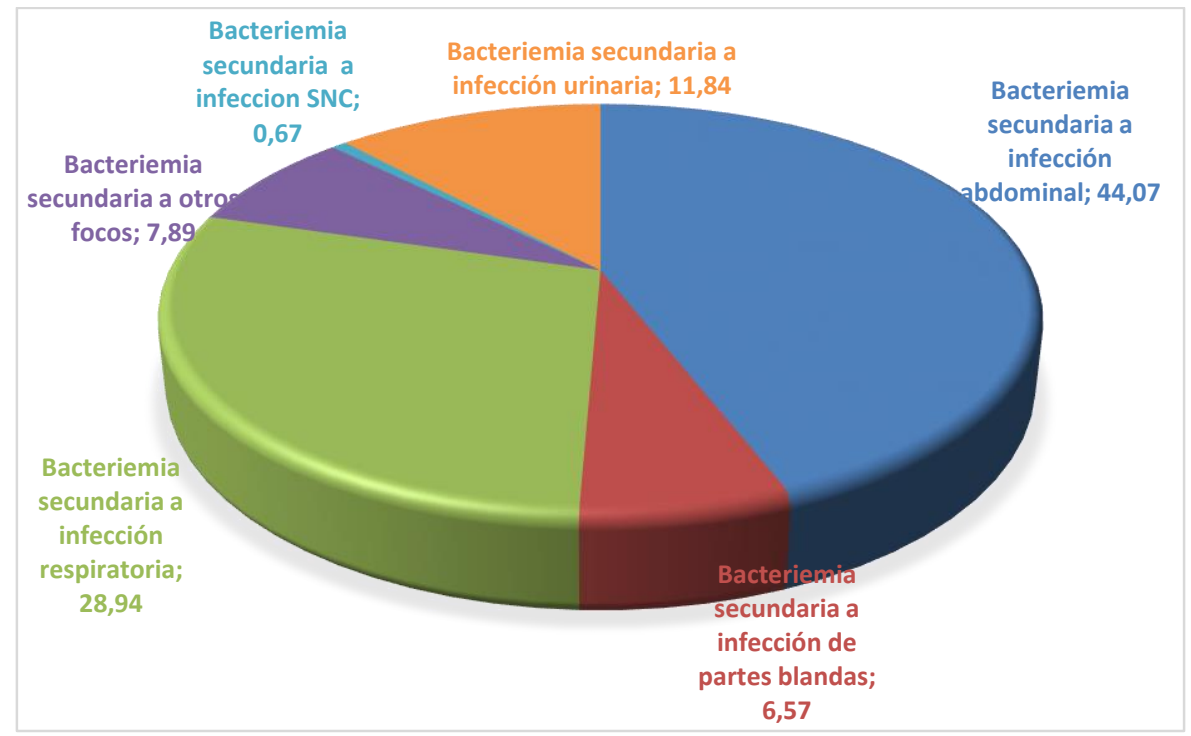

Figura 43: Foco de origen de las bacteriemias secundarias.

La etiología más frecuente de las mismas fue la siguiente:

\begin{tabular}{lcc}
\multicolumn{4}{c}{ MICROORGANISMOS AISLA DOS EN LAS } \\
\multicolumn{1}{c}{ BACTERIEMIAS SECUNDARIAS A INFECCIÓN DE } \\
OTROS FOCOS & N & $\%$ \\
MICROORGANISMO & 25 & 16,44 \\
P. Aeruginosa & 24 & 15,78 \\
E. Coli & 15 & 9,86 \\
S. Epidermidis & 9 & 5,92 \\
A. Baumannii & 6 & 3,94 \\
E. Faecium & 6 & 3,94 \\
C. Albicans & 6 & 3,94 \\
S. Aureus & 5 & 3,28 \\
E. Faecalis & 4 & 2,63 \\
SAMR & 4 & 2,63 \\
S. Coagulasa negativo & 48 & 31,57 \\
Otros & 152 & 100 \\
Total &
\end{tabular}

Tabla 34: Etiología de las bacteriemias secundarias. 
La distribución según el tipo de microorganismos aislados en las bacteriemias secundarias, se muestra en la figura $n^{\circ} 44$.

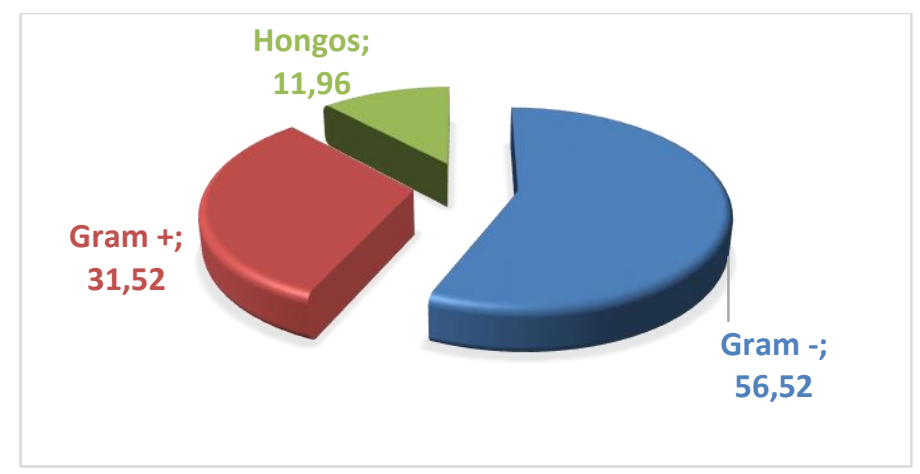

Figura 44: Distribución de los gérmenes en las bacteriemias secundarias.

\section{ESTUDIO COMPARATIVO}

\subsection{COMPARACION POR PERIODOS}

Para la comparación de las infecciones diferenciamos dos periodos: el periodo 1, entre los años 2003 y 2007, previo a la implantación de las medidas de BZ y el periodo 2, entre el 2008 y 2013, durante los cuales se aplicaron las medidas.

Comparando las infecciones asociadas a dispositivos en los dos periodos, observamos que en el primero se produjeron 474 infecciones, y en el segundo 273 (figura 45).

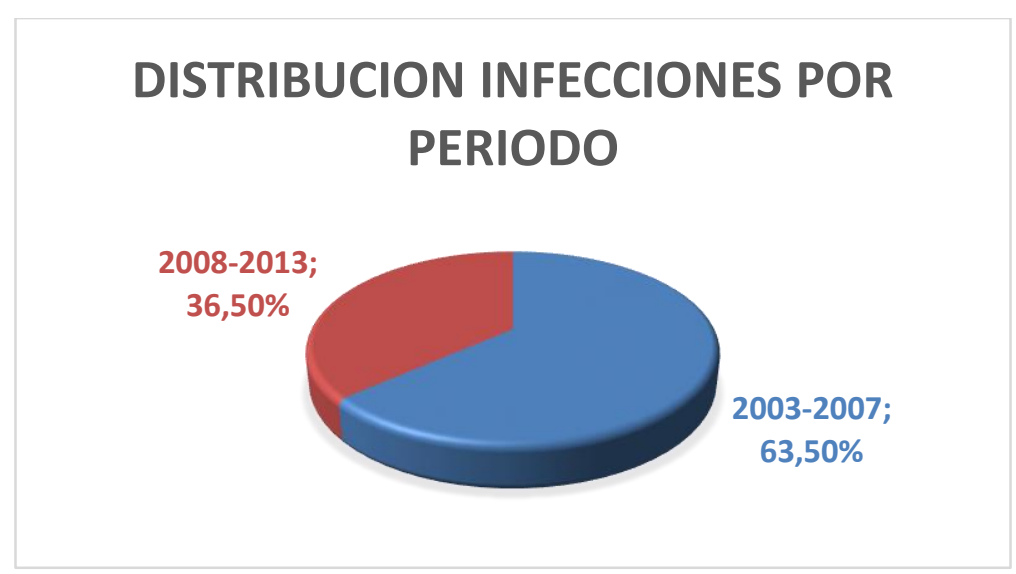

Figura 45: Porcentaje de infecciones por periodos de estudio.

Este descenso, como se puede ver en la figura 46, se produce en todas las infecciones asociadas a dispositivos: en la NAVM se disminuye de 199 a 127 infecciones, 
en la BRCVC de 190 a 76 infecciones, y el descenso es menor en las ITUSV, pasando de 85 a 70 . Este descenso es estadísticamente significativo $(p=0.001)$.

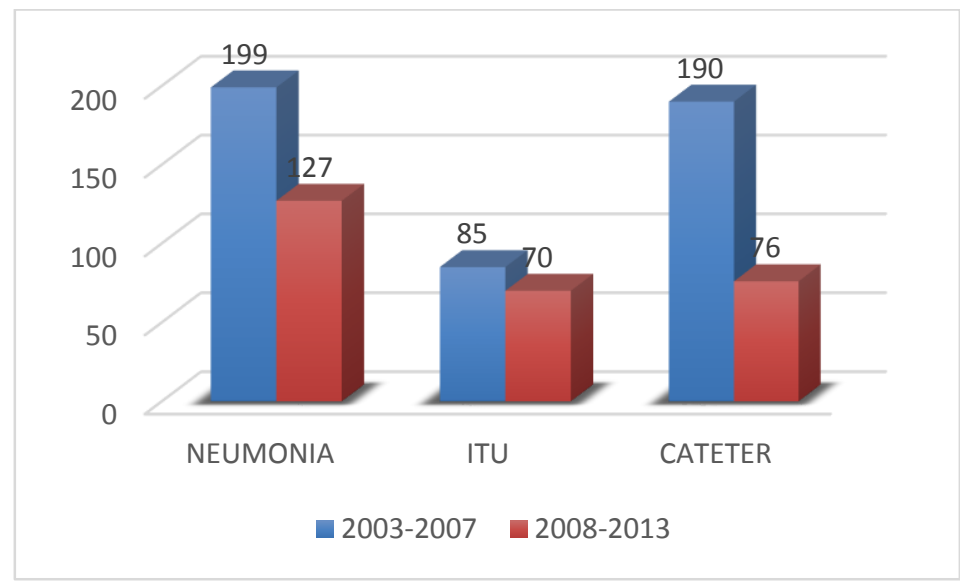

Figura 46: Distribución de las infecciones por periodos de estudio.

Para comparar las poblaciones ingresadas en ambos periodos, realizamos un estudio comparativo de las características de los pacientes: edad, sexo, mortalidad, estancia, y gravedad (valorada por el APACHE II). Analizamos también los motivos de ingreso de los pacientes agrupados por tipos patologías: cardiovascular, respiratorio, digestivo, neurológico, hematológico, y otras patologías. Por último, analizamos factores de riesgo de infección, algunos intrínsecos de los pacientes, como inmunosupresión o neutropenia, y otros extrínsecos, que son los asociados a los dispositivos invasivos utilizados en el ingreso en UCI.

\section{NAVM}

En la tabla $\mathrm{n}^{\circ} 35$, se describen las características de los pacientes diagnosticados de neumonías en los dos periodos. No observamos diferencias estadísticamente significativas en la media de edad, ni en el sexo de los pacientes. La mortalidad de la serie fue elevada, siendo menor en el segundo periodo (33,3\% vs 38,8\%), aunque estas diferencias no fueron estadísticamente significativas. La estancia media de los pacientes con NAVM es muy elevada, sobre todo cuando los comparamos con la de todos los pacientes ingresados. También presentan una gravedad elevada, similar en los dos periodos estudiados con un APACHE II de 21,8 vs 20,41, aunque esta diferencia media no es estadísticamente significativa. 


\begin{tabular}{|c|c|c|c|c|}
\hline & PERIODO 1 & PERIODO 2 & $P$ \\
\hline \multicolumn{2}{|l|}{ EDAD } & $64,93 \pm 14,42$ & $66,28 \pm 13,47$ & 0,40 \\
\hline \multirow[t]{2}{*}{ SEXO } & HOMBRE & $140(70,4 \%)$ & $87(68,5 \%)$ & \multirow[t]{2}{*}{0,723} \\
\hline & MUJER & $59(29,6 \%)$ & $40(31,5 \%)$ & \\
\hline \multirow[t]{2}{*}{ EXITUS } & SI & $77(38,8 \%)$ & $42(33,3 \%)$ & \multirow[t]{2}{*}{0,250} \\
\hline & NO & $117(59,1 \%)$ & $84(66,7 \%)$ & \\
\hline \multicolumn{2}{|c|}{ ESTANCIA } & $34,25 \pm 29,06$ & $36,06 \pm 30,32$ & 0,592 \\
\hline \multicolumn{2}{|c|}{ APACHE II } & $21,80 \pm 6,96$ & $20,41 \pm 6,73$ & 0,076 \\
\hline
\end{tabular}

Tabla 35: Distribución porcentual de las características estudiadas de los pacientes con NAVM, comparando los dos periodos.

\begin{tabular}{|c|c|c|c|c|}
\hline & PERIODO 1 & PERIODO 2 & TOTAL & $P$ \\
\hline CARDIOVASCULAR & $72(36,18 \%)$ & $57(44,88 \%)$ & $129(39,6 \%)$ & \multirow{9}{*}{0.281} \\
\hline RESPIRATORIO & $54(27,13 \%)$ & $34(26,77 \%)$ & $88(27 \%)$ & \\
\hline NEUROLÓGICO & $36(18,09 \%)$ & $14(11,02 \%)$ & $50(15,3 \%)$ & \\
\hline DIGESTIVO & $29(14,57 \%)$ & $17(13,38 \%)$ & $46(14,1 \%)$ & \\
\hline RENAL & $2(1 \%)$ & $0(0 \%)$ & $2(0,6 \%)$ & \\
\hline METABÓLICO & $2(1 \%)$ & $0(0 \%)$ & $2(0,6 \%)$ & \\
\hline HEMATOLÓGICO & $4(2 \%)$ & $4(3,14 \%)$ & $8(2,5 \%)$ & \\
\hline OTROS & $0(0 \%)$ & $1(0,78 \%)$ & $1(0,3 \%)$ & \\
\hline TOTAL & 199 & 127 & 316 & \\
\hline
\end{tabular}

Tabla 36: Distribución porcentual de los diagnósticos de los pacientes con NAVM, comparando los dos periodos.

Respecto al diagnóstico al ingreso, los pacientes con patología cardiovascular (sepsis, sepsis grave, shock séptico, y postoperatorios de cirugía cardiaca) presentaron un $39,6 \%$ de todas las NAVM diagnosticadas. Les siguen los pacientes respiratorios $27 \%$, y los neurológicos $15,3 \%$. No se observaron diferencias estadísticamente significativas 
entre los tipos de diagnóstico, y los periodos estudiados, como se representa en la tabla $\mathrm{n}^{\mathrm{o}} 36$.

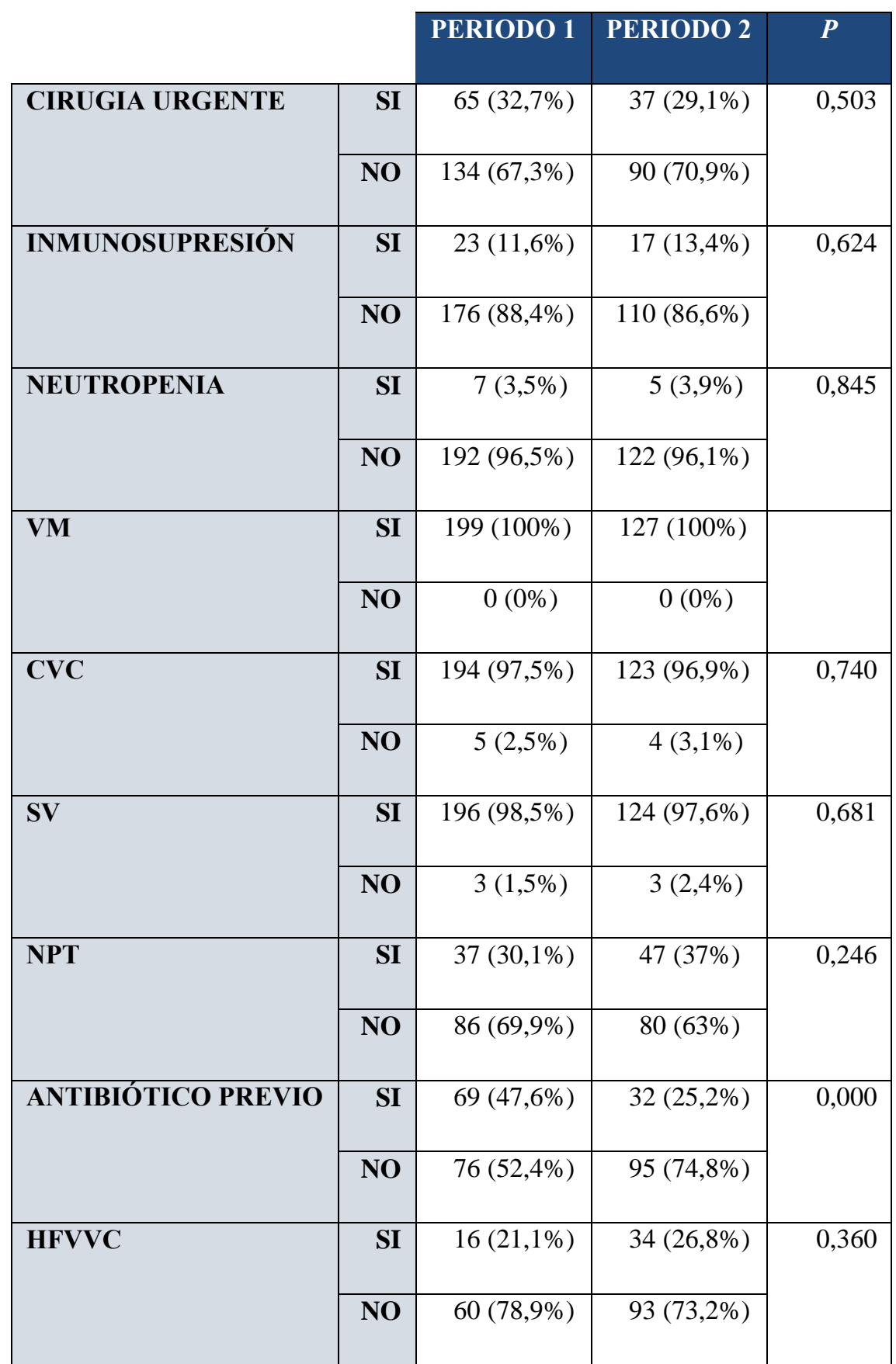

Tabla 37: Distribución porcentual de los factores de riesgo de los pacientes con NAVM, comparando los dos periodos.

En la tabla 37 podemos observar los factores de riesgo de los pacientes con NAVM. Los asociados a dispositivos invasivos fueron más frecuentes (por definición todos los pacientes con NAVM tienen VM), les siguen en porcentajes muy elevados cercanos al $100 \%$, la presencia de CVC y SV. 
La presencia de cirugía urgente fue menor en el $2^{\circ}$ periodo $(29,1 \%$ vs $32,7 \%)$, aunque las diferencias no fueron estadísticamente significativas $(p=0,503)$. Los porcentajes de pacientes con neutropenia e inmunodeprimidos que sufrieron una NAVM, fueron similares en los dos periodos.

Respecto a la utilización de NPT fue mayor en el segundo periodo (37\% vs $30,1 \%$ ), no siendo esta diferencia estadísticamente significativa. En relación con el tratamiento antibiótico previo al ingreso, en el primer periodo fueron un 47,6\% de los pacientes, respecto al $25,2 \%$ del segundo periodo, siendo esta diferencia estadísticamente significativa $(0,001)$.

El tratamiento antibiótico previo al ingreso, en sí mismo, no se puede considerar un factor de riesgo de adquisición de NAVM. Sí está relacionado con la presencia de infección previa al ingreso, que precisa tratamiento. Este hecho, está más unido a la presencia de gérmenes multirresistentes causantes de infección, que con el riesgo de sufrir la propia infección. Respecto al tratamiento con técnicas de remplazo renal (HFVVC), aumenta en el segundo periodo ( $21,1 \%$ vs $26,8 \%$ ), aunque no de modo significativo.

\section{BRCVC}

En la tabla 38, podemos observar las características de los pacientes que presentan BRCVC. No hay diferencias en cuanto a la edad ni al sexo. Presentaron una mortalidad elevada, con un descenso desde el $41,1 \%$, en el primer periodo, al 37,8\% en el segundo periodo, siendo esta mortalidad mayor que la de las NAVM. En el primer periodo la estancia es mayor que en el segundo, 31,9 días vs 28,32 días, siendo este aumento de la estancia, menor que el de las NAVM. La gravedad de los pacientes fue elevada, y similar en ambos periodos. En el análisis estadístico, no hubo diferencias significativas, en ninguna de las variables estudiadas. 


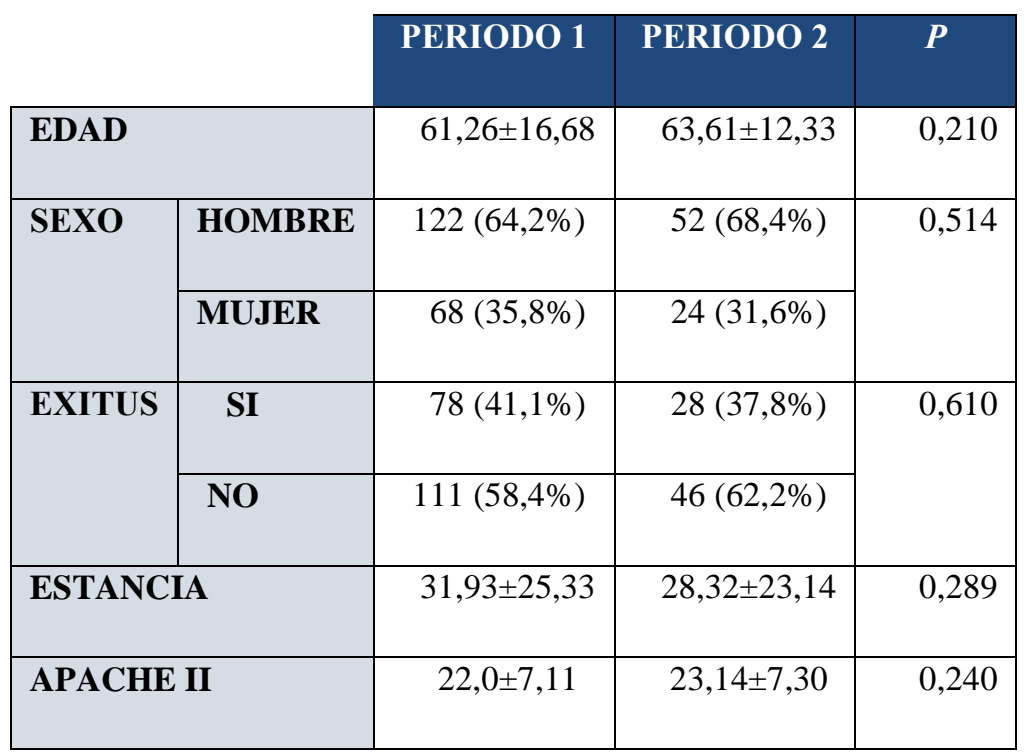

Tabla 38: Distribución porcentual de las características estudiadas de los pacientes con BRCVC, comparando los dos periodos.

Se han encontrado diferencias estadísticamente significativas $(p=0,006)$, en la distribución de los diagnósticos al ingreso de los pacientes con BRCVC en los periodos estudiados, como se observa en la tabla 39. Los pacientes con mayor número de infecciones fueron los cardiovasculares $48,5 \%$, seguidos de los respiratorios $23,7 \%$, y los neurológicos 9,8\%. En el segundo periodo se observó un aumento de los pacientes con patología cardiovascular (56,57\% vs 45,26), y un descenso de los pacientes con patología respiratoria $(11,84 \%$ vs $28,42 \%)$.

Respecto a los factores de riesgo de infección, los dispositivos invasivos fueron los factores presentes en un mayor número de pacientes, sin que hubiera diferencias entre los dos periodos estudiados. Se ha reducido de manera significativa el número de pacientes con cirugía urgente (28,9\% vs $13,2 \%)$, pudiéndose explicar por la apertura de la unidad de reanimación en el año 2005, donde ingresan la mayor parte de ellos, con la consiguiente disminución de ingresos en nuestra unidad.

Esta reducción se puede relacionar también con el menor número de pacientes con NPT, que también son menores significativamente en el segundo periodo (18,4 vs 32,4\%), ya que son los pacientes de cirugía general los que en mayor medida necesitan NPT. 


\begin{tabular}{|c|c|c|c|c|}
\hline & PERIODO 1 & PERIODO 2 & TOTAL & $P$ \\
\hline CARDIOVASCULAR & $86(45,26 \%)$ & $43(56,57 \%)$ & $129(48,5 \%)$ & \multirow{9}{*}{0,006} \\
\hline RESPIRATORIO & $54(28,42 \%)$ & $9(11,84 \%)$ & $63(23,7 \%)$ & \\
\hline NEUROLÓGICO & $20(10,52 \%)$ & $6(7,89 \%)$ & $26(9,8 \%)$ & \\
\hline DIGESTIVO & $19(10 \%)$ & $5(6,57 \%)$ & $24(9,0 \%)$ & \\
\hline RENAL & $0(0 \%)$ & $0(\%)$ & $0(0 \%)$ & \\
\hline METABÓLICO & $2(1,05 \%)$ & $1(1,31 \%)$ & $3(1,1 \%)$ & \\
\hline HEMATOLÓGICO & $7(3,68 \%)$ & $11(14,47 \%)$ & $18(6,8 \%)$ & \\
\hline OTROS & $2(1,05 \%)$ & $1(1,31 \%)$ & $3(1,1 \%)$ & \\
\hline TOTAL BRCVC & 190 & 76 & 266 & \\
\hline
\end{tabular}

Tabla 39: Distribución porcentual de los diagnósticos estudiados de los pacientes con BRCVC, comparando los dos periodos.

Respecto a la inmunosupresión e inmunodeficiencia, los porcentajes no se modifican significativamente. En el segundo periodo, también como en las NAVM, el porcentaje de pacientes que tienen tratamiento antibiótico previo fue significativamente menor (53,2\% vs 21,1\%). Hay un aumento significativo de los pacientes con HFVVC en el segundo periodo $(28,1 \%$ vs $47,4 \%)$, que puede deberse al incremento de las indicaciones de esta terapia, así como la mejora de los equipos de tratamiento, y la mayor disponibilidad de máquinas para tratamiento. 


\begin{tabular}{|c|c|c|c|c|}
\hline & & & & \\
\hline & & PERIODO 1 & PERIODO 2 & $\boldsymbol{P}$ \\
\hline \multirow[t]{2}{*}{ CIRUGIA URGENTE } & SI & $55(28,9 \%)$ & $10(13,2 \%)$ & \multirow[t]{2}{*}{0,007} \\
\hline & NO & $135(71.1 \%)$ & $66(86,8 \%)$ & \\
\hline \multirow[t]{2}{*}{ INMUNOSUPRESIÓN } & SI & $31(16,3 \%)$ & $16(21,1 \%)$ & \multirow[t]{2}{*}{0,360} \\
\hline & NO & $159(83,7 \%)$ & $60(78,9 \%)$ & \\
\hline \multirow[t]{2}{*}{ NEUTROPENIA } & SI & $12(6,3 \%)$ & $9(11,8 \%)$ & \multirow[t]{2}{*}{0,131} \\
\hline & NO & $178(93,7 \%)$ & $67(88,2 \%)$ & \\
\hline \multirow[t]{2}{*}{ VM } & SI & $168(88,4 \%)$ & $72(94,7 \%)$ & \multirow[t]{2}{*}{0,169} \\
\hline & NO & $22(94,7 \%)$ & $4(5,3 \%)$ & \\
\hline \multirow[t]{2}{*}{$\mathrm{CVC}$} & SI & $100(100 \%)$ & $100(100 \%)$ & \multirow[t]{2}{*}{-} \\
\hline & NO & $0(0 \%)$ & $0(0 \%)$ & \\
\hline \multirow[t]{2}{*}{$\mathbf{S V}$} & SI & $187(98,4 \%)$ & $76(100 \%)$ & \multirow[t]{2}{*}{0,560} \\
\hline & NO & $3(1,6 \%)$ & $0(0 \%)$ & \\
\hline \multirow[t]{2}{*}{ NPT } & SI & $46(32,4 \%)$ & $14(18,4 \%)$ & \multirow[t]{2}{*}{0,028} \\
\hline & NO & $96(67,6 \%)$ & $62(81,6 \%)$ & \\
\hline \multirow[t]{2}{*}{ ANTIBIÓTICO PREVIO } & SI & $82(53,2 \%)$ & $16(21,1 \%)$ & \multirow[t]{2}{*}{0,000} \\
\hline & NO & $72(48,8 \%)$ & $60(78,9 \%)$ & \\
\hline
\end{tabular}

Tabla 40: Distribución porcentual de los factores de riesgo estudiados de los pacientes con BRCVC, comparando los dos periodos.

\section{ITUSV}

En la tabla 41 se describen las características de los pacientes con ITUSV. Son similares en los dos periodos analizados, no encontrándose diferencias estadísticamente significativas respecto a la edad, sexo, mortalidad, estancia, y APACHE II. En relación al sexo, las ITUSV son más frecuentes en las mujeres, que en el resto de infecciones estudiadas. 


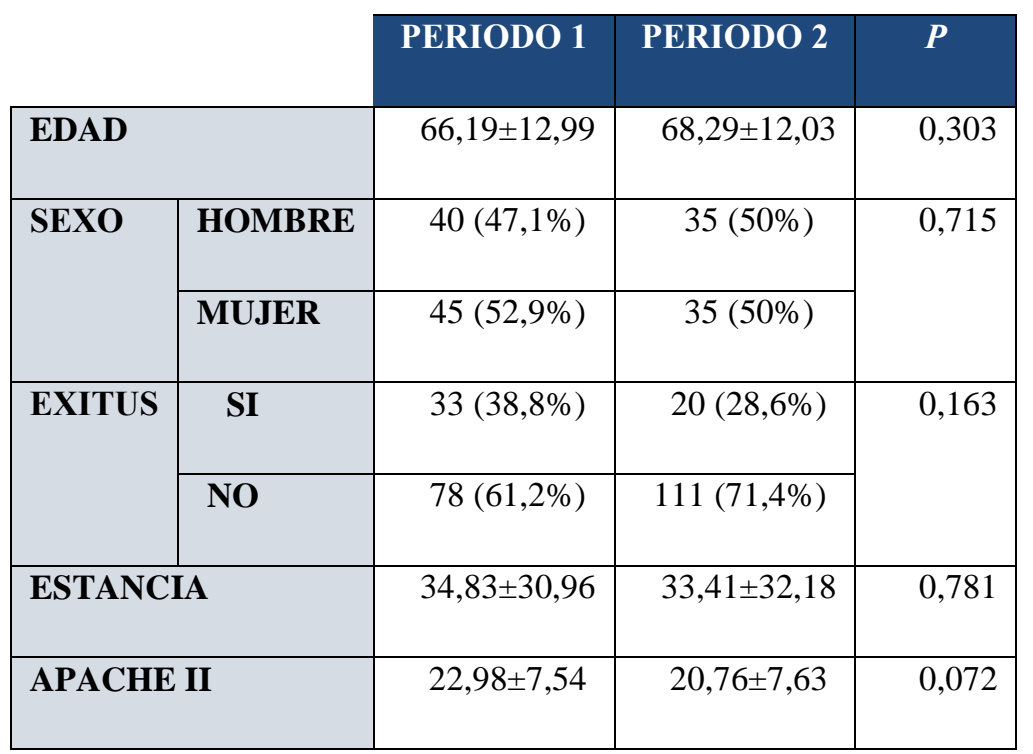

Tabla 41: Distribución porcentual de las características estudiadas de los pacientes con ITUSV, comparando los dos periodos.

Respecto al diagnóstico al ingreso de los pacientes con infección urinaria, no hubo diferencias en ambos periodos respecto al riesgo de sufrir ITUSV. La distribución por patologías fue similar a las otras infecciones, siendo más frecuentes los pacientes cardiovasculares 44,5\%, seguidos de los respiratorios 10,3\%, y de los neurológicos $13,5 \%$.

\begin{tabular}{|l|c|c|c|c|}
\cline { 2 - 4 } \multicolumn{1}{l|}{ PERIODO 1} & PERIODO 2 & TOTAL & \multicolumn{1}{c|}{ P } \\
\hline CARDIOVASCULAR & $35(41,17 \%)$ & $34(48,57 \%)$ & $69(44,5 \%)$ & \\
\hline RESPIRATORIO & $27(31,76 \%)$ & $17(24,28 \%)$ & $44(28,4 \%)$ & \\
\hline NEUROLÓGICO & $15(17,64 \%)$ & $6(8,57 \%)$ & $21(13,5 \%)$ & \\
\hline DIGESTIVO & $5(5,88 \%)$ & $11(15,71 \%)$ & $16(10,3 \%)$ \\
\hline RENAL & $0(0 \%)$ & $1(1,42 \%)$ & $1(0,6 \%)$ \\
\hline METABÓLICO & $2(2,35 \%)$ & $1(1,42 \%)$ & $3(1,9 \%)$ \\
\hline HEMATOLÓGICO & $1(1,17 \%)$ & $0(0 \%)$ & $1(0,6 \%)$ \\
\hline OTROS & $0(\%)$ & $0(0 \%)$ & $00(\%)$ \\
\hline TOTAL & 85 & 70 & 155 \\
\hline
\end{tabular}

Tabla 42: Distribución porcentual de los diagnósticos estudiados de los pacientes con ITUSV, comparando los dos periodos. 
En relación con los factores de riesgo, como se describe en la tabla 43, hubo un menor porcentaje de cirugía urgente en el segundo periodo (18,6 vs $21,2 \%$ ), aunque esta diferencia no es estadísticamente significativa. Son pacientes algo menos instrumentalizados, el porcentaje de pacientes con VM es menor en el segundo periodo (82,9 vs $84,7 \%)$, y también son menores los portadores de CVC (82,9\%vs 84,7\%), siendo estos porcentajes de uso menores que los pacientes con las otras infecciones analizadas.

\begin{tabular}{|c|c|c|c|c|}
\hline & \multirow{2}{*}{\multicolumn{2}{|c|}{\begin{tabular}{c|c} 
PERIODO 1 & PERIODO \\
& 2 \\
\end{tabular}}} & \multirow{3}{*}{$\begin{array}{c}\boldsymbol{P} \\
0,687\end{array}$} \\
\hline & & & & \\
\hline \multirow[t]{2}{*}{ CIRUGIA URGENTE } & SI & $18(21,2 \%)$ & $13(18,6 \%)$ & \\
\hline & NO & $67(78,8 \%)$ & $57(81,4 \%)$ & \\
\hline \multirow[t]{2}{*}{ INMUNOSUPRESION } & SI & $7(8,2 \%)$ & $13(18,6 \%)$ & \multirow[t]{2}{*}{0,090} \\
\hline & NO & $78(91,8 \%)$ & $57(81,4 \%)$ & \\
\hline \multirow[t]{2}{*}{ NEUTROPENIA } & SI & $2(2,4 \%)$ & $1(1,4 \%)$ & \multirow[t]{2}{*}{0,678} \\
\hline & NO & $83(97,6 \%)$ & $69(98,6 \%)$ & \\
\hline \multirow[t]{2}{*}{$\mathbf{V M}$} & SI & $72(84,7 \%)$ & $58(82,9 \%)$ & \multirow[t]{2}{*}{0,755} \\
\hline & NO & $13(15,13 \%)$ & $12(17,1 \%)$ & \\
\hline \multirow[t]{2}{*}{$\overline{C V C}$} & SI & $74(87,1 \%)$ & $58(82,9 \%)$ & \multirow[t]{2}{*}{0,502} \\
\hline & NO & $11(12,9 \%)$ & $12(17,1 \%)$ & \\
\hline \multirow[t]{2}{*}{ SV } & SI & $100(100 \%)$ & $100(100 \%)$ & \\
\hline & NO & $0(0 \%)$ & $0(0 \%)$ & \\
\hline \multirow[t]{2}{*}{$\begin{array}{l}\text { NPT } \\
\end{array}$} & SI & $11(20,8 \%)$ & $27(38,6 \%)$ & \multirow[t]{2}{*}{0,048} \\
\hline & NO & $42(79,2 \%)$ & $43(61,4 \%)$ & \\
\hline \multirow[t]{2}{*}{ ANTIBIÓTICO PREVIO } & SI & $40(59,7 \%)$ & $29(41,4 \%)$ & \multirow[t]{2}{*}{0,032} \\
\hline & NO & $27(40,3 \%)$ & $41(58,6 \%)$ & \\
\hline \multirow[t]{2}{*}{ HFVVC } & SI & $8(32,0 \%)$ & $22(31,4 \%)$ & \\
\hline & NO & $17(68,0 \%)$ & $48(68,6 \%)$ & \\
\hline
\end{tabular}

Tabla 43: Distribución porcentual de los factores de riesgo estudiados de los pacientes con ITUSV, comparando los dos periodos. 


\subsection{GH-BIPLOT}

Se ha analizado cada tipo de infección, mediante la aplicación del análisis multivariante GH-Biplot, con las variables más relevantes de nuestro estudio. Este análisis permite buscar la relación entre todas y cada una de las variables estudiadas. Para su representación gráfica, hemos utilizado el color rojo para diferenciar los periodos de estudio analizados, el color verde para las características de los pacientes, y el color azul para los factores de riesgo de infección.

\section{NAMV}

Realizamos un análisis multivariante, tratando de buscar la relación de las variables analizadas, con los dos periodos estudiados, como se representa en la figura 47.

Analizando la figura 47, podemos ver la fuerza de la asociación de algunas variables entre sí, permitiendo una agrupación lógica, y en ocasiones obvias de algunas de ellas. Las variables que presentan una angulación próxima a los $90^{\circ}$, se consideran que se distribuyen de manera independiente al periodo estudiado.

En relación con las características de los pacientes (en color verde), siguen una distribución independiente del periodo de estudio, aunque el ángulo que forman las variables APACHE II, y mortalidad con el segundo periodo, es un poco inferior a los $90^{\circ}$. Respecto a los factores de riesgo, excepto el tratamiento antibiótico previo que se desplaza hacia el segundo periodo, el resto se distribuye de una manera independiente del periodo.

El comportamiento de las variables entre sí, lo podemos realizar viendo el ángulo que forma entre ellas. Ángulos más pequeños nos indican mayor relación de forma directa, y ángulos obtusos relación inversa. Inmunosupresión e inmunodeficiencia forman un ángulo muy pequeño, por lo que podemos decir que están muy relacionadas; de la misma manera que el APACHE II y la mortalidad, a mayor APACHE II, mayor mortalidad. Así mismo, podemos ver una relación directa de la variable exitus, con factores de riesgo que implican un aumento de la gravedad de los pacientes, como puede ser la presencia de neutropenia e inmunosupresión, y el tratamiento con técnicas de 
HFVVC. Hay una asociación entre otros dispositivos invasivos, como son el CVC y la $\mathrm{SV}$, apreciándose en el ángulo que forman los dos vectores que representan a estas variables.

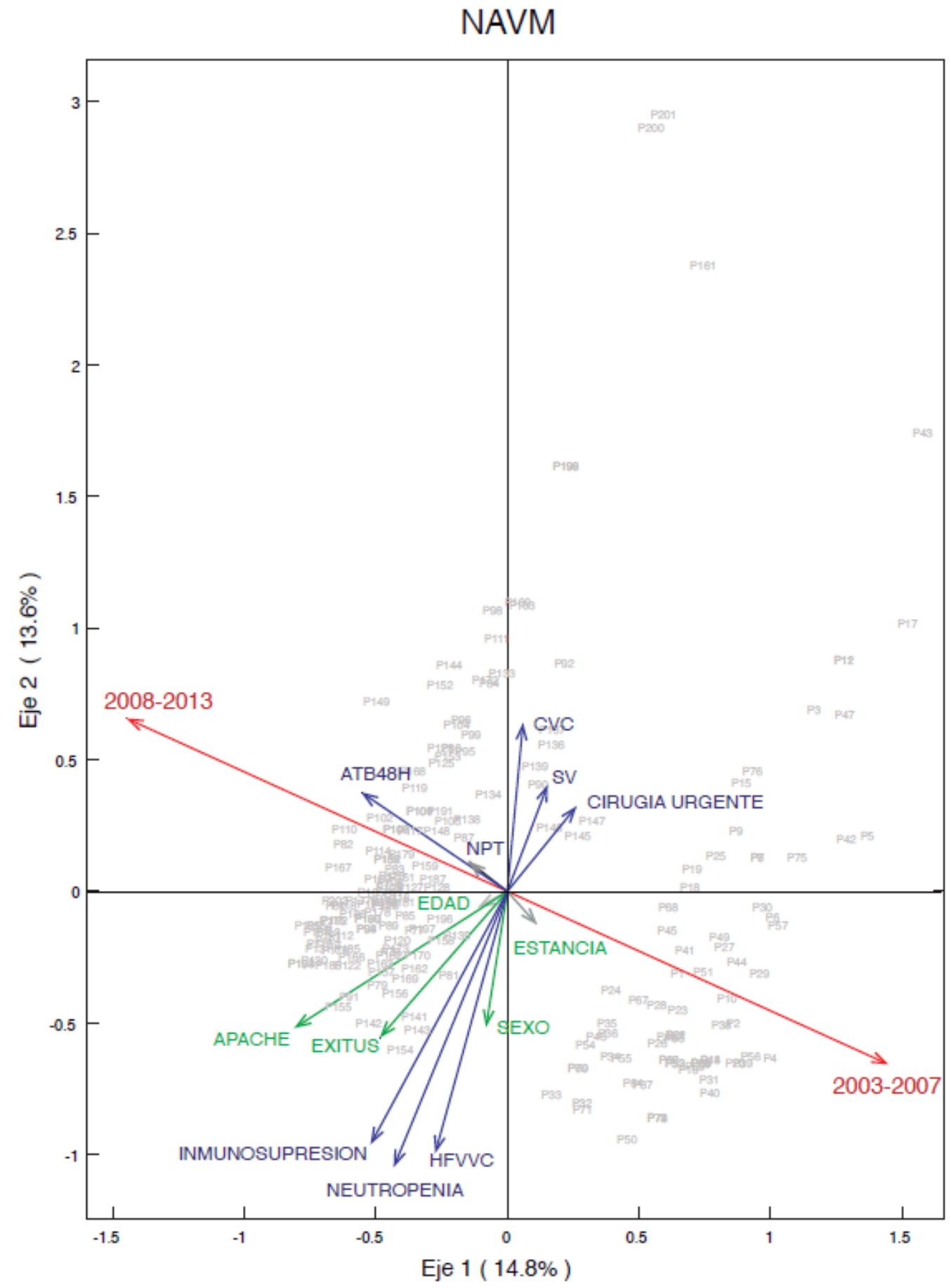

Figura 47: GH-Biplot para NAVM 


\section{BRCVC}

Para las BRCVC, en la figura 48, podemos observar como hay variables que son claramente independientes de los periodos estudiados (estancia, la presencia de SV, NTP, Inmunodepresión, APACHE y VM). Sin embargo, para esta infección, hay una relación directa del periodo 2008-2013, con la variable antibiótico previo, como ya ocurría en las NAVM, y con la cirugía urgente. Este hecho, puede ser debido a que se han realizado menos cirugías urgentes en el segundo periodo, y esas diferencias, como ya vimos anteriormente, eran estadísticamente significativas.

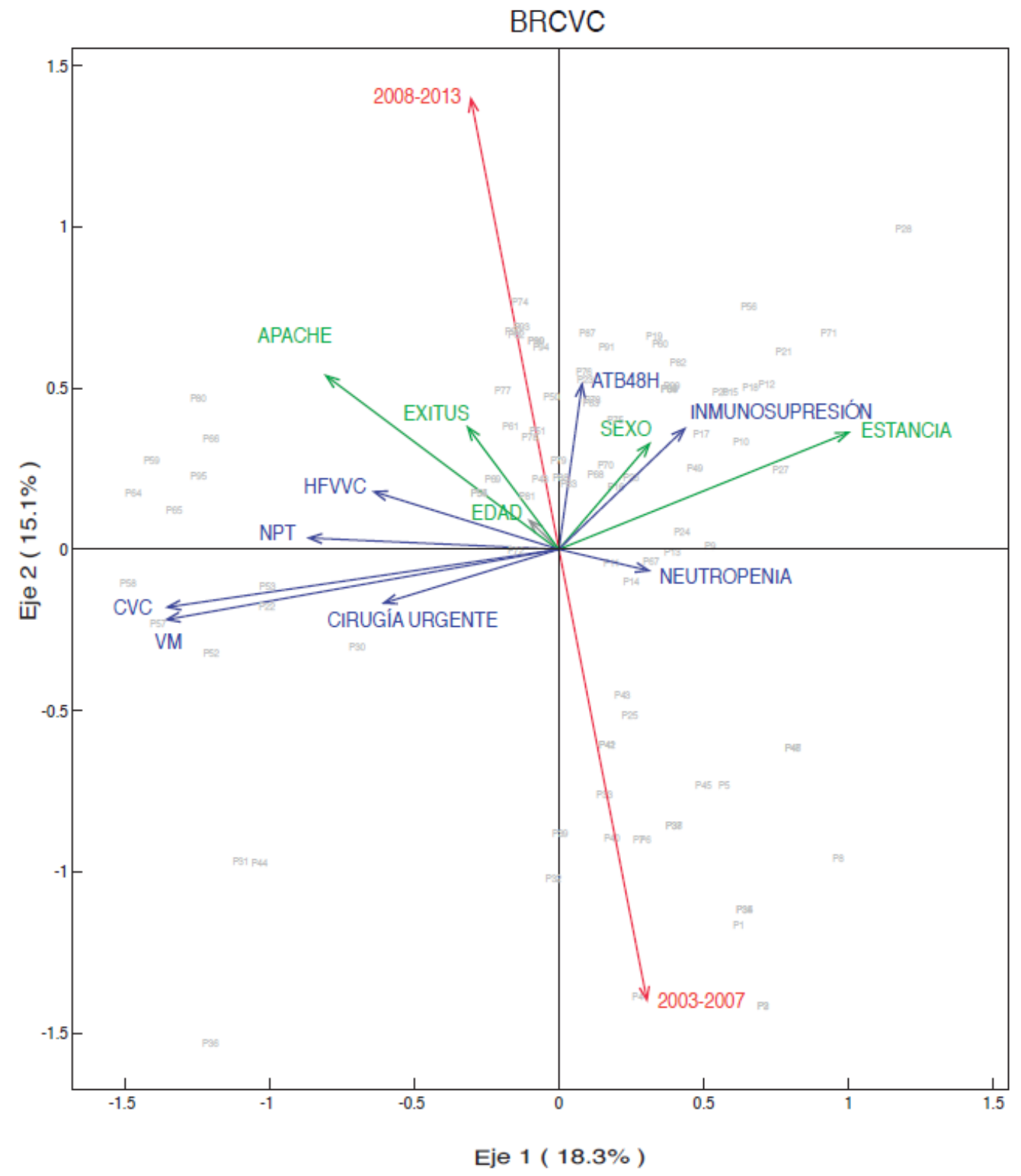

Figura 48: GH-Biplot para BRCVC 


\section{ITUSV}

Como apreciamos en la figura 49, el GH-Biplot de las ITUSV, las variables no forman ángulos próximos a los $90^{\circ}$ con los periodos, como en las otras infecciones estudias. Puede ser debido a que es la infección con menos número de pacientes, y para la que no se ha hecho ninguna intervención específica. APACHE II, exitus, y HFVVC, vuelven a estar muy relacionados de forma directa, como también se detectó en las infecciones anteriores.

En relación a los factores de riesgo $\mathrm{VM}, \mathrm{y} \mathrm{CVC}$, forman un ángulo muy pequeño, por lo que podemos decir que todos los pacientes que tienen VM tienen un CVC. También están muy relacionadas con estas dos variables cirugía urgente y NPT.

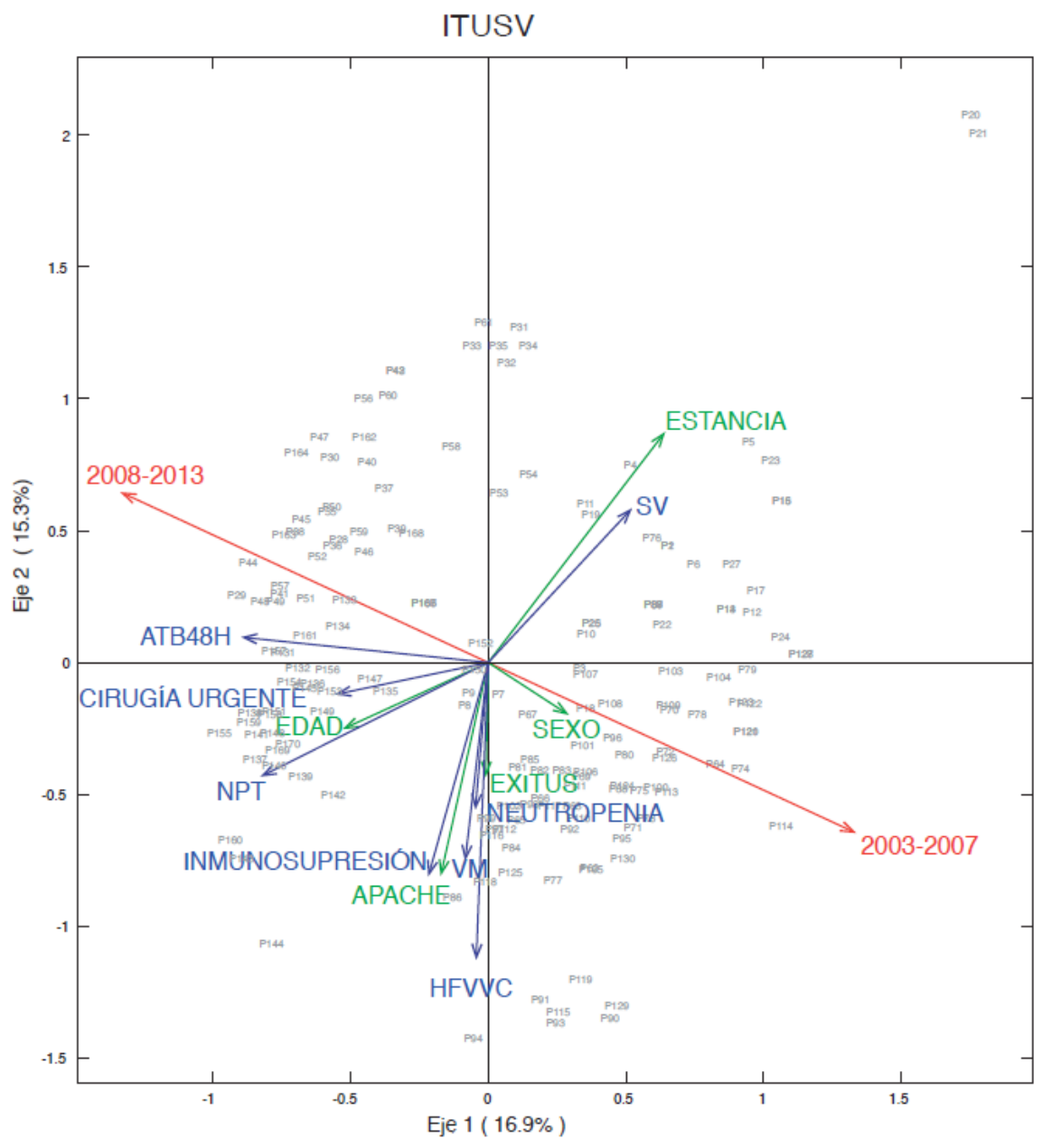

Figura 49: GH-Biplot para las ITUSV 


\section{ESTUDIO DE MINERÍA DE DATOS}

El estudio se ha dividido en dos partes, la primera tiene por objeto el examen de las infecciones, mientras que en la segunda se analiza la mortalidad.

En la primera parte del estudio se han tratado con diferentes algoritmos de minería de datos los datos correspondientes al periodo 2003-2007, posteriormente al periodo 2008-2013 y finalmente al periodo completo 2003-2013.

En la parte dedicada al estudio de la mortalidad, estos algoritmos se aplican a los datos correspondientes al periodo completo.

El propósito del estudio es establecer relaciones entre las variables estudiadas y la adquisición de infección por los pacientes estudiados, por lo que se han establecido dos clases, SI y NO, correspondientes a los pacientes con y sin infección respectivamente. Para el periodo completo se ha creado una nueva variable que recoge el periodo al que pertenece el registro (1 para el periodo 2003-2007 y 2 para el 2008-2013), con el fin de evaluar si el periodo, y por tanto la aplicación de las medidas de BZ y NZ tienen alguna influencia en el desarrollo de infecciones asociadas a dispositivos invasivos.

Para todos los periodos se comienza utilizando métodos de selección de características para determinar cuáles son los atributos (variables) más influyentes en la diferenciación de las clases, es decir qué factores influyen en mayor medida en que se produzcan infecciones o no. Seguidamente, se aplican diferentes métodos de clasificación, para inducir modelos que permitan predecir en futuros pacientes si tendrán o no infecciones. Se utilizarán técnicas de validación cruzada para determinar qué algoritmo proporciona mejores resultados. Finalmente, se aplican algoritmos de asociación para obtener reglas que relacionen los valores de las variables con las clases, y de esta forma disponer de patrones cuyo examen puede ser útil para la toma de decisiones sobre los aspectos en los que hay que incidir, para evitar que se produzcan infecciones. 


\subsection{PERIODO 2003-2007}

En este periodo se dispone de 3146 registros, de los cuales 2710 son de la clase $\mathrm{NO}$, y 436 de la clase SI. La figura 50 muestra la distribución de valores de las variables utilizadas en el estudio. Para cada valor o intervalo de valores de esas variables, se muestra la proporción de registros de cada clase mediante el uso del color rojo para la clase SI, y del color azul para la clase NO. Esta regla que se mantendrá en todos los periodos estudiados.

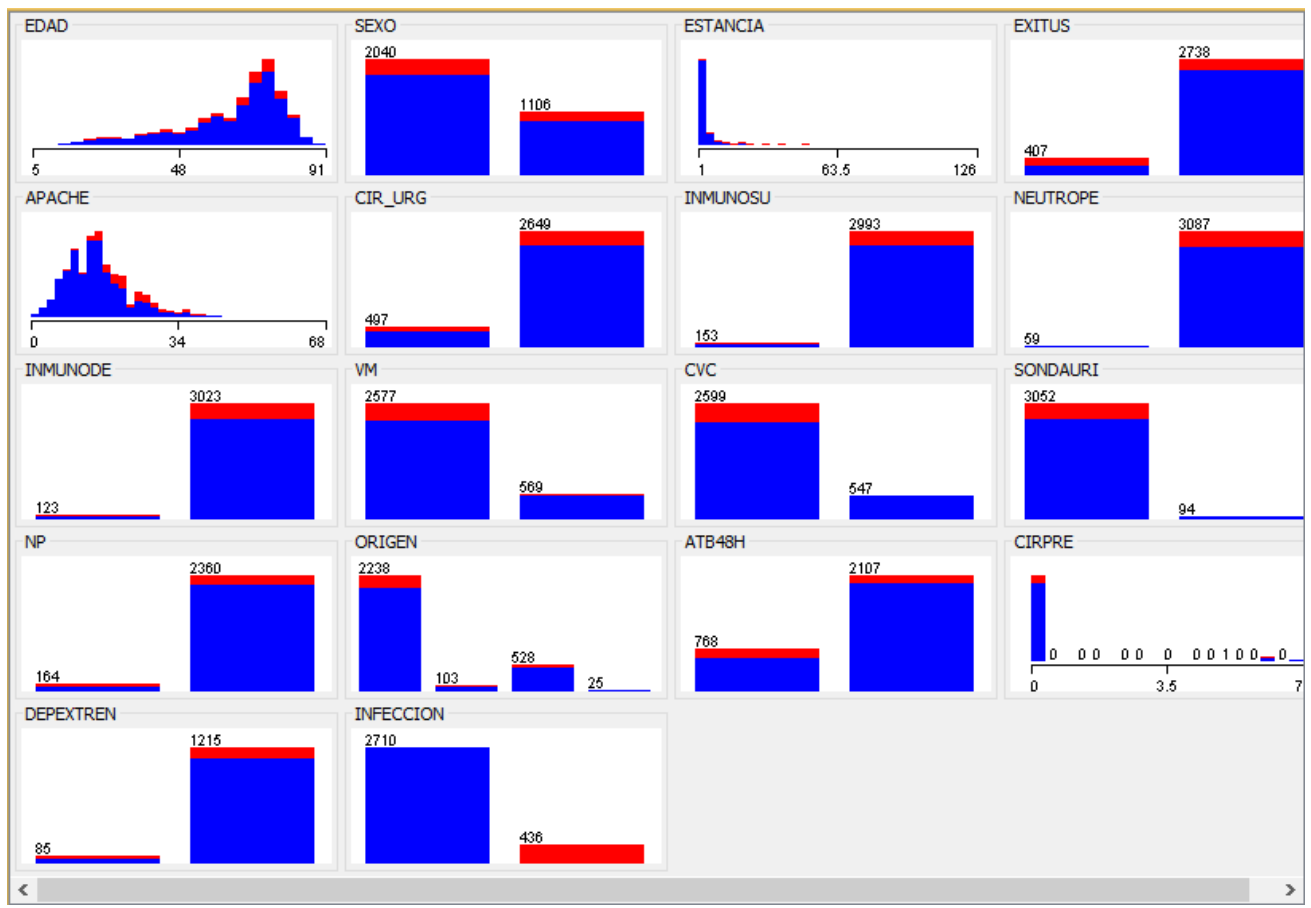

Figura 50: Distribución de valores de las variables para el periodo 2003-2007.

\section{SELECCIÓN DE CARACTERÍSTICAS}

\section{CFS}

Los atributos seleccionados por este método, en orden de importancia para la presencia de infección, son la estancia en UCI, la mortalidad, la presencia de CVC y NPT.

\section{Índice de Ganancia}

Los atributos seleccionados por este método, en orden de importancia, fueron los que aparecen a continuación. A la derecha del nombre del atributo aparece el índice de ganancia de información. Cuanto mayor sea este valor, mayor importancia tendrá el 
atributo en la clasificación. Se han señalado en color azul aquellos que son coincidentes con los seleccionados por el método anterior.

- Estancia: 0.162006

- Exitus: 0.107501

- NPT: 0.080123

- $\quad$ APACHE II: 0.042616

- Cirugía previa: 0.040631

- Inmunosupresión: 0.038723

- Inmunodeficiencia: 0.030379

- CVC: 0.030331

- Tratamiento antibiótico 48 horas previas: 0.024226

- Neutropenia: 0.022525

- Cirugía urgente: 0.02136

- Depuración extrarrenal: 0.018123

- VM: 0.014396

- SV: 0.011598

- Origen del paciente: 0.00213114

- Sexo: 0.0001292

- Edad: 0,00001

\section{ALGORITMOS DE CLASIFICACIÓN}

La desigual proporción de registros de cada clase puede ocasionar que los algoritmos den lugar a una alta exactitud (porcentaje de instancias correctamente clasificadas). Sin embargo, la precisión de la clase minoritaria puede ser muy baja, por lo que el mejor algoritmo será aquel que muestre una exactitud alta, y la menor diferencia entre las precisiones de las clases positiva y negativa.

Los resultados de la aplicación de diferentes algoritmos se muestran en la tabla 44 y en la figura 51. Podemos observar que la mayor exactitud se consigue con el algoritmo Random Forest, sin embargo Bagging con J48 como clasificador de base, muestra una exactitud similar y la diferencia entre la precisión de la clase positiva y la de la clase negativa es mucho menor. 


\begin{tabular}{|l|c|c|c|}
\hline ALGORITMO & EXACTITUD & $\begin{array}{l}\text { PRECISIÓN } \\
\text { CLASE SI }\end{array}$ & $\begin{array}{l}\text { PRECISIÓN } \\
\text { CLASE NO }\end{array}$ \\
\hline Árbol de decisión J48 & $92,9 \%$ & $94,9 \%$ & $78,1 \%$ \\
\hline Random Forest & $\mathbf{9 3 , 8 \%}$ & $95,9 \%$ & $79,5 \%$ \\
\hline Red de Bayes-K2 & $90,3 \%$ & $95,9 \%$ & $62,4 \%$ \\
\hline Red de Bayes-TAN & $92,2 \%$ & $95,3 \%$ & $72,7 \%$ \\
\hline Random Committee & $93,5 \%$ & $95,6 \%$ & $78,8 \%$ \\
\hline AdaBoost-J48 & $93,4 \%$ & $95,8 \%$ & $77,7 \%$ \\
\hline Bagging-J48 & $\mathbf{9 3 , 6 \%}$ & $\mathbf{9 5 , 2 \%}$ & $\mathbf{8 1 , 8 \%}$ \\
\hline
\end{tabular}

Tabla 44: Resultados de los algoritmos de clasificación para el periodo 2003-2007.

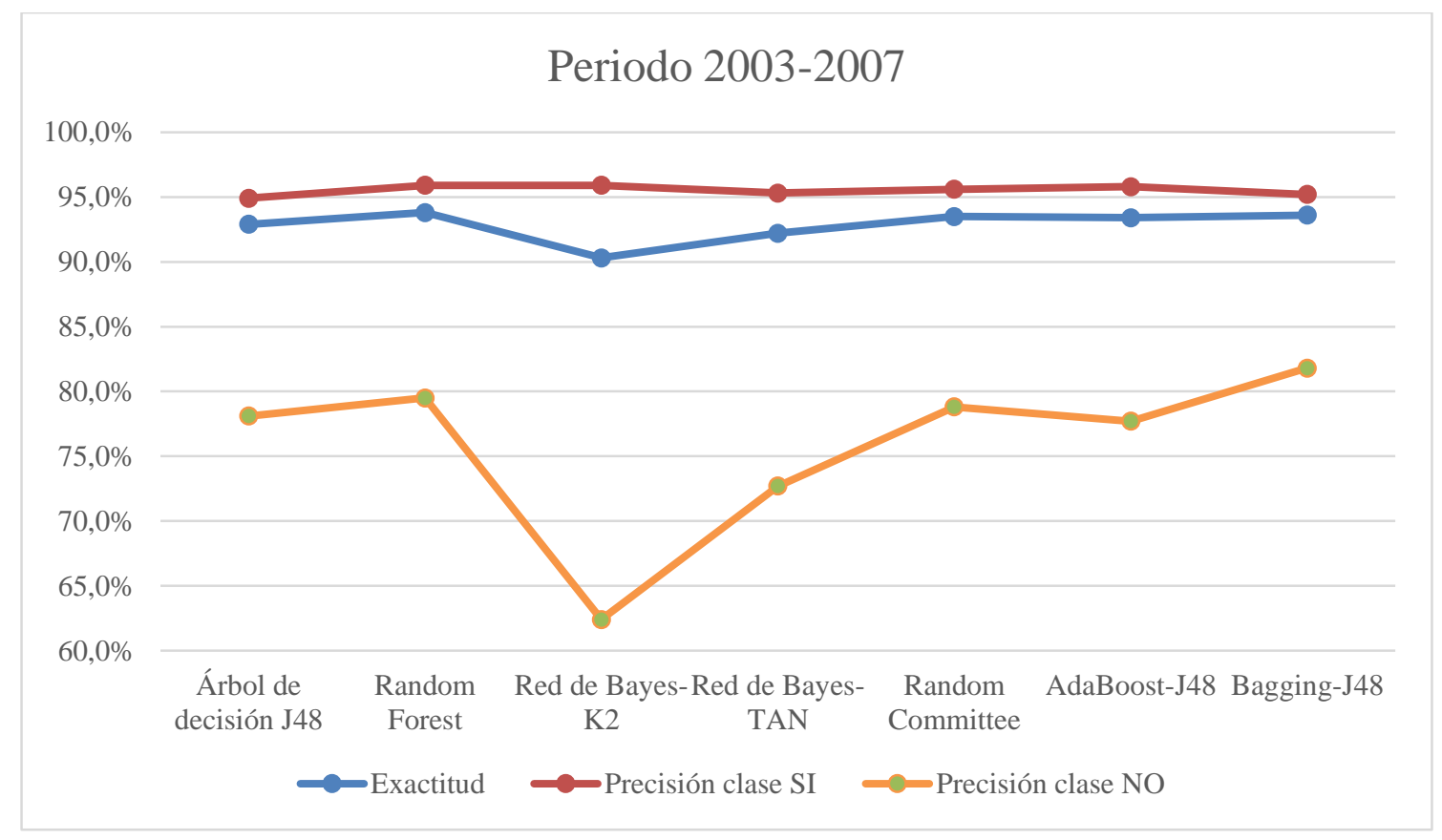

Figura 51: Exactitud y precisión para cada clase según tipo de algoritmo con los datos del periodo 2003 2007.

A continuación se muestra el árbol de decisión obtenido con el algoritmo J48, en el que se observan las variables seleccionadas por el algoritmo para construir el modelo. Las variables de los niveles superiores son las más importantes de cara a la clasificación. En este caso la variable más importante sería estancia. 


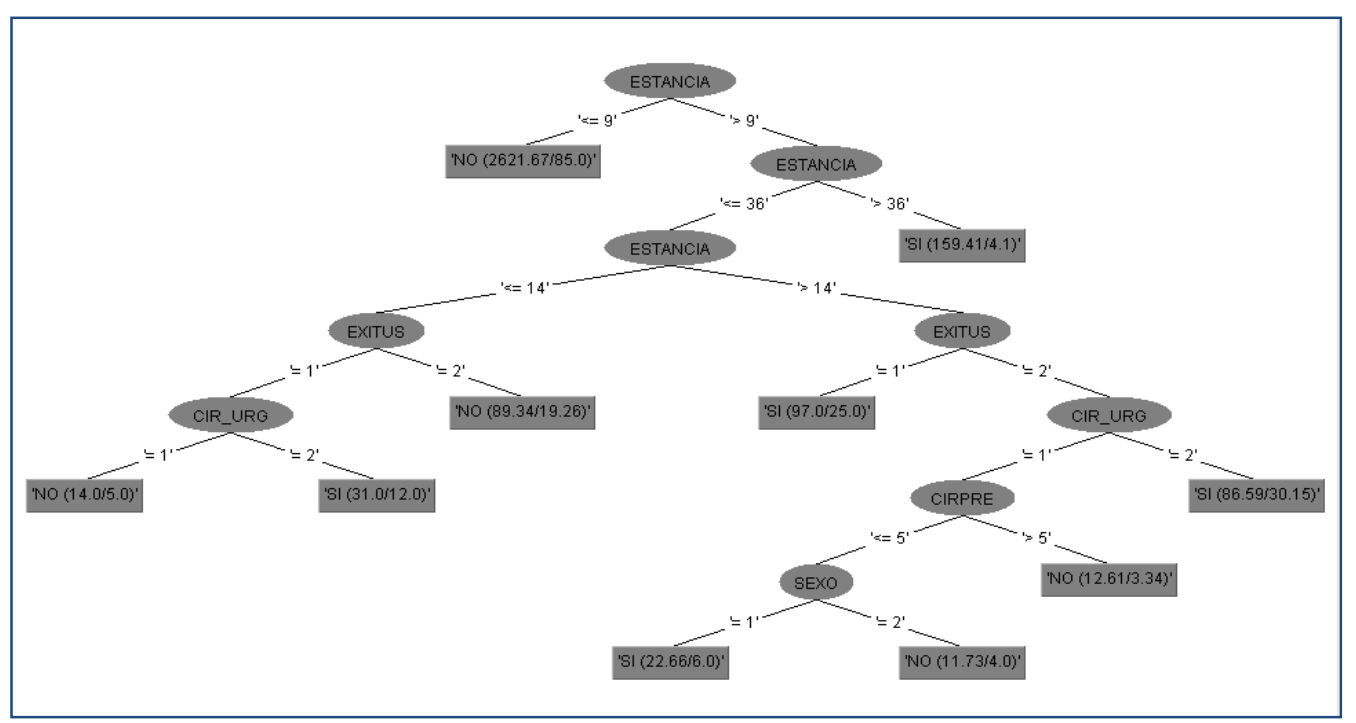

Figura 52: Árbol de decisión J48 para el periodo 2003-2007

\subsection{PERIODO 2008-2013}

En este periodo se disponen de 4616 registros, de los cuales 4305 son de la clase

NO, y 311 de la clase SI. La figura 53 muestra la distribución de valores de las variables utilizadas en el estudio.

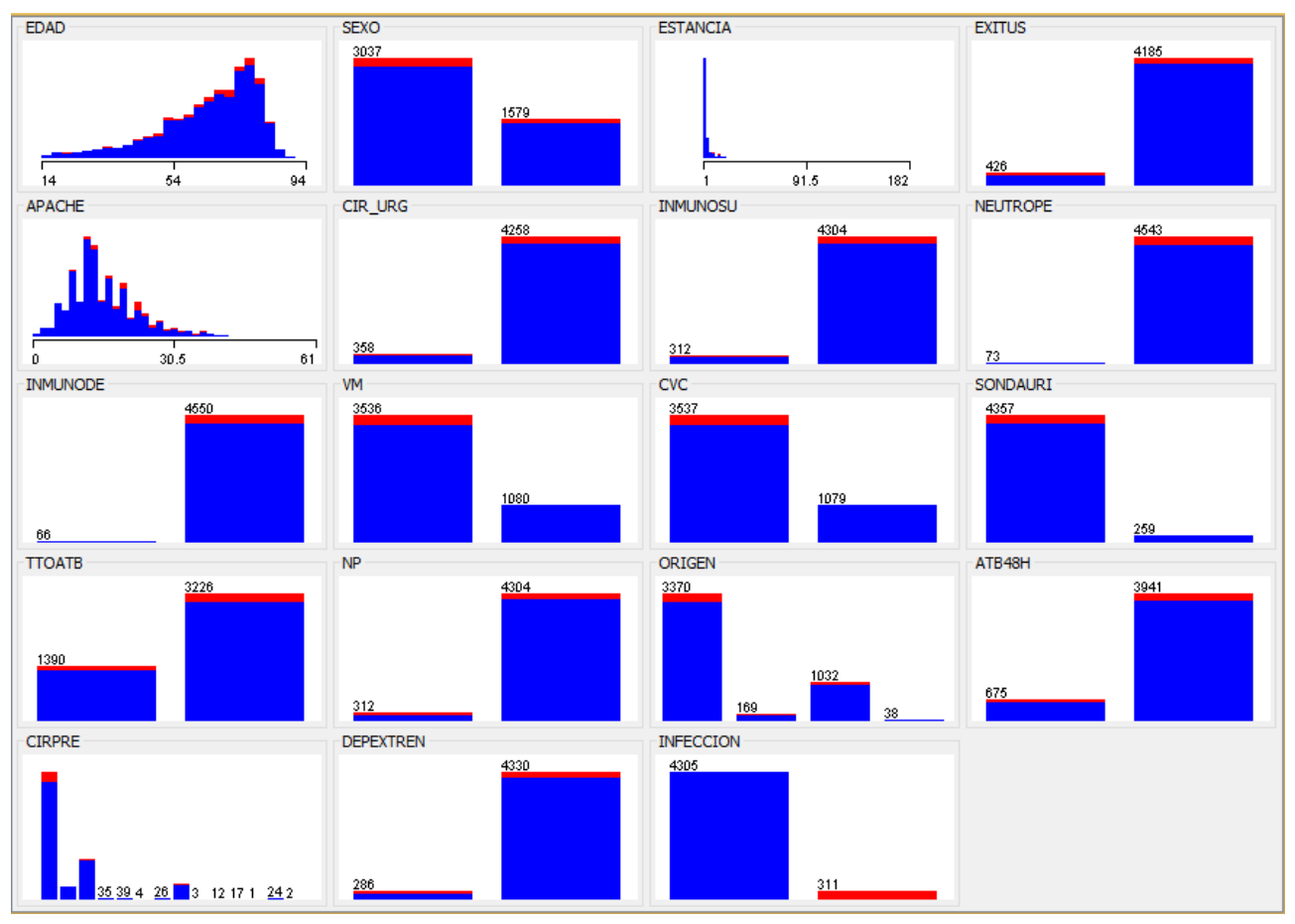

Figura 53: Distribución de valores de las variables para el periodo 2008-2013 


\section{SELECCIÓN DE CARACTERÍSTICAS}

\section{CFS}

Los atributos seleccionados por este método en orden de importancia fueron: estancia, neutropenia, NPT, depuración extrarrenal.

\section{Índice de Ganancia}

Los atributos seleccionados por este método, en orden de importancia, fueron los que aparecen a continuación. Al igual que para el periodo anterior, a la derecha del nombre del atributo se ha colocado el índice de ganancia de información, cuyo valor es mayor cuanto mayor sea la importancia del atributo en la clasificación.

- Depuración extrarrenal: 0.114507

- NPT: 0.0928014

- Estancia: 0.0915806

- Exitus: 0.0538788

- Cirugía urgente: 0.0298357

- Neutropenia: 0.0277313

- $\quad$ APACHE II: 0.0229348

- Inmunosupresión: 0. 0182328

- CVC: 0.0162552

- VM: 0.0155723

- Antibiótico 48horas previas: 0.0149812

- SV: 0.0068115

- Origen: 0.0037732

- Inmunodeficiencia: 0.0019894

- Sexo: 0.0000547

- Cirugía previa: 0

- Edad: 0

\section{ALGORITMOS DE CLASIFICACIÓN}

En este periodo también se presenta una desigual proporción de registros de cada clase, la cual puede provocar una baja precisión de la clase minoritaria, aun cuando la exactitud de la clasificación sea alta. Los resultados de la aplicación de diferentes 
algoritmos se muestran en la tabla y en la figura siguiente. En ellas se puede ver que la mayor exactitud se consigue con el algoritmo Random Forest.Sin embargo tanto Random Committee como Bagging con J48 presentan una exactitud similar y la diferencia entre la precisión de la clase positiva y la de la clase negativa es mucho menor.

\begin{tabular}{|l|c|c|c|}
\hline ALGORITMO & EXACTITUD & $\begin{array}{l}\text { PRECISIÓN } \\
\text { CLASE SI }\end{array}$ & $\begin{array}{l}\text { PRECISIÓN } \\
\text { CLASE NO }\end{array}$ \\
\hline Árbol de decisión J48 & $94,9 \%$ & $96,4 \%$ & $67,1 \%$ \\
\hline Random Forest & $\mathbf{9 5 , 8 \%}$ & $96,7 \%$ & $78,2 \%$ \\
\hline Red de Bayes-K2 & $91,7 \%$ & $97,0 \%$ & $41,9 \%$ \\
\hline Red de Bayes-TAN & $93,9 \%$ & $96,7 \%$ & $54,5 \%$ \\
\hline Random Committee & $\mathbf{9 5 , 7 \%}$ & $\mathbf{9 6 , 7 \%}$ & $\mathbf{7 5 , 7 \%}$ \\
\hline AdaBoost-J48 & $95,3 \%$ & $97,0 \%$ & $67,4 \%$ \\
\hline Bagging-J48 & $\mathbf{9 5 , 5 \%}$ & $\mathbf{9 6 , 5} \%$ & $\mathbf{7 5 , 0 \%}$ \\
\hline
\end{tabular}

Tabla 45: Resultados de los algoritmos de clasificación para el periodo 2008-2013.

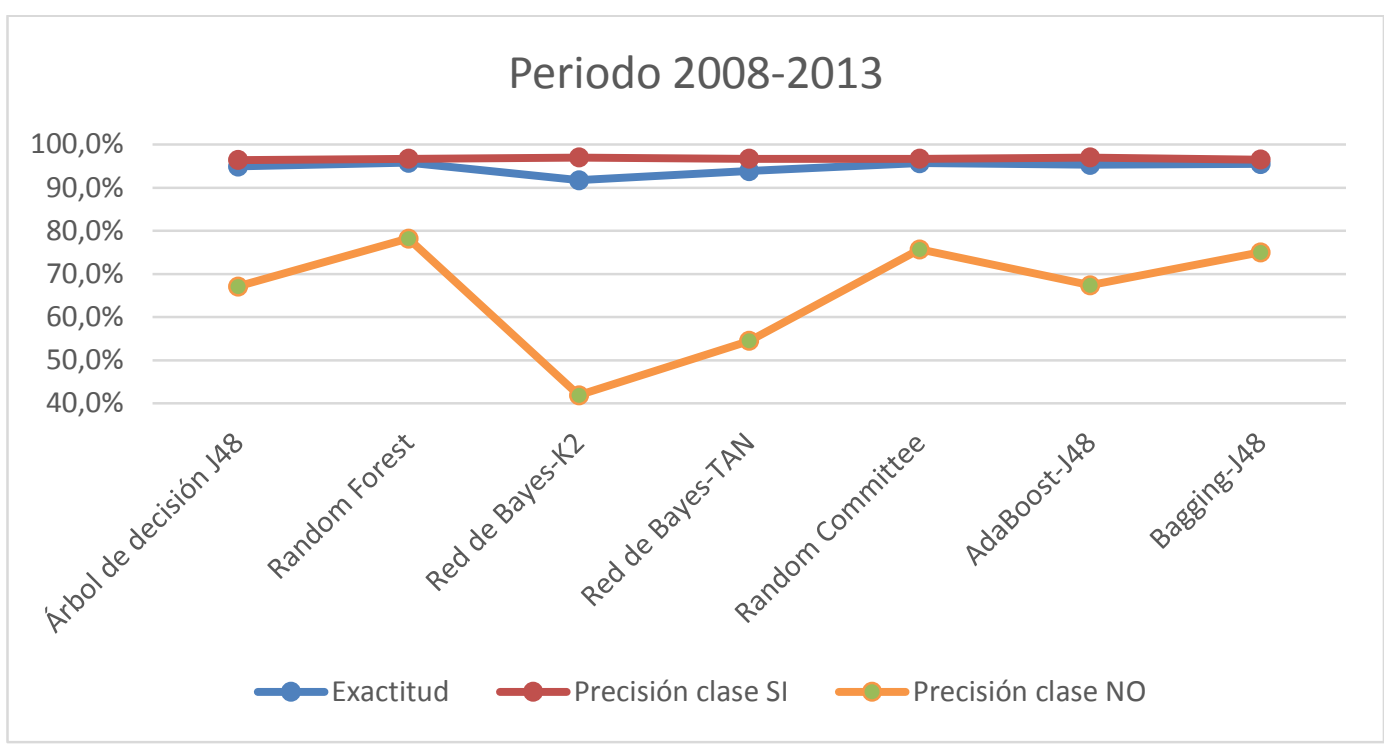

Figura 54: Exactitud y precisión para cada clase según tipo de algoritmo con los datos del periodo 20082013.

A continuación se muestra el árbol de decisión obtenido con el algoritmo J48, en el que se observan las variables seleccionadas por el algoritmo para construir el modelo. Al igual que en el periodo anterior, la variable situada en el primer nivel del árbol y por tanto la más importante es estancia. 


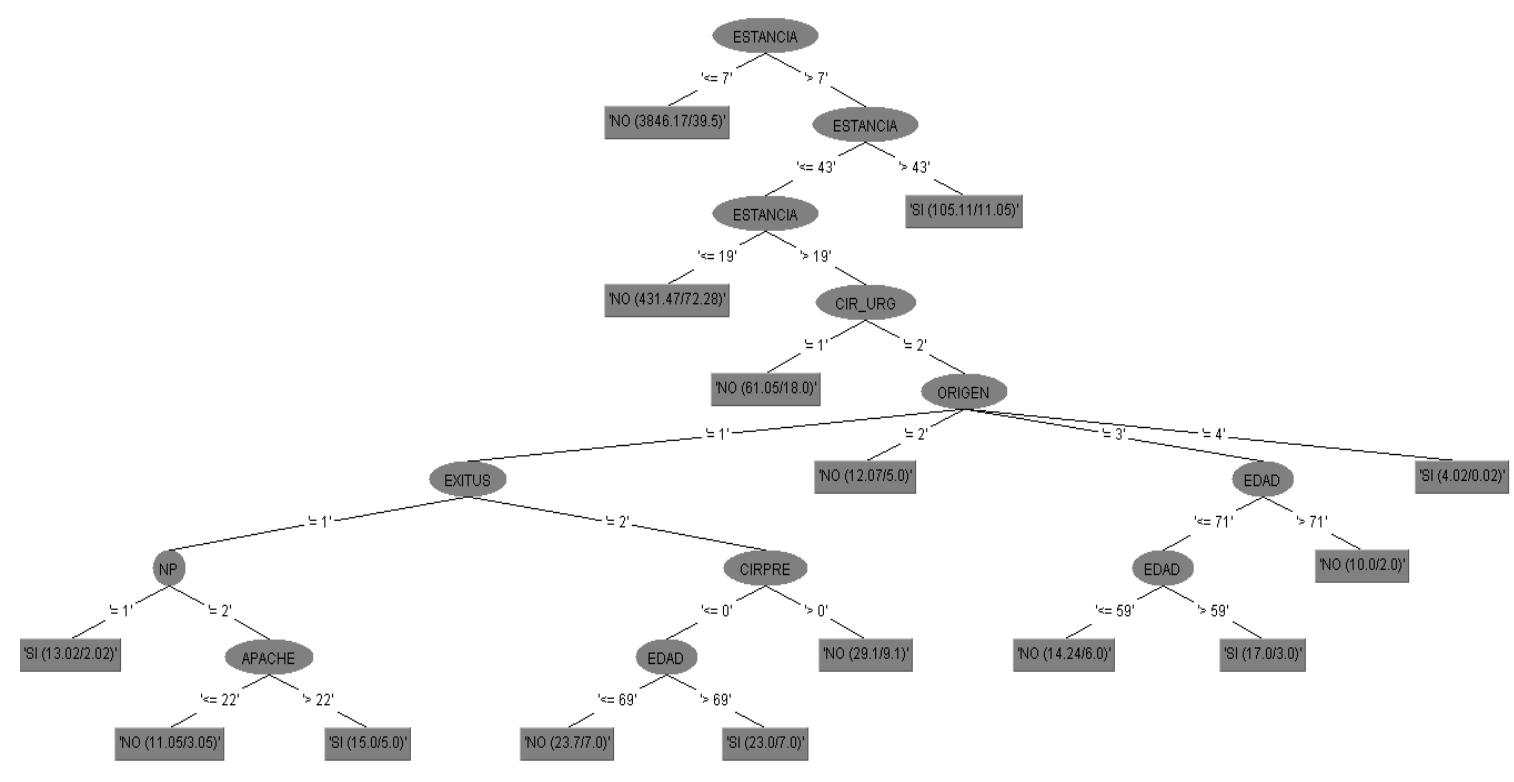

Figura 55: Árbol de decisión J48 para el periodo 2008-2013.

\subsection{PERIODO 2003-2013. ESTUDIO DE LAS INFECCIONES}

En este periodo se dispone de 7762 registros, de los cuales 7015 son de la clase NO, y 747 de la clase SI. La figura 56 muestra la distribución de valores de las variables utilizadas en el estudio.

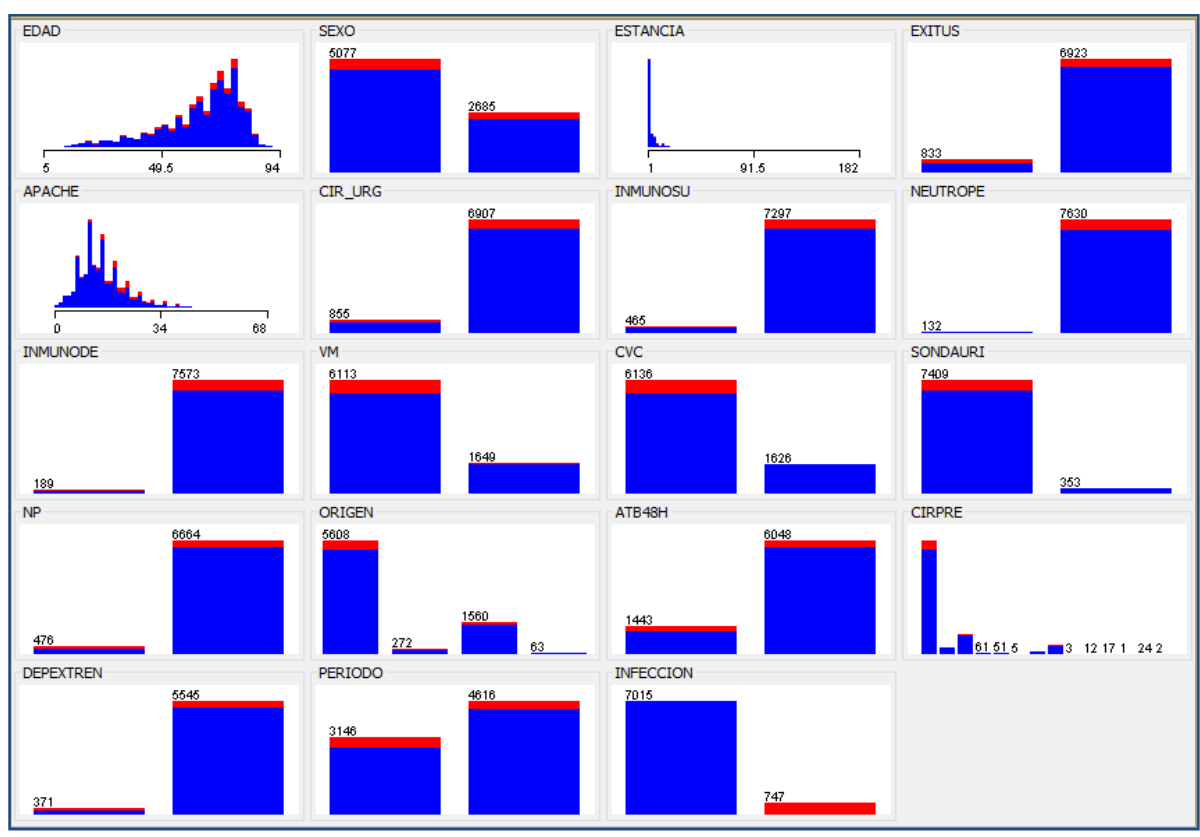

Figura 56: Distribución de valores de las variables para el periodo 2003-2013. 


\section{SELECCIÓN DE CARACTERÍSTICAS}

\section{CFS}

Los atributos seleccionados por este método en orden de importancia fueron: estancia en UCI, exitus, CVC, NPT y el periodo de estudio analizado.

\section{Índice de Ganancia}

A continuación se muestran los atributos seleccionados por este método en orden de importancia, junto con el índice de ganancia de información. Los atributos coincidentes con los seleccionados por el método CFS aparecen en azul:

- Estancia: 0.108409

- NPT: 0.083655

- Exitus: 0.082978

- Depuración extrarrenal: 0.060828

- Cirugía urgente: 0.029367

- APACHE II: 0.026051

- Neutropenia: 0.025506

- CVC: 0.023222

- Inmunodepresión: 0.022746

- Antibióticos 48 horas previas: 0.022398

- Inmunosupresión: 0.022173

- VM: 0.015934

- Periodo: 0.010188

- SV: 0.010063

- Cirugía previa: 0.005725

- $\quad$ Edad 0.005616

- Origen 0.002781

- $\quad$ Sexo 0.000103

Podemos observar que con ambos métodos se selecciona la variable PERIODO, como una de las más influyentes en la clasificación. 


\section{ALGORITMOS DE CLASIFICACIÓN}

El problema de desequilibrio entre los registros de las dos clases, como es obvio, aparece también para el periodo completo, por lo que es necesario prestar atención a la precisión alcanzada por los algoritmos para ambas clases. Los resultados se muestran en la tabla 46 y figura 57. Random Forestes el algoritmo con el que se alcanza la mayor exactitud. Sin embargo, tanto Random Committee como Bagging con J48, presentan una exactitud similar y la diferencia entre la precisión de la clase positiva y la de la clase negativa es mucho menor.

\begin{tabular}{|l|c|c|c|}
\hline ALGORITMO & EXACTITUD & $\begin{array}{l}\text { PRECISIÓN } \\
\text { CLASE SI }\end{array}$ & $\begin{array}{l}\text { PRECISIÓN } \\
\text { CLASE NO }\end{array}$ \\
\hline Árbol de decisión J48 & $94,9 \%$ & $96,4 \%$ & $67,1 \%$ \\
\hline Random Forest & $\mathbf{9 5 , 8 \%}$ & $96,7 \%$ & $78,2 \%$ \\
\hline Red de Bayes-K2 & $91,7 \%$ & $97,0 \%$ & $41,9 \%$ \\
\hline Red de Bayes-TAN & $93,9 \%$ & $96,7 \%$ & $54,5 \%$ \\
\hline Random Committee & $\mathbf{9 5 , 7 \%}$ & $\mathbf{9 6 , 7 \%}$ & $\mathbf{7 5 , 7 \%}$ \\
\hline AdaBoost-J48 & $95,3 \%$ & $97,0 \%$ & $67,4 \%$ \\
\hline Bagging-J48 & $\mathbf{9 5 , 5 \%}$ & $\mathbf{9 6 , 5 \%}$ & $\mathbf{7 5 , 0 \%}$ \\
\hline
\end{tabular}

Tabla 46: Resultados de los algoritmos de clasificación para el periodo 2003-2013

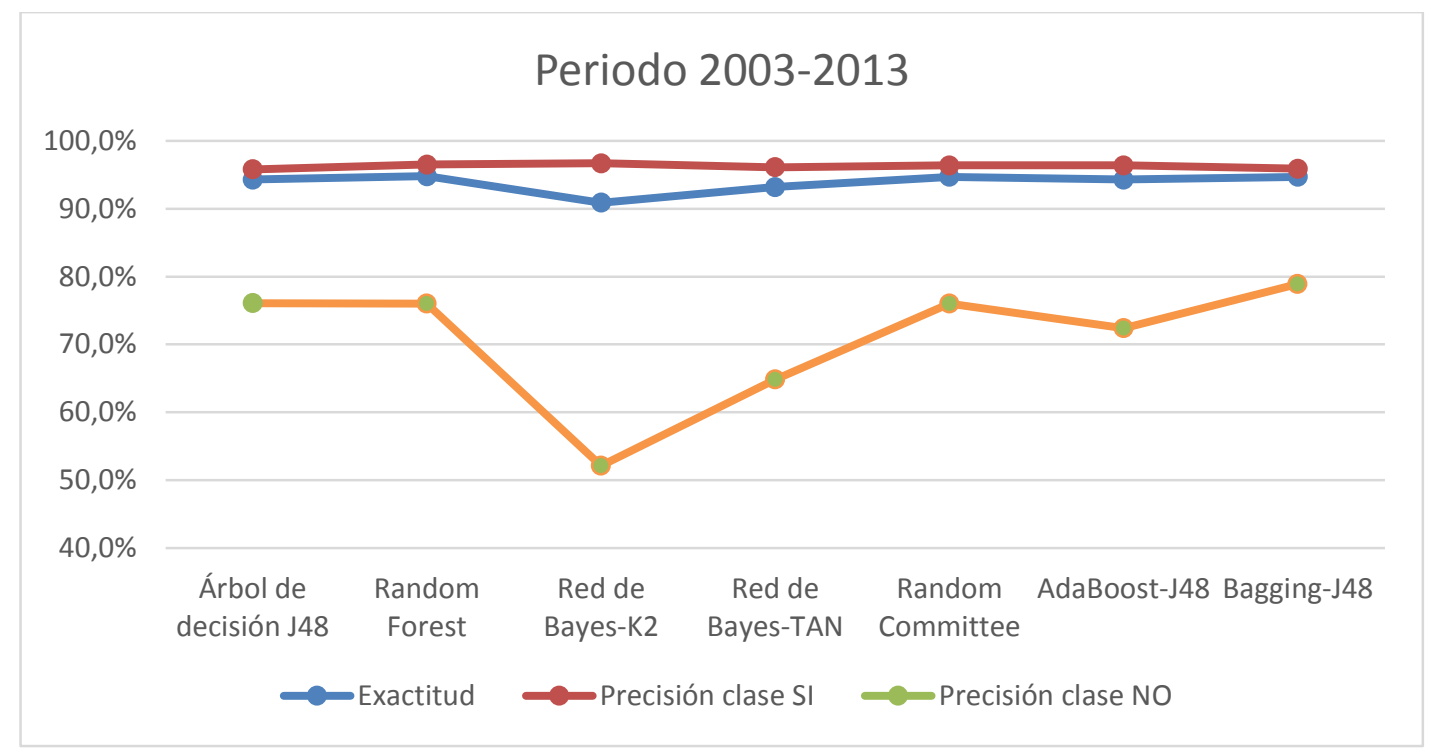

Figura 57: Exactitud y precisión para cada clase según tipo de algoritmo con los datos del periodo 2003 2013. 
A continuación se muestra el árbol de decisión obtenido con el algoritmo J48 para este periodo. Como en los casos anteriores la variable más importante es estancia, pero aquí observamos que en el tercer nivel del árbol aparece la variable periodo. Si analizamos las dos reglas marcadas en el árbol podemos comprobar que el periodo 2 se asocia con la clase NO mientras que el periodo 1 se asocia con la clase SI. Confirmando que el primer periodo se relaciona con el mayor riesgo de infección y el segundo con un menor riesgo.

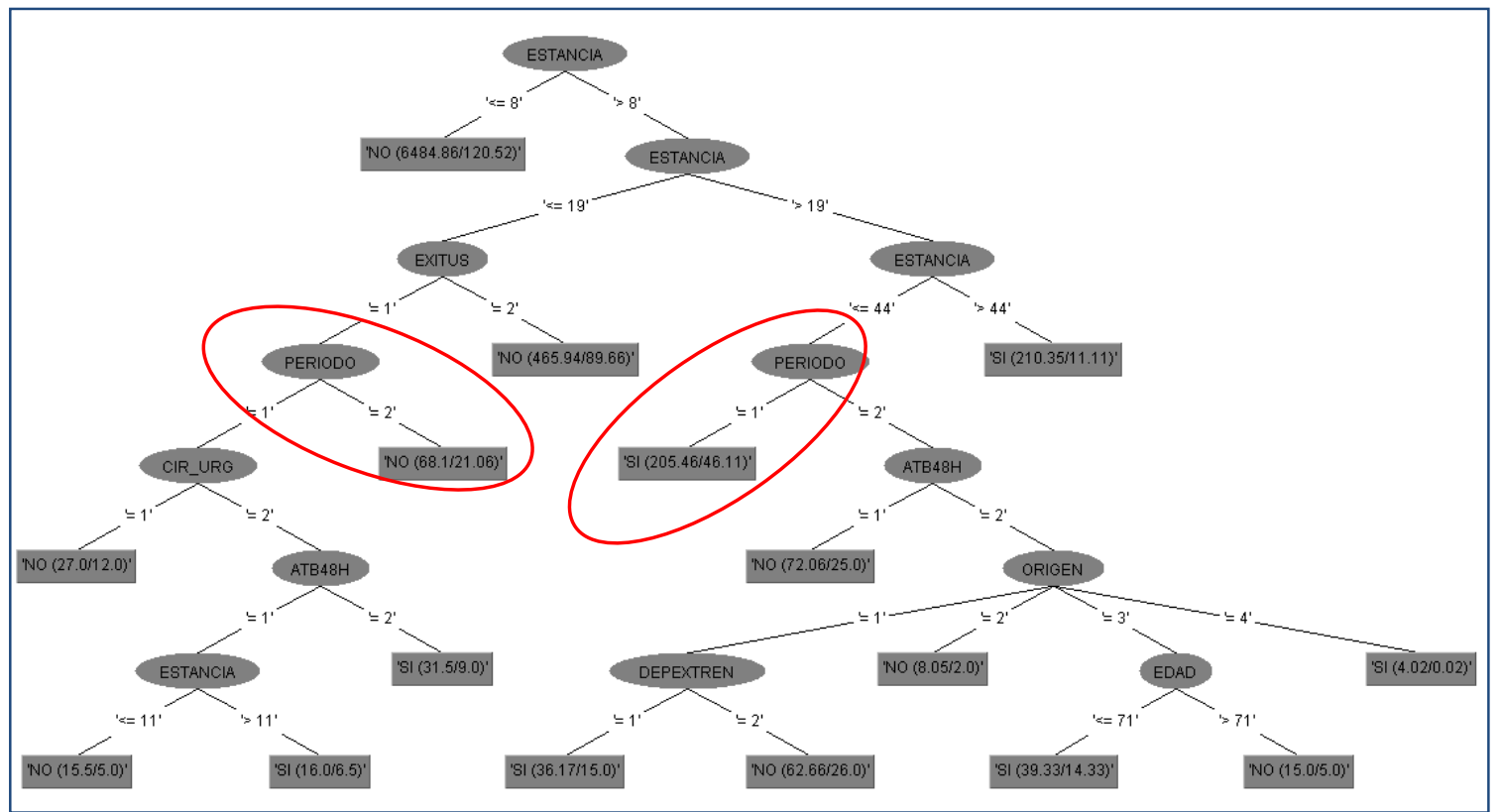

Figura 58: Árbol de decisión J48 para el periodo 2003-2013.

\section{ALGORITMOS DE ASOCIACIÓN}

Se han aplicado los algoritmos Apriori y Predictive Apriori descritos en el apartado de métodos. En ambos se ha especificado que la parte consecuente de las reglas contenga únicamente el atributo de clase, por lo que ambos generan reglas de asociación de clases.

Para evitar la inducción de reglas muy complejas, los atributos seleccionados para generar las mismas han sido únicamente los mejores proporcionados por los métodos de selección de características: Estancia, exitus, CVC, NPT y periodo. 
Estableciendo un umbral de confianza del 95\%, y de soporte del 5\%, el algoritmo Apriori generó múltiples reglas. Del examen de las mismas podemos destacar que todos los pacientes con estancias menores a 2,5 dias, tengan o no tengan CVC o NPT, se asocian con no desarrollo de infección. Cuando se incluye el periodo de estudio en el algoritmo, es el segundo periodo el que se asocia con no desarrollo de infección.

Con el algoritmo Predictive Apriori se obtienen reglas de predicción, como en el algoritmo anterior. La mayoría predicen el no desarrollo de infección, debido a la mayor proporción de registros de esa clase. La regla que predice el desarrollo de infección establece, con una exactitud del 98,7\%, que si la estancia es mayor de 32,5 días, los pacientes son portadores de CVC, han precisado NPT, no fallecen y están en el primer periodo de estudio, entonces sí desarrollan infección.

\subsection{PERIODO 2003-2013. ESTUDIO DE LA MORTALIDAD}

En este estudio se pretende analizar la influencia de las variables disponibles en la mortalidad de los pacientes, en especial la influencia de la variable infección. Por este motivo, se ha seleccionado como atributo etiqueta la variable exitus. De los 7756 registros totales, 6923 son de la clase 2 (NO), y 833 de la clase 1 (SI).

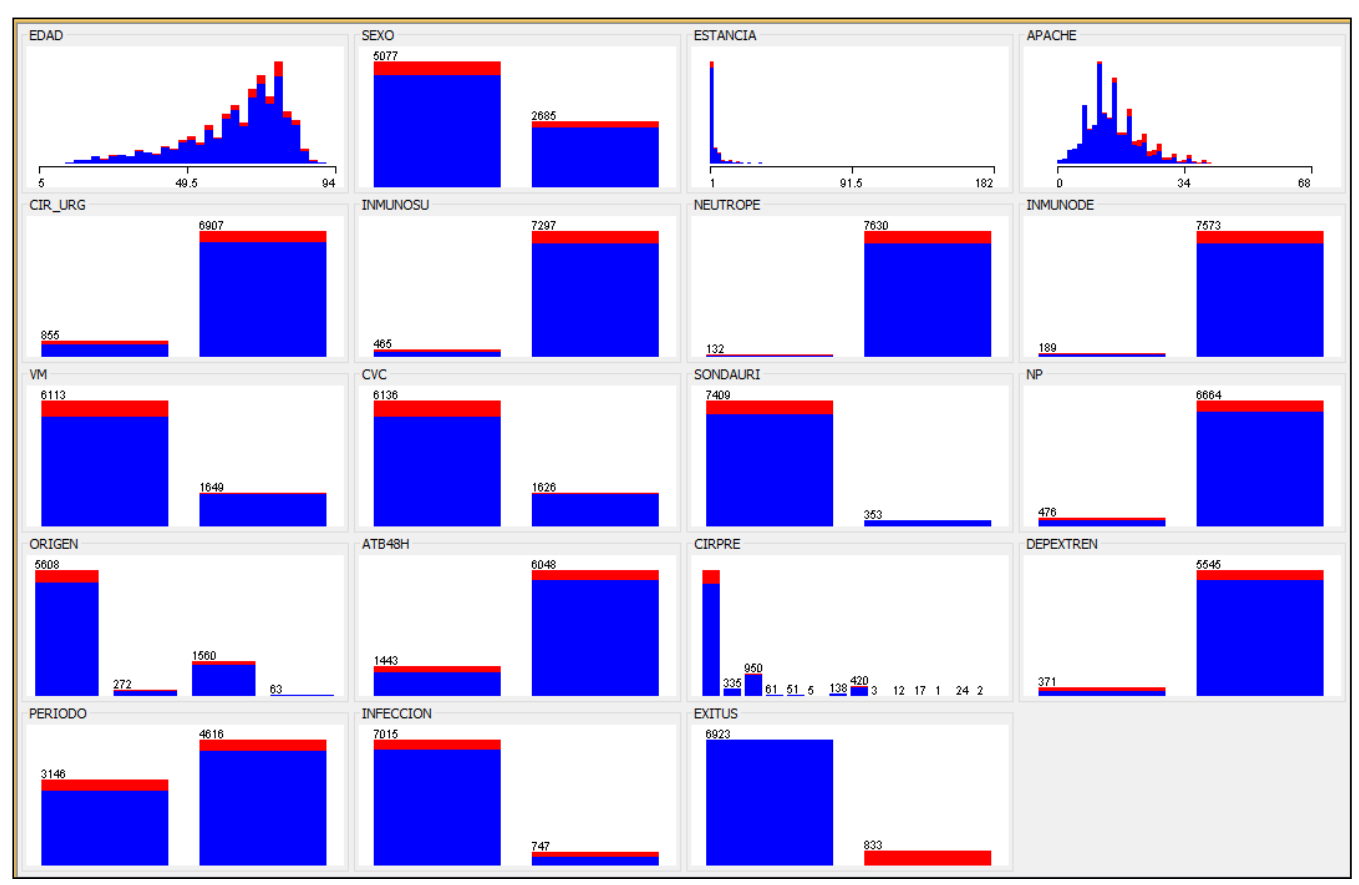

Figura 59: Distribución de valores de las variables para el estudio de mortalidad. 


\section{SELECCIÓN DE CARACTERÍSTICAS}

\section{CFS}

Los atributos seleccionados por este método en orden de importancia fueron: estancia, APACHE II, Inmunosupresión, depuración extrarrenal, y el diagnóstico de infección en UCI.

\section{Ganancia de Información}

Los atributos seleccionados por este método, en orden de importancia, junto con el valor de ganancia de información fueron los que aparecen a continuación. Se puede destacar el hecho de que, teniendo en cuenta la ganancia de información, infección es el atributo más influyente en la mortalidad, mientras que el atributo periodo tiene una menor influencia:

- Infección: 0.039584

- Depuración extrarrenal: 0.021691

- Antibiótico en las 48 horas previas al ingreso: 0.015229

- Inmunosupresión: 0.013692

- Cirugía urgente: 0.012297

- Nutrición parenteral: 0.011966

- CVC: 0.009681

- VM: 0.009637

- Neutropenia: 0.009401

- Inmunodeficiencia: 0.008709

- Cirugía previa: 0.007625

- Sonda urinaria: 0.003316

- Periodo: 0.002447

- Origen: 0.001544

- $\quad$ APACHE II: 0.000486

- Sexo: 0.000299 


\section{ALGORITMOS DE CLASIFICACIÓN}

Al igual que con las clases de infección, con las de exitus también nos encontramos con una proporción mucho mayor de registros de una clase que de otra.

Los resultados de la aplicación de diferentes algoritmos se muestran en la tabla 47 y en la figura 60. Podemos observar que aunque las diferencias en la exactitud no son muy significativas, los mayores valores se consiguen con los algoritmos Random Forest y Bagging con J48, al igual que la menor diferencia entre la precisión de la clase positiva, y la de la clase negativa es mucho menor.

\begin{tabular}{|l|c|c|c|}
\hline ALGORITMO & EXACTITUD & $\begin{array}{l}\text { PRECISIÓN } \\
\text { CLASE 2 (NO) }\end{array}$ & $\begin{array}{l}\text { PRECISIÓN } \\
\text { CLASE 1 (SI) }\end{array}$ \\
\hline Árbol de decisión J48 & $91.5 \%$ & $93.0 \%$ & $67.8 \%$ \\
\hline Random Forest & $\mathbf{9 2 . 2 \%}$ & $93.7 \%$ & $71.1 \%$ \\
\hline Red de Bayes-K2 & $86.8 \%$ & $94.1 \%$ & $41.1 \%$ \\
\hline Red de Bayes-TAN & $88.6 \%$ & $92.8 \%$ & $46.1 \%$ \\
\hline Random Committee & $91.9 \%$ & $93.8 \%$ & $68.1 \%$ \\
\hline AdaBoost-J48 & $91.3 \%$ & $94.3 \%$ & $61.1 \%$ \\
\hline Bagging-J48 & $\mathbf{9 1 . 9 \%}$ & $\mathbf{9 3 . 3 \%}$ & $\mathbf{7 1 . 1 \%}$ \\
\hline
\end{tabular}

Tabla 47: Resultados de los algoritmos de clasificación

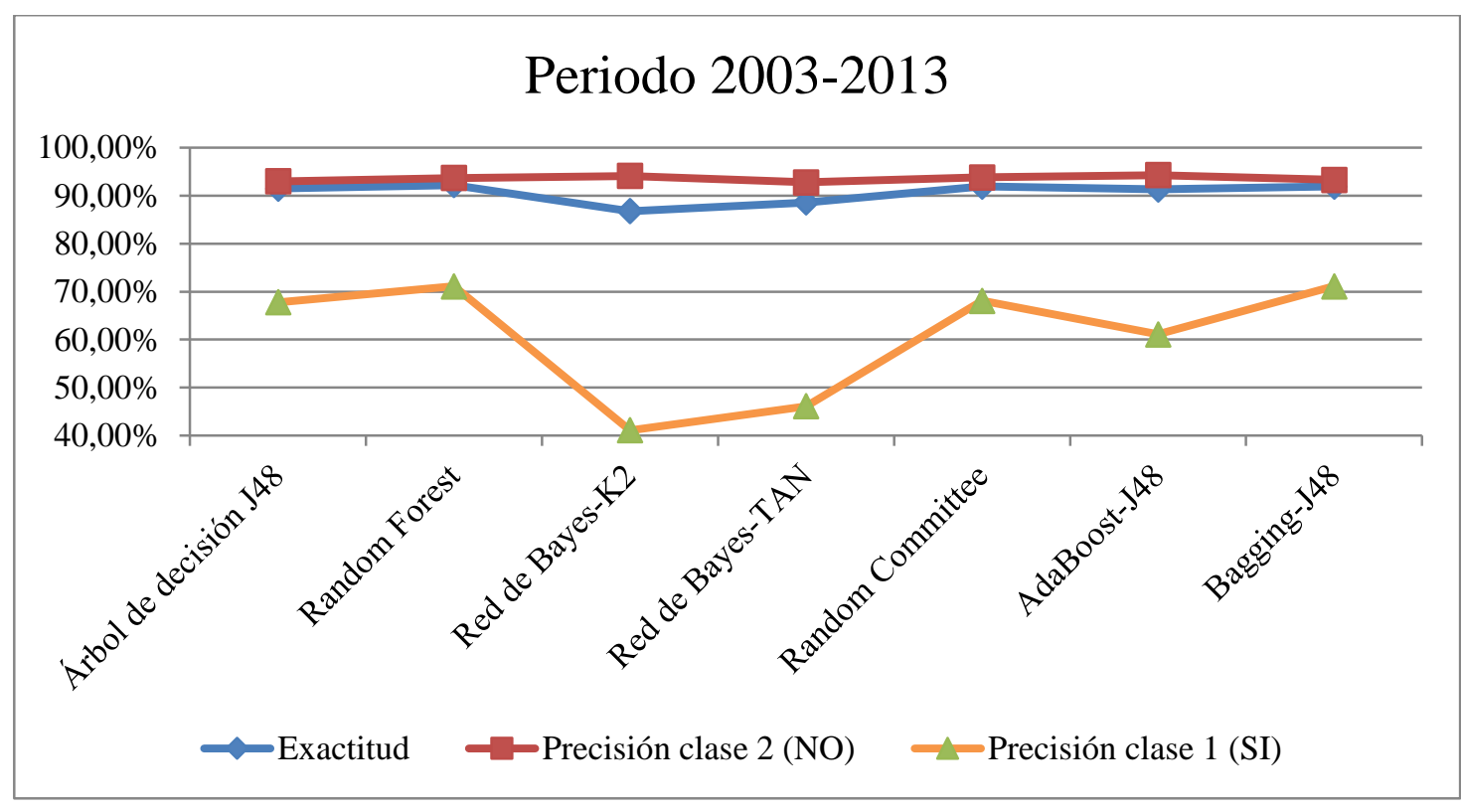

Figura 60: Exactitud y precisión para cada clase según tipo de algoritmo. 
Seguidamente se muestra el árbol de decisión obtenido con el algoritmo J48, en el que se observan las variables seleccionadas por el algoritmo para construir el modelo. La variable más importante para la clasificación es $A P A C H E$ II, seguida de infección y CVC.Si analizamos las dos reglas marcadas en el árbol, podemos comprobar que el valor de infección NO se asocia con la clase 2 (exitus NO), mientras que el valor SI de infección se asocia con la clase 1 (exitus SI).

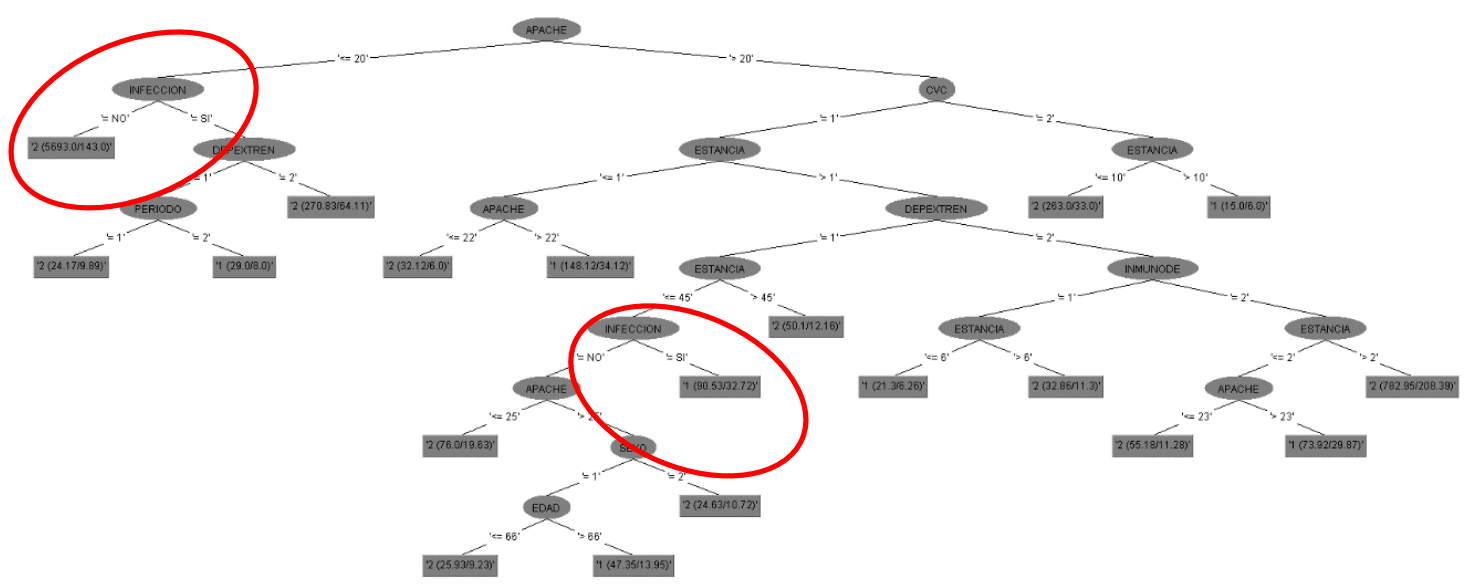

Figura 61: Árbol de decisión J48 para el atributo mortalidad.

\section{ALGORITMOS DE ASOCIACIÓN}

Para un umbral de confianza del 95\%, y de soporte del 5\%, se pueden destacar las siguientes reglas obtenidas con el algoritmo Apriori: Los pacientes con estancias menores de 19,1 dias, APACHE II bajos (entre 6,8-13,6), sin inmunosupresión, ni depuración extrarrenal y que no sufran infección nosocomial, no fallecerán (confianza > 99\%). Lo mismo ocurre para pacientes de mayor gravedad (APACHE II 13,6-20,4) siempre que la estancia sea menor de 19,1 días y no tengan infección adquirida en UCI(confianza de 96\%).

Con el algoritmo predictive Apriori se encuentran reglas de asociación en las que la presencia de infección se asocia con la no mortalidad: En pacientes con estancias menores a 19,1 dias, con APACHE II bajos (entre 6,8-13,6), no inmunodeprimidos, con o sin depuración extrarrenal, la presencia de infección se asocia con la no mortalidad. (exactitud $=96.7 \%$ ). Los pacientes con estancias más prologadas entre 91 y 109 días se asocian con no mortalidad (exactitud $=92,55 \%)$. 


\section{Discusión}




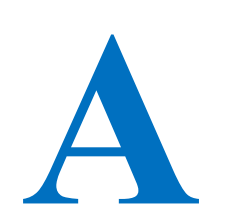

unque en los últimos años las IN adquiridas en las UCIs han disminuido de manera considerable, todavía tienen una alta incidencia según demuestran estadísticas nacionales, e internacionales. Las infecciones asociadas a dispositivos presentan una alta mortalidad y morbilidad, con un aumento de la estancia media, y de los costes sanitarios. Por lo tanto, la vigilancia de la IN es una medida fundamental en las UCIs para conocer la epidemiología, la etiología, los factores de riesgo de infección, y para valorar el efecto de las medidas de prevención, y control ${ }^{89}$.

\section{EPIDEMIOLOGIA}

Según datos del EPINE $2014^{90}$, la tasa de IN de los hospitales españoles que participan de forma voluntaria en el estudio, es de 5.6\%. Si bien solo el 3.42\% de los pacientes estudiados, lo fueron de unidades de críticos. En este pequeño grupo, la prevalencia de IN es del 21.59\%. Aunque esta tasa es elevada, ha ido disminuyendo su incidencia desde los primeros datos del EPINE donde había tasas en torno al 40\%.

Para conocer la prevalencia de IN en las UCIs, se han realizado dos estudios europeos: el European Prevalence of Infection in Intensive Care (EPIC) ${ }^{91}$, en 1992, y el EPIC II ${ }^{92}$, en 2007. El EPIC reclutó 10.038 pacientes de 1.417 UCIs de 17 países europeos, de los cuales el $20.6 \%$ presentaban alguna infección adquirida durante el 
ingreso en UCI. De estas, las más frecuentes fueron las infecciones pulmonares $64.7 \%$, seguidas de la ITUSV $17.6 \%$, y de las bacteriemias. Analizaron los factores de riesgo de infección, siendo los más significativos la estancia mayor de 24 horas, la presencia de VM, la patología traumática, la profilaxis de la úlcera de estrés, la presencia de CVC, catéter de arteria pulmonar y SV.

El EPIC II reclutó 14.414 pacientes de 1.265 UCIs, en un total de 75 países europeos. El 51\% de los pacientes ingresados presentaban algún tipo de infección, aunque no se distinguía si eran comunitarias, o nosocomiales. Las infecciones pulmonares fueron las más frecuentes, $63.5 \%$, seguidas de las infecciones intraabdominales, 19.6\%, y la bacteriemia, 15.1\%. La mortalidad fue más elevada en el grupo de pacientes con algún tipo de infección, $25 \%$, frente al 11\% de los pacientes sin infección.

Los datos epidemiológicos del estudio norteamericano del National Healthcare Safety Network (NHSN) ${ }^{93}$, recogen pacientes de 4.444 UCIs, de las cuales el $72 \%$ son unidades de hospitales generales con pacientes polivalentes agudos y traumáticos. Presentan unas TI asociada a dispositivos más bajas que las europeas, variando las tasas, y el uso de dispositivos, dependiendo del tipo de UCI analizada. Encuentran una DI de BRCVC que varía entre el 0,9-3,4\% días de CVC, con una tasa de utilización de CVC muy variable, entre el 1\% y 59\%, según el tipo de unidad que se considere. La DI de NAVM es también menor, oscilando entre 0,5 y 5\% días de VM, con un uso menor del $40 \%$ en los pacientes estudiados. La DI de ITUSV también es menor, entre el 0,5 y 4,4\%o días de SV, con una tasa de utilización de SV menor que la europea.

Los estudios del consorcio internacional de la infecciones (INICC) ${ }^{94}$, incluyen 606.310 pacientes de 503 UCIs de Sudamérica, Europa, Australia, y Asia. Presentan unas TI más elevadas, la DI de NAVM es de 16,8\% días de VM, la DI de BRCVC es de 4.9\%o días de CVC, y la DI de ITUSV es de 5,5\% días de SV. El porcentaje de uso de dispositivos invasivos es menor que los del ENVIN, con un uso de VM del 38\%, de CVC del $53 \%$, y de SV del 62\%. Son países poco representativos de la realidad occidental, ya que el $68 \%$ de los pacientes incluidos en el estudio son de países en vías de desarrollo. 
A pesar de la magnitud de estos trabajos, los que aportan mayor información sobre la epidemiología, etiología y evolución en el tiempo de las TI, son los sistemas de vigilancia, adaptados a la realidad local, realizados en cada país.

Uno de los sistemas de vigilancia nacional similar al ENVIN es el sistema implantado en las UCIs de Bélgica ${ }^{95}$, donde se recogen pacientes ingresados desde el 1997 al 2010. Detectaron unas cifras globales de DI de NAVM de 12\% días de VM, una DI de BRCVC de 3.2\% días de CVC, y una DI de BRCVC de 2.3\%o días de CVC. A lo largo del periodo estudiado, encontraron una disminución de la DI de NAVM de 27 a 12\%o días de VM, y una disminución de la tasa de BRCVC de 4.7 a 2.3\% días de CVC.

El sistema italiano de vigilancia ${ }^{96}$, recoge una DI de $17.1 \%$ días de estancia en UCI. Junto a ello, encuentran unas DI de NAVM de 15,6\% días de VM, con una ratio de uso de VM de 0,55. Una DI de BRCVC de 1,6\%o días de CVC, con una ratio de uso de CVC de 0,88, y una DI de ITUSV de 4,2\%o días de SV.

El sistema alemán ${ }^{97}$ presenta unas cifras más elevadas, la DI de NAVM es 25\%o días de VM, con una ratio de uso de VM de 0,58, la DI de BRCVC de 4\%o días de CVC, con una ratio de uso de CVC de 0,61, y la DI de ITUSV es de 9\% días de SV, con una ratio de uso de SV de 0,86 .

Los datos de la evolución de las tasas de infección adquirida en UCI del ENVINHELICS, también demuestran ese descenso de las TI adquirida en UCI, especialmente de NAVM y de BRCVC. Las tasas de NAVM han descendido desde 20,1\%o días de VM en 1997, hasta 7,7\%o en 2012, y las tasas de BRCV han disminuido desde 8,3\%o días de CVC en 1998, hasta $2,7 \%$ o $2012^{89}$.

Nuestros datos como veremos, también mantienen una tendencia descendente de modo paralelo a la tasa nacional. 


\subsection{TASA GENERAL DE INCIDENCIA}

En la UCI del Hospital Clínico Universitario, la TI de infección sin incluir las bacteriemias secundarias, es de 16,9\% de estancia en UCI. La evolución de la TI, presenta una tendencia descendente, desde 25,95\% días de estancia en UCI del año 2003, hasta un $13,52 \%$ al finalizar el periodo de estudio. Este descenso, es paralelo al experimentado por las tasas nacionales recogidas en los informes ENVIN, durante el mismo periodo.

En la evolución de las TI de infección, podemos observar dos periodos. El periodo inicial hasta el año 2007, previo a los programas BZ y NZ, donde nuestras TI estaban por encima de 20\% días de estancia en UCI, muy por encima de las tasas nacionales. El segundo periodo, a partir del año 2008, con unas tasas por debajo de 15\% días de estancia en UCI (con una menor diferencia respecto a las tasas españolas).

Las TI iniciales eran inapropiadamente elevadas desde unos estándares de calidad. El primer paso para el control de la infección en la UCI, es el conocimiento de las TI, por eso, en nuestra unidad implantamos un sistema de vigilancia epidemiológica, mediante la recogida continua de los datos en la base ENVIN, que nos permitió conocer de las TI de manera continuada a lo largo de todos los meses del año, y no sólo los tres meses de recogida de la información, que se aporta al estudio nacional.

Se introdujeron medidas de control, y se pudo evaluar su eficacia, mediante esta vigilancia permanente. En nuestro servicio, se aumentó la formación del personal, se introdujeron medidas de control de brotes por gérmenes multirresistentes (P. Aeruginosa y A. Baumanii), se comenzaron a realizar cultivos de vigilancia epidemiológica (que permiten la detección precoz de los pacientes colonizados por multirresistentes y su aislamiento preventivo), y se cambió el protocolo de higiene diaria del paciente. Ya con estas medidas, se pudo iniciar un descenso de las tasas de infección, incluso antes de implantar los proyectos BZ y NZ. 
A partir de 2008, con las medidas de control propuestas en los programas BZ y del 2010 con NZ, han permitido disminuir la TI hasta mantener unas cifras similares, e incluso inferiores a las nacionales.

Para facilitar la comparación de datos en este apartado de discusión, mostramos seguidamente, en la tabla 48, la comparación de la DI de las infecciones estudiadas, en los principales estudios anteriormente descritos, con las tasas de nuestro estudio.

\begin{tabular}{|c|c|c|c|}
\hline & DI NAVM & DI BRCVC & DI ITUSV \\
\hline NHSN $^{93}$ & $0,3-4,4 \%$ о & $0,5-3,4 \%$ & $0,7-4,7 \%$ o \\
\hline INICC $^{94}$ & $16,5 \%$ & $4,9 \%$ & $5,3 \%$ \\
\hline BELGICA $^{95}$ & $12 \%$ & $3.2 \% 0$ & $2,3 \%$ o \\
\hline ITALIA $^{96}$ & $15,6 \%$ & $6,3 \%$ & $4,2 \%$ \\
\hline ALEMANIA $^{97}$ & $25 \%$ & $4 \%$ & $9 \%$ \\
\hline HELICS $^{98}$ & $9,9 \%$ & $3,5 \%$ & - \\
\hline ENVIN $2013^{31}$ & $6,8 \% 0$ & $2,77 \%$ & $3,3 \%$ o \\
\hline SALAMANCA & $11,9 \%$ & $3,1 \%$ & $3,5 \%$ \\
\hline
\end{tabular}

Tabla 48: Comparación de la DI infección adquirida en UCI en los estudios analizados.

De igual modo, en la tabla 49, se adjuntan los porcentajes de utilización de dispositivos invasivos en estos estudios, y su comparación con nuestra unidad, siendo este uso mucho más elevado en nuestros pacientes. 
\begin{tabular}{l|l|l}
\hline USO VM & USOCVC & USO SV
\end{tabular}

\begin{tabular}{|l|c|c|c|}
\hline NHSN $^{\mathbf{9 3}}$ & $9-45 \%$ & $6-59 \%$ & $3-70 \%$ \\
\hline INICC $^{94}$ & $38 \%$ & $53 \%$ & $62 \%$ \\
\hline BELGICA $^{\mathbf{9 5}}$ & $56,7 \%$ & - & - \\
\hline ITALIA $^{\mathbf{9 6}}$ & $55 \%$ & $58 \%$ & - \\
\hline ALEMANIA $^{\mathbf{9 7}}$ & $58 \%$ & $61 \%$ & $86 \%$ \\
\hline HELICS $^{\mathbf{9 8}}$ & $49 \%$ & $65 \%$ & - \\
\hline ENVIN 2013 $^{\mathbf{3 1}}$ & $48 \%$ & $76 \%$ & $85 \%$ \\
\hline SALAMANCA & $59 \%$ & $95 \%$ & $95 \%$ \\
\hline
\end{tabular}

Tabla 49: Comparación del uso de dispositivos invasivos en los estudios analizados.

\subsection{NAVM}

La DI de NAVM de todo el periodo estudiado, es de 11,9\% días de VM. La evolución de la DI se muestra en la figura 33. Se observa una disminución progresiva de la tasa de NAVM, desde el 19,67\% días de VM en 2003, hasta un 7,7\%o días de VM en 2013. Este descenso es paralelo al experimentado por las tasas nacionales durante el mismo periodo, que disminuyen desde el 15,5\%o días de VM, hasta 6,87\%o días de VM, siendo menor la diferencia de nuestras tasas con las nacionales.

En nuestro caso, solo con las medidas del programa BZ, sin haber realizado ninguna medida específica para el control de la NAVM, en el año 2009, conseguimos una disminución de las tasas de NAVM hasta 7,26\% días de NAVM, cifra ya inferior a 8\%o días de NAVM, que era el objetivo propuesto por el programa NZ. A nivel nacional, este objetivo esperado solo se consiguió a partir del año 2012, tras completar el programa NZ.

La tasa de uso de VM en nuestra unidad, en el periodo estudiado es de 59\%, siendo elevada comparada con los estudios internacionales (tabla 50). El uso de VM ha disminuido a lo largo del periodo de estudio, desde el $60 \%$ al $51 \%$ de nuestros pacientes, pero manteniéndose en todo el periodo por encima del estudio español. Este porcentaje es similar al nacional del estudio ENVIN, aunque en todo el periodo estudiado se ha 
mantenido por encima de la española. La tasa de uso de VM es muy variable, dependiente de los estudios analizados, oscilando entre el 4\% del NHSN, el 38\% del INICC, y el 57\% de UCI europeas ${ }^{98}$.

En cuanto al diagnóstico clínico de NAVM, se realiza de manera similar a las UCIs españolas. Sin embargo, nuestros datos difieren de los nacionales en cuanto al criterio microbiológico, que es de calidad N1 en un porcentaje muchísimo más elevado que a nivel nacional: $76,3 \%$ vs $17,6 \%$.

Respecto a la respuesta inflamatoria, solo el 7,55\% de nuestros pacientes no la tienen, frente al 15,7 del estudio nacional. Este hecho apoya el diagnóstico adecuado de NAVM, ya que es difícil explicar que una NAVM no produzca respuesta inflamatoria, algo que es más frecuente en las traqueobronquitis.

\subsection{BRCVC}

Considerando las bacteriemias sin foco conocido, y las BRCVC de forma conjunta, son las segundas en frecuencia en nuestra serie. La DI de BRCVC en el periodo de estudio es de 3,15\% días de CVC. También se ha producido un descenso pronunciado de las TI de BRCVC desde el año 2003, con 4,7\%o días de CVC, hasta un 2,14\%o días de CVC. Este descenso se ha producido de manera progresiva en el tiempo. Las cifras iniciales eran inaceptablemente elevadas.

Tras la realización del programa BZ, las BRCVC se redujeron a niveles mínimos, llegando a una cifra de 0,95\% días de CVC en 2011.Tras finalizar el periodo de realización del estudio, se produce un ligero aumento progresivo, hasta una TI de 2,14\%o días de CVC en el año 2013. Es una tasa menor de 4\% días de CVC, que era objetivo de BZ, y es el indicador de calidad de los SMI. Pero como podemos comprobar, dejar de realizar de manera estricta y controlada las medidas del protocolo BZ, supone un incremento de las tasas de infección.

La ratio de utilización de CVC y CA en nuestra unidad, es muy superior a la utilización a nivel nacional. Durante el periodo estudiado, se ha mantenido constante en 
torno a 1,8. Esto quiere decir prácticamente casi todos nuestros pacientes tienen un CVC y un CA al día.

\subsection{ITUSV}

En nuestra serie estas infecciones son las terceras en frecuencia, frente al estudio nacional que las segundas.

La DI de ITUSV del periodo estudiado es de 3,5\% días de SV. Esta DI siempre se ha mantenido por debajo de la tasa nacional, y también observamos un descenso de la DI a lo largo del periodo de estudio, desde 5,5\%o días de SV, hasta 1,85 \%o días de SV. Aunque no se han realizado medidas específicas para el control de estas infecciones, las realizadas con los proyectos $\mathrm{NZ}$ y BZ, con la mejoría del cuidado de los pacientes, y las medidas de higiene de manos y el plan de seguridad integral, han supuesto un descenso mayor en el segundo periodo estudiado.

La tasa de uso de SV está por encima de la nacional, se mantiene de manera constante durante el periodo, y por encima del $95 \%$ de los pacientes frente al $85 \%$ de la nacional.

\subsection{BACTERIEMIAS SECUNDARIAS}

Durante los años 2003-2005 nuestra tasa era muy superior a la nacional, posteriormente experimentamos un descenso progresivo de la misma hasta igualarnos con las tasas nacionales, durante los años 2006-2012. En el último año hemos sufrido un ascenso de las bacteriemias secundarias hasta 3,56\% días de estancia.

En nuestra serie, el principal origen de las bacteriemias secundarias es el foco abdominal, $44,19 \%$ frente a un $23,08 \%$ de las nacionales. Le siguen las secundarias a foco respiratorio, con un $22,89 \%$ en nuestra serie, frente a un $44,41 \%$ en la española.

El programa europeo HELICS $^{98}$ analiza todas las bacteriemias secundarias diagnosticadas en la UCI, siendo las más frecuentes, las secundarias a infección de CVC 
con un $60 \%$. Un $9 \%$ son de foco desconocido, y el $31 \%$ restante son secundarias a otros focos. De estas, las más frecuentes son la de origen respiratorio $46 \%$, seguidas por la de foco digestivo $13 \%$, urinario $13 \%$, y herida quirúrgica $13 \%$.

\section{ETIOLOGÍA}

En términos generales, los programas de vigilancia estadounidense, europeo, y español, describen de manera pormenorizada los microorganismos responsables de las distintas infecciones estudiadas. De manera global, en todas las series revisadas, los microorganismos más frecuentes son los gramnegativos 55-65\%, seguidos de los grampositivos 25-35\%, y de los hongos $10-20 \%$.

En nuestra unidad, en el periodo estudiado, el microorganismo aislado con más frecuencia es la P. Aeruginosa, con un 15,62\%, le sigue S. Epidermidis con un 10,82\%, A. Baumanii con un 10,17\%, E. Coli con un 9,47\%, y en quinto lugar C. Albicans, con un $6,26 \%$.

Conocer el orden de frecuencia de los microorganismos responsables de las infecciones, tiene mayor importancia a nivel local, ya que está muy influido por la epidemiología de cada hospital, y de cada unidad, así como de los posibles brotes epidémicos. Tiene un gran interés su conocimiento junto con el patrón de resistencias, a la hora de iniciar un tratamiento antimicrobiano empírico.

Según el grupo de gérmenes, los más frecuentes son los gramnegativos 56,6\%, seguidos de los grampositivos, 29,29\%, y los hongos, con un 12,83\%. Esta distribución es similar a la descrita en los informes nacionales, y en otras series de pacientes.

Respecto a la etiología de las NAVM, los gérmenes más frecuentes son los gramnegativos, en especial P. Aeruginosa, y A. Baumanii, seguidos en menor porcentaje de S. Aureus, que se aísla más frecuentemente en las neumonías precoces. 
La etiología de las BRCVC es similar a la nacional. Comparándonos con el último informe nacional del 2013, los grampositivos suponen en nuestra serie 58,94\% de los aislamientos respecto a $56,92 \%$ de los nacionales. Los gramnegativos $31,13 \%$ vs $36,16 \%$, y los hongos $7,28 \%$ vs $6,60 \%$, siendo el germen más frecuentemente aislado en ambas series S. Epidermidis.

En las ITUSV los gérmenes difieren de la serie nacional, ya que en nuestros pacientes no encontramos gérmenes grampositivos, frente al $20 \%$ del último informe 2013. Diagnosticamos hasta un $46,48 \%$ de infección urinaria por Cándida, frente a un $19,63 \%$ de los datos nacionales.

Respecto a la etiología de las bacteriemias secundarias, es bastante similar a la nacional, aunque destaca un mayor porcentaje de aislamientos de hongos, $11,96 \%$ en nuestra serie, frente a 5,92 de la nacional.

\section{CARACTERISTICAS DE LOS PACIENTES}

En cuanto a las características de la población, nuestra serie refleja el envejecimiento de la misma en nuestra área de influencia, con una edad media de 64,66 años, respecto a los 63,17 años del estudio nacional. Es superior, sobre todo, el porcentaje de pacientes mayores de 75 años, $31.91 \%$ en nuestro trabajo, respecto a un $28.52 \%$ del último informe ENVIN publicado en el año 2013. La edad media es mayor respecto a los datos europeos del HELICS ${ }^{98}$, siendo de 60,9 años. No encontramos diferencias en cuanto a la distribución por sexo.

La enfermedad de base de nuestros pacientes, se distribuye de manera diferente a la nacional. En nuestra serie predominan los pacientes quirúrgicos, con un 51,8\% de los ingresos, en relación con el $28.17 \%$ del informe nacional. Los pacientes con patología médica son el 38,5\%, respecto al 43,66\% del ENVIN, y al 68,8\% del HELICS-ICU. En nuestro servicio el porcentaje de pacientes traumáticos es menor que la nacional, y la europea: 3.80 vs $6.11 \%$ vs $9 \%$, respectivamente. 
La diferente distribución de pacientes, la podemos explicar por las características de nuestro hospital, y de nuestra unidad, en la que la mayoría de los pacientes traumáticos ingresan en la UCI del Hospital Virgen de la Vega, y donde los pacientes coronarios son tratados por el Servicio de Cardiología en la Unidad Coronaria. Esta diferencia es importante, ya que nuestro porcentaje de pacientes coronarios es anecdótico, 1,03\%, frente al 22,05\% del registro nacional, y al 16\% del Europeo. Esta ausencia de pacientes coronarios es clave, ya que éstos necesitan menor instrumentalización, lo que influirá en las tasas de uso de dispositivos, y por tanto tendrán menor riesgo de infección.

La tasa de mortalidad es similar a la nacional $10,7 \%$, en nuestro estudio, frente a un $9.7 \%$ en el informe nacional, y $15,1 \%$ del informe europeo.

La gravedad global de nuestros pacientes, expresada por el APACHE II, es similar a la española 15.35 vs 14.57. Sin embargo, el porcentaje de pacientes menos graves (APACHE II $<10$ ), es menor en nuestro trabajo, 26.27\% del total, frente a un $36.61 \%$ de los datos nacionales. Este dato también se puede explicar por la diferente distribución de los pacientes, ya que en los coronarios, el APACHE II es menor. No podemos comparar la gravedad con los pacientes del HELICS, ya que en este estudio se utiliza el SAPSII como indicador de gravedad, siendo de 35,9.

La estancia media es de nuestros pacientes es 6.22 días, frente 7.52 días de los españoles, y 10,7 días de los europeos. Estas diferencias pueden deberse a la distinta distribución de los pacientes ingresados en nuestra unidad, con mayor porcentaje de pacientes quirúrgicos postoperados de cirugías programadas, donde la estancia media, sino hay complicaciones, es más pequeña.

\section{FACTORES DE RIESGO EXTRINSECO}

El programa ENVIN considera en las definiciones de los factores de riesgo extrínseco, aquellos dispositivos invasivos que están asociados con el aumento del riesgo de las infecciones estudiadas. Así, es más importante la vía aérea artificial que la propia ventilación mecánica, por lo que se registra el periodo de tiempo de utilización de vía aérea artificial. 
Se considera VM no invasiva cuando el paciente recibe algún tipo de asistencia respiratoria mecánica, sin intubación ni traqueotomía. Para el caso de CVC, lo que importa es la fecha de inicio y final, en la que el paciente es portador de uno o más CVC. Hay que recordar que en las definiciones del ENVIN, un paciente con dos CVC simultáneos, no cuenta como dos, sino como un solo paciente portador de CVC.

En nuestro trabajo, la presencia de pacientes con dispositivos invasivos es mayor que en que el registro nacional. Este hecho se debe principalmente a la diferente distribución de la población estudiada, sin prácticamente pacientes coronarios.

La presencia de pacientes que han precisado vía aérea artificial es mucho mayor, $76,38 \%$, frente a $41,22 \%$ de la española, y $49 \%$ de la europea. SV $94.86 \%$, frente a $73.22 \%$, y CVC del 92,83\%, frente al $63,12 \%$ de la española, y $65 \%$ de la europea. La tasa de uso de antibióticos durante la estancia en UCI es mayor en la nuestra que en las españolas, $85,21 \%$ vs $62,95 \%$. Este hecho también puede explicarse por la ausencia de pacientes coronarios.

El porcentaje de pacientes con cirugía urgente es $10,98 \%$, similar a la nacional, $10,53 \%$,y a la europea 10,4\%. El uso de NPT también es menor, 6,22\% vs 9,03\%.

La tasa de uso de terapias de reemplazo renal extracorpóreo es mayor en nuestros pacientes, que en el estudio nacional $6,27 \%$ vs $5,42 \%$.

Estas diferencias del uso de dispositivos invasivos pueden explicarse en función del diferente origen de los pacientes en nuestra serie. La mayoría de los pacientes ingresan procedentes de plantas de hospitalización (muchos de ellos ingresados previamente a cirugías programadas), $68,35 \%$ vs $44,43 \%$, lo que puede aumentar el riesgo de adquisición de IN.

Respecto a los pacientes que ingresan procedentes de la comunidad, también observamos diferencias, $21,71 \%$ vs $52,46 \%$, lo que puede representar diferentes etiologías de infección. Respecto a otras procedencias, como traslados de otras UCIs, o 
pacientes procedentes de centros de larga estancia, el porcentaje es igual de escaso en nuestra serie, que en la española.

Respecto al tipo de cirugía, también encontramos diferencias respecto a la nacional, ya que en nuestra serie el porcentaje de pacientes con cirugía cardiaca es mucho mayor, $20,42 \%$ vs $7,85 \%$ de la serie nacional, y muchos menos pacientes postoperatorios de cirugía general, $6,56 \%$ vs 10,49\%, explicando, probablemente, la menor utilización de NPT.

\section{ANALISIS DE LOS DATOS GENERALES}

La presencia de cirugía urgente constituye un aumento del riesgo de presentar infección, $18.22 \%$ vs 3,94\%. También tienen mayor mortalidad que los que no han sido operados, $22,29 \%$ vs $7,9 \%$. Además, incrementa la estancia media hasta $14,62 \%$, frente a 5,49\% de los pacientes no intervenidos. Estos datos también se reflejan en el informe nacional, aunque la mortalidad de los pacientes con cirugía urgente es menor en la serie nacional que la nuestra, $16.66 \%$ vs $22.29 \%$, y el porcentaje de infección también es menor en la nacional, $14.47 \%$ vs $18.22 \%$.

En cuanto a la distribución por tramos de edad, no hay diferencias en la estancia media, aumentado el APACHE II según la edad. La mortalidad se incrementa por tramos de edad, siendo mayor entre 75-79 años. Excepto en los pacientes menores de 40 años, que presentan menor número de infecciones, el riesgo de adquisición de infección se mantiene constante en todos los tramos de edad.

Cuando analizamos la distribución por gravedad, en función de los tramos de APACHE II, las infecciones adquiridas en UCI aumentan sobre todo a partir de APACHE II $>20$, siendo el porcentaje de infección mayor en nuestra serie que en la nacional.

Respecto a los pacientes fallecidos, éstos tienen mayor estancia media, mayor gravedad, y mayor número de infecciones, que los que sobreviven. En nuestra serie los 
pacientes fallecidos tienen mayor estancia media: $12,52 \%$ vs 10,71 , mayor APACHE II: $25,27 \%$ vs 24,16 , y más infecciones $20,25 \%$ vs $16,11 \%$, que en las tasas nacionales.

\section{INTERVALO DE APARICIÓN DE LA INFECCIÓN}

Considerando la aparición de la infección respecto al ingreso en el hospital, nuestras infecciones aparecen más tardías que las del estudio nacional, en cuanto a las NAVM, 23,45 días vs 18,9 días; las ITUSV, 33 días vs 22 días; las BRCVC, 24 días vs 19 días; y las bacteriemias secundarias, de 27 a 24 días.

Considerando la fecha de aparición de la infección respecto del ingreso en UCI, nuestras infecciones se producen más tarde que las del estudio nacional, aunque esta diferencia se acorta, en cuanto a las NAVM: 17,4 días vs 14,8 días; las ITUSV: 23,5 días vs 17,5 días; las BRCVC, 18,9 días vs 15.5 días. No hay diferencias en las bacteriemias secundarias de 17,4 días en ambos estudios.

Sin embargo, el porcentaje de infecciones precoces (las que aparecen en los primeros cuatro días de estancia), son mayores que las nacionales, $24,17 \%$, frente a $11,4 \%$. Este dato, puede deberse al mayor número de pacientes que ingresan desde otros servicios de hospitalización.

El mayor riesgo de infección asociada a dispositivos, no se relaciona tanto con la estancia en la unidad, sino con la duración de la utilización del dispositivo. Así, la mediana de aparición de NAVM es de 14 días, la de CVC de 21 días, y de ITUSV de 17 días, desde el inicio del tratamiento ${ }^{97}$. Otros estudios demuestran que el riesgo de IN aumenta al $35 \%$ a partir del $10^{\circ}$ día de ingreso, y sigue aumentando un $1 \%$ cada por cada día de ingreso ${ }^{99}$.

\section{MINERIA DE DATOS}

Analizando los datos obtenidos tras la aplicación de los diferentes algoritmos de minería de datos, para identificar predictores de infección la selección de atributos 
mediante CFS, o mediante ganancia de información, se obtiene como principal atributo predictor de infección, en el periodo global de estudio, el tiempo de estancia en UCI, los dispositivos invasivos como CVC y NPT, y en menor medida la pertenencia al primer periodo de estudio.

Como predictores de la mortalidad mediante CFS, o mediante ganancia de información, se obtiene como principal atributo la presencia de infección. Respecto a la mortalidad, la pertenencia a uno de los periodos de estudio tiene menor influencia.

\section{PREVENCIÓN}

Aunque los pacientes de las UCIs suponen un pequeño porcentaje de los pacientes ingresados en el hospital, son los que mayor riesgo presentan de adquirir infección, dada su mayor gravedad, y la mayor instrumentalización respecto a otras las áreas del hospital.

Para prevenir la infección asociada a dispositivos en las UCIs, se debe realizar una aproximación multidisciplinar que incluya a los comités de prevención de la infección, programas sobre el uso de antibióticos, paquetes de medidas, mejoras de la cultura de seguridad de los pacientes con valoración diaria de objetivos, identificar y minimizar los factores de riesgo, mejorar la formación del personal, y realizar medidas basadas en la evidencia y guías clínicas ${ }^{99}$.

La primera medida de prevención para disminuir las infecciones asociadas a dispositivos, es evitar su uso innecesario, y fomentar su retirada precoz cuando no es preciso, siendo esta una de las medidas de ambos proyectos. En BZ y NZ se incluyó la valoración diaria de la retirada de los $\mathrm{CVC}$, y la posibilidad de retirar la VM de todos los pacientes.

El principal factor de riesgo para la infección es la presencia de dispositivos invasivos de manera prolongada en el tiempo. En un estudio italiano ${ }^{101}$, la mediana de 
tiempo para presentar NAVM es de 8 días, y de BRCVC es de 13 días. En nuestros pacientes, la tasa de uso de dispositivos es elevada respecto a las descritas en el ENVIN, y en otros estudios.

La segunda medida para prevenir las infecciones son las medidas generales, como el lavado de manos, con implantación de productos de base alcohólica en las habitaciones de los pacientes, y las medidas de asepsia durante la colocación y mantenimiento de los dispositivos invasivos, que también se han realizado durante ambos proyectos, y se mantienen en el tiempo.

Hay otra serie de medidas relacionadas con aspectos generales del cuidado y tratamiento del paciente, que han demostrado ser eficaces en la disminución de las infecciones adquiridas en las UCIs, como son la: mejora del estado nutricional ${ }^{102}$, el correcto control glucémico ${ }^{103}$, la adecuada carga de trabajo mejorando las ratio de personal de enfermería por paciente ${ }^{104}$, un buen entorno de trabajo en las UCIs ${ }^{105}$, estudios de colonización con cultivos de vigilancia y medidas de aislamiento ${ }^{106}$, el baño diario de los pacientes con clorhexidina al $2 \%{ }^{10}$, la educación del personal, y la utilización de medidas basadas en sistemas de buenas prácticas ${ }^{108}$. En nuestros datos no es posible conocer el impacto de estas medidas, aunque desde el año 2005 se realizan cultivos de vigilancia epidemiológica, y se modificó el aseo del paciente, y aumentó la formación del personal.

Por último, las medidas específicas para evitar cada tipo de infección, que vienen recogidas en las guías de práctica clínica ${ }^{108}$, y que habitualmente se realizan en forma de paquetes de medidas, para mejorar su eficacia que realizadas de manera aislada.

\section{IMPACTO DE LA IN EN EL PACIENTE CRITICO}

La medición del impacto que tiene la IN es un tema de debate, y del que quedan muchos aspectos no resueltos. Responder a la pregunta si el paciente fallece por la IN o con la infección, es complejo. Pueden influir más variables dependiendo del paciente, 
como la edad, la comorbilidad asociada, las expectativas de vida, la enfermedad de base, y la gravedad del paciente.

Hay otras variables dependientes de la propia infección, y de su agente etiológico, como pueden ser la resistencia del germen, el tiempo de estancia previo a la adquisición de la infección, la adecuación del tratamiento antimicrobiano, y otros tratamientos de soporte. Esta complejidad, ha propiciado estudios sobre la medición del impacto de la IN.

En nuestros resultados podemos observar como entre los pacientes que fallecen, un 20,25\% sufren alguna infección, mientras que entre los que sobreviven solo se infectan el 3,59\%. La mortalidad es elevada en cada tipo de infección para los enfermos con NAVM, siendo del 36,5\%, la de los pacientes con BRCVC es del 39,84\%, y la de los que sufren ITUSV 34,19\%. Respecto a la estancia en UCI, la infección asociada a dispositivos supone un aumento de la misma. Los pacientes con NAVM tienen una estancia media es 35,55 de días, los que tienen BRCVC tienen una estancia de 30,25 días, y en las ITUSV se prolonga hasta los 34,12 días.

En un estudio ${ }^{109}$ realizado para analizar el riesgo de fallecer por IN, se concluye que el efecto sobre la mortalidad es altamente probable para la NAVM, dudoso para la BRCVC, e incierto para la ITUSV. El riesgo de infección se incrementa con la duración de la estancia en la UCI, dependiendo de la etiología de la misma.

Hay datos discrepantes sobre la influencia de la NAVM en la mortalidad, dependiendo de numerosos factores. Hay estudios que demuestran relación directa entre mortalidad y NAVM, como son: tratamiento empírico inicial inadecuado la etiología de la NAVM, y el momento de la aparición de la NAVM, ya que tienen influencia sobre la mortalidad las NAMV tardías, no así en las precoces. Fuera de estas situaciones, anteriormente descritas, probablemente las NAVM tienen menor impacto sobre la evolución de los pacientes ${ }^{110}$.

La NAMV es la infección que conlleva mayor mortalidad, aunque es un tema muy discutido en la literatura. Un metanálisis ${ }^{111}$ que incluye 24 ensayos clínicos sobre 
prevención de NAVM, encuentra una mortalidad atribuible del 13\%, siendo mayor la mortalidad en pacientes quirúrgicos, y con gravedad moderada.

Otro estudio ${ }^{112}$ sobre coste atribuido a NAVM, asocia un total de $17015 €$ por cada episodio de NAVM, y una mayor estancia media de 36 días, siendo atribuible 9 días por episodio de NAMV.

Con respecto a las BRCVC también hay datos discordantes, con estudios ${ }^{113}$ en los que se encuentra un aumento de la mortalidad asociada entre el 10 y el 35\%, y otros en los que no aumenta el riesgo, al ajustar otras variables de confusión.

Los factores que influyen en el impacto sobre la mortalidad son: la etiología de la bacteriemia, el foco de la misma, y la gravedad de los pacientes, siendo mayor el impacto en los de menor gravedad. Un estudio realizado con los pacientes del ENVIN nacional ${ }^{114}$, calcula que, el impacto de la mortalidad atribuible a la bacteriemia primaria y a las BRCVC, es del 9.4\%, con una prolongación de la estancia media de 13 días por episodio de BRCVC, siendo mayor en las primarias que en las relacionadas con catéter.

Respecto a las ITUSV, se ha recogido en diversos estudios, que no tienen impacto sobre la mortalidad en pacientes críticos.

Considerando la morbilidad, no queda ninguna duda que la IN siempre se asocia con un aumento de la estancia, y por tanto de los costes de la asistencia sanitaria ${ }^{115}$. En términos generales, el aumento de la estancia por infección adquirida en UCI puede oscilar entre 5 y 15 días. Sin embargo, Puede variar en función de la localización de la infección, siendo mayor en la NAVM y en las bacteriemias secundarias, y menor en la ITUSV y BRCVC. Otros factores que influyen en la morbilidad son: el tipo de germen responsable de la infección, y la adecuación del tratamiento antibiótico empírico ${ }^{116}$.

Respecto al impacto sobre los $\operatorname{costos}^{117}$, resulta difícil analizar el mismo, dados todos los factores que influyen: días de estancia, gastos de medicación, y pruebas 
diagnósticas. Hay que tener en cuenta otros costes no cuantificables, como los de las bajas laborables, la prolongación de la estancia hospitalaria, etc.

Existe un metanalisis ${ }^{118}$ realizado con los estudios publicados sobre el coste atribuible a las principales infecciones nosocomiales: BRCVC, NAVM, infección de la herida quirúrgica, e ITUSV, que demuestra los costes actualizados a dólares americanos de 2012.

En el mismo, se observó que, infección por infección, que las BRCVC fueron las más costosas (46.000\$), seguidas por las NAVM (40.000\$), las infecciones quirúrgicas (21.000\$), y las ITUSV (900\$). Teniendo en cuenta las cifras de incidencia publicadas por el CDC, el coste anual de las principales infecciones fue de 9.800 millones $\$$, de los cuales el 34\% fue atribuible a las IHQ, el 32\% a las NAVM, el 19\% a las BRCVC, el 1\% a las ITUSV. Dado que se consideran evitables el 65-70\% de las BRCVC, de las ITUSV, y el $55 \%$ de las IHQ y las NAVM, con las medidas preventivas actuales, se puede asegurar que la implantación las mismas, es costo-efectiva a corto plazo, pudiendo conseguir con muy escasos recursos, enormes ahorros.

En el periodo estudiado ha habido un descenso significativo de número de infecciones adquiridas en UCI, con pacientes de similares características, atribuible a las medidas de prevención realizadas (así se ha experimentado una reducción de 72 NAVM, y 114 BRCVC). Haciendo una extrapolación de la estancia y mortalidad, respecto a las NAVM, habríamos evitado 10 fallecimientos, y 670 estancias. Con la disminución de BRCVC evitaríamos 11 fallecimientos, y 1500 estancias aproximadamente, con la disminución de costes económicos asociados.

\section{LIMITACIONES DEL ESTUDIO}

Nuestro estudio presenta algunas limitaciones. Podemos considerar, en primer lugar, que a pesar del elevado número de pacientes, se trata de un solo hospital, con unas características concretas, diferentes de otras UCIs del resto del país, lo que hace que sea difícil su extrapolación. 
La segunda limitación es que, al ser un estudio realizado en un periodo de tiempo muy prolongado, se han producido cambios en la población que ha ingresado en la unidad, con menores pacientes con cirugías urgentes. Además, otras medidas que se han llevado a cabo de forma no protocolizada, ni registradas, pueden haber influido en la disminución de las tasas de infección.

Esta evolución en el tiempo supone otra limitación al estudio, ya que la base de datos ENVIN, ha sufrido modificaciones de los datos recogidos, lo que impide analizar todos los factores de riesgo, y otras características de los pacientes que se comienzan a recoger desde el año 2006, y por lo tanto no se disponen de estos datos de todo el periodo estudiado.

Por eso hemos solo hemos analizado los factores de riesgo de infección, y las características de los pacientes que son comunes en la base de datos, en todo el periodo estudiado. 



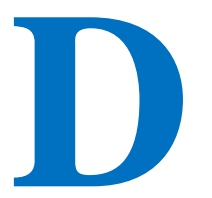

espués de realizar un estudio retrospectivo, sobre la evolución de las tasas de infección nosocomial asociada a dispositivos en una la unidad de cuidados intensivos del Hospital Universitario de Salamanca (Hospital Clínico), analizando la eficacia de las medidas de los programas de bacteriemia y neumonía-zero en el control de estas infecciones, hemos llegado a las siguientes conclusiones:

Primera. La vigilancia de la infección adquirida en nuestra unidad de cuidados intensivos, y en el resto de unidades de otros hospitales, es una herramienta de trabajo imprescindible en la actividad asistencial de las mismas.

Segunda. Con el conocimiento de las tasas de infección, se inician medidas internas de control de la infección, y se mejora la formación del personal de la unidad, logrando una tendencia descendente de dichas tasas.

Tercera. El desarrollo de los programas bacteriemia-zero y neumonía zero en nuestra unidad, ha supuesto un descenso significativo de las tasas de infección adquiridas en la misma, en especial las bacteriemias relacionadas con catéteres centrales, y las neumonías asociadas a ventilación mecánica, que son las infecciones para las que se ha realizado un programa específico de control. La realización de estas medidas han permitido igualar nuestras tasas de infección asociadas a dispositivos invasivos, a las tasas nacionales, manteniéndolas dentro de los 
estándares de calidad promovidos por la Sociedad Española de Medicina Intensiva y Unidades Coronarias.

Cuarta. El descenso de las tasas de infección, observado en nuestro estudio, no se debe a cambios en las características de los pacientes, en los diagnósticos de ingreso, ni en los factores de riesgo intrínsecos, o extrínsecos.

Quinta. De acuerdo a nuestro estudio, los principales factores de riesgo para desarrollar infección, son la estancia prolongada en la unidad, y la presencia de dispositivos invasivos.

Sexta. A la luz de nuestros resultados, y de la totalidad del análisis en general, las medidas realizadas, objeto de nuestro estudio, son eficaces en términos de disminución de infecciones, número de muertes y número de estancias. Estas medidas también tienen una repercusión económica con la disminución de gastos sanitarios, con menores estancias hospitalarias, y menor consumo de antibióticos.

Séptima, y última. Nuestro estudio retrospectivo, realizado en la unidad de cuidados intensivos del Hospital Universitario de Salamanca (Hospital Clínico), demuestra, mediante un análisis clínico, estadístico, y de minería de datos, la eficacia de las medidas de los programas de bacteriemia y neumonía-zero en el control de las infecciones objeto de análisis. Cabe destacar, el mecanismo doble y redundante de manejo de los datos, con el fin de extraer los resultados, utilizándose no sólo métodos estadísticos, sino también novedosas técnicas de minería de datos, que validan, en mayor medida, los resultados y conclusiones de este trabajo de Tesis Doctoral. 
1. Kohn LT, Corrigan JM, Donaldson MS, Editors Committee on Quality of Health Care in America. To Err Is Human Building a Safer Health System INSTITUTE OF MEDICINE NATIONAL ACADEMY PRESS Washington, D.C. ISBN 0-309-06837-1

2. Leape L. Reporting of Adverse Events. N Engl J Med 2002, 347:1633-1638

3. National Nosocomial Infections Surveillance (NNIS) System Report, data summary from January 1992 through June 2004, issued October 2004 Am J Infect Control 2004 Dic; (32)8,470-485.

4. WHO Library Cataloguing-in-Publication Data. World Alliance for Patient Safety. Global Patient Safety Challenge: 2005-2006 / World Alliance for Patient Safety. 1. Patient care-standards 2.Cross infection-prevention and control 3.Infection control methods. 4. Health facilities-standards I. Title. ISBN 9241593733

5. Pittet D, Donandson L. Challenging the world: patient safety and health careassociated infection. Int J Qual in Heath care 2006 Feb; 18(1):4-8. Jan 5.

6. Estudio Nacional sobre los Efectos Adversos ligados a la Hospitalización. ENEAS 2005. Informe. Febrero 2006. MINISTERIO DE SANIDAD Y CONSUMO. 
SECRETARÍA GENERAL TÉCNICA. CENTRO DE PUBLICACIONES Depósito Legal: M-19200-2006.

7. Aranaz JM, Aibar C, Vitaller J, Ruiz P, Limón R, Perol E; ENEAS work group. Incidence of adverse events related to health care in Spain: results of the Spanish National Study of Adverse Events. J Epidemiol Community Health 2008; 62:1022-9.

8. Wenzel R, Edmond MB. Team-Based Prevention of Catheter-Related Infections. N Engl J Med 2006, 355:2781-2783.

9. Pronovost P, Needham D, Berenholtz S, Sinopoli D, Chu H, Cosgrove S, et al. An intervention to decrease catheter-related bloodstream infections in the ICU. N Engl J Med $2006 ; 355: 2725-2732$.

10. Incidentes y eventos adversos en medicina intensiva. Seguridad y riesgo en el enfermo crítico. SYREC 2007. Informe, mayo 2009. Madrid: Ministerio de Sanidad y Política Social; 2009.

11. Sociedad Española de Medicina Intensiva. Grupo de Trabajo de Enfermedades Infecciosas (SEMICYUC-GTEI). Estudio Nacional de Vigilancia de Infección Nosocomial en UCI (ENVIN-UCI). Informes de los años 2001-2009. En la web: http://hws.vhebron.net/envin-helics/

12. Álvarez F, Palomar M, Olaechea P, Otal JJ, Insausti J, Cerdá E; Grupo de Estudio de Vigilacia de Infección Nosocomial en UCI. National Study of Control of Nosocomial Infection in Intensive Care Units. Evolutive report of the years 2003-2005. Med Intensiva. 2007 Jan-Feb;31(1):6-17.

13. Palomar M, Álvarez F, Riera MA, León C, López MJ, Díaz C, et al. Prevention of bacteriema related with ICU catheters by multifactorial intervention: a report of the pilot study. Med Intensiva. 2010 Dec;34(9):581-9. 
14. Palomar M, Álvarez F, Riera A, Díaz MT, Torres F, Agra Y, et al. Impact of a national multimodal intervention to prevent catheter-related bloodstream infection in the ICU: the Spanish experience. Crit Care Med. 2013 Oct;41(10):2364-72.

15. Proyecto Prevención Neumonía Asociada a Ventilación Mecánica: http://hws.vhebron.net/Neumonia-zero/descargas/Diapositivas NZero.pdf

16. Olaechea PM, Insausti J, Blanco A, Luque P. Epidemiology and impact of nosocomial infections. Med Intensiva. 2010 May; 34(4):256-67.

17. Palomar M, Vaque J, Álvarez F, Pastor V, Olaechea P, Fernández J. Nosocomial infection indicators. Med Clin (Barc). 2008 Dec;13.1 Suppl 3:48-55.

18. Indicadores de calidad en el enfermo crítico. Sociedad Española de Medicina Intensiva Crítica y Unidades Coronarias. ISBN: 609-5974-0. Primera edición. Mayo 2005

19. Indicadores de calidad en el enfermo crítico. Sociedad Española de Medicina Intensiva Crítica y Unidades Coronarias. ISBN: 978-84-615-3670-2 Segunda edición. Actualización 2011.

20. Centers for Disease Control and Prevention. Updated guidelines for evaluating public health systems: Recommendations from guidelines working group. MMWR Morb Mortal Wkly Rep 2001; 50: 1-35.

21. Pottinger JM, Hearwald LA, Peri TM. Basics of Surveillance-An overview. Infection Control and Hospital Epidemiology 1997; 18:513-27

22. Comunidad de Madrid Promoción de la Calidad. Guía de buenas prácticas. Prevención y control de la infección nosocomial. Comunidad de Madrid.

23. National Nosocomial Infections Surveillance (NNIS). NNIS manual. U.S. Department of Health human services.Centers for Disease Control and Prevention (CDC). 1992. IX-1-9. 
24. Emori TG, Culver DH, Horan TC, Harvis WR, White JW, Olson DR, et al. National Nosocomial Infections Surveillance System (NNIS): Description of surveillance methods. Am J Infect Control 1991; 19:19-35.

25. Dolores M, Rancaño I, García V, Vallina C, Herranz V, Vázquez F. Use of different patient safety reporting systems: much ado about nothing?. Rev Calid Asist. 2010 Jul-Aug;25(4):232-6.

26. Vaqué J, Rosselló J, Arribas JL. Prevalence of nosocomial infections in Spain: EPINE study 1990-1997. EPINE Working Group. J Hosp Infect. 1999 Dec;43 Suppl:S105-11.

27. Sánchez J, Bischofberger C, Lizan M, Lozano J, Muñoz Platón E, Navarro J, et al. Nosocomial infection surveillance and control: current situation in Spanish hospitals. J Hosp Infect 2009 May;72(1):50-6

28. Hospital in Europe Link for Infection Control through Surveillance (HELICS). Version 6.1. Sep. 2004. Surveillance of Nosocomial Infections in Intensive Care Units. En: http://www.ecdc.europa.eu/IPSE/protocols/icu protocol.pdf.

29. Knaus WA, Wagner DP, Draper EA, Zimmerman JE. APACHE II: a severity of disease classification system; Crit Care Med 1985; 13: 818-829.

30. Garner JS, Jarvis WR, Emori TG, Horan TC, Hughes JM. CDC definitions for nosocomial infections. Am J Infect Control 1988; 16:128-140.

31. Informes ENVIN-HELICS 2007, 2008, 2009, 2010, 2011, 2012 у 2013. http://hws.vhebron.net/envin-helics/

32. Moro ML, Jepsen OB. Infection control practices in intensive care units of 14 European countries. The EURONIS Study Group. Intensive Care Med. 1996 Sep;22(9):872-9. 
33. López MJ, Olaechea P, Palomar M, Insausti J, Alvarez F; ENVIN-HELICS Study Group. Quality control of the surveillance programme of ICU-acquired infection (ENVIN-HELICS registry) in Spain. J Hosp Infect 2013 Jun;84(2):126-31.

34. Mertens R, Van Den Berg JM, Fabry J, Jepsen OB. HELICS: a European project to standardise the surveillance of hospital adquired infection, 1994-1995. Euro Surveill 1996 Apr;1(4):28-30.

35. Rosselló J. Nosocomial infection surveillance and control activities in Spain under HELICS and NosoMed programs frame. J Hosp Infect 2004 Apr;56 Suppl 2:S55-7.

36. De la Cal MA. Fisiopatología de la infección nosocomial y estado de portador. En Prevención y control de la infección y de la resistencia bacteriana. Grupo de trabajo de Enfermedades Infecciosas y Sepsis (GTEIS-SEMICUYC). Ed Entheos. ISBN 978-84695-9027-0. Madrid. 2013.

37. Mermel LA, Farr BM, Sherertz RJ, Raad II, O'Grady N, Harris JS, et al. Guidelines for the management of intravascular catheter-related infections. Clin Infect Dis $2001 ; 32: 1249-1272$.

38. Safdar N, Maki DG. The pathogenesis of catheter-related bloodstream infection with noncuffed short-term central venous catheters. Intensive Care Med 2004; 30:62-67.

39. Merrer J, De Jonghe B, Golliot F, Lefrant JY, Raffy B, Barre E, et al. Complications of femoral and subclavian venous catheterization in critically ill patients: a randomized controlled trial. JAMA 2001 Aug; 8 286(6):700-7.

40. Chastre J, Fagon JY. Ventilator-associated pneumonia. Am J Respir Crit Care Med 2002;165:867-903. 
41. Tejerina E, Frutos F, Restrepo MI, Anzueto A, Abroug F, Palizas F, et al. Incidence, risk factors, and outcome of ventilator-associated neumonia. J Crit Care 2006; $21: 56-65$.

42. Gould CV, Umscheid CA, Agarwal RK, Kuntz G, Pegues DA; Healthcare Infection. Control Practices Advisory Committee. Guideline for prevention of catheterassociated urinary tract infections 2009. Infect Control Hosp Epidemiol 2010 Apr;31(4): 319-26.

43. Chenoweth C, Saint S. Preventing catheter-associated urinary tract infections in the intensive care unit. Crit Care Clin 2013 Jan;29(1):19-32.

44. Martín F, Paz M, Pérez E, Ballesteros JC, González J, Albalá N, et al. Evolución de las tasas de infección nosocomial en un Servicio de Medicina Intensiva. XLIII Congreso Nacional SEMICYUC. Valencia. 2008 Com. Nº P054.

45. Pérez E., Eizguirre JC, Pascual MJ, Paz M, GonzálezJ, Ballesteros JC, et al. Utilidad de una serie de medidas para el control de la infección en una UCI polivalente. Med Intensiva.2010;34 Supl C: 28 .

46. Venkatram S, Rachmale S. Kanna B. Study of device use adjusted rates in health care-associated infections alter implementation of "bundels" in closed-model medical intensive care unit. J. Crit Care 2010; 25: 174, e11-8.

47. O'Grady, NP, Alexander, M, Burns L, Dellinger EP, Garland J, Heard SO, et al. Guidelines for the Prevention of Intravascular Catheter-related Infections. CID 2011May;52(9):e162-93

48. Resar R, Griffin FA, Hapden C. Nolan TW. Using care bundles to improve healthcare quality. IHI Innovation series. White paper. Cambridge. Massachusetts: Institute for Healthcare Improvement 2012. 
49. Proyecto Nacional para la prevención de bacteriemas relacionadas con catéter venoso central (BZ) http://hws.vhebron.net/formacion-BZero/intervenciones.html.

50. Pittet D, Hugonnet S, Harbarth S, Mourouga P, Sauvan V, Touveneau S, et al. Effectiveness of a hospital-wide programme to improve compliance with hand hygiene. Infection Control Programme. Lancet. 2000 Oct 14;356(9238):1307-12. Erratum in: Lancet 2000 Dec; 23-30;356(9248):2196.

51. Maki DG, Ringer M, Alvarado CJ. Prospective randomised trial of povidoneiodine, alcohol, and chlorhexidine for prevention of infectionassociated with central venous and arterial catheters. Lancet. 1991 Aug; 10, 338(8763):339-43

52. Raad II, Hohn DC, Gilbreath BJ, Suleiman N, Hill LA, Bruso PA, et al. Prevention of central venous catheter-related infections by using maximal sterile barrier precautions during insertion. Infect ControlHosp Epidemiol 1994 Apr;15(4 Pt 1):231-8.

53. Goetz AM, Wagener MM, Miller JM, Muder RR. Risk of infection due to central venous catheters: effect of site of placement and catheter type. Infect Control Hosp Epidemiol 1998 Nov;19(11):842-5.

54. Salzman MB, Isenberg HD, Rubin LG. Use of disinfectants to reduce microbialcontamination of hubs of vascular catheters. $\mathrm{J}$ Clin Microbiol 1993Mar;31(3):475-9.

55. Yébenes JC, Vidaur L, Serrat M, Sirvent JM, Batlle J, Motje M, et al.Prevention of catheter-related bloodstream infection in critically ill patients using a desinfectable, needle-free connector: a randomized controlled trial. Am J Infect Control2004 Aug;32(5):291-5.

56. Pronovost PJ, Goeschel CA, Olsen KL, Reducing health care hazards: lessons from the commercial aviation safety team.Health Aff (Millwood). 2009 MayJun;28(3):w479-89 
57. Proyecto neumonia-zero. Accesible en http://hws.vhebron.net/neumoniazero/nzero.asp

58. Álvarez F, Sánchez M, Lorente L, Gordo F, Añon JM, Alvarez J, et al. Guidelines for the prevention of ventilator associated pneumonia and their implementation. The Spanish “'Zero-VAP'” bundle. Med Intensiva 2014. May;38(4):226-36

59. Kunz R, Burnand B, Schünemann HJ. Grading of Recommendations, Assessment, Development and Evaluation (GRADE) Working Group. [The GRADE System. An international approach to standardize the graduation of evidence and recommendations in guidelines]. Internist (Berl). 2008 Jun;49(6):673-80.

60. Resar R Pronovost P, Haraden C, Simmonds T, Rainey T, Nolan T. Using a bundleapproach to improve ventilator care processes and reduce ventilator-associated pneumonia. Jt Comm J Qual Patient Saf 2005 May;31(5):243-8.

61. Pittet D, Hugonnet S, Harbarth S, Mourouga P, Sauvan V, Touveneau S, et al. Effectiveness of a hospital-wide programme to improve compliance with hand hygiene. Infection Control Programme. Lancet2000;356:1307-12.

62. Nseir S, Zerimech F, Fournier C, et al. Continuous control of tracheal tube cuff pressure and microaspiration of gastric contents in critically ill patients. Am J Respir Crit Care Med 2011; 184; 1041-1047.

63. Carvajal C, Pobo A, Diaz E, Lisboa T, Llaurado M, Rello J. Oral hygiene with chlorhexidine on the prevention of ventilator-associated pneumonia in intubated patients: A systematic review of randomized clinical trials. Med Clín (Barc) 2010, 135 (11) 491497.

64. Drakulovic MB, Torres A, Bauer TT, Nicolas JM, Nogue S, Ferrer M. Supine body position as a risk factor for nosocomial pneumonia in mechanically ventilated patients: a randomised trial. Lancet. 1999;354:1851-8. 
65. Saura P, Blanch L, Mestre J, Vallés J, Artigas A, Fernández R. Clinical consequences of the implementation of a weaning protocol. Intensive CareMed. 1996;22:1052-6.

66. Keenan SP, Powers C, McCormack D, Block G. Noninvasive positive pressure ventilation in acute respiratory failure. JAMA. 2000;284:2376-8.

67. Kress JP, Pohlman AS, O'Connor MF, Hall JB. Daily interruption of sedative infusions in critically ill patients undergoing mechanical ventilation. N Engl J Med 2000;342:1471-7.

68. Cook D, DeJonghe B, Brochard L, Brun-Buisson C. Influence of airway management on ventilator-associated pneumonia: evidence from randomized trials. JAMA1998;279:781-7.

69. Babcock HM, Zack JE, Garrison T, Trovillion E, Jones M, Fraser VJ, et al. An educational intervention to reduce ventilator-associated pneumonia in an integrated health system: a comparison of effects. Chest 2004;125:2224-31.

70. Taylor N, Van Saene HK, Abella A, Silvestri L, Vucic M, Peric M Descontaminación digestiva selectiva: ¿Por qué no aplicamos la evidencia en la práctica clínica? Med Intensiva 2007; 31(3): 126-132.

71. Dezfulian C, Shojania K, Collard HR, Kim HM, Matthay MA, Saint S. Subglottic secretion drainage for preventing ventilator-associated pneumonia: a metaanalysis. Am J Med. 2005;118:11-8.

72. Vallés J, Peredo R, Burgueño MJ, Rodrigues de Freitas AP, Millán S, Espasa M, et al. Efficacy of single-dose antibiotic against early-onset pneumonia in comatose patients who are ventilated. Chest 2013 May;143(5):1219-25.

73. Garner JS, Jarvis WR, Emori TG, Hughes JM. CDC definitions for nosocomial infections. Am J Infect Control1988;16:128-40. 
74. Levy MM, Fink MP, Marshall JC, Abraham E, Angus D, Cook D, et al. International Sepsis Definitions Conference. 2001 SCCM/ ESICM/ ACCP/ ATS/ SIS International Sepsis Definitions Conference. Intensive Care Med 2003; 29: 530-538

75. National Nosocomial Infection Surveillance System. National Nosocomial Infections Surveillance (NNIS) System Report, data summary from January 1992 through June 2004, issued October 2004. Am J Infect Control 2004 32:470-485.

76. Villardón JL. MULBIPLOT: A package for Multivariante Analysis using Biplots. Matnlab Sofware.*biplot.usal.es/ClassicalBiplot/index.html. 2010

77. Gabriel K. The biplot-graphic display of matrices with application to principal component analysis. Biometrika (1971) 58, 453-467.

78. Galindo MP, Cuadras CM. Una extensión del método Biplot a su relación con otras técnicas. Publicación de Bioestadística y Biomatemática. Universidad de Barcelona. No 17. 1986.

79. Gabriel KR, Odorroff CL. Biplot in biomedical research. Statistics in Medicine (1990) 9, 469-485.

80. Hall MA. "Correlation-based Feature Selection for Machine Learning", $\mathrm{PhD}$ Thesis, University of Waikato, Hamilton, Nueva Zelanda, 1999.

81. Quinlan JR. “C4.5: Programs for Machine Learning”. Morgan Kaufmann, San Mateo, CA., USA, 1993

82. Breiman L.: "Random Forests”. Machine Learning. 45(1), 5-32, 2001.

83. Cooper GF, Herskovits E, "A Bayesian Method for the induction of probabilistic networks from data". Machine Learning, 9, 309-347, 1992. 
84. Friedman D. Geiger M. Goldszmidt (1997). Bayesian network classifiers. Machine Learning. 29(2-3):131-163.

85. Breiman L. "Bagging predictors". Machine Learning, 24(2), 123-140, 1996.

86. Freund Y, Schapire RE. "Experiments with a new boosting algorithm". Proceedings 13th International Conference on Machine Learning, 148-156, 1996.

87. Agrawal R. Srikant R. "Fast Algorithms for Mining Association Rules in Large Databases". In: 20th International Conference on Very Large Data Bases, 478-499, 1994.

88. Scheffer T. "Finding Association Rules That Trade Support Optimally against Confidence". In: 5th European Conference on Principles of Data Mining and Knowledge Discovery, 424-435, 2001.

89. Zaragoza R, Ramírez P, López MJ. Nosocomial infections in intensive care units. Enferm Infecc Microbiol Clin. 2014 May; 32(5):320-7.

90. EPINE: EVOLUCIÓN 1990-2014, CON RESUMEN DE 2014 consultado el 5/2/2015. http://hws.vhebron.net/epine/Descargas/EPINE\%201990-2014\%20web.pdf.

91. Vincent JL, Bihari DJ, Suter PM, Bruining HA, White J, Chanoin MH,et al. The prevalence of nosocomial infection in Intensive Care Units in Europe. Results of the European Prevalence of Infection in Intensive Care (EPIC) study. EPIC International Advisory Committee. JAMA 1995, 274:639-44.

92. Vincent JL, Rello J, Marshall J, Silva E, Anzueto A, Martin CD, EPIC II Group of Investigators. International study of the prevalence and outcomes of infection in intensive care units. JAMA 2009;302:2323-29.

93. Dudeck MA, Weiner LM, Allen-Bridson K, Malpiedi PJ, Peterson KD, Pollock DA, et al. National Healthcare Safety Network (NHSN) report, data summary for 2012, Device-associated module. Am J Infect Control 2013 Dec;41(12):1148-66. 
94. Rosenthal VD, Maki DG, Mehta Y, Leblebicioglu H, Memish ZA, Al-Mousa HH et al. International Nosocomial Infection Control Consortium (INICC) report, data summary of 43 countries for 2007-2012. Device-associated module. Am J Infect Control 2014 Sep;42(9):942-56.

95. Mertens K, Morales I, Catry B. Infections acquired in intensive care units: Results of national surveillance in Belgium, 1997-2010. J Hosp Infect 2013; 84:120-125.

96. Agodi A, Auxilia F, Barchitta M, Brusaferro S, D'Alessandro D, Montagna MT, et al. Building a benchmark through active surveillance of intensive care unit-acquired infections: the Italian network. SPIN-UTI. J Hosp Infect. 2010 Mar;74(3):258-65.

97. Van der Kooi TI, de Boer AS, Manniën J, Wille JC, Beaumont MT, Mooi BW, et al. Incidence and risk factors of device-associated infections and associated mortality at the intensive care in the Dutch surveillance system. Intensive Care Med. 2007 Feb;33(2):271-8.

98. Suetens C, Morales I, Savey A, Palomar M, Hiesmayr M, Lepape A, et al. European surveillance of ICU-acquired infections (HELICS-ICU): methods and main results. J Hosp Infect. 2007 Jun; 65 Suppl 2:171-3

99. Smith C, Salgado P, Mauldin J, Zhang J, Bosso A.(2014)"Relationship Between Days in Hospital and Infection with a Multidrug Resistant Gram-negative Pathogen". 54th Interscience Conference on Antimicrobial Agents and Chemotherapy (ICAAC®) Washinton DC. September 5-9.

100. Osman MF, Askari R., Infection Control in the Intensive Care Unit. Surgical Clinics of North America 2014; 94 (6) 1175-1194.

101. Malacarne P, Langer M, Nascimben E, Moro ML, Giudici D, Lampati L, et al. Building a continuous multicenter infection surveillance system in the intensive care unit: findings from the initial data set of 9,493 patients from 71 Italian intensive care units. Crit Care Med 2008 Apr; 36(4):1105-13. 
102. Rubinson L, Diette GB, Song X, Browier RG, Krishnan JA. Low caloric intake is associated with nosocomial bloodstream infections in patients in the medial intensive care unit. Crit Care Med 2004;32(2):350-7.

103. Latham R, Lancaster AD, Covington JF, Pirolo JS, Thomas CS. The association of diabetes and glucose control with surgical-site infections among cardiothoracic surgery patients. Infect Control Hosp Epidemiol 2001;22(10):607-12.

104. Hugonnet S, Chevrolet J, Pittet D. The effect of workload on infection risk in critically ill patients. Crit Care Med 2007;35(1):76-81.

105. Misset B, Timsit JF, Dumay MF, Garrouste M, Chalfine A, Flouriot I, et al. A continuous quality-improvement program reduces nosocomial infection rates in the ICU. Intensive Care Med 2004; 30(3):395-400.

106. Muto CA, Giannetta ET, Durbin LJ, Simonton BM, Farr Bm, et al. Costeffectiveness of perirectal surveillance cultures for controlling vancomycin-resistant Enterococcus. Infect Control Hosp Epidemiol 2002;23(8):429-35.

107. Climo MW, Yokoe DS, Warren DK, Perl TM, Bolon N, Herwaldt LA, et al. Effect of daily chlorhexidine bathing on hospital-acquired infection. N Engl J Med 2013; 368(6): 533-542.

108. Boyce JM, Pittet D, Healthcare Infection Control Practices Advisory Committee, Society for Healthcare Epidemiology of America, Association for Professionals in Infection Control, Infectious Diseases Society of America, Hand Hygiene Task Force. Guideline for hand hygiene in health-care settings: recommendations of the Healthcare Infection Control Practices Advisory Committee and the HICPAC/SHEA/APIC/IDSA Hand Hygiene Task Force. Infect Control Hosp Epidemiol 2002;23(12 Suppl):S3-40.

109. Fagon JY, Novara A, Stephan F, Girou E, Safar M. Mortality attributable to nosocomial infections in the ICU. Infect Control Hosp Epidemiol. 1994;15:428-3. 
110. Valles J, Pobo A, García-Esquirol O, Mariscal D, Real J, Fernández R. Excess ICU mortality attributable to ventilator associated pneumonia: The role of early vs late onset. Intensive Care Med. 2007;33:1363-8.

111. Melsen WG, Rovers MM, Groenwold RH, Bergmans DC, Camus C, Bauer TT, et al. Attributable mortality of ventilator-associated pneumonia: a meta-analysis of individual patient data from randomised prevention studies. Lancet Infect Dis $2013 ; 13: 665-71.38$

112. Leistner R, Kankura L, Bloch A, Sohr D, Gastmeier P, Geffers C. Attributable costs of ventilator-associated lower respiratory tract infection (LRTI) acquired on intensive care units: A retrospectively matched cohort study. Antimicrob Resist Infect Control 2013;2:13.39.

113. Barnett AG, Page K, Campbell M, Martin E, Rashleigh-Rolls R, Halton K, et al. The increased risks of death and extra lengths of hospital and ICU stay fromhospitalacquired bloodstream infections: A case-control study. BMJ Open2013 Oct; 31;3(10):e003587

114. Olaechea PM, Palomar M, Álvarez F, Otal JJ, Insausti J, López MJ, ENVINHELICS Group. Morbidity and mortality associated with primary and catheter-related bloodstream infections in critically ill patients. Rev Esp Quimioter 2013;26:21-9.41.

115. Fabbro-Peray P, Sotto A, Defez C, Cazaban M, Molinari L, Pinede M, et al. Mortality attributable to nosocomial infection: A cohort of patients with and without nosocomial infection in a French university hospital. Infect Control Hosp Epidemiol. $2007 ; 28: 265-72$.

116. Blot S. Limiting the attributable mortality of nosocomial infection and multidrug resistance in intensive care units. Clin Microbiol Infect 2008;14:5-13. 
117. DiGiovine B, Chenoweth C, Watts C, Higgins M. The attributable mortality and costs of primary nosocomial bloodstream infections in the intensive care unit. Am $\mathbf{J}$ Respir Crit Care Med 1999;160:976-81.

118. Zimlichman E, Henderson D, Tamir O, Franz C, Song P, Yamin CK, et al. Health Care-Associated Infections: A Meta-analysis of Costs and Financial Impact on the US Health Care System. JAMA Intern Med 2013 Dec; 9-23;173(22):2039-46 